\title{
III Tiergartenleben und Brunnenfreiheit - Orte, Medien und Themen der Berliner Salongesellschaft 1794/1795. Momentaufnahmen eines kommunikativen Netzes
}

\section{Das Tableau vivant - ein methodischer Versuch}

\subsection{An einem Freitag im August [...] - Anliegen des Kapitels}

Fragen Sie die Prächtig-Äugige, ob ihr der Mittwoch Mittag recht ist. H wird schon auch wollen, obschon er sich vorgenommen hat in 14 Tagen nicht einmal zur Stadt zu kommen. er ist aber so gut und ist so gerne gefällig dass er gewiß seinen Vorsaz ändert. Sagen Sie es auch Burgsdorf und sich dass ich Sie zu kommen bitte. H.

Henriette Herz in Berlin an Gustav von Brinckmann in Berlin, über Wilhelm vom Humboldt in Tegel, 21. August 1795

B.[urgsdorf] küsst Ihnen die Hände und freut sich wie ein Kind auf Ihre Bekanntschaft. Nüchtern wird er wohl bis dahin noch nicht sein, denn jetzt ist er so berauscht wie möglich.

Gustav von Brinckmann in Berlin an Rahel Levin Varnhagen in Karlsbad, über Wilhelm von Burgsdorf, 21. August 1795

Auch werden unsere jungen Freunde vor Gewalt dümmer, und da sich jetzt keiner mit ihrer Erziehung abgiebt, so wachsen sie auf, wie die gemeinsten Menschen. - Komm recht gesund zurück! Dein treuer Bruder. M. Lewin

Markus Levin in Berlin, an Rahel Levin Varnhagen in Karlsbad, über Gustav von Brinckmann, Nachschrift in dessen obigem Brief, 21. August 1795

Die Fränkel [...] ist hier und ob ich gleich mit ihr in einer strasse wohne so habe ich sie noch nicht gesehen; sie gehet und färt aus wie ich gehört habe [...] Gott: du bleibst noch sehr lange für meine schwanckende Seele, doch stelle ich mir dir mit rohten backen vor; und daß tröstet mich.

Friederike Liman in Berlin an Rahel Levin Varnhagen in Karlsbad, über Sophie Meyer Fränkel, 21. August 17951

1 Henriette Herz an Gustav von Brinckmann, 21. 8. 1795, ungedruckt, BA H; Gustav von Brinckmann an Rahel Levin Varnhagen, 21. 8. 1795, ungedruckt, BA V; Markus Theodor und Hendel Levin an Rahel Levin Varnhagen, 21. 8. 1795, BA V, ohne Brinckmanns Text gedruckt in: ERLV III, S. 54, da als ,Levin' gelesen; Friederike Liman an Rahel Levin Varnhagen, in: Bosold 1996, S. 33.

DOI 10.1515/9783110271744.141, (c) BY-NC-ND , published by De Gruyter.

This work is licensed under the Creative Commons Attribution-NonCommercial-NoDerivs 4.0 License. 
An einem Tag in Berlin, Tegel, Karlsbad, Weimar und Breslau: Der in diesem Kapitel unternommene Querschnitt zielt darauf, die Orte, Themen und Tonarten der Berliner Salongesellschaft zu einem ausgewählten Zeitpunkt näher zu bestimmen. Dem unerfüllbaren Wunsch nachgehend, zugehört zu haben, worum es eigentlich ging, zu erfahren, wer mit wem unter welchen Umständen worüber sprach, wurde das, was darüber 200 Jahre später noch Auskunft geben könnte, in einem methodisch ungewöhnlichen Versuch neu systematisiert, nicht nach-, sondern nebeneinander. Um der Kommunikation der Salons nachzuspüren, bleibt über die Entfernung von zwei Jahrhunderten nur, sich Briefe zu Gesellschaftern zu machen, beziehungsweise, in den Worten eines Salongastes, mit diesen die Schokolade zu trinken: ${ }^{2}$ In diesem Kapitel werden die Briefe ausgewählter Salonièren und Gäste innerhalb eines Beispieljahres, vom Sommer 1794 bis zum Sommer 1795, parallel gelesen.

Die Ausgangsüberlegung zu dieser Herangehensweise bestand darin, nicht noch eine Liste der Themen oder Personen zu erstellen, wie sie in der Literatur oft angeführt werden, um das Außergewöhnliche der Salons zu beweisen, und in welchen oft überblicksartig ein „best of“ dieses Phänomens gesammelt wird. Anliegen dieser Untersuchung ist vielmehr eine exemplarische Momentaufnahme, die andeuten soll, welches Themen- und Personenspektrum an den Teetischen der jüdischen Häuser Berlins verhandelt wurde. Um ein zeitgenössisch populäres Gesellschaftsspiel zu zitieren: Die Akteure der Salongesellschaft werden für diese Untersuchung in der Bewegung gebremst, erstarren zu einem „lebenden Bild“, einem „tableau vivant“. ${ }^{3}$ Das Stimmengewirr wird für einen Moment angehalten.

Da auch bei einem Querschnitt durch ein Jahr die Zahl der zu betrachtenden Personen ins Unendliche gesteigert werden könnte, wird hier mit einer

2 „Ihr Brief ist mir eine wahre Gesellschaft: ich habe mir auch Chokolade dazu machen lassen.“ David Veit an Rahel Levin Varnhagen, 23. 10. 1794, in: GW VII/I, S. 253.

3 Tableaux vivants lassen sich umschreiben als „szenische Arrangements von Personen, die für kurze Zeit stumm und bewegungslos gehalten werden und sich so für den Betrachter zu einem Bild formieren." Birgit Jooss: Lebende Bilder: Körperliche Nachahmung von Kunstwerken in der Goethezeit, Berlin 1999, S. 13. Lebende Bilder als solche sind schon seit der Antike bekannt, vor allem aus Prozessionen. Seit Ende des 18. Jahrhunderts entwickelte sich eine Unterhaltungsform, von wohlhabenden Privatleuten für Privatleute arrangiert, bevorzugt als Nachstellung eines berühmten Gemäldes mit ausgewählten Gästen. Die Salonfrau Meyer Eybenberg beschrieb in einem Brief an Goethe den besonderen Aufwand, der in Wien mit solchen Inszenierungen verbunden war. Vgl. Marianne Meyer Eybenberg an Johann Wolfgang von Goethe, 3. 4. 1805, in: Geiger 1893, S. 42. In den Briefen Rahel Levin Varnhagens findet sich ein Hinweis, dass verschiedene Damen ihrer Bekanntschaft „tableaus bei hoffe machen mussten“. Rahel Levin Varnhagen an Markus Levin, 7. 12. 1814, in: ERLV III, S. 466. 
Auswahl von Sprechern und Sprecherinnen gearbeitet, die sich an den Ergebnissen der bisherigen Salonforschung orientiert. So wird in diesem Großkapitel Ort für Ort untersucht, wie Salonkommunikation stattgefunden haben könnte. Salonkommunikation bedeutet dabei zunächst die schriftliche oder mündliche Unterhaltung zweier oder mehrerer Teilnehmer der Salongesellschaft. Letzterer Begriff umschreibt eine wesentliche These dieser Arbeit: Wie zu zeigen sein wird, ist das Bild einzelner Salons mit eigenen Gästegruppen nicht stimmig, sondern es muss von einer Gruppe von Frauen und Männern ausgegangen werden, die in unterschiedlicher Verbindlichkeit, verschiedenen Zusammensetzungen und mit wechselnden Rollen als Gast oder Gastgeber/in an vielen verschiedenen Orten miteinander kommunizierten. So vergrößerte und verkleinerte sich ein Gesprächskreis, etwa um einen Teetisch, durch hinzukommende oder sich entfernende Gäste, die auch paarweise aufbrachen, ihr Gespräch unterwegs miteinander oder an einem neuen Ort mit neuen Gesprächspartnern fortsetzen.

An jedem hier untersuchten Ort wird die Frage aufgeworfen, welche Themen im Beispieljahr verhandelt werden, inwieweit und welche verschiedenen Positionen dabei erkennbar sind. Ebenso wie nach dem „Wo“ fragt die Untersuchung nach dem „Wie“ der Kommunikation innerhalb der Salongesellschaft. Vorgestellt und untersucht werden verschiedene Medien, sozusagen die materiellen Seiten der Kommunikation. Damit verbunden ist die erwähnte These, dass verschiedene Kommunikationsformen, i. e. Briefe, Billets und Gespräche nicht nur nebeneinander zur Geltung kamen, sondern auch gleichzeitig als unterschiedliche Ebenen der Kommunikation genutzt werden konnten. Dem angeschlossen ist die Frage nach einem potentiellen salonspezifischen Tonfall, bzw. den Sprachebenen und -formen, in denen Gäste und Gastgeberinnen, oder einzelne Gästegruppen miteinander kommunizierten.

Dieses Kapitel präsentiert und belegt die These, dass Salonkommunikation nicht nur in verschiedenen jüdischen Häusern, sondern an unterschiedlichen Orten der Stadt, weiteren Ortschaften und auf unterschiedlichen Wegen zwischen diesen stattgefunden hat. Für einen Moment wird also die Variable „Zeit“ ausgeblendet, um dafür umso differenzierter die Variable „Ort“ zur Geltung zu bringen. Dabei kann es nicht darum gehen, ein möglichst vollständiges Bild der jeweiligen Orte nachzuzeichnen, sondern spezielle an und zwischen ihnen entwickelte Kommunikationsformen und mögliche Treffpunkte aufzuzeigen. Es geht nicht um Lokal-, geschweige denn Politikgeschichte bedeutender Orte deutscher Geschichte, sondern um eine Topografie des Salon-Netzes im ausgewählten Zeitabschnitt. Aufgrund der Zweidimensionalität eines Textes müssen leider bei der Untersuchung die Kommunikationen an den verschiedenen Orten nacheinander dargestellt werden, die eigentlich großteils zeitgleich 
stattfanden. Die Untersuchung führt nach einer kurzen Vorstellung der Zeit und der handelnden Personen [1.2.-1.4.] nach Berlin [2.], Breslau [3.], Weimar und Jena [4.] sowie in verschiedene Badeorte [5.]. Abschließend werden die Ergebnisse daraufhin untersucht, inwieweit von einem eigenen Salon-Ton die Rede war und sein kann [6.].

\subsection{Zur Auswahl des Zeitabschnitts und der Quellengrundlage}

Die Auswahl des Zeitabschnitts zwischen Sommer 1794 und Sommer 1795 leitet sich aus folgenden Überlegungen her: Die so genannte „Blütezeit“ der Berliner Salons wird in den allermeisten Darstellungen auf die Zeit 1783/1790-1806 fixiert. ${ }^{4}$ Den gesamten Zeitraum zu überblicken ${ }^{5}$ und damit eine weitere Entwicklungsgeschichte der Berliner Salons zu schreiben, schien weder sinnvoll noch der Forschungsfrage angemessen. Es schien aber lohnend, aus der ange-

4 Die beiden Anfangsjahre sind die Daten der vermuteten „Eröffnungen“ der Salons der beiden berühmtesten Salonièren, Rahel Levin Varnhagen und Henriette Herz. Wobei gesagt werden muss, dass der Herzsche Salon der 1780er-Jahre in der aktuellen Sekundärliteratur oft erwähnt, aber wesentlich seltener behandelt wird. Das Jahr 1806 wird mit dem Einzug Napoleons in Berlin, der Flucht oder dem Tod mehrerer Salongäste durchweg als vorläufiger Endpunkt dieser Berliner Geselligkeit gesetzt. Diese Daten aufzuweichen bzw. fließendere Übergänge anzuregen, ist ein weiteres Anliegen der Arbeit.

5 Wie in I.2 erläutert, werden die Quellen der Salongesellschaft vor dem historischen Hintergrund der „Sattelzeit“ genannten gesellschaftlichen Umbruchphase gelesen, wobei der hier zu untersuchende Zeitabschnitt und örtliche Fokus vielleicht passender mit dem von de Bruyn geprägten Begriff „Berlins Kunstepoche“ zu fassen sind, welcher zugleich eine besondere Dichte und ein Nebeneinander verschiedener kultureller Strömungen bezeichnen soll. De Bruyn 2006. Historische Ereignisse haben nicht unbedingt eindeutige Effekte auf die Salonkultur gezeitigt. Die Entwicklung der einzelnen Orte und damit der Geselligkeitskultur innerhalb dieser Generation ist vielmehr verschieden und oft zeitversetzt verlaufen. Der Vergleich Berlins mit Weimar unter diesem Aspekt zeigt, dass ein wesentliches politisches Ereignis, etwa die französische Besetzung Preußens, gegensätzliche Wirkungen nach sich ziehen konnte: Der Einzug Napoleons brachte die Salongeselligkeit in Berlin mehr oder weniger zum Erliegen, während die disparate Situation in Weimar es einer bürgerlichen Frau, Johanna Schopenhauer, erst möglich machte, eine gemischte Geselligkeit zu etablieren. Die Unterschiede in der Geselligkeit einer langjährig aktiven Frau, etwa zwischen dem „Salon“ Herz und späteren „Teegesellschaften“ der Witwe, aufzuzeigen, die beides selbst nicht so separiert oder genannt hat, wäre eine wichtige, noch zu leistende Detailarbeit. Für den Hinweis auf anregende „Tees der Herz / Witwe eines jüdischen Arztes“ 1810 vgl. eine Randbemerkung Ludwig Gerlachs in den Erinnerungen seines Bruders Leopold, Militär und Freund Friedrich Wilhelm IV., in: Hans-Joachim Schoeps (Hrsg.): Aus den Jahren preußischer Not und Erneuerung. Tagebücher und Briefe der Gebrüder Gerlach und ihres Kreises 18051820, Berlin 1963, S. 76, Anm. 77. 
nommenen und doch sehr wechselvollen „Blütezeit“ einen Zeitraum auszuwählen, innerhalb dessen sich die meisten der Salonièren längere Zeit in Berlin aufhielten, also in der Sprache der traditionellen Salonforschung die Salons „geöffnet“ waren. ${ }^{6}$ Die für die Untersuchung wichtigen Personen sollten gelegentlich abwesend sein aus Berlin - ein Umstand, dem die Freunde und die Forschung längere schriftliche Erörterungen zu Salonzusammenhängen erst verdanken -, aber die Abwesenheit durfte nicht so lang dauern, dass die Korrespondenz abgebrochen wurde. Ein weiteres saloninternes Kriterium war die Bekanntschaft der Salonièren mit dem Habitué, fleißigen Korrespondenten und wesentlichen Überlieferer der meisten hier genannten Frauen, Gustav von Brinckmann. Seine überlieferte Korrespondenz mit den meisten Salonfrauen setzte 1792/93 ein.

Um 1794 sind einige, aber noch nicht alle, der später als berühmt geltenden Bekanntschaften bereits gemacht. Die Brüder Alexander und Wilhelm von Humboldt und der Diplomat Brinckmann können als Habitués mehrerer jüdischer Häuser gelten, Friedrich von Gentz und Friedrich Schleiermacher sind zumindest in einigen Häusern eingeführt, andere bedeutende Bekanntschaften wie Friedrich Schlegel oder Prinz Louis Ferdinand stehen noch aus. Man könnte sagen, das kommunikative Netz „Salon“ befindet sich in der Ausbauphase. Auch da die Berliner Salons als Zentrum der frühen Goethe-Verehrung gelten, wurde das Jahr gewählt, in dem mehrere Salonfrauen die Bekanntschaft des Dichters machten.

Der wesentliche Grund für die Auswahl 1794/95 ist aber, dass sich an diesem Jahr besonders gut zeigen lässt, wie sich zwischen Berlin und verschiedenen Badeorten einerseits und Berlin und Weimar-Jena andererseits die Kommunikation entspann, da die Überlieferung hier eine relative Dichte an Material versprach. Als hauptsächliche gedruckte Quelle ist der bekannte Jugendbriefwechsel Rahel Levin Varnhagens mit David Veit zu nennen, der gerade im ausgewählten Zeitraum besonders intensiv ist. Ebenfalls gut überliefert ist die Korrespondenz Rahel Levin Varnhagens mit Friederike Liman, die vorbildlich ediert im Internet veröffentlicht, aber bisher wenig genutzt wurde. Dazu kommen zahlreiche ungedruckte Konvolute, die in den beschriebenen Sammlungen speziell unter dieser Fragestellung eingesehen und ausgesucht wurden. Als zeitgenössische Vergleichsgrößen für die Informationen zur Berliner Geselligkeit wurden Schriften solcher Personen herangezogen, die höchstwahrscheinlich ,auf den selben Wegen gingen` wie die Teilnehmer der Salonge-

6 Das engt den Zeitraum auf die Zeit zwischen 1791 und 1803 ein, dem Jahr, in dem Markus Herz verstarb und seine Frau Henriette sich finanziell sehr einschränken musste. 
sellschaft. ${ }^{7}$ Angesichts des Umfangs dieses Kapitels und der Heterogenität der zu untersuchenden Orte werden die spezifischen Quellen und die wesentliche Forschungsliteratur in den jeweiligen Abschnitten angeführt. Da Tagebücher oder Erinnerungen, geschweige denn authentische Berichte über Salonabende von Salonteilnehmenden um 1800 nicht existieren, sind wesentliche Quellen für dieses Kapitel Briefe und Billets, die zwischen den ausgewählten Sprechern im Beispieljahr hin- und hergingen. „Relative Dichte“ der Quellen bedeutet dabei Folgendes: Tatsächlich ist der zitierte 21. August 1795 der einzige Tag jenes Jahres, von dem aus der sehr gesprächigen Salongesellschaft mehr als vier Stimmen der Sprecher und Sprecherinnen überliefert sind.

\section{3, „[...] daß man Sie auf jedem bekannten, vielbesessenen Saupha wiederfindet" - Offene Häuser und das Modell der Salongesellschaft}

Mit zu diesem Erfolg trug seine Frau Henriette Herz bei, deren berühmter Salon in Berlin die Romantiker Jean Paul, die Brentanos, Schlegels und Tiecks ebenso anzog wie die Wissenschaftler Alexander und Wilhelm von Humboldt.

Tageszeitung, 2006

Sie ging im Salon auf und ab, zupfte an einem Spitzendeckchen, rückte einen Fauteuil gerade [...] bis endlich die Gäste kamen.

Biografie Henriette Herz', $2005^{8}$

7 Als eine wichtige Parallelquelle zu den Äußerungen der Salonteilnehmer wurde das heute noch wenig bekannte, in seinen Details umso reizvollere Tagebuch des stadtbekannten Arztes Heim herangezogen, der mit Personen aller Stände, auch einzelnen Teilnehmern der Salongesellschaft, verkehrte und darüber in prägnanter Form berichtete. Ernst Ludwig Heim: Tagebücher und Erinnerungen. Ausgewählt und herausgegeben von Wolfram Körner, Leipzig 1989. Heim verkehrte im Haus der Humboldts, aus späteren Jahren sind einige Kontakte zur Familie Levin überliefert. Vgl. eine Randbemerkung Karl August Varnhagens, dass Heim die jahrelange „Kammerjungfer“ Rahel Levin Varnhagens, Karoline Brack, genannt Line, untersucht habe, SV 202, in ERLV II, Fn. 7, S. 612. Vgl. auch verschiedene Einträge Sommer 1806 im Tagebuch Heims. Heim 1989, S. 138. Um 1800 häufig Gast in Berlin und dezidiert in verschiedenen sozialen Kreisen verkehrend wurde die Autorin und Dame der Gesellschaft Elisa von der Recke mit ihrem „Journal“ als Zeitzeugin interessant. Vgl. Träger 1984. Hinzu kommen zahlreiche Berichte heute kaum mehr bekannter Reisender, die Berlin als zunehmend populäres Ziel entdeckten.

8 Gemeint ist der Erfolg des jüdischen Krankenhauses in Berlin. Rolf Lautenschläger: Von der hohen Heilkunst zum offenen Haus, in: taz. die tageszeitung, 3. 8. 2006; Huizing 2005, S.13. Dieser Roman macht auf eine lang vernachlässigte Forschungsaufgabe aufmerksam: eine wissenschaftliche Biografie über Henriette Herz. Selbst sagt er mehr über Lesergeschmack und Spitzendeckchen aus als über seine Protagonistin. Das Zitat im Titel: Wilhelm von Burgsdorf an Gustav von Brinckmann, 14. 8. 1796, in: Alfons Fedor Cohn (Hrsg.): Wilhelm von Burgsdorff: Briefe an Brinkman, Henriette von Finckenstein, Wilhelm von 


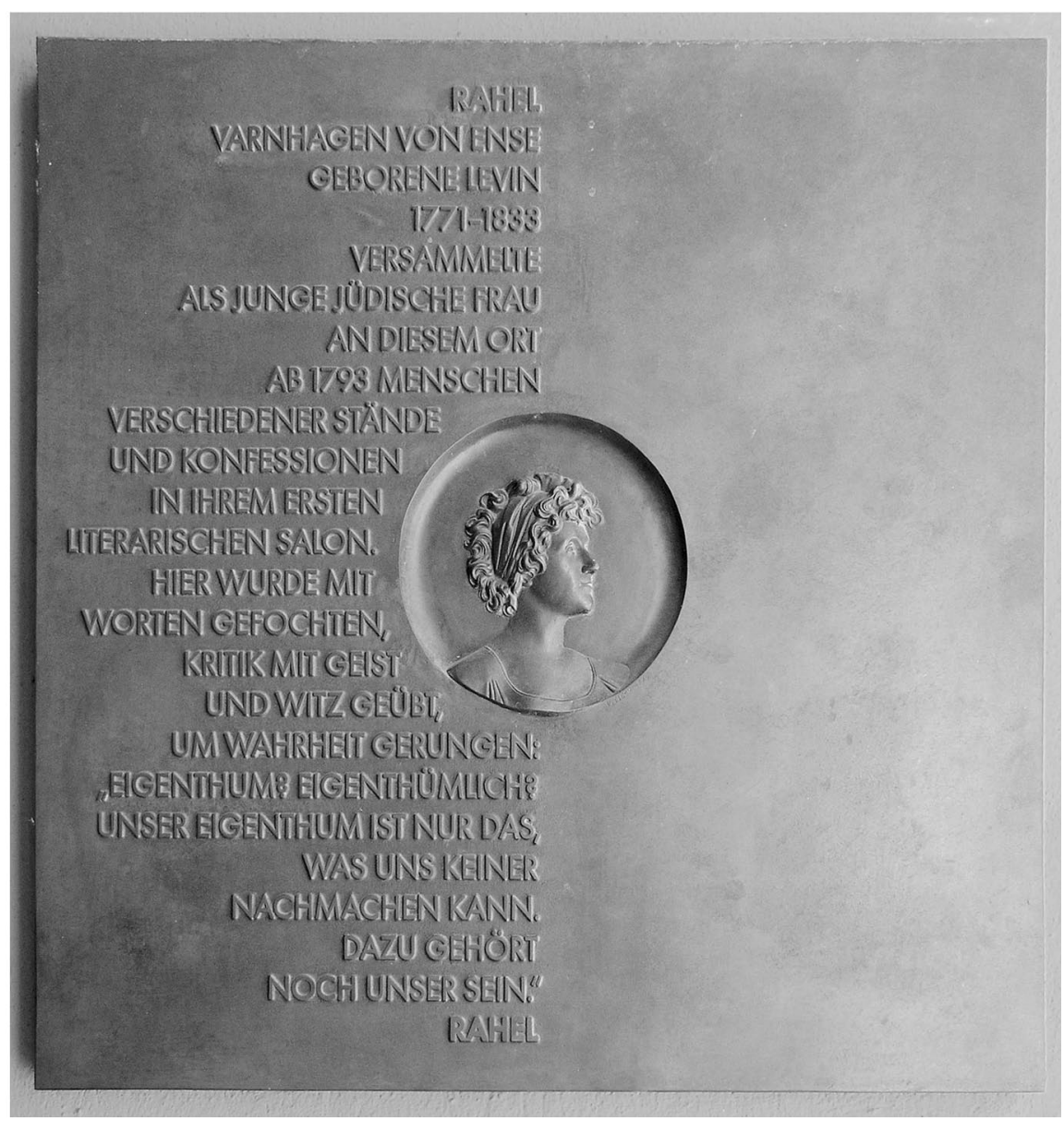

Abb. 9: Ein in Bronze gegossenes Ideal - Gedenktafel an der Jägerstraße in Berlin.

„Salon“: Sucht man nach einem Ausgangspunkt für Recherchen, welche Gäste zu einem bestimmtem Zeitpunkt in welchen Berliner Salons verkehrt haben könnten, stößt man in wissenschaftlichen wie populärwissenschaftlichen Darstellungen vor allem auf die erwähnten Reihungen berühmter Gäste, der Art „Männer wie ... verkehrten bei ...“, wobei diese Aufzählungen entweder dazu dienen, das Renommee eines Salons in nur einem Satz zu kennzeichnen oder aber den Salon an eine bestimmte Schicht oder Szene zu binden, um eine

Humboldt, Friedrich Tieck, Ludwig Tieck und Wiese, Berlin 1907, unter: http:// www.gnu.franken.de/Tieck/Dokumente/Burgsdorff-briefe/ (1. 9. 2011), S. 3. 
qualitative Einordnung vornehmen zu können, etwa durch Nennung vieler Schriftstellernamen den Titel „literarischer Salon“ zu rechtfertigen. Auf die Frage, wie oft und wie lange diese Personen tatsächlich bei den einzelnen Frauen verkehrt haben, wird in den allermeisten Fällen nicht eingegangen.

Solche Reihungen sind nicht nur üblich bei historischen Überblickswerken zu bestimmten Epochen, etwa zur nachfridericianischen Zeit Preußens, als in den Salons Männer ,von den Brüdern Alexander und Wilhelm von Humboldt, August Wilhelm und Friedrich Schlegel, über Jean Paul bis zu Prinz Louis Ferdinand zusammen[kamen]".9 Sondern sie sind auch häufig der Fall in der romantisierenden Salonliteratur, etwa zum „berühmtesten Salon“ Rahel Levin Varnhagens:

Markus Herz und die kritische Intelligenz Berlins gehörten dazu, Prinz Louis Ferdinand pflegte auf Rahels Klavier seine frühromantischen Kompositionen vorzustellen [...]. Zum schillernden Spektrum dieses berühmtesten Salons [...] trugen ferner Wilhelm von Humboldt, der Fürst von Ligne, Jean Paul, Friedrich Schlegel, die Töchter Moses Mendelssohns u. a. bei. ${ }^{10}$

Abgesehen von der logischen Frage, welche bescheidene Dachstube so viele Menschen nebst einem Klavier hätte aufnehmen können, werden in diesen Darstellungen oft primäre Kur-Kontakte (Prinz de Ligne) und kurzzeitige Besucher (Jean Paul) gleichberechtigt neben langjährigen Bekannten genannt. Der unmöglich zu realisierenden Versuchung, ein mehrere Jahre oder Jahrzehnte umspannendes geselliges Engagement in einem Absatz differenziert darzustellen, ist auch eines der neuesten Überblickswerke über die „deutsch-jüdische Epoche“ erlegen:

Zu ihren [Rahel Levin Varnhagens] zahlreichen Verehrern gehörten Henriettes Freunde, Schleiermacher, die Gebrüder Humboldt, Kleist, Schlegel und Tieck sowie mehrer junge jüdische Dichter und Dramatiker, einige preußische Adlige und Offiziere wie Friedrich von Gentz [...] außerdem Opernsängerinnen, ausländische Diplomaten, der polnische Fürst Radziwill, der mit der Nichte Friedrichs II. verheiratet war, sowie Friedrichs Neffe Prinz Louis Ferdinand. ${ }^{11}$

Auch diese relativ detaillierte Schilderung arbeitet mit Häufungen, die über den Umstand hinwegtäuschen, dass Kleist, Humboldts und Schlegel sich „bei

\footnotetext{
9 Thomas Grosser / Willi Kreutz: Höfische und bürgerliche Kultur zwischen Aufklärung, Romantik und Klassizismus. in: Manfred Schlenke (Hrsg.): Preussen Ploetz. Eine historische Bilanz in Daten und Deutungen, Köln 2003, S. 210-216, hier S. 214.

10 Die märchenhafte und nicht selten verzerrende Darstellung bei von Heyden-Rynsch gilt noch heute als ein Salon-Klassiker. Von der Heyden-Rynsch 1995, S. 144. 11 Amos Elon: Zu einer anderen Zeit. Porträt der deutsch-jüdischen Epoche. 1743-1933, München [u.a.] 2002, S. 81.
} 
Rahel“ nie begegnet sind, und sie ignoriert die große Anzahl jüdischer Freundinnen in Levin Varnhagens Geselligkeitsgewebe, vielleicht weil diese nicht zum Maßstab einer gelungenen Akkulturation taugen? Ganze Gästegruppen, die zum Umgangston eines Salons sicher viel, zur postumen Berühmtheit eines Salons aber scheinbar wenig beitrugen, werden so ignoriert.

Forschende, die in die ,Prominenz-Falle، der Salongeschichtsschreibung tappen, übersehen oft, dass zum Zeitpunkt ihrer häufigen Salonbesuche beispielsweise „die Gebrüder Humboldt“ noch nicht als solche ein Begriff und keineswegs Berühmtheiten, sondern zwei unbekannte, wenn auch hochbegabte junge preußische Junker auf der Suche nach Arbeit waren.

\section{Die Salongesellschaft als kommunikatives Netz}

Mit diesem Kapitel wird, diesem Fixierbild entgegen, die These hergeleitet und vertreten, dass die Rollen als Gast und Gastgeberin stündlich wechseln konnten, es zwar Lieblingsfreundschaften und Feindschaften gab, aber keine Exklusivgäste. An nur einem Tag konnten von denselben Gästen und Gästegruppen verschiedene „Salons“ und andere kommunikative Orte aufgesucht werden. Was einer der Beteiligten spöttisch als „ein endemisches Übel bei den Berlinern, nicht zu Hause zu sein“ bezeichnete, kann man anhand der überlieferten Billets auch so verstehen, dass sie sich dauernd gegenseitig besuchten. ${ }^{12}$

Die Eingangszitate eines Freitags im August in Orte übersetzt bedeuten: An ein und demselben Tag bat Henriette Herz Gustav von Brinckmann per Billet zu sich zum Tee, der gerade im Haus der Levins weilte. Dort nutzte er eben den Schreibtisch des Hauses, um der abwesenden Salonière, Rahel Levin Varnhagen, brieflich Burgsdorf als einen neuen Gast anzutragen. Sie las dann in Karlsbad nicht nur von dem Befinden Burgsdorfs, sondern - im selben Brief - von ihrer Familie. Ihr Bruder teilte das Papier mit seinem Gast, um von den Kindern zu berichten. Friederike Liman informierte sie am selben Tag, dass der Kontakt zu einer anderen gemeinsamen Freundin noch nicht aufgenommen wurde, obwohl sie in derselben Straße wohne. Währenddessen erörterte Humboldt Schiller brieflich seine Pläne, nannte seinen Aufenthalt in Preußen „sehr gestört“ ${ }^{13}$ unter anderem nämlich durch die Einladungen in die Stadt, denn auch er war von der Herz zum Tee gebeten und konnte, wie diese ahnte, nicht widerstehen. Um Brinckmann zu locken, bot Henriette Herz ihm

12 Wilhelm von Humboldt an Friedrich von Schiller, 4. 8. 1795, in: Leitzmann 1900, S. 69. 13 „Nur bin ich in einer sehr gestörten Lage gewesen. [...] Ich wünschte herzlich, ich wäre wieder bei Ihnen.“ Wilhelm von Humboldt an Friedrich von Schiller, 21. 8 1795, in: Leitzmann 1900, S. 89. 
Gelegenheit, eine von ihm verehrte Frau anzusprechen, die „prächtig-äugige“ Friederike Unzelmann. Er sollte die Einladung mündlich weitergeben und sie gleich mitbringen. Die Unzelmann war wiederum eine enge Freundin der Liman und Levin Varnhagens.

Wie mit dieser Kurzzusammenfassung angedeutet und im Folgenden detaillierter dargelegt werden wird, bietet es sich an, für Berlin um 1800 statt von separierten Salons von einer größeren geselligen Gruppe, von einer Salongesellschaft zu sprechen, die in einer Art loser Stammbesatzung an den verschiedenen Orten, verschiedenen Teetischen und Städten, ihre Themen fortgesetzt diskutierte, auf verschiedenen Wegen einander einlud, auf dem Laufenden hielt und vermittelte. „Gesellschaft“ wird dabei im Sinne des 18. und 19. Jahrhundert verstanden als „im weitesten Sinne des Wortes eine durch gemeinsame Zwecke und Interessen zur Einheit verbundene, zusammengehörende Individuengruppe, eine (der Dauer, Ausdehnung, Innigkeit nach verschiedene) Lebensgemeinschaft“. ${ }^{14}$ In Anbetracht der Tatsache, dass das 18. Jahrhundert dadurch gekennzeichnet ist, sich in Gesellschaften zusammenzuschließen, von denen Lesegesellschaften und Gelehrte Gesellschaften nur die bekanntesten sind, ${ }^{15}$ ist hier von Bedeutung, dass unter „Salongesellschaft“ nicht eine bewusste Gründung, sondern ein informeller und temporärer Zusammenschluss verstanden wird, wie etwa eine per Billet zusammengerufene „Thee-Gesellschaft“. Beziehungsweise

14 „Gesellschaft“, in: Meyers Großes Konversationslexikon. Ein Nachschlagewerk des allgemeinen Wissens, Sechste, gänzlich neubearbeitete und vermehrte Auflage, 20 Bde., Leipzig [u. a.] 1903-1909, Bd.7 (1905), S.717-720, hier S. 717; Der Begriff Salongesellschaft wird in einem dieser Arbeit möglicherweise vergleichbaren Sinne von Peter Gradenwitz angewandt, allerdings ohne jede Definition oder Begründung. Peter Gradenwitz: Literatur und Musik im geselligen Kreise. Geschmacksbildung, Gesprächsstoff und musikalische Unterhaltung in der bürgerlichen Salongesellschaft, Stuttgart 1991, passim. Die Begriffswahl hat nichts mit dem gleichnamigen 2004 gegründeten Zusammenschluss zu tun, der auf einem ehemaligen Weingut „die klassische Tradition in neuem Gewand“ fortsetzen will, und „Tafelkultur, Stil und Etikette“ anbietet. Vgl. Pressemitteilung der „Salongesellschaft“ unter: http://www.openPR.de/news/102527/Auslaufmodell-Freundschaft-Die-Salongesellschaft-im Gespraech-mit-dem-Autor-Martin-Hecht-html (1. 7. 2007).

$15 \mathrm{Vgl}$. aus der umfangreichen Literatur zum Sozietätswesen des 18. Jahrhunderts zu Gesellschaften als Charakteristikum der Epoche besonders: Ulrich Im Hof: Das gesellige Jahrhundert. Gesellschaft und Gesellschaften im Zeitalter der Aufklärung, München 1982 und Richard van Dülmen: Die Gesellschaft der Aufklärer. Zur bürgerlichen Emanzipation und aufklärerischen Kultur in Deutschland, Frankfurt/M. 1986. In dieser Arbeit bedeutet die Verwendung des Begriffs Gesellschaft im Zusammenhang mit Salon nicht notwendigerweise eine Verortung des Phänomens Berliner Salon in der Aufklärung, deren Gesellschaften in der Forschung ein „ernsthafter Ton“ und ein moralisch-sittlicher Anspruch attestiert wird. Auf die Voraussetzungen, die die jüdischen Gastgeberinnen in der aufgeklärten Haltung und Geselligkeit der Vätergeneration fanden, kann hingegen nicht genug hingewiesen werden. 
es entstehen, in den Worten des zeitgenössischen Philosophen Christian Garve, „wenn nämlich die Menschen in Gesellschaft leben, [...] von selbst gewisse stillschweigende Verträge unter ihnen, wie sie die Sachen, die sie gemeinschaftlich vorzunehmen haben, auch gleichförmig thun wollen“. ${ }^{16}$ Diese stillschweigenden Übereinkünfte seien zwar der Mode unterworfen, hielten „während gewisser Perioden“ aber stand.17 Unter Berliner Salongesellschaft wird in dieser Arbeit die Gesamtheit der in der Zeit um 1800 in den als Salons bekannten geselligen Kreisen regelmäßig verkehrenden Personen verstanden. Deren „stillschweigende Übereinkünfte“ und deren Grenzen sind Untersuchungsgegenstand dieser Arbeit.

In der Berliner Salongesellschaft wurden mehrere Freundschafts- oder Gesprächsbeziehungen über Jahrzehnte aufrecht erhalten, sodass man auch moderner von einem kommunikativen Netz sprechen kann, mit allerdings sehr unterschiedlichen Fadenlängen und -dicken. Ein Netzwerk im Sinne eines absichtsvoll und zielorientiert gegründeten Verbundes ist die Salongesellschaft schon ihrer Entstehungsgeschichte nach nie gewesen. ${ }^{18}$ Inwieweit man mit der soziologischen Definition einer „sozialen Gruppe“ arbeiten kann, ließe sich fragen. Der hochinteressante Ansatz Astrid Köhlers, die das Salongeschehen im Hause Johanna Schopenhauers in Weimar als Gruppenphänomen analysiert, lässt sich für Berlin aufgrund der ungleich geringeren Datenbasis leider nicht übernehmen. ${ }^{19}$

16 Christian Garve: Versuch über verschiedene Gegenstände aus der Moral, der Litteratur und dem gesellschaftlichen Leben, 5 Bde., Breslau 1792, Bd. 1, S. 157. Zur gesellschaftstheoretischen Einordnung der Betrachtungen Garves vgl. Manfred Riedel: „Gesellschaft, Gemeinschaft“, in: Brunner / Conze / Koselleck 1992-1997, Bd. 2, S. 801-862, bes. S. 819 f. 17 Garve 1792, S. 158. Garve formuliert als wesentliche Bestandteile einer Gesellschaft Conventionen und eine gemeinsame Sprache - eine Definition, die wie weiter unten dargestellt, genau zum Befund dieser Arbeit passt.

18 Obwohl der Begriff in der Sekundärliteratur zu Salons gelegentlich fällt, ist er in sozialwissenschaftlicher Definition in diesem Zusammenhang nicht haltbar. Auch wenn einzelne Personen ihre im Salon gemachten Bekanntschaften für verschiedene Zwecke ausnutzten, kann von einem bewussten Zusammenschluss zu einem gemeinsamen Zweck nicht die Rede sein. Auch die Methoden soziologischer Netzwerkanalyse sind auf mein Thema nicht nur aufgrund des historischen Abstands, sondern auch wegen der fragmentierten Quellenlage nicht anwendbar. Vgl. Johannes Weyer (Hrsg.): Soziale Netzwerke: Konzepte und Methoden der sozialwissenschaftlichen Netzwerkforschung, München 2000.

19 Das mag paradox klingen angesichts der „vielen“ Salons in Berlin, aber genau dieser Umstand erleichtert die Forschungssituation in Weimar. So gibt es aus Weimar nicht nur umfängliche Selbstaussagen der Salonière, Reflexionen und Absichtserklärungen im Hinblick auf die Geselligkeit, sondern auch viele beschreibende Erinnerungen von Gästen, die etwa auf das Interieur des Salons Rücksicht nehmen, während aus Berlin nicht einmal zu rekonstruieren ist, wo zwei der „berühmtesten Salonièren“ überhaupt gewohnt haben. 


\section{4 „[...] eine Menge umgänglicher Bekannte von meinem Gehege“ - Zur Auswahl der handelnden Personen}

Die zwei grundlegenden sozialhistorischen Überblickswerke zum Berliner Salon zählen für die Zeit um 1800 unterschiedlich viele Gastgeberinnen jüdischer Herkunft: Nach Deborah Hertz kann für Berlin um 1800 von einer Gesamtzahl von zwölf Salonièren ausgegangen werden, von denen neun jüdischer Herkunft waren, Petra Wilhelmy nennt aus diesem Zeitraum 16 Frauen mit eigenem Salon, darunter sechs Jüdinnen, wobei die Datierung der einzelnen Salons bei beiden Wissenschaftlerinnen oft unterschiedlich, bisweilen konträr ausfällt. ${ }^{20}$ Auch gibt es bereits zwischen diesen beiden Arbeiten keine Übereinstimmung, welchen Geselligkeiten der Titel eines echten "Salons“ zukäme, was sich besonders deutlich am Beispiel Dorothea Veit Mendelssohn Schlegels zeigt, die laut Hertz in den 15 Jahren ihrer ersten Ehe versuchte, einen echten Salon zu führen, was in einer „rein jüdischen Vorlesegesellschaft“ mündete, bzw. laut Wilhelmy in einem „Lesekränzchen“, die aber nichtsdestotrotz in beiden Arbeiten zu den bekanntesten jüdischen Salonièren gezählt wird. ${ }^{21}$

Aufgrund dieser Unschärfen scheint es sinnvoll, bei der Suche nach „Salons um 1800“ auf detailliertere Abgrenzungen zwischen „echten“ Salons und „salonartiger Geselligkeit“ vorläufig zu verzichten, insbesondere im Hinblick auf die erwähnte Tatsache, dass keine der genannten Frauen diesen Begriff selbst für ihr Tun verwendet hat. Im Zusammenhang dieser Arbeit werden die Untersuchungen von Hertz und Wilhelmy als gut begründete Hinweise darauf gelesen, welche Frauen in Berlin um 1800 über einen längeren Zeitraum als Gastgeberinnen gemischter Gesellschaften aufgesucht wurden.22 Von den

20 Das Zitat in der Überschrift: Rahel Levin Varnhagen an Alexander von der Marwitz über Teplitz, 28. 6. 1811, in: GW I, S. 521. Die Zugehörigkeit zum Kanon führte dabei in den seltensten Fällen zu einer gründlicheren Untersuchung der Salontätigkeit in der nachfolgenden Forschung. Die wiederholte Nennung ihres Namens in der Forschungsliteratur schützt eine Salonière weder vor falschen Lebensdaten noch vor einander widersprechenden Thesen: Beispielsweise geht Wilhelmy davon aus, dass Marianne Meyer Eybenberg erst nach 1799 „in Wien eine salonartige Geselligkeit aufbaute“, wohin der Tod ihres Mannes sie verschlagen hatte, während Hertz feststellt: „Sie muss ihren Salon vor seinem Tod im Jahre 1799 geführt haben, als sie noch die materiellen Vorteile und den Status einer Fürstin von Reuß besaß.“ Hertz 1991, S. 146; Wilhelmy-Dollinger 2000, S.79. Den Status einer Fürstin hat Meyer Eybenberg allerdings nie besessen, nur den Titel von Eybenberg ohne fürstliche Rechte.

21 Hertz 1991, S. 143; Wilhelmy-Dollinger 2000, S. 63.

22 Nach Hertz' Analyse waren um 1800 folgende Salonièren jüdischer Herkunft in Berlin tätig: Rahel Levin Varnhagen, Henriette Herz, Sarah Levy, Marianne Meyer Eybenberg, Sara Meyer Grotthus, Dorothea Mendelssohn Veit Schlegel, Amalie Beer, Philippine Cohen und 
in beiden Werken übereinstimmend genannten Salonièren wurden für dieses Kapitel zunächst die beiden bekanntesten, Rahel Levin Varnhagen und Henriette Herz, auch trotz ihrer Berühmtheit ausgewählt, weil sich in ihrem Umfeld noch viel ungedrucktes Material finden ließ. Dazu kommen die viel genannten, aber noch wenig erforschten Schwestern Sara und Marianne Meyer, die spätere Frau von Grotthus respektive Frau von Eybenberg. ${ }^{23}$ Bei einem Umfang der Salongesellschaft von geschätzten mindestens 100 Personen $^{24}$ galt es, auch aus den Gästelisten eine Auswahl zu treffen. Auch diese wird gleichermaßen von

Rebecca Friedländer. Wilhelmy, deren Untersuchung bis ins Jahr 1914 reicht, nennt aus der so genannten „klassischen Epoche der Berliner Salons“ um 1800 als Salonièren jüdischer Herkunft Herz, Meyer Grotthus, Cohen, und Levin Varnhagen, den Salon der Sara Levy rechnet Wilhelmy einer späteren Epoche der „patriotischen Romantik“ zu, Amalie Beer wird mit einem musikalischen Salon erwähnt. Als nichtjüdische Salonièren werden von beiden übereinstimmend Friederike Helene Unger und die Herzogin Dorothea von Kurland genannt. Hertz erwähnt noch die (hier nicht bevornamte) Frau des Graveurs Abrahamson. Beim Salon im Hause des Buchhändlers Reimer erweist sich die Unschärfe der Definitionen. Hertz, die auch Männer unter den Salongastgebern duldet, nennt Andreas Reimer, während Wilhelmy die Gattin Minna Reimer als Salonière betrachtet. Wilhelmy nennt außerdem aus dieser Zeit noch die Verlegergattin Sophie Sander sowie die Fürstin Luise von Radziwill und Henriette von Crayen, aus der späteren Zeit Elisabeth von Stägemann, Amalie von Beguelin und Luise von Voss. Zu den Listen und zeitlichen Einordnungen vgl. Hertz 1991, bes. S. 329 ff. und Wilhelmy-Dollinger 2000, bes. S. $73 \mathrm{ff}$.

23 Die Auswahl der Sprecher dieses Querschnittskapitels zum Jahre 1794/95 wurde von der Absicht geleitet, sich nicht vom späteren Berühmtheitsgrad einer Person leiten zu lassen, sondern die Personen nach der tatsächlichen Möglichkeit und der Frequenz ihrer Salonbesuche im gewählten Zeitraum bzw. der brieflichen Nähe zu den Salonièren auszuwählen. Ein zweites wesentliches Kriterium musste die Quellenlage sein; es können nur zu solchen Gästen und Gastgeberinnen fundierte Aussagen getroffen werden, zu denen mehrere verlässliche zeitgenössische Zeugnisse aus der fraglichen Zeit vorliegen. Aus diesem Grunde wurde beispielsweise die Salonière Philippine Cohen ausgeklammert, zu der es zwar ein paar verlässliche Zeugnisse vor allem eines Gastes, Karl August Varnhagen, gibt, die aber, wie die wenigen noch vorhandenen Briefe der Cohen selbst, aus viel späteren Jahren stammen. Vgl. Karl August Varnhagen: Denkwürdigkeiten des eigenen Lebens. Dritte vermehrte Auflage, Bd. 1 (Ausgewählte Schriften von K. A. Varnhagen von Ense, hrsg. von Ludmilla Assing, 1. Abteilung, 1. Bd), Leipzig 1871 sowie Briefe in der Sammlung Varnhagen, meines Wissens alle ungedruckt, SV 48. Im BA ist kein Briefwechsel mit Philippine Cohen [auch nicht unter dem Geburtsnamen Zülz] überliefert, lediglich ein Wechsel eines Bankiers Cohen, vom 4. 3. 1795. Vgl. BA C.

24 Deborah Hertz hat in ihrer Kollektivbiografie der Salongesellschaft eine Liste von 69 Männern und 31 Frauen erstellt, die regelmäßig um 1800 in Berlin Salons aufgesucht hätten. Davon seien acht Männer und zwölf Frauen jüdischer Herkunft gewesen. Die Gästelisten Petra Wilhelmys sind wesentlich umfangreicher, umfassen aber jeweils die ganze Lebenszeit einer Salonière. Bei beiden wird allerdings wenig zwischen Habitués und gelegentlichen Gästen unterschieden. 
der Rezeption, von der Quellensituation und den Realitäten im gewählten Untersuchungszeitraum bestimmt. Viele der als bedeutend geltenden Bekanntschaften der Frauen waren, wie erwähnt, 1794/95 noch nicht gemacht. ${ }^{25}$ Als wesentliche Sprecher der Jahre 1794/95 wurden daher als preußische Inländer Wilhelm und Alexander von Humboldt gewählt, die nachweislich mit den genannten Frauen seit Ende der 1780er- bzw. Anfang der 1790er-Jahre verkehrten, sowie der schwedische Diplomat von Brinckmann. Dazu kommen der jüdische Medizinstudent David Veit sowie die Jugendfreundin Friederike Liman, ebenfalls jüdischer Herkunft. Alle Gäste verkehrten oder waren bekannt mit den ausgewählten vier Salonièren. Die Briefnachlässe dieser Genannten dienen sozusagen als Ausgangs- oder Knotenpunkte der Untersuchung. Die im Netz dieser Bekanntschaften weiter erwähnten Personen werden im Laufe des Kapitels vorgestellt. Dabei galt das besondere Augenmerk der Frage, wie das Verhältnis der Salonièren zu den jeweiligen Brief- und Gesprächspartnern eingeschätzt oder am Umgangston ablesbar wird und wie sich die Gastgeberinnen in der Berliner Gesellschaft damit selber verorteten. Einerseits relativiert sich dabei die Bedeutung mancher so genannten prominenten Bekanntschaft für die einzelnen Salons. Besonders bemerkenswert sind andererseits bisher in der Salonforschung noch nicht oder nicht mehr bekannte Namen von Gästen und Gastgeberinnen, die sich aus dem Studium noch ungedruckten Materials ergaben.

\section{Namen- und wurzellos? Eine Anmerkung zur Verortung der Personen}

Grüßen Sie die kleine Levy [...]

Wilhelm von Humboldt über Rahel Levin Varnhagen

(Rahel, damit Sie mich kennen;) Friederike Varnhagen.

Rahel Levin Varnhagen über sich selbst ${ }^{26}$

25 Friedrich und August Wilhelm Schlegel beispielsweise wurden erst 1797 mit den Salonièren persönlich bekannt, auch Friedrich Schleiermacher, der später engste Vertraute von Henriette Herz, war 1794/95 nur auf der Durchreise mit ihr flüchtig bekannt geworden. Die Bekanntschaft Levin Varnhagens mit Jean Paul (1800) und Heinrich von Kleist (1810) fällt ebenso in spätere Jahre wie der Aufenthalts Ludwig Börnes im Hause Herz (1802/03). Auch der engere Umgang mit den aristokratischen Frauen fand überwiegend in späteren Zeiten statt, wie etwa der Aufenthalt der Herzogin von Kurland in Berlin oder die Bekanntschaft mit den Gräfinnen Schlabrendorf und Pachta.

26 Wilhelm von Humboldt an Gustav von Brinckmann, 3. 11. 1794, in: Leitzman 1939, S. 80; Rahel Levin Varnhagen an Gustav von Brinckmann, 18. 4. 1824, in: GW III, S. 158. Sie fährt fort: „Meine Namen sind: Rahel, Antonie, Friederike; mit dem letzten unterschreibe ich alles Offizielle. Der Zug R bleibt mein Wappen.“ Ebd. 
Für Zeitgenossen, mehr noch aber für Forschende, gibt es Namens- bzw. Verortungsprobleme mit den handelnden Personen. Vor allem in der Frage der richtigen Benennung tut sich ein grundlegendes Problem der Salonforschung auf. Eine mittlerweile vielfach bestätigte These besagt, dass der mangelnde einheitliche Autorenname von Schriftstellerinnen im 18. und 19. Jahrhundert ein wesentlicher Grund für ihre schlechte Überlieferung ist. Allgemeiner gilt das für viele in der Vergangenheit gesellschaftlich aktiven Frauen, die ,vergaßen“, sich einen eigenen Namen zu machen und deren Taten so nur „unter falschen Namen“ oder gar nicht überliefert wurden. ${ }^{27}$ Bei den hier erwähnten Frauen jüdischer Herkunft um 1800 werden diese Probleme nicht nur durch mehrfache Eheschließungen, sondern vor allem dadurch potenziert, dass viele sich taufen ließen und einen neuen Vornamen annahmen. ${ }^{28}$ Einige wählten schon vor der Taufe einen christlich klingenden Vor- oder Nachnamen. So wurde bekanntlich aus Rahel Levin Mademoiselle Rahel Robert, durch Taufe und Eheschließung Friederike Antonie Varnhagen von Ense. In der zeitgenössischen Korrespondenz findet man sie aber vor allem als „die Kleine“ oder auch „die kleine Levi[!]“. Unterschiedliche Namensschreibungen sind um 1800 auch bei guten Freunden die Regel, was im konkreten Fall der Salonforschung oft Raum für Interpretation schafft, beispielsweise wenn Humboldt Brinckmann mahnt: „Grüßen Sie die Levy, oder was sonst beschnitten oder unbeschnitten an mich denkt, jene aber ganz vorzüglich.“ Hier wäre denkbar, dass er sich Sara Levy empfiehlt, wahrscheinlicher ist aber, aus dem brieflichen Kontext zu schließen, dass es sich um Rahel Levin handelt. ${ }^{29}$ Untereinander werden unter jüdischen Freundinnen auch nicht primär Vornamen verwendet, vielfach Abkürzungen oder Kosenamen, auch männlichen Geschlechts. ${ }^{30}$ Übereinander sprach man, vor allem bei verheirateten Frauen, mit dem aktuellen Nachnamen. Von den

27 Wie im Falle der Hitzel Wilhelmine Fließ Boye Sparre, getaufter Johanna Hedwig, zu zeigen ist, sind einige Salonfrauen schlecht überliefert, weil ihr Nachlass buchstäblich unter verschiedenen Namen separat bewahrt wird. So endete die Freundschaft Levin Varnhagens mit „der Boye“ scheinbar in Stralsund, während sie mit „der Sparre“ noch bis an deren Lebensende korrespondierte. Vgl. zur Namensproblematik schreibender Frauen auch grundlegend Hahn 1990(b) und Kord 1996.

28 Zur Namensverwirrung in dieser Zeit kommt hinzu, dass der Nachname jüdischer Kinder traditionell der Vorname des Vaters war. Rahel Levin hieß so als Tochter des Levin Markus. Das Edikt von 1812 sah vor, dass zur „Bürgerwerdung“ ein fester Nachname gehörte, den sich die jüdischen Bürger auswählten und bestimmten, so wurde Levin der Nachname der ganzen Familie, (die sich allerdings zuvor schon Robert genannt hatte).

29 Wilhelm von Humboldt an Gustav von Brinckmann, 3. 11. 1794, in: Leitzmann 1939, S. 80.

30 Friederike Liman nennt ihre Freundin „Liebe R.“, selbst wird sie als Franz, auch als „Du Liemann, lieber Franz“ angeredet. Vgl. Bosold 1996, passim und speziell Rahel Levin Varnhagen an Friederike Liman, 4. 2. 1815, in: Bosold 1996, S. 61. 
Töchtern Mendelssohns schrieb Rahel Levin Varnhagen: „Jettchen [...] und die Veit sind auch enchantirt von Ihnen“. ${ }^{31}$

Die Vielheit der Namensformen und der damit verbundenen Wertungen lässt sich am besten verdeutlichen am Beispiel der Salonfrau Dorothea Mendelssohn Veit Schlegel: Als Friedrich Schleiermacher von seiner Freundin Dorothea Schlegel gebeten wurde, ihr ihren Lieblingsregenschirm mit Initialen nachzuschicken, wusste er, dass er nach „BV“ für Brendel Veit suchen musste. Zweihundert Jahre später und vor allem bei weniger prominenten Frauen sind solche Zusammenhänge weniger offensichtlich. Moses Mendelssohns älteste Tochter Brendel wurde dem Bankier Simon Veit verheiratet und nannte sich bereits während der Zeit der ersten Ehe, noch vor ihrer Taufe, in den 1790erJahren, Dorothea. 1802 erst konvertierte sie und heiratete Friedrich Schlegel. Moderne Autorinnenlexika kennen sie meist unter dessen Namen, Dorothea Schlegel wird als die Verfasserin des Florentin erwähnt, ihre Briefe aber sind bis heute nur in der Kritischen Friedrich-Schlegel-Ausgabe überliefert. In der traditionellen Romantikforschung wird sie wie alle „großen Romantikerinnen“ als „Dorothea“ oder noch intimer als „die Dorothea“ geführt, eine Vertrautheit, die „dem Friedrich“ oder „dem August Wilhelm“ nie widerfährt, bis heute aber vielen prominenten Frauen im öffentlichen Leben. ${ }^{32}$ In den Briefen ihrer Freunde hingegen war Dorothea noch als Lebenspartnerin Schlegels „die Veit“. Abgesehen davon, dass es grundsätzlich fragwürdig ist, die Persönlichkeit einer Frau durch die Nennung ihres Mannes bestimmen zu wollen - oder sie zur Kultfigur zu erheben, indem man alle Nachnamen fortlässt und sie dabei ebenfalls eines eindeutigen Autorinnennamens beraubt - blendet jede Auswahl an Namen einen Teil der Biografie aus, zumeist den jüdischen ersten Ehemann. ${ }^{33}$ Wenn man weder die prägnante, aber zynische Variante Heinrich

31 Rahel Levin Varnhagen an David Veit, 1. 4. 1793, in: GW VII/I, S. 13. „Jettchen“ ist Henriette Mendelssohn, die Schwester der „Veit“.

32 Noch zu Beginn des 21. Jahrhunderts wurde die französische Präsidentschaftskandidatin Ségolène Royal oft mit dem Vornamen abgekürzt, und der Wahlkampf gegen Nicolas Sarkozy so zwischen „Sego“ und „Sarko“ ausgetragen, was, wie eine Kommentatorin zu Recht meinte, „eine Menge über die Gleichstellung“ aussagt. Nicht nur Zufall kann es sein, dass der Artikel über diesen Wahlkampf und Geschlechter in der Politik mit einem Zitat eines englischen Salonbesuchers aus dem 18. Jahrhundert beginnt: „Wenn eine Frau eine Predigt hält, so ist das, wie wenn ein Hund auf seinen Hinterbeinen läuft: Gut macht sich das nicht, man ist überrascht, es überhaupt zu erleben." Samuel Johnson, 1763. Alles nach: Franziska Augstein: Tanzende Hunde. Was können Frauen? Beobachtungen anlässlich der Präsidentschaftswahlen in Frankreich, in: Süddeutsche Zeitung, 4. 5. 2007.

33 Somit impliziert jede Namensauswahl eine Vermutung darüber, von welchem dieser Teile sich die katholisch gewordene Tochter eines Juden, die sich mit ihrem ungeliebten ersten Mann in späteren Jahren wieder gut vertrug, unter dem geliebten zweiten viele Entbehrungen zu erleiden hatte, wohl am ehesten distanziert hätte. 
Heines wählen möchte, von Schlegel ,seine würdige Gattinn Dorothea, geborne Mendelssohn und entlaufene Veit"34 $\mathrm{zu}$ sprechen, noch die Leser durch historische korrekte laufende Namenswechsel ermüden möchte, bleibt die Möglichkeit, dem Plädoyer der kritischen Salonforschung folgend, eine Kunstform einzuführen, die als solche erkennbar und eindeutig ist, wie Rahel Levin Varnhagen. „Auch dies ist ein ,falscher“ Name, den die so Bezeichnete selbst nie benutzte, aber er ist so falsch, dass er zum Nachdenken zwingt“. 35 Diese Variante wird für alle Frauen verwendet, deren Biografik durch zahlreiche Namensverschiedenheiten erschwert wurde. Frauen, die wie Henriette Herz in der Forschung eine eindeutige Bezeichnung besitzen, behalten sie auch in dieser Arbeit. Die Sprecherinnen des Querschnittkapitels sind demnach: Rahel Levin Varnhagen, Henriette Herz, Marianne Meyer Eybenberg, Sara Meyer Grotthus und Friederike Liman.

\title{
2, ,[...] gestren Abend führte uns dass Ungefähr bei Itzigs vorbey" -
}

Berlin 1794/95: Salons in der Hauptstadt Preußens

\author{
theile mir nur soviel es Dir möglich ist: alles mit: \\ ich werde nicht ermanglen zu goutiren. \\ Friederike Liman an Rahel Levin Varnhagen ${ }^{36}$
}

Dieses Kapitel präsentiert die Berliner Treffpunkte der Salongesellschaft im Jahr 1794/95. Ausgehend von der These Deborah Hertz', dass „die jüdischen Salons im alten Berlin“ ihre Attraktivität wesentlich daher bezogen, dass sie eine Lücke im Geselligkeitsangebot schlossen,,37 wurde der ausgesuchte Quellenkorpus daraufhin befragt, ob und wie die Mitglieder der Salongesellschaft die Teetische jüdischer Frauen im Wechsel mit anderen Orten geistigen oder geselligen Vergnügens aufsuchten und im welchem Verhältnis diese Kommunikationsorte zueinander standen. Die ,Salonbeschau' beginnt in den bekannten Salons, um von dort die Protagonisten und Protagonistinnen hinaus auf die

34 Heinrich Heine: Geständnisse. Geschrieben im Winter 1854, in: ders.: Historisch-kritische Gesamtausgabe der Werke (Düsseldorfer Ausgabe), hrsg. von Manfred Windfuhr, Bd. 15, Hamburg 1982, S. 9-57, hier S. 20.

35 Hahn 1990(b), S. 18.

36 Friederike Liman an Rahel Levin Varnhagen, 22. 6. 1797, in: Bosold 1996, S. 43 f. Das Zitat in der Überschrift: dies. an Rahel Levin Varnhagen, Frühjahr 1795, in: Bosold 1996, S. 5.

37 Vgl. die Bemerkungen zur Entstehung der Salons zwischen den „kommerziellen, höfischen oder intellektuellen Freizeiteinrichtungen“ in: Hertz 1990, S. 106 ff. 
Straße und an andere Orte Berlins zu begleiten und so die Salons in der Sozialgeschichte der Stadt zu verorten.

Nach einer kurzen Charakterisierung der preußischen Hauptstadt aus zeitgenössischer Perspektive ${ }^{38}$ wird das Geschehen in den Häusern der ausgesuchten Salonièren aus den vorhandenen Briefwechseln heraus beschrieben. Vorgestellt werden die Salons oder Teetische der ausgewählten Salonièren Rahel Levin Varnhagen, Henriette Herz, Sara Meyer Grotthus und Marianne Meyer Eybenberg sowie Gastgeberinnen, die in der Salonliteratur bisher kaum erwähnt wurden [2.1]. Anschließend begleitet Abschnitt 2.2 die Protagonisten in den Tiergarten und das Theater, zwei Orte, die sich für Salonkommunikation als wesentlich erwiesen. Abschließend wird danach gefragt, inwieweit Emanzipation am Teetisch zum Tragen kam, in Form und Struktur der Zusammentreffen [2.3] oder als Thema [2.4].

\section{Nachrichten von verschiedenen Dingen - Berlin in zeitgenössischen Beschreibungen}

Die Hauptstadt Preußens war im 18. Jahrhundert rasant gewachsen und zur sechstgrößten Stadt Europas geworden, die um 1790 ca. 150.000 Einwohner zählte. ${ }^{39}$ Die Anzahl der Häuser ist aus dem Jahr 1791 mit über 6.000 überliefert. ${ }^{40}$ In Wanderstunden gemessen wird der Vergleich zu den anderen im Kapitel untersuchten genannten Orten sinnfällig: Vier Stunden brauchte ein Wanderer 1801 zur Umrundung Berlins, eine Viertelstunde für Jena.

38 Als wohl bekannteste und detaillierteste Beschreibung Berlins im Untersuchungszeitraum kann der „Wegweiser“ Friedrich Nicolais gelten, eine 1793 erschienene modernisierte Kurzfassung seiner berühmten „Beschreibung der königlichen Residenzstädte Berlin und Potsdam“, die in aufklärerischer Tradition alle relevanten Informationen zur Stadt, von den Armenanstalten bis zu den Zuckerpreisen enthält. Friedrich Nicolai: Beschreibung der Königlichen Residenzstädte Berlin und Potsdam und aller daselbst befindlicher Merkwürdigkeiten. Nebst einem Anhange, enthaltend die Leben aller Künstler, die seit Churfürst Friedrich Wilhelms des Großen Zeiten in Berlin gelebet haben, oder deren Kunstwerke daselbst befindlich sind. Berlin 1769; ders.: Beschreibung [...]. Dritte völlig umgearbeitete Auflage, Berlin 1786; ders.: Wegweiser für Fremde und Einheimische durch die Königl. Residenzstädte Berlin und Potsdam und die umliegende Gegend, enthaltend eine kurze Nachricht von daselbst allen befindlichen Merkwürdigkeiten. In einem bis jetzt fortgesetzten Auszuge der großen Beschreibung von Berlin und Potsdam. Berlin 1793. Im Vergleich ähnlich detailliert, aber weniger rezipiert ist die Arbeit des Oberstabsmedicus Ludwig Formey: Versuch einer medicinischen Topographie von Berlin, Berlin 1796.

39 Formey zählt Ende des Jahres 1794149.952 und Ende des Jahres 1795156.218 Personen. Formey 1796, S. 66.

40 Nicolai 1793, 1793, Einleitung, S. II. Gerechnet wurden die Vorderhäuser. 
Durchweg gepriesen wurde die elegante Bauart im Zentrum der Stadt, die dieser den Titel einer der schönsten wenn nicht der schönsten Stadt in Europa einbrachte. ${ }^{41}$ Nicht weit von der regelmäßig angelegten Friedrichs- und Dorotheenstadt, in der sich die meisten Wohnungen der Salonteilnehmer befanden, gab es aber Ackerbauern, Ställe und mittelalterliche Gassen. Es gab „mittelmäßige“ Straßenbeleuchtung, und vielerorts wurden Nachttöpfe trotz entsprechender Verbote in die Straßen entleert. ${ }^{42}$ Durch solche Straßen musste auch, wer 1794 ein Billet zu überbringen und generell oder gerade keinen Dienstboten zur Verfügung hatte, denn städtische Briefboten wurden erst ab 1800 eingesetzt. ${ }^{43}$ Das Droschkenwesen war nicht allgemein und teuer, sodass man sich die meisten Berliner als Fußgänger vorstellen muss, Anmarschwege von drei bis vier Stunden galten nicht als ungewöhnlich.

Da es in der Salonforschung wesentlich um das Verhältnis jüdischer und nichtjüdischer Teilnehmer, Gelehrter und Dilettanten, Frauen und Männer geht, dienen folgende Zahlen dazu, einen Eindruck von der Zusammensetzung der Stadtbevölkerung, und damit von der Umgebungsgesellschaft zu bekommen: ${ }^{44}$ Bezeichnend für das Selbstverständnis der Zeit ist die Nicolaische Form der Einteilung in folgende „sechs Stände“: Militär, „Eximinierte“ (von der städtischen Gerichtsbarkeit Ausgenommene, wie Personen des Adels und königliche Räte), die „Bürgerschaft deutscher Nation“, die „französische Kolonie“, die

41 „Berlin ist ohnstreitig die schönste Stadt in Europa.“ Karl Heinrich Krögen: Freie Bemerkungen über Berlin, Leipzig, Prag [1785], Leipzig 1986, S. 8.

42 „Die Strassen werden auf öffentliche Kosten zwar so viel als möglich gereinigt und in gutem Stande erhalten, bei anhaltendem Regen nimmt jedoch der Koth so überhand, daß man in manchen Gegenden der Stadt nicht zu Fuß durchkommen kann.“ Formey 1796, S. 10. „Mittelmäßig erleuchtet“. Ebd., S.11. Formey warnte davor, die Nachteimer in die Spree zu entladen, da das Wasser zum Bierbrauen verwendet werde und Berlin ohne diese Sitte jährlich 200 Tote weniger hätte. Ebd. S. $12 \mathrm{f}$.

43 Die Hauptstadt Preußens war aus fast allen Himmelsrichtungen nur über Sandpisten zu erreichen, die einzige befestigte Chaussee im Land war die Verbindung nach Potsdam, und selbst die schönste Promenade der Stadt, Unter den Linden, war so staubig, dass man um 1800 Wasserspritzen einsetzte.

44 Aussagen über die ständische oder geschlechtsspezifische Aufteilung der Stadt sind nur vorsichtig zu treffen, da diese Unterteilungen in den zeitgenössischen Statistiken kaum oder vergröbert unternommen werden. Friedrich Nicolai bietet in der dreibändigen Ausgabe seines Stadtführers von 1786 eine „nach den Geschlechten u. Ständen“ geteilte Tabelle, die durchgängig einen gewissen Frauenüberschuss zeigt, allerdings bei den Juden und beim Militär die Frauen bzw. mitgerechneten Soldatenfrauen nicht separat aufführt. 1784 hatte es in Berlin demnach u. a. 3.372 Juden, 971 Böhmen, 5.168 Angehörige der französischen Kolonie gegeben. Zu den 33.386 Personen in der Garnison (,mit ihren Weibern und Kindern, aber ohne Beurlaubte“) kamen 52.249 Männer und 59.286 Frauen verschiedenen Zivilstandes. Nicolai 1786, Bd.1, S. 241. 
„böhmische Kolonie“, und die „Judenschaft“. 45 Die Zahl der Juden in Berlin lag zwischen 1780 und 1803 relativ konstant bei 3.000 bis 3.600 Personen, das waren etwa zwei Prozent der Einwohnerschaft. ${ }^{46}$ Der Anteil der Militärpersonen mit Familien belief sich 1790 auf etwa 28.000 Personen (ca. 18\%), im Textilgewerbe, dem stärksten Berufszweig der Stadt arbeiteten ebenfalls etwa 28.000 Personen. ${ }^{47}$ Selten erwähnt, aber nicht unwesentlich im Stadtbild waren die Armen, zu denen etwa 13.000 Personen gezählt werden müssen. ${ }^{48}$ Eine Folge der hohen Frauenarmut zum Beispiel war die in Reisebeschreibungen der Zeit vielfach diskutierte Prostitution in Berlin. Trotz eines Bordellreglements von 1792 war die hohe Anzahl der Bordelle in der Stadt, zu denen auch zahlreiche „Tabagien“ und Tanzböden gerechnet werden mussten, für Besucher wie Behörden immer wieder Anlass zur Debatte. ${ }^{49}$

Reisende, die sich dafür interessieren, erwähnen als weiteren Nachteil der Großstadt, gleichauf mit dem hohen Niveau verschiedener Künste in der Stadt, auch die große Menge der Ungebildeten. ${ }^{50}$ Vor dem Hintergrund dieses stark verknappten Bildes muss an dieser Stelle daher noch einmal betont werden:

45 Nicolai 1786, Bd.1, S. 242-260.

46 Vgl. die Zahlen bei Stefi Jersch-Wenzel: Jüdische Bürger und Kommunale Selbstverwaltung in Preussischen Städten (Veröffentlichung der Historischen Kommission zu Berlin beim Friedrich-Meinecke-Institut der Freien Universität Berlin, Bd. 21.), Berlin 1966, S. 19. Nach Jersch-Wenzel schwankte der Anteil der Juden zwischen 1750 und 1817 zwischen 1,7 und 2,8\% der Stadtbevölkerung. Bruer zählt 1750 2.188 Juden in Berlin, 1790 3.379. Albert Bruer: Preußen und Norddeutschland 1648-1871, in: Kotowski / Schoeps / Wallenborn 2001, Bd.1, S. 47-66, hier S. 51.

47 Zahlen nach Ilja Mieck: Berlin um 1800, in: Wolfgang Ribbe (Hrsg.): Geschichte Berlins. 1. Band: Von der Frühgeschichte bis zur Industrialisierung. (Berlin-Forschungen der Historischen Kommission zu Berlin. Bd. 2/1) Berlin 1980, S. 407-421.

48 Eine Beschreibung von 1801 zählte hierzu die so genannten „Stadtarmen“, die bei der königlichen Armendirektion gemeldet waren, dazu arme Personen in Armenhäusern und Hospitälern. Mieck 1980, S. $417 \mathrm{f}$.

49 In dem Reglement wurde Prostitution verboten, aber geduldet, solange die Frauen sich registrieren ließen. Alle Registrierten und Bordellwirte mussten in eine „Hurenheilungskasse“ einzahlen, von der Behandlungen in der Charité finanziert wurden. In der lang anhaltenden Debatte gewannen im Laufe des 19. Jahrhunderts die Gegner der Prostitution die Oberhand, allerdings blieb nicht die Abschaffung der Prostitution, sondern ihre Reglementierung maßgebliches Ziel der Behörden. Ludwig Formey zählte 1796 über 80 Bordelle, was dem „Niveau“ einer Großstadt entsprach. Formey 1796, S. 112. Vgl. grundlegend: Dietlind Hüchtker: Prostitution und städtische Öffentlichkeit. Die Debatte über die Präsenz von Bordellen in Berlin 1792-1846, in: Ulrike Weckel / Claudia Opitz / Olivia Hochstrasser / Brigitte Tolkemitt: Ordnung, Politik und Geselligkeit der Geschlechter im 18. Jahrhundert, Göttingen 1998 (Das Achtzehnte Jahrhundert. Supplementa), S. 345-364.

50 „Die Erziehung bei vornehmen und geringen Personen ist so elend [...]. Man sollte nicht glauben, dass in einer Stadt, wo der Sammelplatz alles Schönen und alles Vortrefflichen und 
wenn nach Emanzipation qua Salon gefragt wird, handelt es sich um ein sehr elitäres Phänomen.

\subsection{Emanzipation in oder von der Jägerstraße? Teetische, Dachstuben und offene Häuser}

\section{Offenes Haus - Zu Gast bei „Rahel“ und Familie Levin}

Mit Blick auf die in der Forschung formulierte These, „Rahels Dachstube“ sei symbolischer Ausdruck für die Entfernung der Salonièren zu ihren Herkunftsfamilien, ${ }^{51}$ stellt sich die Frage, wie sich, sofern an den Quellen ablesbar, das Verhältnis zwischen der Geselligkeit und der Familie einer Salonièren gestaltete. Um im Bild zu bleiben: inwieweit machte der Salon für Rahel Levin Varnhagen, topografisch und familienhistorisch, den Abstand $\mathrm{zu}$ ihrer Herkunft möglich und nötig, ging es um die Emanzipation von oder in der Jägerstraße?

Der Stadtteil Friedrichsstadt galt Ende des 18. Jahrhunderts als ,jetzt der ansehnlichste Theil von Berlin“, in dem viele vornehme Familien ihre Wohnhäuser hatten.52 Zwar gab es noch verschiedene Gewerke in der Gegend, das Hauptkomptor der Seehandlung ebenso wie einen Kräuter- und Fischmarkt auf dem zentralen Platz, aber seit die Pferdeställe des namensgebenden Regiment Gensd'armes 1773 verlegt worden waren und der Platz vergrößert war, hatte die Gegend ein mondänes Zentrum gewonnen. Die Erscheinung der französischen Kirche wie der „neuen Kirche“ „macht einen ungemeinen Eindruck“.53 Um Hannah Arendts Formulierung fortzuführen, war der Salon Levin Varnhagen ein ,exterritorialer Ort‘54 - mitten in der Stadt. Rahel Levin Varnhagens Gäste hatten Wohn- und Arbeitsorte in der Nähe. Um einige der um 1795 relevanten zu nennen: Die Familie Humboldt hatte ein Stadthaus gleich in der Jägerstraße gegenüber, Prinz Louis Ferdinand ein Palais in der Friedrichstraße, gegenüber dem heutigen Bahnhof. Der Stammgastdiplomat Brinckmann hatte eine Wohnung

Außerordentlichen ist, die Sitten so ruchlos und verwildert und die Aufklärungen gleichsam noch in ihrer Kindheit seien.“ Krögen 1986, S.12.

51 Peter Seibert sieht die Dachstube als Ort für den „Rückzug“ von der Familie, „als notwendiges Ausgliedern des Kerns ihrer Geselligkeitsformation aus dem jüdisch-orthodoxen Haus“. Seibert 1993(a), S. 109.

52 Nicolai 1786, Bd.1, S. 183.

53 Nicolai 1786, Bd.1, S. $202 \mathrm{f}$.

54 Die These der - doppelten - Exterriorialität wurde erstmals formuliert von Hannah Arendt: „Der jüdische Salon in Berlin war der soziale Raum außerhalb der Gesellschaft, und Rahels Dachstube stand noch einmal außerhalb der Konventionen und Gepflogenheiten auch des jüdischen Salons“. Arendt 2001, S.71. 
am Wilhelmsplatz, später beim schwedischen Botschafter in der Letzten Straße, sein portugiesischer Kollege Navarro wohnte Unter den Linden. Die Schauspielerinnen Baranius, Eigensatz und Unzelmann wohnten direkt ,am Gensd'armesmarkt" ${ }^{55}$ Friederike Liman wohnte in der Jägerstraße in unmittelbarer Nähe. Ihr Mann, der Kaufmann Nathan Liepmann, erwarb das Eckhaus Jägerstraße 20 / Ecke Charlottenstraße 1795. Der Kaufpreis verrät ebenfalls etwas über den Wohnwert in dieser Straße, er betrug 11.300 Reichsthaler. ${ }^{56}$ Bezeichnend daneben der Bericht, den Friederike Liman über ihr neues Zuhause an ihre Freundin schrieb: „in der gäger strasse über dem Jensd'arme margt dicht am französischen weisen haus von der Ecke ein sehr niedliches neues Haus 7 ben fenster breit, mit ein gärtchen dabey kurts wo man sehr glücklich seyn kann“. ${ }^{57}$ Dass ihre Freunde auch von der Jägerbrücke $e^{58}$ als Metapher für den Salon bzw. das Haus Rahel Levin Varnhagens sprachen, lag daran, dass das Haus der Levins nicht unweit eines jetzt trockengelegten Flussarmes lag, und dass bis zum Nachbarhaus die damals noch notwendige Jägerbrücke reichte. ${ }^{59}$

Als David Veit 1793 Berlin verließ, muss die Geselligkeit im Hause Levin bereits so etabliert und rege gewesen sein, dass die Briefe - er hatte um regel-

55 Adreß-Calender der Königlich=Preußischen Haupt= und Residenz=Städte Berlin und Potsdam besonders der daselbst befindlichen hohen und niederen Collegien, Instanzen und Expeditionen auf das Jahr 1795. Mit Genehmigung der Königl. Preuß. Academie der Wissenschaften, Berlin 1795, S. 162 f., 396 f. Die Adressangaben der „Geschäftsträger“ verschiedener Provenienz und zahlreicher Schauspieler im Adreß-Calender Berlin 1794 und 1795 bestätigen ,Laufnähe' der Gäste zum Haus der Levins.

56 Vgl. Grundbucheintrag Friedrichstadt 897, Kaufvertrag mit dem Bankier Abraham Nathan Liepmann, vom 27. 9. 1795, Grundbucheintragung vom 11. 3. 1796. Das Haus wurde 1821 an Rahels Bruder Markus Theodor Robert-Tornow verkauft. Für diesen Hinweis danke ich Sebastian Panwitz.

57 Friederike Liman an Rahel Levin Varnhagen, 4. 8. 1795, in: Bosold 1996, S. 29 f. Alle Schreibung original.

58 Jägerbrücke war sowohl die Adresse wie auch ein Synonym für den geselligen Ort: Esther Gad adressierte 1798 einen Brief nur „An die Demoiselle Rahel Lewin wohnt auf der Jägerbrüke in Berlin“. Esther Gad an Rahel Levin Varnhagen, 4. 2. 1798, ungedruckt, SV 53. Liman berichtete 1795, dass trotz der Abwesenheit ihrer Freundin deren Kraft „auf mich hinprelt und mich nach der Jägerbrüke hinschnelt“. Friederike Liman an Rahel Levin Varnhagen, 6. 6. 1795, in: Bosold 1996, S. 7. Und Brinckmann schrieb aus Ostpreußen nostalgisch: „Von der Memel bis zur Jägerbrücke ist noch ein langer Weg [...].“ Gustav von Brinckmann an Rahel Levin Varnhagen, 2. 8. 1807, dies Zitat ungedruckt, SV 38.

59 Vgl. die Eintragung im Berliner Adressbuch von 1799: Mit den Häusern der Witwe Huob in Nr. 27 bzw. der Witwe Estienne wird die Jägerstraße zur Jägerbrücke. Karl Neander von Petersheiden: Anschauliche Tabellen von der gesammten Residenz-Stadt Berlin, worin alle Straßen, Gassen und Plätze in ihrer natürlichen Lage vorgestellt, $u$. in denenselben alle Gebäude oder Häuser wie auch der Name u. die Geschäfte eines jeden Eigenthümers aufgezeichnet stehen, Berlin 1799, S. 60. 
mäßigen Bericht über ihre Unternehmungen und ihre Lebenssituation gebeten - nicht selten damit begannen, die Besucher des jeweiligen Tages zu nennen. Tatsächlich empfing sie keineswegs nur an einem Wochentag, sondern es verging kaum ein Tag, an dem niemand Visite machte. Klagen über durch Besucher unterbrochenes Schreiben waren die Regel, allerdings wurden auch Klagen, dass sie niemanden sähe, von Besuchern unterbrochen.

Hinweise zum Ablauf der Besuche wurden hingegen kaum gegeben, vermutlich weil Veit als enger Freund des Hauses dessen Gepflogenheiten kannte. Es ist aber auffallend, dass Rahel Levin Varnhagen mal von „meinen“ und mal von „unseren“ Besuchern sprach. So räsonierte sie: „Was kommen für Visiten jetzt in unser Haus“, aber auch über „die Herz ganz allein bei mir oben“.60 Detailliertere Berichte über Ereignisse, in die Familienmitglieder involviert waren, nannte sie „unsere Hausnachrichten“, daneben wurden Einzelgespräche in ihrem Zimmer erwähnt. ${ }^{61}$ Anders als oft vermutet, gibt es nach dem Leseeindruck anno 1794/95 kein Entweder-Oder zwischen Familienangelegenheit und individuellem Salon, sondern beide Formen der Geselligkeiten standen zumindest in diesen Jahren nebeneinander.62 Die Treffen „bei Rahel“ oben hatten vermutlich intimeren Charakter, vor ihrer Tür erwähnte sie zum Beispiel einen Spind mit Weißzeug, das heißt ihre Besucher mussten an einem Wäscheschrank vorbei. ${ }^{63}$ In ihrem Zimmer standen zumindest ein Lesetisch, ein Ofen und das vielzitierte „Sopha“, an welches Gustav von Brinckmann sich später als grün erinnerte. ${ }^{64}$ Nicht nur der schwedische Diplomat schwärmte von der Dachstube, Rahel selbst benutzte dieses Wort, und zwar bereits $1794 .{ }^{65}$ Wichtig

60 Rahel Levin Varnhagen an David Veit, 25.1. 1794 und 10. 10. 1793, in: GW VII/I, S. 132 bzw. 32.

61 Rahel Levin Varnhagen an David Veit, 13.12. 1794, in: GW VII/I, S. 83.

62 Dafür spricht u. a. auch eine nostalgische Briefstelle Karl August Varnhagens, der rückblickend an seine Frau schrieb: „Gestern abend stand ich lange, lange vor Deinen Fenstern in der Jägerstraße, sah nach der Wohnstube, nach der Dachstube, dachte an alles, was da geschehen und erlebt worden.“ Karl August Varnhagen an Rahel Levin Varnhagen, 20. 6. 1815, in: Kemp II, S. 302.

63 „Meine Schwägerin, die vor meiner Thür an ihrem Weißzeugspinde packt“, Rahel Levin Varnhagen an David Veit, 31. 10. 1794, in: GW VII/I, S. 258.

64 Gustav von Brinckmann an Rahel Levin Varnhagen, 2. 8. 1807, dies Zitat ungedruckt, SV 38. Hier spricht er von „Ihrem grünen Sofa, dessen elastische Kissen sich jedem Verhältnis so gut anzuschmiegen wussten“. Hervorhebung im Original. Den „Offen“ bat Rahel Levin Varnhagen vor ihrer Rückkehr putzen zu lassen. Rahel Levin Varnhagen an Line Brack, in einem Brief an Markus Levin, 23. 8. 1794, in: ERLV III, S. 32.

65 „Ihre zwei besten Freunde sitzen jetzt in meiner Dachstube.“ Rahel Levin Varnhagen an David Veit, 3. 1. 1794, in: GW VII/I, S. 105. Der früheste Nachweis von Brinckmanns

Nostalgisierung findet sich m. W. 1798, als er seiner Freundin aus Paris versicherte, „daß ich weit öfters, als Sie es ahnden mögen, mit meinem Geist in Ihrem freundlichen Dachstübchen zugegen bin.“ Gustav von Brinckmann an Rahel Levin Varnhagen, 7. 10. 1798, SV 38. 
ist außerdem, dass die Besucher der Dachstube nicht notwendigerweise alle zur selben Zeit kamen. Zum „Salon der Rahel“ gehört neben größeren „Nachtthees" ebenso eine Reihe von Einzelbesuchern, die ohne Einladung vorbeischauten. ${ }^{66}$

Aus mehreren Korrespondenzen gewinnt man den Eindruck, dass Geselligkeit im Haus Levin in den 1790er-Jahren als eine Art Familienbetrieb stattfand. ${ }^{67}$ David Veit wechselte Grüße mit allen Familienmitgliedern, stand in engerem Kontakt auch mit Rahels Bruder Markus, den er mehrfach auf der Leipziger Messe traf. So wie er „die Liman“ in fast jedem Brief erwähnte, so pflegte auch diese einen innigen Grußaustausch mit der ganzen Familie Levin. ${ }^{68}$ Sie berichtete der abwesenden Freundin Interna aus deren Familie und sprach dabei von deren Familie als von „Mama“ und „Röschen“ bzw. von Rahels Schwägerin als „Hans“, dem familieninternen Spitznamen. Könnte man hier noch vermuten, dabei handele es sich um besonders innige Freundschaftsverhältnisse innerhalb der jüdischen Oberschicht, ändert sich das Bild, wenn man einen Blick auf den Briefwechsel Levin Varnhagens mit Brinckmann wirft. Auch der schwedische Diplomat, der in der Forschung als ihr „Habitué“, also Stammgast ihres Salons geführt wird, stand in brieflichem Kontakt mit der ganzen Familie Levin. Mehr noch: Während der Abwesenheit der Salonière besuchte er deren Familie, teilte mit ihnen gelegentlich ein Abendbrot und führte Debatten, unter anderem über das Talent verschiedener Schauspielerinnen. Der Bericht darüber an seine Freundin Rahel Levin Varnhagen „Abends $10 \mathrm{Uhr}$ an dem Schreibtisch Ihres Bruders“ begann in medias res:

,Fangen Sie nicht mit der Unzelmann an, lieber mit der Baranius ‘ - So rief mir Ihre Mutter zu, als ich beim Aufstehen vom Tische den Entschluß fasste, Augenblicklich an Sie zu schreiben. Sie können hieraus also auf den Inhalt unseres Gesprächs schließen. In der

66 Vgl. das weiter unten und das eingangs zitierte Billet: „Sie sind gewiß schon vom König. Bei uns ist heut Nacht=Thee; [...] Bringen Sie doch Ihren Nachbar mit, wenn er schon zu Hause ist, und hinterlassen Sie's ihm, wenn er's nicht ist. Ich erwarte Sie. R. L.“ Rahel Levin Varnhagen an Gustav von Brinckmann, o. D., ungedruckt, SV 38. Der Nachbar war Wilhelm von Burgsdorf, damit ist das Billet vermutlich vor dessen Reise nach Paris 1797 zu datieren. 67 Die Briefe dieser Familie, Nachlass und auch Abbild dieses „Betriebes“, in der Sammlung Varnhagen überliefert, sind erst 2009 veröffentlicht worden. Vgl. ERLV III. Der Band enthält 644 Briefe, formal nicht mit aufgenommen, aber inhaltlich ausgewertet wurden kleinere Billets und Zettel mit praktischen Informationen. In dieser Arbeit wird vorrangig nach den Originalen zitiert. Die Forschung zu diesem einzigartigen Material steht erst am Anfang. Auch der gedruckte Briefwechsel mit Ludwig Robert bietet noch viele unerledigte Forschungsaufgaben.

68 Vgl. Friederike Liman an Rahel Levin Varnhagen, in: Bosold 1996, passim. 
That, meine liebe Freundin! wie kann man eine Mutter haben, die in einem solchen Götzendienst lebt, und die B. in allem Ernst der göttlichen U. vorzieht. ${ }^{69}$

Bildlich gesprochen war er damit nicht nur Gast an ,Rahels Teetisch', sondern ebenso am Esstisch der Familie, deren Schreibtische er ebenfalls mitbenutzte. Ähnlich zuhause muss sich Brinckmann auch im Hause der Familie Ephraim gefühlt haben, aus dem er frohgemut einen Brief mit folgender Absenderangabe schrieb: „Berlin, den 21. Juli 1794, und zwar von Jeannettens Schreibtisch in Gegenwart aller drei Schwestern also doch gewiß hinlänglich begeistert“".70 Bei einer umfangreicheren Quellenlage könnte untersucht werden, ob auch Schreibtische durchgängig zu den öffentlichen Orten der Salonkommunikation gezählt werden können. Der geteilte Tee- und Schreibtisch spiegelte sich auch optisch in manchen Briefen wieder. Nicht nur wurden Dialoge nacherzählt, mehrfach kam es zu gemeinsam erschriebenen Dialogen Brinckmanns mit Mitgliedern der Familie Levin an die abwesende älteste Tochter. Am eingangs zitierten Freitag, 21. 8. 1795, schrieb Brinckmann beispielsweise aus dem Hause Levin über seine letzten Unternehmungen und Bekanntschaften. Markus Levin gab auf demselben Bogen seiner Freude Ausdruck, dass es seiner Schwester gut gehe und vermisste sie in der Erziehung „unserer jungen Freunde“, womit seine Kinder gemeint waren, um die die Tante sich sehr kümmerte. Das wiederum kommentierte seine Frau Hendel Levin mit „Wohl gesprochen alter Maulwurf!“ und einer Anmerkung zum Theaterprogramm der Stadt..11

Der öffentliche Charakter der Briefe muss derart selbstverständlich gewesen sein, dass, sollte etwas privat bleiben, explizit darum gebeten werden musste, etwa indem Rahel ihre Freundin Friederike Liman instruierte, Briefe vorab zu lesen, damit ihre Mutter nichts in die Hände bekäme, was sie nicht wissen solle. ${ }^{72}$ Im Allgemeinen waren aber die Briefe der ,Organisatoren' untereinander sehr offen und lassen auf eine Zusammenarbeit der Familie in der Geselligkeit schließen. ${ }^{73}$ Nicht nur mahnte die Salongastgeberin in ihren Brie-

69 Gustav von Brinckmann an Rahel Levin Varnhagen, 5. 7. 1793, ungedruckt, BA V.

70 Gustav von Brinckmann an Rahel Levin Varnhagen, 21. 7. 1794, ungedruckt, SV 38.

71 Gustav von Brinckmann, Markus und Hendel Levin an Rahel Levin Varnhagen, 21. 8. 1795, BA V, teilweise in: ERLV III, S.54. Mit „Well said, old Mole“ zitiert Hendel Levin hier Shakespeare, Hamlet $(1,5)$.

72 Als Liman nach Freienwalde ging, bat sie eine Freundin darum, diesen Postservice zu übernehmen, „daß sie sie erbricht um zu sehen daß auch nichts drin stehet was mama nicht lesen soll.“ Friederike Liman an Rahel Levin Varnhagen, 30. 6. 1795, in: Bosold 1996, S. 20. 73 Zum familiären Zusammenhalt der Familie Levin s. jetzt: Renata Buzzo Màrgari Barovero: Rahel Levin Varnhagen. Familienbriefe. Nachwort, in: ERLV III, S. 1415-1451. 
fen etwa aus Breslau bei ihrer Familie Grüße an ihre Gäste und Bekannte an. ${ }^{74}$ Ihre Familie in Berlin traf die Gäste durchaus auch in Eigeninitiative. „Was mich sihet läst dich grüßen“, hieß es von Chaie Levin $1795 .{ }^{75}$ Bei ihr und „Hans“, ihrer Schwiegertochter Hendel, trafen sich in Abwesenheit der Salonière dann auch Friederike Liman, Brinckmann, Navarro und „die Fränkel“ zum Tee, gelegentlich luden die Frauen auch Künstlerinnen wie die Sängerin Marchetti oder die Schauspielerin Unzelmann ein. ${ }^{76}$ Der Übergang zwischen der Kontaktpflege zu Rahels Gästen und einer Einladung in Eigeninitiative war fließend, wie ein Brief der Schwägerin zeigt: „Denke Dir, ich traue meinen Augen kaum! so eben kommt Scholz herein [...] er bedauert Dich nicht zu finden etc. -.- ich habe ihn gleich zu einem kleinen Soupé, welches ich heute gebe gebeten. Ich mus Dir auch die Personen schreiben. Die Marchetti Sartori Navarro Q. die Flies, die Eigen. Liepmanns, die Sal. und Nanette“.77

Man kann sagen, in den Familienbriefen wird der Salon als Familienunternehmung augenfällig. Auch das Aphoristische, Springende, das die Forschung an den Briefen Rahel Levin Varnhagens mehrfach konstatiert und untersucht hat, findet sich bei fast allen Familienmitgliedern. So hieß es im oben zitierten Brief von Markus nahtlos weiter: „Dass übrigens ein Jeder relatif so ohnmächtig ist als ich, kann einen Narren trösten, und einen Vernünftigen närrisch machen. Ich bitte nur den Unerbittlichen mir meinen pflanzenartigen Gemüth zu erhalten, und erkenne dankbar dieses große Geschenk“". ${ }^{78}$ Und Chaie Levin begann ihre Briefe an Rahel mit Sentenzen wie: „ich bite dich laße die Welt

74 Mancher Brief enhält eine längere Liste Grußaufträge, unter anderem mit Wünschen wie „Grüß die Unzin“, „Marcus vergeß Schechtitzky Pr: Meyer und Plöschke nicht, Franz grüß Schechtitz“, „Grüßt Navarro und vielevielemale Brinckmann der diesen Brief lesen soll“. Rahel Levin Varnhagen an Markus Levin, 16. 8. 1794, in: ERLV III, S. 30. „Unzin“ ist Friederike Unzelmann, „Schechttitz“steht für Karl Czechtitzky, Schauspieler.

75 Chaie Levin, auf der Rückseite eines Briefes von Rose Levin an Rahel Levin Varnhagen, 23. 6.[?] 1795, SV 214, auch in: ERLV III, S. 49.

76 Chaie Levin an Rahel Levin Varnhagen, 23. 6. 1795 und 29. 8. 1795; Hendel Levin an Rahel Levin Varnhagen, 29.9. 1795, SV 214, auch in: ERLV III, S. 50 und 57. Die Gesellschaften bei „Mama“ und „Hans“ werden von Friederike Liman bestätigt, mehrfach tauchen

Formulierungen auf wie: „Hans hat die Marchetti diese Woche bitten lassen“, Friderike Liman an Rahel Levin Varnhagen, 3. 10. 1795, in: Bosold 1996, S. 40.

77 Hendel Levin an Rahel Levin Varnhagen, 13. 10. 1795, in: ERLV III, S. 58. „Q.“ könnte für Peter Gualtieri stehen, der auch Peter „Qualtieri“ geschrieben wurde „Nanette“ ist Nanette (später Anna Conradine) Marcuse, eine Nichte Friederike Limanns. „die Eigen“ meint die Schauspielerin Christel Eigensatz oder ihre Mutter, „Flies“ meint die weiter unten vorgestellte Salonfrau Hitzel Fließ Boye Sparre.

78 Markus Levin an Rahel Levin Varnhagen, 21. 8. 1795, als Nachschrift in einem Brief Gustav von Brinckmanns, BA V, dieser Teil auch in: ERLV III, S. 54. 
aus ihre fugen, du krigst sie nicht wieder rein“"19 Daneben stand Sachliches und Organisatorisches. Markus Levin beschrieb seinen Anteil an der Geselligkeit einmal explizit, an dem eingangs zitierten Tag:

\begin{abstract}
Schreibe mir nur wie alles zum Empfang der Gräfin besorgt werden soll, und du kannst Dich alsdann darauf verlassen dass es geschieht.//. brauchst Du mir Deinen Dank zu äußern? Gib ihn andern guten Menschen doppelt, den es noch wohlthut: ermuntert zu werden, zur Vernunft und richtigen Empfindung. Ich vermag so wenig! und wenn $D u$ vollends dafür danken willst, so fühle ich das schwehr. ${ }^{80}$
\end{abstract}

Dieser Ton unterfüttert sozusagen die Leichtigkeit anderer Billets aus dieser Zeit und deutet an, dass Geselligkeit nicht nur einen Ton, sondern auch eine Infrastruktur brauchte. Quellen wie diese legen zugleich nahe, sich das Haus Levin als ein für Gäste verschiedener Herkunft offenes Haus vorzustellen, mit der Möglichkeit etagenübergreifender Geselligkeit. Anders herum betrachtet war zur Aufrechterhaltung einer regelmäßigen Geselligkeit im Hause Levin die Einbeziehung der Familie auch höchst notwendig, da die Salonière oft monatelang, 1794 und 1795 jeweils von Juni bis September, nicht in Berlin weilte. ${ }^{81}$

Die Frage, wer 1794/95 alles zu den Besuchern dieser prägnant formulierenden Familie zählte, wer in den Worten Rose Levin Assers „un des notres“ war, ${ }^{82}$ ist nicht vollständig zu beantworten. Vergleicht man allein in den zeitgleichen Briefen Rahel Levin Varnhagens an Veit und Liman die namentlich genannten Gäste des Hauses Levin, ergeben sich unterschiedliche Gästelisten. Die zahlreichen und regelmäßigen Besuche der Schauspielerin Unzelmann oder bei der Unzelmann finden überwiegend bei der Liman Erwähnung. Als gemeinsamen Bekannten erwähnt Rahel Levin Varnhagen umgekehrt einen Doktor Bing, vermutlich Abraham Herz Bing, 83 auch Mediziner, nur gegenüber

79 Chaie Levin an Rahel Levin Varnhagen, 1. 8. 1795, SV 214, leicht anders gelesen („kanst“) auch in: ERLV III, S. 44.

80 Markus Levin an Rahel Levin Varnhagen, 21. 8. 1795, als Nachschrift in einem Brief Gustav von Brinckmanns, BA V, dieser Teil auch in: ERLV III, S. 54.

81 Im Juni und Juli 1794 in Freienwalde, unternahm sie im August eine Reise nach Breslau, war im September wieder in Berlin. Anfang Juni 1795 ging es über Dresden nach Karlsbad und Teplitz, wo sie bis September blieb, um denn wieder nach Leipzig zu fahren. Die Reisetätigkeit einer Salonière wird dabei am Beispiel der bestüberlieferten Frau Berlins um 1800 nachvollzogen, ist aber auch bei anderen Salonièren nachzuweisen. Zumindest von den wohlhabenden Meyers kann angenommen werden, dass sie sich regelmäßig zu Kur- oder Geschäftsreisen außerhalb der Stadt befanden.

82 Rose Levin Asser an Rahel Levin Varnhagen (über einen neuen Gast der Familie), 22. 8. 1796, in: ERLV III, S. 59.

83 Abraham Herz Bing (1769-1835) war Arzt in Berlin und Mitglied der Gesellschaft der Freunde. Panwitz 2005, S. 127; Jacob Jacobson (Hrsg.): Jüdische Trauungen in Berlin 17591813. Mit Ergänzungen für die Jahre 1723 bis 1759, (Veröffentlichungen der Historischen 
David Veit. Mehrfach machte Gelegenheit das Thema: Das Ehepaar Stieglitz ${ }^{84}$ wurde beispielsweise Liman gegenüber nicht erwähnt, mit Veit aber ausführlich diskutiert, da er sie gerade in Hannover getroffen hatte. In den Korrespondenzen mit Veit, Liman und ihren Familienmitgliedern übereinstimmend und mehrfach aus dem Zeitraum 1794/95 als häufige Gäste von Rahel Levin Varnhagen wurden folgende Personen genannt: der spätere preußische Geschäftsträger Hieronymus Scholz (oder Scholtz), Hauptmann Ferdinand Cuhn, Musikdirektor Carl Bernhard Wessely, die Diplomaten Navarro D'Andrado und Gustav von Brinckmann. Damit trafen sich im Salon Levin wirklich Personen verschiedener Nationalitäten und Stände, wenn auch andere, als oft berichtet. ${ }^{85}$ Besonders häufig genannt wurden weiterhin die Schauspielerin Friederike Unzelmann und die Sängerin Maria Marchetti. ${ }^{86}$ Damit fanden sich repräsentative Vertreterinnen der zwei großen hauptstädtischen Bühnen bzw. zwei der populärsten Künstlerinnen Berlins um 1800 im engeren Freundeskreis der Levins. ${ }^{87}$ Wichtig ist festzuhalten, dass alle in den Briefen sowohl einzeln als auch in verschiedenen Zusammenstellungen auftraten. Einen einzigen Tag beschrieb die Gastgeberin einmal so: „Schreiben Sie einmal, wenn Mad. Lüdeken, zwei Kinder aus Hamburg, Scholz, Markus, Bing, Fließ, Peschier, Brinckmann, Herr Koch, die Veit, Jettchen, die Marchetti, und wer weiß was noch in einem Vormittag zu Ihnen kommen". ${ }^{88}$ Neben dem schwedischen Adligen Brinckmann

Kommission zu Berlin beim Friedrich-Meinicke-Institut der Freien Universität Berlin, 28; Quellenwerke, 4), S. 440.

84 Israel (später Johann) Stieglitz, auch Israel Hannover genannt (1767-1840), Jugendfreund Wilhelm von Humboldts, war nach einem Medizinstudium in Göttingen Arzt in Hannover, später Obermedizinalrat, Autor medizinischer Schriften. Zu seiner Frau Jente / Jeannette s. u. „Wiederzuentdeckende Gastbegerinnen“.

85 Rodrigo Navarro d'Andrado (1774-1839), auch als D’Andrago überliefert, war portugiesisches Gesandtschaftsmitglied in Berlin. Carl Bernhard Wessely (1768-1826), war Komponist und Orchesterleiter, Verwandter des Philosophen Naphtali Hartwig Wessely. Über Ferdinand Cuhn vermerkt Varnhagen: „Haupt-mann, nachher Major von Cuhn, erst in waldeckischen, dann in darmstädtischen Diensten. Ein merkwürdiger Mensch, voll Kraft, brennender Begier, heißer Gewalt!“, SV 50, zit. nach: Bosold 1996, S. 10, Fn. 29.

86 Vgl. die Einträge im Handbuch über den königlich preussischen Hof und Staat auf das Jahr 1794, Berlin. Maria Marchetti Fantozzi (1767-1807) war seit 1792 Primadonna der Hofoper mit 3.000 Talern Jahresgehalt, Friederike Unzelmann, mit vollständigem Namen Christiana Friederike Augustine Conradine Bethmann-Unzelmann (1760-1815), war die bekannteste Schauspielerin des Nationaltheaters. Von zahlreichen Mitgliedern der Salongesellschaft sind komplimentierende Gedichte an sie überliefert.

87 Besonders im Familienbriefwechsel werden noch weitere Personen aus dem Umfeld der Schauspielerinnen erwähnt, so der Schauspieler Karl Cechtitzky, und Herr von Quast, sowie Madame Eigensatz, die Mutter der Schauspielerin Christel Eigensatz.

88 Rahel Levin an David Veit, 24. 4. 1795, in: GW VII/I, S. 220. Die 1795 mehrfach genannten Mad. Koch und Herr Koch sind vermutlich das Schauspielerehepaar Koch aus Berlin. Ob es 
bestand ihr Umgang an diesem Vormittag damit gleichermaßen aus Familienmitgliedern oder Jugendfreundinnen (Markus, Kinder, [Dorothea] Veit, Jettchen [Mendelssohn]) und einem jüdischen Mediziner (Bing), sowie aus Künstlern (Koch, Marchetti) und heute wenig bekannten preußischen Beamten (Scholz). ${ }^{89}$ Unter ihren Besuchern waren nicht wenige Personen, die in der Sekundärliteratur zum Salon nicht genannt sind, und deren Biografien heute schwierig zu recherchieren sind, wie etwa die Jugendfreundinnen Hitzel Fließ Boye Sparre und Sophie Meyer Fränkel, auf die nachstehend noch eingegangen wird. ${ }^{90}$ Wichtig festzuhalten ist weiterhin, dass Namen christlicher bürgerlicher Frauen nicht unter den Gästen zu finden sind, und dass die Bekanntschaft Rahel Levin Varnhagens mit hochrangigeren Adligen wie die des Prinzen de Ligne oder der Gräfin Pachta in die späteren Monate des Jahre 1795 außerhalb Berlins fielen bzw. es dafür eines anderen Ortes als Treffpunkt bedurfte [s. III.5]. Gelegentlich äußerte sich die Salonière Veit gegenüber, wie schwer es ihr falle, Gäste ihrer Wahl zu bekommen und beklagte sich über ihren Stand. Nicht nur wüsste sie Goethe bei einem potentiellen Treffen als Mädchen und als Jüdin nichts Gescheites zu sagen. ${ }^{91}$ Auch im Falle des Komponisten Johann Friedrich Reichardt beispielsweise, von dem sie sich sehr beeindruckt zeigte, wünschte sie sich, ein Mann und sogar ein Geschäftsmann zu sein, wie es ihr Vater gelegentlich sich ausgemalt hatte. Sie wolle auf seinem Grab weinen, wenn dieser sie ,zu einer Geschäftsperson, wenn auch mit Gewalt, gebildet hätte; so wär ich jetzt eine Art Ding, wäre mittausend Menschen in Konnexion, könnte dreist sein, ein Wort mitsprechen, und kennen lernen wen mir nur einfiele; denn Sie glauben gar nicht, wie ich ohne Dummdreistheit mit den

sich bei Peschier um den Pharmazeuten und Gelehrten Jacques Peschier oder einen Verwandten der Wiener Bankiersfamilie handelt, lässt sich nur mehr vermuten.

$89 \mathrm{Da}$ in den Briefwechseln immer nur der Nachname Scholz genannt wird, ist nur zu vermuten, dass es sich hierbei um den preußischen Geschäftsträger Hieronymus Scholz (?-1833, Rom) handelt, den Karl August Varnhagen in seinen gesammelten Charakterschilderungen zu dieser Epoche erwähnt. Demnach handelte es sich um einen schönen, begabten, aber übermäßig faulen „Sonderling“, der aufgeklärten Idealen lebenslang treu blieb, dem aber persönliches Wohlbehagen über alles ging. Vgl.: Karl August Varnhagen: Scholz, in: ders.: Vermischte Schriften. Dritte vermehrte Auflage, Bd.2, Leipzig 1875, S. 146-152.

90 Zu Fließ Boye Sparre s. u. den Absatz über wiederzuentdeckende Gastgeberinnen, zu Meyer Fränkel s. IV.

91 „dass ich ein Mädchen bin, und in meiner Situation, ein Judenmädchen. Sie haben Recht; lächerlich könnte ich mich wohl machen [...] aber was sollte der Mann denken, als was ich mich ihm präsentiren?“ Rahel Levin Varnhagen an David Veit, 31. 10. 1794, in: GW VIII/I, S. 264. Hervorhebung im Original. 
Leuten bekannt werden kann; wenn ich nun noch gar wichtig wäre, und sie ohnehin mit mir zu thun haben müssten“!92

Reichardt hatte früher in geschäftlichen Dingen mit ihrem Vater verkehrt, ${ }^{93}$ 1794 musste sich Rahel Levin Varnhagen für ein erneutes Kennenlernen eines Tricks versichern: „Man hat mir an drei Orten versprechen müssen, wo Reichardt hingeht, mich sofort holen zu lassen, wenn er kommt. Wir armen Lumpenhunde! wenn ich die mindeste große Dame wäre, ließe ich ihn holen; oimé"!94 Unter anderem bat sie Henriette Herz um sofortigen Bescheid, wenn der Komponist bei ihr erscheine. Anscheinend war es $\mathrm{zu}$ diesem Zeitpunkt noch wahrscheinlicher, im Hause Herz prominentere Gäste zu treffen, Levin Varnhagen erwähnte verschiedene Professoren und Theaterdirektoren aus diesem Kreis.

Wenn man den Stadtführer Friedrich Nicolais von 1793 als Maßstab nimmt, verkehrte von den damals als Berliner Gelehrte bekannten Personen niemand im Haus Levin, mit der Marchetti, und später Hans Genelli aber zwei ihm namhafte Künstler.95 Von den heute als Stammbesetzung der Berliner Salons bekannten Personen hingegen wurde als [ehemaliger] Gast Wilhelm von Humboldt kaum und nur dann genannt, wenn ihr Gegenüber ihn erwähnte [s. III.4]. Wenn man dem Verleger Johann Daniel Sander, der alle Beteiligten kannte, aber nicht dazu gehörte, glauben darf, hatte Rahel Levin Varnhagen in den 1790er-Jahren in der Berliner Gesellschaft nicht nur keinen Status als Berühmtheit, sondern nicht einmal den besten Ruf, ,weil sie fast nur mit Wüst-

92 Rahel Levin Varnhagen an David Veit, 3. 1.1794, in: GW VII/I, S. 105 f.

93 Ein anderer bekannter Komponist der Zeit, der ebenfalls Levin Markus gut gekannt hatte, aber mit seiner Schwester augenscheinlich nicht verkehrte, war Carl Friedrich Zelter. Er berichtet in einem Brief an Goethe, er habe den Vater der Frau von Varnhagen „recht gut als Humoristen“ gekannt und erzählt eine Anekdote von dessen Todestag. Im Familienbriefwechsel der Levins erscheint er gelegentlich als Person ,auf Sichtweite‘. Vgl. ERLV III, S. 468, 516, 540. Zelter war allerdings Habitué im Hause Abraham und Lea Mendelssohns, das in der Geschichte der Berliner Salons endlich einen Platz verdient hätte. Max Hecker (Hrsg.): Briefwechsel zwischen Goethe und Zelter 1799-1832, 3 Bde., Frankfurt/ M. 1987, Bd.3, S.144. Zelter war auch gut bekannt und im Briefwechsel mit Dorothea Mendelssohn Veit Schlegel. Vgl. Kritische Friedrich-Schlegel-Ausgabe [im Folgenden KFSA], Bd. 25, S. 41, 65, sowie bes. S. 90-93.

94 Rahel Levin Varnhagen an David Veit, 3. 1. 1794, in: GW VII/I, S. 105 f. Hervorhebung im Original. „Oimé“, ital.: „Wehe mir!“

95 Ein anderes zeitgenössisches Überblickswerk nennt als jetztlebende Schriftsteller auch Maimon, Gentz, und Euchel, die bei Herzens verkehrten und die Rahel Levin Varnhagen zumindest dem Umgang nach kannte. Valentin Heinse Schmidt/Daniel Gottlieb Gebhard Mehring (Hrsg.): Neuestes gelehrtes Berlin: oder literarisches Nachrichten von jetztlebenden Schriftstellern und Schriftstellerinnen, 2 Bde., Berlin 1795, passim. Als Schriftstellerinnen werden u. a. Königinmutter Elisabeth Christine und Helene Unger aufgeführt. 
lingen beiderlei Geschlechts zu tun hat"“.96 Sander bestätigte die Einrichtung des Nachttees und als Gäste des „Cirkel“ unter anderen die Frauen Fließ und Unzelmann, Fürst Reuß, Herrn von Schack und einen portugiesischen Gesandten [Navarro]. In seiner Schilderung, die gleichermaßen aus Klatschfreude wie Frustation des nicht Eingeladenen gespeist sein kann, liest sich Salongeschehen wie folgt: „Wenn es Ihnen einfällt, kommen sie noch Nachts um 11 u. 12 zum Thee zusammen, holen die Fehlenden aus den Betten $u$. treiben mancherlei Unfug“. 97 Interessant sind Sanders Schilderungen vor allem wegen der verwendeten Begriffe. Er sprach, tendenziell abwertend, von Rahel Levin Varnhagens „Bureau d'esprit“, ihrem „Cirkel“, und der dort verkehrenden „Clique“.

$\mathrm{Zu}$ dieser gehörten dann auch andere als Salonièren bekannte Frauen. Dorothea Mendelssohn Veit Schlegel wurde als „die Veit“ häufig besucht oder als Gast genannt, auch passte Rahel Levin Varnhagen gelegentlich auf deren Sohn Jonas auf, Brinckmann trank bei beiden Schwestern Dorothea und Henriette Mendelssohn Schokolade; von Gesellschaften oder einem „Salon“ im Haus der Veit ist nicht die Rede. ${ }^{98}$ „Madame Herz“ wurde von Rahel Levin Varnhagen als nur gelegentlicher Gast genannt. Ebenfalls selten waren anscheinend ihre Besuche bei Herzens, die als Gastgeber meist im Plural genannt sind. Allerdings schickte man sich immer wieder Empfehlungen über gemeinsame Gäste wie Brinckmann, und im Familienbriefwechsel der Levins wurde das Ehepaar häufig und mit großer Achtung genannt. Mit einigen Philososphen, die als Gäste Herzens bekannt sind, verkehrte Rahel Levin Varnhagen gelegentlich: Gemeinsame Spaziergänge mit Isaak Euchel wurden erwähnt, Salomon Maimon wurde rezipiert und kann 1794 zumindest als langjährige Grußbekanntschaft gelten. 99

96 Johann Daniel Sander an Carl August Böttiger, 14. 1. 1797, in: Bernd Maurach (Hrsg.): Die Briefe Johann Daniel Sanders an Carl August Böttiger, 4 Bde., Bern [u. a.] 1990-1993, Bd. 2, S. $86 \mathrm{f}$.

97 Johann Daniel Sander an Carl August Böttiger, 14. 1. 1797, in: Maurach 1990, Bd. 2,

S. $86 \mathrm{f}$. Sander betonte mehrfach, dass er sich eine Einladung wohl verschaffen könnte, aber nicht wolle „weil die ganze Clique in so üblem Rufe steht, daß keine rechtlichen Menschen unter sie kommen dürfen." Ebd.

98 Allerdings verbrachte „die Veit“ einen Großteil des hier gewählten Untersuchungszeitraums in Strelitz.

99 So „geht Euchel von der Doktorin Lemos bis zur Heiligengeiststraße mit mir“, Rahel Levin Varnhagen an David Veit, 3. 1. 1794, in: GW VII/I, S. 107; im Briefwechsel mit David Veit werden immer mal wieder Thesen Maimons diskutiert und noch 1800 ließ Rahel Levin Varnhagen eine Freundin ihre Grüße an Maimon überbringen. „Maimon aber war sehr erfreut über Ihr Andenken“, Karoline von Schlabrendorf an Rahel Levin Varnhagen, 20. 5. 1800, in: Varnhagen 1836, S. 73. 


\section{„Partheiungen“ im Hause Herz?}

Hr. Markus Herz, Doktor der Arzneygelahrtheit, Hofrath und Leibarzt des Fürsten von Waldeck.

Er ist durch philosophische und medicinische Schriften berühmt.

Er wohnt in der Spandauerstraße.

Friedrich Nicolai: Jetztlebende durch Schriften bekannte Gelehrte, $1786^{100}$

In der Forschungsliteratur werden dem Salon Herz zwei Besonderheiten attestiert: Er gilt als der „erste echte“ Salon Berlins und wird gelegentlich als „Doppelsalon“ bezeichnet, bei dem Ehemann und Ehefrau zwei verschiedene Zirkel nebeneinander in verschiedenen Zimmern geleitet haben sollen. Da die Definitionen wie „echte Salons“ und „Doppelsalon“ posthum an die Berliner Geselligkeitsgeschichte herangetragen wurden, ist es historisch schlicht korrekter, auf den Umstand hinzuweisen, dass Markus Herz, Arzt und Philosoph, bereits als Junggeselle seit etwa 1777 vor Personen verschiedenen Standes, Juden und Nichtjuden, in seiner Privatwohnung Vorträge und Vorlesungen gehalten hat und diese Tätigkeit auch als verheirateter Mann fortsetzte. ${ }^{101}$ Während der Salon von Henriette Herz erst in der nachfolgenden Forschung als ,Institution galt, wurde ihr Mann bereits in zeitgenössischer Stadtbeschreibung zu den „jetztlebenden Gelehrten“ gezählt und seine Vorlesungen wurden in der Berliner Tagespresse angekündigt. ${ }^{102}$ Die Idee des Doppelsalons ist in der Forschung mit einem Nebeneinander des Geschmacks und der Umgangsformen verbunden, oft stilisiert zu einer räumlichen und ideellen Trennung zwischen den Vertretern der Aufklärung, die sich um den Hausherrn versammelten und eher gefühlsbetonten Dichtern, je nach Salonbericht Goetheverehrer oder Romantiker, im Salon der Hausherrin. Diese Vorstellung wird an den Erinnerungen des Bildhauers Schadow festgemacht, der in den 1780er-Jahren im Hause Herz verkehrte und von dem zitiert wird, dass Markus Herz an Gesell-

100 Nicolai 1786, Bd. 3, Anhang, S. 9 Ein Druckfehler ist im Original überliefert: „Er ist durch pholosophische und medicinische Schriften berühmt. Er wohnt in der Spandauerstraße.“ 101 Jahresangabe nach Landsberg 2000, S. 49. Zur Biografie Markus Herz’ s. Davies 1995 sowie, vor allem zu Herz' Tätigkeit als Arzt: Christoph Maria Leder: Die Grenzgänge des Marcus Herz, München 2007.

102 Zum Beispiel 1784: „Herr Dr. Herz wird heute mit seinen Vorlesungen über die Experimentalphysik den Anfang machen und sie den Winter über zweymal wöchentlich fortsetzen, Montags und Donnerstags von 5 bis 7 Uhr Abends.“ Königlich privilegirte Berlinische Staats- und Gelehrte Zeitung, 142stes Stück, Donnerstag, den 25. November 1784. Die Anzeige erschien im selben Wortlaut auch in den „Berlinischen Nachrichten von Staats- und Gelehrten Sachen“ und im „Neuen Berliner Intelligenzblatt“. Vgl. auch das Eingangszitat von Nicolai. 
schaftsabenden junge Ärzte, Gelehrte und Staatsmänner um sich versammelt habe, hingegen ,im Salon der Hausfrau daneben waren zugleich mehrere jüngere Männer, der deutschen Dichtkunst ergeben“. ${ }^{103}$ Diese Formulierung stammt allerdings aus dem Jahr 1849 und nachweislich von einem begabten Anekdotenerzähler. ${ }^{104}$ Henriette Herz sprach selbst für die ersten Jahre ihrer Ehe eher allgemein von einer wöchentlich sich zusammenfindenden „Lesegesellschaft" beim Kastellan Bauer sowie von viel Besuch aufgrund der Vorlesungen ihres Mannes:105 „H. ward mehr u. mehr als guter Arzt bekandt u. las philosophische Collegia, dadurch kamen viele $u$. bedeutende Leute in unser Haus, die auch zuweilen zu Abendmahlzeiten eingeladen worden - doch meistens nur Männer, $u$. so jung $u$. unwissend ich auch war unterhielten sie sich doch viel mit mir". 106

Tatsächlich gab es einen großen Alters-, und zumindest anfänglich, sicherlich auch Interessensunterschied zwischen den Eheleuten. Markus Herz, 17 Jahre älter als seine Gattin, war Schüler und Freund Moses Mendelssohns, hatte bei Immanuel Kant studiert, mit dem er in Briefkontakt stand und dessen Ideen er in Berlin verbreitete. Daneben bot er physikalische und medizinische Themen an. So brachte das Interesse am Blitzableiter auch den Hofmeister Gottlob J. C. Kunth in die Herzsche Wohnung, der mit seinen Schülern, den beiden Brüdern Humboldt, kam, die in der Folge allerdings mehr mit Henriette Herz umgingen. Nicht zu vernachlässigen ist aber der Umstand, dass neben ihrem Vater Benjamin de Lemos, auch Markus Herz ganz wesentlich für die Ausbildung seiner Frau verantwortlich war, etwa durch Lektüreempfehlungen und Hauslehrerauswahl. Dieses Kapitel stellt daher erneut die Frage an das Haus Herz, welche Art von Geselligkeit 1794 stattfand und was für ein Verhältnis zwischen den Gastgebern bestand.

103 Johann Gottfried Schadow: Kunstwerke und Kunstansichten. Ein Quellenwerk zur Berliner Kunst- und Kulturgeschichte zwischen 1780 und 1845. Hrsg. von Götz Eckardt, 3 Bde., Berlin 1987, Bd.1, S. 15 f.

104 Dabei wird der Quellenwert dieser Erinnerungen keineswegs in Abrede gestellt. Wie der Herausgeber aber bemerkt, wurden die Erinnerungen inklusive der hier zitierten Vorrede im Abstand von 60 Jahren zum Ereignis formuliert. Für die Jahre vor 1800 standen dem Künstler als Erinnerungsstütze nur Ausgabenbücher, keine Tagebücher zur Verfügung. Insofern ist Schadows Vorrede der Tendenz nach sicherlich, im Detail nur bedingt historisch zuverlässig. Vgl. Götz Eckardt: Zur Entstehungsgeschichte der „Kunstwerke und Kunstansichten“ und des Tafelbandes, in: Eckardt 1987, Bd.3, S. 837-848.

105 „die eingerichtet ward u. die aus den damals gescheidesten, ausgezeichnetesten Leuten bestand. Dohm, Engel, Klein, H. Zöllner u. wir dazu gehörigen Frauen. K. u. die H-s waren auch dabei.“ Herz 1896, S. 182.

106 Henriette Herz 1896, S. 166. 
Bemerkenswerterweise gibt es aus der so genannten Hoch-Zeit der Berliner Salons, speziell zwischen 1792 und 1798, keine überlieferten Autografen und keine gedruckten Briefwechsel der „berühmten Salonière“ Henriette Herz - mit Ausnahme ihrer ungedruckten Billets in der Sammlung Brinckmann und eines einzigen gedruckten Briefes von Alexander von Humboldt. ${ }^{107}$ Die immer noch zitierten ,Memoiren' der Henriette Herz, die neben anderen ein so viel versprechendes Kapitel Zur Geschichte der Gesellschaft und des Konversationstones in Berlin enthalten, sind, wie erwähnt, das Werk eines nachlebenden Journalisten. 108

Topografisch ist festzuhalten, dass der Adresskalender 1794 Markus Herz als Hofrat und Professor im „Haus des Kaufmanns Löhder“ aufführt und sich daraus ergibt, dass der „Salon Herz“ 1794/95 in der Neuen Friedrichstraße 22 stattgefunden haben muss, die damals etwa entsprechend der heutigen S-Bahn vom Hackeschen Markt bis zum Alexanderplatz verlief. ${ }^{109}$

Aus den hier untersuchten Briefen ihrer Gäste untereinander wird zunächst deutlich, dass es 1794 im Hause Herz, im Unterschied zum Haus der Familie Levin, einen etablierten Freitag als Empfangstag gab. Enge Freunde des Hauses Herz, wie Brinckmann, Humboldts, oder Burgsdorf wurden auch an anderen Tagen zum Mittag- oder Abendessen oder zum Tee - und Kartenspiel[!] - gebeten. ${ }^{110}$ Der Freitag bei Herzens scheint aber sprichwörtlich gewesen zu sein, da er in vielen Korrespondenzen ebenso bekannt wie bei der jüngeren Generation gefürchtet war. ${ }^{111}$ „Jüngere Generation“ ist hierbei ebenso in

107 Vgl.: Lexikon deutsch-jüdischer Autoren, Bd.11, S. 158-167. Vgl. auch Alexander von Humboldt an Henriette Herz, 4. 8. 1796, in: Landsberg 2000, S. $203 \mathrm{ff}$.

108 Fürst 1850. Vgl. als unkritische Wiederaufnahme dieses Kapitels z. B. Janetzki 1984, S. 43-54.

109 Vgl. den Eintrag zu Markus Herz: „Prof. d Philososphie und Fürstl. Waldeckscher Hofrath. w. in der neuen Friedrichstr. in d. Kaufmann Löhder H.“, in: Adress-Calender 1794, S. 416. 1788 und 1790 war Herz noch als in der Spandauer Straße unweit des Berlinischen Rathauses wohnhaft verzeichnet. Die Benennung des Henriette-Herz-Platzes am Hackeschen Markt ist irreführend und einer Frauenquote des Bezirksamts geschuldet.

110 Für die Existenz von Kartenspielen, bisher im Zusammenhang mit den Berliner Salons nicht thematisiert, gibt es mehrere kleine Andeutungen in Billets. Beispielsweise als Mahnung, „aber absagen hätten Sie mir eigentlich müssen weil Burgsdorf spielen sollte“. Henriette Herz an Gustav von Brinckmann, 18. 8. 1795, ungedruckt, BA H. Marianne Meyer Eybenberg an denselben: „Wie richtig Sie gestern wieder Calculirt dass ich am Spieltisch gefesselt gewesen, bestärkt mich immer mehr in meinem Urtheil über Ihr Combinierungs Vermögen [...]“, 16. 1. 1794, ungedruckt, BA E. In Bad Freienwalde wurde u. a. L'hombre gespielt, eine dem Skat ähnliche Vergnügung. Vgl. Rahel Levin Varnhagen an Gustav von Brinckmann, 25. 7. 1795, nur teilweise gedruckt in: Hahn / Bosold / Isselstein 1998, S. 170. 111 Für einen Generationsunterschied bzw. eine unterschiedliche Wahrnehmung als Gastgeber spricht auch die unterschiedliche Bezeichnung in Grüßen. Alexander von Humboldt beschloss seine Briefe nach Berlin mit „empfehlen Sie mich [...] an den lieben 
Hinsicht auf das Lebensalter als auch in literarisch-philosophischer Hinsicht gemeint. Sowohl Brinckmann als auch Levin Varnhagen beschrieben 1794 Abende bei Herzens, an denen sie sich, trotz oder wegen zahlreicher anwesender Professoren, sehr gelangweilt hätten: „Gestern war ich, seit ich wieder in Berlin bin, das erstemal bei Herzens. Professor Meyer saß neben mir, und der Buchhändler Michaelis gegen mir über.“ Nach ihrer Bekanntschaft mit Veit gefragt, habe sie - davon ausgehend, dass ihre Tischherren ihre Art der Freundschaft nicht verstünden - beschlossen, den engeren Kontakt zu leugnen: „Ich hätts auch gesagt, aber Hr. Michaelis sah zu schafig aus. [...] so viel, grobes, dummes Zeug hab ich gestern hören müssen und bin ihm nun so abgewöhnt“. ${ }^{112}$ Nichtsdestoweniger wurden von einigen ihrer Gäste regelmäßig Besuche bei Herzens verzeichnet und Formulierungen wie „Die Herz, bei der ich gestern soupiert habe, hat mir sehr viel freundschaftliche Empfehlungen an Sie aufgetragen" sind mehrfach überliefert.113

Die berühmte Anekdote, nach der Markus Herz einen Gast zur Klärung eines Goethezitates rüde an seine Frau verwiesen haben soll, ist keineswegs gesichert. ${ }^{114}$ Aber die literarische Positionierung des Herrn des Hauses bzw. die oppositionelle Positionierung jüngerer Gäste wird durch die Worte bestätigt, mit denen Rahel Levin Varnhagen ein neuer Gast für ihren Zirkel empfohlen wurde: „Ein gewisser Schede, der jetzt Freitags bei Herz ist, verdient Ihre Aufmerksamkeit, ist gescheidt und äußerst brav, lacht Herz aus, und betet Goethe $\mathrm{an}^{\text {". }} 115$

Eine Frage, die bisher leider noch nicht verfolgt wurde, wäre, inwieweit die Aufteilung unterschiedlicher Gästegruppen in einem Haus auf die Ehepartner nicht auch ein mehr oder minder bewusst eingeschlagener Weg gewesen sein kann, sich als Ehepaar in ein neues Lebensumfeld hinein zu bewegen, ohne die Bindungen an das alte zu verlieren. Eine Beschreibung, die auf diese

Hofrath und seine vortreffliche Frau [...]“ aber im selben Brief: „Grüßen Sie doch die Veit, die Levi und das ganze pp. meiner Bekannte“. Alexander von Humboldt an Ephraim Beer, November 1787, in: Jahn / Lange 1973, S. 5.

112 Rahel Levin Varnhagen an David Veit 1. 11. 1794, in: GW VII/I, S. 265 f.

113 Gustav von Brinckmann an Rahel Levin Varnhagen, 17. 5. 1794, ungedruckt, SV 38.

114 Selbst Hans Landsberg formuliert vage: „es klingt so unwahrscheinlich nicht, wenn er [Markus Herz] zu David Friedländer, der ihn um die Erklärung einer dunklen Stelle bei Goethe angeht, gesagt haben soll: ,Gehen Sie zu meiner Frau; die versteht die Kunst, Unsinn zu erklären.““ Landsberg 2000, S. 53.

115 David Veit an Rahel Levin Varnhagen, 22. 12. 1795, in: GW VII/II, S. 217. Die Identität Schedes konnte nicht eindeutig geklärt werden. Das Register der Rahel-Bibliothek (GW) führt ihn als Karl Schede, mit dem sie auch 1808 f. noch verkehrte und der ebenfalls Gast bei Verleger Sander und bei Burgsdorf war. 
Strategie hindeutet, findet sich aus einem noch wenig untersuchten Salon in Wien, dessen Salonière die aus Berlin gebürtige Cäcilie Wulff Eskeles war:

Während in den Zimmer der Frau von Eskeles alles, durch Pracht und Geschmack der Ausstattung wie durch Vornehmheit der Gesellschaft und Gesprächstons, mit den höchsten Kreisen Wiens wetteiferte [...] so pflegte Eskeles selbst, nachdem er eine Weile nach Gebühr und Würden in dieser vornehmen Welt erschienen, alsbald in eine Hinterstube $\mathrm{zu}$ entschlüpfen, wo er die Besuche seiner Glaubensgenossen empfing, [...] und bei Taback und Bier rücksichtslos und behaglich den Rest des Abends hinbrachte. ${ }^{116}$

\section{Generationen im Salon}

Dem Umstand, dass der berufliche Vielschreiber Gustav von Brinckmann an einem Posttag vor lauter Arbeit nicht aus dem Haus kam und die Ereignisse des vorigen Abends, die er seiner Freundin Rahel Levin Varnhagen sonst mündlich mitzuteilen pflegte, schriftlich niederlegen musste, verdankt sich eine der wenigen Schilderungen, wenn nicht die einzige, einer Salondebatte an einem Herzschen Freitag: Am 27. Juni 1794 wurde unter anderem der Zusammenhang von der charakterlichen Moral und dem Talent eines Autors diskutiert. Auffällig ist dabei die Selbststilisierung Brinckmanns, der die moralischen Bedenken der jüdischen Aufklärer, der Maskilim, ironisch abtat. Wegen der Seltenheit der Überlieferung und der Charakterisierung der deutlichen literarischen „Partheiung“ wird das ungedruckte Billet ${ }^{117}$ hier komplett wiedergegeben und, den Randbemerkungen des Überlieferers Karl August Varnhagen, als [V:] gekennzeichnet, folgend, kurz aufgeschlüsselt, in der Überlegung, inwieweit es Parteiungen, aus Freude an der Diskussion oder aus Überzeugung, aufscheinen lässt.

///,Da es an Posttagen so ungewiß ist ob ich Sie sehe, fühle ich immer umso mehr das Bedürfniß Ihnen zu schreiben, Ich hoffe Sie haben sich gestern Abend gut amusirt; ich ziemlich; Jeanette und Adel [V: Jeanette und Adele Ephraim] wollten zur Herz zum Thee

116 Kommentar Karl August Varnhagens, zu einer Briefstelle seiner Frau über Bernhard Eskeles, „den ich sehr liebe, weil inn seine Klugheit aus den Poren dringt [...] weil er ganz altväterlich geblieben ist, mit geistigen Gaben, und ein reiches Leben über ihn weggegangen ist, welches er ganz nach seiner Art bearbeitet hat.“ Rahel Levin Varnhagen an Karl August Varnhagen, ohne Datum, beides zitiert von Karl August Varnhagen: Denkwürdigkeiten des eigenen Lebens, in: ders.: Werke in fünf Bänden, hrsg. von Konrad Feilchenfeldt, Frankfurt/ M. 1987-1994, Bd.1-3, hier Bd.1, S. 686. Auch wenn man Varnhagens bekannten Hang zur Stilisierung in Betracht zieht, scheint es glaubhaft, dass im repräsentativeren Wien Herr Eskeles traditionell lebende Freunde nicht mit der gemischten Gesellschaft zusammenbringen wollte. 117 Gustav von Brinckmann an Rahel Levin Varnhagen, 28. 6. 1794, SV 38. 
kommen, allein wir warteten bis acht Uhr vergebens auf sie, ich mußte mich unterdeß mit [V: David] Friedländer und Herz herumstreiten, denen Genz Imoralität so erschrecklich anstößig ist, weil dadurch seine - politischen Schriften nothwendig viel verlieren müssen!!! -

Erklären Sie mir, wie sonst gute Köpfe so verflucht windisch sein können. Friedländer sprach auch mit Einem Wort über Stollbergs Reisen ab, die er nicht sehen mochte, denn er liest kein Buch von einem Grafen! Herz lese wohl von einem Grafen, aber nicht von einem der so albern viel Religion hat, wie Stolberg! Kurz ich schwöre Ihnen prächtige Sachen kamen da zum Vorschein. Ich der nun Bücher von Grafen und Kaufleuten gleich gern lese, und mich immer nicht überzeugen kann, dass die Religion auf den Reisewagen und individuelle Imoralität auf Grundsätze des Staatsrecht Einfluß zu haben braucht, warf mich denn dabei zum Vertheidiger des Teufels und Jesu Christi wechselweise auf. Unsre Damen kamen, und Jeanette hat uns und aller Welt - denn es waren viel Leute da - so oft und so absichtlich versichert, wie unbeschreiblich glücklich sie sei, weil sie recht eigentlich ein plattes gemeines Weib geworden, dass ich beinah Lust bekommen hätte, das erste zu bezweifeln und das letztere in vollem Ernst zu glauben. Doch dies unter uns, denn ich erkläre mich noch darüber; denken Sie sich hernach bey Tische der Professor Meyer [V: Bramstedter Meyer] so aimable und unterhaltsam dass ich noch zweimal die Linden mit ihm auf und ab gegangen bin.

Adieu. Br.“///

Die Freundschaft von Markus Herz zu David Friedländer, einem der bekanntesten Vorkämpfer der jüdischen Emanzipation und Reform, ist zu diesem Zeitpunkt bereits mehrere Jahrzehnte alt. ${ }^{118}$ Der diskutierte Graf ist Friedrich Leopold Graf zu Stolberg-Stolberg [sic!], der gemeinsam mit seinem Bruder Christian in den Briefen der Salongesellschaft wegen seines Lebenswandels und seiner Werke immer mal wieder zum Diskussionsgegenstand wurde. ${ }^{119}$ Bei dem Buch handelt es sich vermutlich um seinen aktuellen Reisebericht aus

118 David Friedländer (1750-1834) war zudem eine der bedeutendsten Verbindungspersonen zwischen jüdischen und nichtjüdischen Lebenswelten im Berlin um 1800. Als Kaufmann und Autor, Schwiegersohn Daniel Itzigs und Freund Moses Mendelssohns sowie Herzens war Friedländer gesellschaftlich ebenso engagiert wie gut vernetzt. Martin L. Davies sieht in Herz und Friedländer die personifizierte Verbindung zwischen den Zentren der jüdischen Aufklärung in Berlin und Königsberg. Davies 1995, S. 23.

119 Die Brüder Friedrich Leopold Graf zu Stolberg (1750-1819) und Christian Graf zu Stolberg (1748-1821) sind in der Literaturgeschichte nicht nur bekannt als Mitglieder des Göttinger Hains, sondern vor allem wegen ihrer Bekanntschaft mit Klopstock und Goethe. Gemeinsam mit letzterem hatten sie 1775 in Zürich durch Nacktbaden für einiges Aufsehen gesorgt. Die Diskussion im Hause Herz antizipierte späteren Aufruhr, den der Graf 1800 dadurch auslösen sollte, dass er zum katholischen Glauben übertrat und nun nicht mehr „unser“ Stolberg war. Brinckmanns Aussage, er sei „Verteidiger Christi“ gewesen, bezieht sich vermutlich ironisch auf die christliche Prägung der Stolbergschen Werke, die bereits seiner Reisebeschreibung anzumerken war. Leopold Stolberg arbeitete auch als Übersetzer und Dichter, einige seiner Lieder wurden von Schubert vertont. 
Deutschland und Italien, der 1794 erschienen war, und der an anderen Teetischen der Zeit nachweislich gelesen wurde.120 Da Varnhagen bei „Meyer“ „Bramstedter Meyer“ an den Rand schrieb, war der Gast bei Herzens höchstwahrscheinlich der Jurist und Schriftsteller Friedrich Ludwig Wilhelm Meyer aus Holstein, dessen vielfältige publizistische Tätigkeit heute vergessen ist.121 Als Übersetzer tagespolitischer Werke hätte Meyer Auslöser politischer Debatten im Salon sein können. ${ }^{122}$ Stattdessen aber erscheint Moral als heiß diskutiertes Thema dieser Abendgesellschaft, in mehrfachem Sinne. Friedrich von Gentz, hier als „Teufel“ erwähnt, war zu dieser Zeit gleichermaßen bekannt wegen seiner politischen, zunehmend konservativen Publikationen, und berüchtigt wegen seiner bekanntermaßen mangelnden Scheu vor Schulden und Ehebruch. Während sich Herz und Friedländer anscheinend über diese Diskrepanz zwischen Poltik und Lebenswandel mokiert hatten, erhob sich Brinckmann amüsiert über deren Moralvorstellungen. Was er ablehnte, und, wie er anahm, Rahel Levin Varnhagen gleich ihm, war übertrieben zur Schau gestellte Moralität, bei Markus Herz ebenso wie bei Jeannette Ephraim Stieglitz. Die erwähnten Frauen, Adele und Jeannette, waren die als sehr gebildet bekannten Enkelinnen des berühmten so genannten „Münzjuden“ Veitel Heine Ephraim, damit auch Cousinen von Sara und Marianne Meyer.123

120 Beispielsweise finden sich ein Kupfer[stich] aus dem Buch von 1794 sowie verschiedene Werke beider Stolbergs in der Büchersammlung von Fürst Reuß / Marianne Meyer Eybenberg. Vgl. „Catalogus der Bücher zu der Verlassenschaft“, in: „88a Acta manualia, des h.[p?] Uhden betr. die Angelegenheiten der Frau Witwe d. Prinzen Reuß des 14. 1799“, ThStA Greiz, Geh. Kab. Greiz I nr. 88a, S. 31-50.

121 Friedrich Ludwig Wilhelm Meyer (1759-1840), viel reisender Publizist, Philosophieprofessor in Göttingen und seit 1796 Besitzer des Guts Bramstedt. Bramstedt war auch Geburtsort des Grafen von Stolberg, möglicherweise war das Thema so entstanden. Meyer arbeitete in den 1790er-Jahren journalistisch in Berlin, u. a. am „Berlinischen Archiv der Zeit und ihres Geschmackes“. Kurz nach seinem Tod hieß es: „Der Weltmann, der reichbegabte Mann, ist in seinem 81 Jahre langen Leben nie imstande gewesen, ein Werk zu schreiben, das ihn überdauert. 13 dicke Bände, darunter viele Theaterstücke, waren schon zu Lebzeiten vergessen.“ „Urteil der Literaturgeschichte“, ohne Quelle, in: Jan-Uwe Schadendorf: Geschichte und Geschichten aus Bad Bramstedt in Holstein, unter: http:// www.alt-bramstedt.de/Inhalt/schlossbesitzer/flwmeyer/flwmeyer.htm (31. 1. 2010).

1221794 gerade übersetzte Meyer das Tagebuch eines englischen Revolutionsbeobachters. Friedrich Ludwig Wilhelm Meyer: Dr. Johann Moore's Tagebuch während eines Aufenthalts in Frankreich, vom Anfange des August bis Mitte Decembers 1792, Berlin 1794.

123 Sie waren Töchter von Benjamin Veitel Ephraim, Kaufmann, Dichter und Politiker, u. a. in preußischen Staatsdiensten in Paris tätig. 1806 wurde er unter Spionageverdacht festgenommen und schrieb „Über meine Verhaftung und einige anderer Vorfälle meines Lebens“ ein Buch. Als jüngster biografischer Aufsatz zu ihm: Liliane Weissberg: Wie schnell kann man verhaftet werden? Benjamin Veitel Ephraim, Preußens erster Geheimrat, reflektiert über das Berufsrisiko um 1800, in: Willi Jasper / Joachim H. Knoll (Hrsg.): Preußens Himmel 
Bei allem hier zum Ausdruck kommenden Spott wurde der Haushalt Herz 1794/95 zugleich als ein sehr gebildeter Haushalt auf der Höhe der Zeit betrachtet. Der Hausherr Professor Herz trat in der Korrespondenz der Salonteilnehmer wenig in Erscheinung, aber diesen wenigen Quellen nach wurde er durchweg als respektabler Vertreter der Aufklärung wahrgenommen. Als sie einmal unklar formulierte, musste Rahel Levin Varnhagen an ihn denken: „Ausgedrückle, würde Professor Herz sagen“.124 An anderer Stelle erwähnte sie ihn achtungsvoll als „der große H“..125 Und der einzige Brief, den der reisende Alexander von Humboldt in dieser Zeit überhaupt an Bekannte aus Salonkreisen schrieb, ging als Zeichen „der Dankbarkeit, der Freundschaft, des wissenschaftlichen Interesses“ an Markus Herz. ${ }^{126}$ Herz wurde von Alexander von Humboldt, der sich zu dieser Zeit stark zu naturwissenschaftlichen Experimenten hinwandte, zu den „guten Köpfen“ gezählt, für die man Freunden Empfehlungen mitgab; eine zunehmende Distanzierung zum Hause Herz, wie sie den Briefen Wilhelm von Humboldts zu entnehmen ist, zeichnete sich in den Briefen des Bruders nicht ab. ${ }^{127}$ Mehrfach verwies auch David Veit seine Freundin für Lektüretipps an Herzens. Bei „Mad. Herz“ war Veit allerdings, wie mehrere ihrer Gäste, vor etwas Klatsch nicht gefeit: Um die Rezension des Roman Woldemar zu bekommen, möge Rahel Levin Varnhagen der Herz nur sagen, dass sie von Humboldt sei und dass viel über Frauen drin stehe. ${ }^{128}$ Damit spielte er auf die frühere Leidenschaft des jungen Wilhelm von Humboldt zu Henriette Herz an. Nach dessen Verheiratung mit Caroline von Dacheröden

breitet seine Sterne ... Beiträge zur Kultur-, Politik- und Geistesgeschichte der Neuzeit (Festschrift zum 60. Geburtstag von Julius H. Schoeps), 2 Bde., Hildesheim [u. a.] 2002, Bd. 1, S. 85-106. Die biografische Information zu den Frauen der bedeutenden Berliner Familie Ephraim ist noch immer spärlich. Sie werden als gebildet und mehrsprachig geschildert, Adele besonders galt als künstlerisch begabt. Über Jeannette und Adele, auch Edel, Adelaide und Adelheid (1763-1840) genannt, berichtet Carl Friedrich Zelter in seiner Autobiografie. Vgl. Johann-Wolfgang Schottländer (Hrsg.): Carl Friedrich Zelters Darstellung seines Lebens. Zum ersten Male vollständig nach den Handschriften herausgegeben (Schriften der Goethe-Gesellschaft, 44) Weimar 1931, bes. S. $136 \mathrm{f}$.

124 Rahel Levin Varnhagen an David Veit, 8. 10. 1793, in: GW VII/II, S. 22.

125 Rahel Levin Varnhagen an Gustav von Brinckmann, 11. 10. 1794, ungedruckt, SV 38. 126 Alexander von Humboldt an Markus Herz, 15. 6. 1795, in: Jahn / Lange 1973, S. 433. Humboldt gab hier auch die Gründe für sein sonstiges Schweigen an: „Ich mußte alle Correspondenz mit Freunden aufgeben, um die wenige Muße, welche mir blieb, den Wissenschaften, die ich nun einmal als Beruf ansehe, zu widmen.“ Das mag natürlich auch eine captatio benevolentiae an den Wissenschaftler Herz gewesen sein. Ebd.

127 Zumindest nicht in den Jugendbriefen Alexander von Humboldts bis 1799, in denen Herz durchweg als Autorität erscheint. Alexander von Humboldt an Christoph Girtanner, 12. 2. 1793, in: Jahn / Lange 1973, S. 236.

128 David Veit an Rahel Levin Varnhagen, 10. 11. 1794, in: GW VII/I, S. 272. 
hatten sie allerdings keinen engen Kontakt mehr. ${ }^{129}$ Erst Mitte des Jahres 1795 wurde das Haus Herz wieder zu einem wesentlichen Anlaufpunkt für Wilhelm von Humboldt, da er es nutzte, um Berliner Meinungen über die Werke seines neuen Freundes Schiller zu sammeln [s. III.4].

Die im Tagebuch Humboldts erwähnten gelegentlichen Briefe ,an die Herz“ aus dem Jahr 1794/95 sind leider nicht überliefert. ${ }^{130}$ Unter anderem muss er ihr einen kurzen Brief, der ihr die Geburt seines Sohnes mitteilte, geschickt haben. Die Reaktion der Herz war wiederum ihrem Stammgast Brinckmann umgehend eine Lästerei wert:

Humboldt hat einen Jungen! Und seine Frau befindet sich dabei ziemlich gut. Er hat dies selbst in drei Zeilen an die Herz berichtet und die ist dabei in Extase gerathen, weil dies sie doch überzeugt wie gut er eigentlich ist. Sie war wirklich hierüber gerührt, und ich segnete dabei den süßen Genuß einer so leichten Überzeugung. Sie selbst ist doch wirklich sehr gut.131

Andererseits, diesem Bild der gebildeten Naiven zum Trotz, ist aus dem Jahr 1795 ein launiges Billet überliefert, mit dem Levin Varnhagen und Herz gemeinsam um den Besuch Brinckmanns baten:

///Wenn Sie zu Hause sind, sagt die Herz, möchten Sie ein bischen herkommen, ich glaub' es nicht, aber im Fall, so bitt ich. Sie haben gar kluge Dictionaire. Aber alles was man hat kann man sich doch nicht zu lieben entschließen, dass ist auch das Einzige was einem dieses irdische Paradies verbittert, $u$ dann noch das nicht $\mathrm{zu}$ haben was man braucht. Wie ich den jetzt verzweiffle kein Siglak u Papier zu haben: weil ich weiß wie Sie das haßen. Ihr geliebtes Datum soll doch etwas ersetzen. Berlin den 3ten Jan: $1795 / / / 132$

129 Etwa 1785 waren Wilhelm und Alexander von Humboldt erstmals von ihrem Hauslehrer Gottlob Johann Christian Kunth zu den Vorlesungen von Markus Herz mitgenommen worden und hatten sich bald verstärkt dem Kreis um die Dame des Hauses zugewandt. Von 1786 datieren schwärmerische Liebesbriefe des älteren Bruder Humboldt an Henriette Herz, teils in deutschen, teils in hebräischen Lettern, die er und sein Bruder von ihr gelernt hatten. Bereits 1789 distanzierte er sich aber von der aussichtslosen Verbindung. 1791 heiratete er. 130 Von einem engen Briefkontakt kann bis etwa 1791 gesprochen werden. Überliefert sind Briefe Wilhelm von Humboldts bis 1792. Vgl. „27 Briefe von Wilhelm von Humboldt an Henriette Herz (1786-1792)“, in: Ludmilla von Assing (Hrsg.): Aus dem Nachlaß Varnhagen's von Ense. Briefe von Chamisso, Gneisenau, Haugwitz, W. v. Humboldt, Prinz Louis Ferdinand, Rahel, Rückert, L. Tieck u. a. nebst Briefen, Anmerkungen und Notizen von Varnhagen von Ense, Bd.1, Leipzig 1867, S. 21-132.

131 Gustav von Brinckmann an Rahel Levin Varnhagen, 13. 5. 1794, ungedruckt, SV 38.

132 Rahel Levin Varnhagen (und Henriette Herz) an Gustav von Brinckmann, 3. 1. 1795, BA V. Hervorhebung im Orginal, eine Anspielung Levin Varnhagens auf die bekannte Ordnungsliebe des Diplomaten. 
Andere Billets von Henriette Herz' Hand an den Diplomaten lassen ebenfalls aufhorchen. Aus dem Jahr 1795 findet sich eine quasi formelle Einladung zum Soupè: ///, Ich ersuche die Herrn v. Brinckmann und v. Burksdorf um das Vergnügen, künftigen Donnerstag in Gesellschaft unsers Humbolds bey mir eine Suppe zu essen. 11ten Aug. $95 \sim \sim$ M Herz“///133

Dieses Billet ist in der Handschrift Henriettes, aber im Namen des Hausherrn verfasst. Für sich selbst formulierte Henriette Herz auffällig lockerer. Nur zehn Tage nach obigem Text lud sie dieselben drei Herren zum Mittagessen mit dem eingangs zitierten Billet, nachdem „H.“ bestimmt seinen Vorsatz, nicht zu kommen, ändere, wenn die „Prächtig-Äugige“ käme. ${ }^{134}$ Henriette Herz nannte sich Brinckmans „Freundin“ und warnte schon mal scherzhaft vor ihres Mannes Launen bzw. warb loyal um Verständnis für dessen „verdrüßlich“ Sein. ${ }^{135}$ Ein Billet, in dem sie Brinckmann zum Mitverschwörer machte, der sie vor einer komplizierten Gästemischung bewahren möge, lautet komplett:

///Das wäre auch entsezlich wenig mir mit Christlicher Liebe die Hand zu küssen wenn ich Sie G. sehen lasse. Im Ernst lieber B. ich weiß noch kein Wort von G. es wäre mir fatal wenn er diesen Abend zu mir käme, ich habe so viele sonderbare Menschen hier. Ich werde ihn in einem Billet bitten mir zu bestimmen wann er morgen kommen will. Er logirt in der Stadt Rom gehen Sie doch zu ihm, u sagen ihm so viel gutes von mir als Sie wissen, $\mathrm{u}$ wenn Sie mir gut sind, als Sie wünschen dass ich hätte.

H. ${ }^{136} / / /$

Über die Bedeutung des christlichen Handkusses wird noch zu reden sein [s. III.6]. Festzuhalten ist zunächst, dass Henriette Herz durchaus Sinn für Ironie besaß und diese einsetzte, um ihre Gästegruppen zu sortieren. Die schwierigste „Partheiung“ in ihrem Hause sollte auf sie zukommen mit der Scheidung ihrer Jugendfreundin Dorothea Mendelssohn Veit Schlegel. Das Verhältnis war so ver-

133 Die Schleifen stehen für handschriftliche Verzierungen auf dem Billet. Henriette Herz an Gustav von Brinckmann, 11. 8. 1795, ungedruckt, BA H.

134 Henriette Herz an Gustav von Brinckmann, 21. 8. 1795, ungedruckt, BA H. Schreibung im Original.

135 „Herz ist sehr verdrüßlich und eben sehr beschäftigt. Ich bin diesen Mittag in Schöneberg was ich unmöglich ausschlagen konnte so gern ich auch zu Hause gewesen wäre. Es dünkt mich also für Sie besser wenn Sie diesen Mittag nicht bei uns wären und dafür Morgen Abend zu uns kämen.“ Und: „Es thäte mir sehr weh, wenn Herz dadurch bei Ihnen verlöre, dass er in einer üblen Laune etwas gesagt was er bei heitererer Seele gewiß nicht denkt, wie oft sagt man nicht etwas in einer verdrüßlichen Gemüthsstimmung, was man im Moment drauf nicht mehr denkt." Henriette Herz an Gustav von Brinckmann, 28. 6. 1790 und 29.7.1790, ungedruckt, BA H.

136 Henriette Herz an Gustav von Brinckmann, 3. 5. 1793, ungedruckt, BA H. „G.“ bezieht sich auf Friedrich von Gentz. 
trauensvoll, dass man sich gegenseitig Briefe zeigte und für einander antwortete: „Ihren vorletzten Brief habe ich Ihnen nicht selbst beantwortet, weil ich glaubte, dass die Herz Ihnen vorlesen würde, was ich an sie darüber schrieb“.137 Diesen Kontakt hielt Henriette Herz aufrecht trotz der sich 1794 anbahnenden und später skandalisierten Ehekrise der Veit und trotz der Tatsache, dass Markus Herz darin die Position des Ehemanns unterstützte. Zusammenfassend lässt sich sagen: Insofern im Hause Herz Grabenkämpfe zwischen aufgeklärten, klassischen und romantischen Dichtungs- und Lebensidealen stattgefunden haben, hat die Hausherrin eine Mittlerinnenposition eingenommen.

\section{„Salon“, „Zirkel“, „Kränzchen“: Das Nebeneinander der Formate}

Wie das oben zitierte Billet Brinckmanns, so deuten mehrere Quellen darauf hin, dass es im Haus Herz in den frühen 1790er-Jahren vier bis fünf ineinander übergehende Geselligkeitsformen gegeben zu haben scheint. Neben den in den Erinnerungen erwähnten „Collegia“ gab es nachmittäglichen Tee und Abendessen, wobei der Tee das weniger formelle, bei den jüngeren Gästen beliebtere Element gewesen zu sein scheint. ${ }^{138}$ Während sie in ihrem Memoirenfragment als gemeinsame Gäste ihrer selbst und ihres Mannes vor allem Aufklärer und Wissenschaftler nannte, deutete beispielsweise das Billet vom 21. 8.1795 darauf hin, dass sie selbst einen Schillerfreund wie Humboldt, einen späteren Förderer des Romantikers Ludwig Tieck wie Burgsdorf und die Schauspielerin Unzelmann zum Tee bitten konnte. Als Beispiel für den fließenden Übergang zwischen verschiedenen Geselligkeitsformen in diesen Häusern muss viertens ein „Damentee“ erwähnt werden, auch „Kränzchen“ genannt, das sich Anfang der 1790er-Jahre regelmäßig und unter anderem bei Henriette Herz traf. ${ }^{39}$ Friedrich von Gentz beschrieb, wie sich eine festgelegte Gruppe jeden Dienstag zusammenfand: „Sie versammelt sich einmal bei der Demoiselle Hainchelin, einmal bei Madame Herz, einmal bei der Kriegsrätin Eichmann und einmal bei

137 Auch kann Humboldt einen: „Brief an die Veit durch die Herz“ schicken. Dorothea Veit an Gustav von Brinckmann, 20.7. 1794, ungedruckt, BA S und Wilhelm von Humboldt, Tagebucheintrag 25. 8. 1794, in: Albert Leitzmann (Hrsg.): Wilhelm von Humboldts Tagebücher. Erster Band 1788-1798, (Wilhelm von Humboldts Gesammelte Schriften Bd. XIV), Berlin 1916, S. 250.

138 Friedrich Schlegel sollte wenig später deutlich formulieren: „Könnten Sie nicht einmahl heute Abend etwa vor halb sieben bey der Herz zubringen, wo sie auch die kleine Rahel treffen und die blonde Vließ. Versteht sich nur bis acht Uhr. Denn was drüber, ist vom Übel.“ Friedrich Schlegel an Gustav von Brinckmann, Oktober 1797, in: KFSA, Bd. 24, S. 26.

139 Aus Briefen Humboldts ist die Existenz des Kränzchen 1790 und 1791 unter diesem Namen belegt, allerdings hatte es sich nach Humboldts Meinung bereits 1790 „verplattisirt“. Wilhelm von Humboldt an Gustav von Brinckmann, 9. 11. 1790, in: Leitzmann 1939, S.12. 
Mademoiselle Dietrich. $\mathrm{Zu}$ diesem Tee sind folgende junge Mannspersonen ein für allemal geladen: Spalding, Humboldt, ein sehr artiger und wohlunterrichteter Graf Dohna, der seit einiger Zeit hier ist, Ancillon und ich“. ${ }^{140}$

Diese Beschreibung einer Teegesellschaft ist aus zwei Gründen bemerkenswert, einerseits deswegen, weil hier jüdische und nichtjüdische Gastgeberinnen wechselten und dieselben Gäste einluden, die heute alle auch als Gäste der Salons bekannt sind. Gentz fuhr fort: „Außer diesen bittet aber jede Dame, bei welcher der Tee ist, noch wen sie will.“ Damit handelte es sich, wenn man es formalisiert betrachten will, um eine teilweise offene Veranstaltung, in der Regie einer Frau. Henriette Herz bestätigte dies durch die Formulierung dass „jenes Theekränzchen durch hinzukommende Fremde vergrössert wurde“.141 Die Organisation entspricht außerdem genau dem Vorgehen des berühmtesten englischen Salons, des „Bluestocking Circle“, dessen Beteiligte sich wechselnd in den Häusern der einzelnen Gastgeberinnen trafen.

Initiiert hatte dieses Berliner „Institut“ des diensttäglichen Tees aber andererseits, wie Gentz weiter verrät, Gustav von Brinckmann. ${ }^{142}$ Es stellt sich die Frage, ob von einem Salon zu sprechen ist, wenn Frauen einer Gesellschaft präsidieren oder nur wenn sie sie initiieren, wie es in den meisten Salondefinitionen gefordert wird. Die Ähnlichkeiten zwischen dieser Teegesellschaft und dem bekannt gewordenen „Salon“ von Henriette Herz sind in Form und Beteiligten auffallend, und es ist zu fragen, welchen Sinn es hat, an einer Definition eines „echten Salons“ festzuhalten, bzw. ob Salon nicht nur ein Oberbegriff für verschiedene Formen der Geselligkeit sein kann. ${ }^{143}$ Auch der - 1794 allerdings nicht mehr aktive - „Tugendbund“, ein Freundschaftszirkel im Stil der Empfindsamkeit, gehört als fünftes Format in die Reihe der unterschiedlichen Geselligkeitsformen mit zum Teil denselben Gästen im selben Hause Herz. ${ }^{144}$

140 Friedrich von Gentz an Christian Garve, 5. 12. 1790, in: Friedrich Carl Wittichen (Hrsg.): Briefe von und an Friedrich von Gentz, Bd.1: Briefe an Elisabeth Graun, Christian Garve, Karl August Böttiger und andere, München [u. a.] 1909, S. 183 f. Gemeint sind Alexander Graf zu Dohna-Schlobitten (1771-1831), späterer preußischer Staatsminister, und der Berliner Philologe Georg Ludwig Spalding (1762-1811), Sohn des Propstes.

141 Herz 1896, S. 183.

142 „Dieses Institut hat der jetzt nach Schweden zurückgekehrte Brinckmann kurz vor seiner Abreise zustande gebracht“, damit also vermutlich 1789. Zit. nach: Wittichen 1909, S. 184.

143 Petra Wilhelmy weist darauf hin, dass es um das Ehepaar Herz verschiedene Formen von Geselligkeiten gegeben habe, die auf den Salon, den Henriette führte, zurückwirkten. Ihre Definition von Salon stellt Wilhemy jedoch nie in Frage. Wilhemy 2000, S. $62 \mathrm{ff}$.

144 Es handelte sich um einen 1787 gegründeten Freundschaftsbund, der der gegenseitigen „Veredelung“ dienen sollte und dessen Umgangston von der Empfindsamkeit geprägt war. Es gab offizielle, wenn auch geheim gehaltene, Empfehlungen, Aufnahmen und Statuten. Mitglieder waren u. a. Henriette Herz, Dorothea Veit, Karl Laroche, Wilhelm von Humboldt, 
Von Henriette Herz selbst haben wir nur eine ganz knappe Zusammenfassung ihres Jahrzehnte überspannenden gesellschaftlichen Lebens. Ihre Jugenderinnerungen brechen bekanntlich genau an der Stelle ab, an der die Schilderung ihres eigenen geselligen Engagements beginnen sollte. Als sie das Manuskript 1829 wieder las, fügte sie ihm ein kurzes Postskriptum an, in dem sie ein paar Namen ihrer Bekannten flüchtig hinwarf:145

D. 27 t. August 1829. - Ich beschlisse[!] diese Zeilen hiermit die ich weiter ausführen wollte - wozu das Leben mich durch den Umgang mit ausgezeichneten Menschen gemacht hat dafür danke ich allein Gott. Eine lange Reihe von Jahren lebte ich mit allen den vorzüglichen Menschen Berlins in geselligem Verkehr - einige nur will ich nennen: früher mit Gentz, Brinkmann, Leuchsenring, Graf Bernstorf, Ancillon waren von einem kleinen Theekränzchen. Die beiden Humboldts, Dohm, Klein, Engel, Zöllner in jener obenbenannten Lesegesellschaft, die, wie jenes Theekränzchen durch hinzukommende Fremde vergrössert wurden, wie das durch La Roche u. C. Dohm geschah. Später entstand die Fesslersche Lesegesellschaft woran Künstler u. Staatsmänner, Gelehrte u. Frauen Theil nahmen, mehrere von diesen kamen in unser Haus, so wie jeder an Geist bedeutende Fremde fast es besuchte. [...] $\mathrm{Zu}$ den früheren großen Gesellschaften gehört auch ein Kränzchen, das wir mit Nicolai, Klein, Görke und einigen andern hatten, wozu jeder im Hause eingeführte Fremde eingeladen wurde. ${ }^{146}$

Abgesehen von der etwas stereotyp wiederkehrenden Formulierung ,jeder an Geist bedeutende Fremde“ bietet diese Darstellung kaum Detailinformation darüber, wer wann wozu eingeladen wurde. Die oben erwähnten Personen, überwiegend männlichen Geschlechts, die sich in verschiedenen Zusammensetzungen trafen, könnten als „prominente preußische Staatsbedienstete und Aufklärer“ zusammengefasst werden, scheinen sich in den verschiedenen Zirkeln aber nach Generationen zusammengefunden $\mathrm{zu}$ haben. ${ }^{147}$ Die eine

Caroline von Dacheröden und Caroline von Wolzogen. Vgl. Peter Seibert: Der „Tugendbund“. Ein soziokulturelles Experiment des späten 18. Jahrhunderts, in: Altenhofer / Heuer 1990, S. 48-66. Der so genannten „Tugendbund“ war mit der Verlobung zweier Mitglieder, Wilhelms und Carolines, so gut wie aufgelöst. Vgl. Wilhelmy 1989, S. 53.

145 Die Schilderungen ihrer „berühmten“ Gäste in den späteren so genannten Memoiren sind ebenfalls von J. Fürst verfasst. Selbst wenn die Namen der Gäste stimmen, sind die Wertungen und die Betrachtungen zu ihrem Salon nicht als die originären Herzschen zu betrachten.

146 Herz 1896, S.183, in modernisierter Schreibung in Herz 2000, S. $153 \mathrm{f}$.

147 Mit Christian Wilhelm Dohm (1751-1820) gehörte der Verfasser des Plädoyers „Über die bürgerliche Verbesserung der Juden“ und der Prototyp des gelehrten Beamten, „dessen politisiertes Denken und Handeln gesellschaftlichem Wandel verpflichtet“ war, zu Herzens Bekannten. Heinrich 2001, S. 44. Ernst Ferdinand Klein (1743-1810) war Jurist und unter anderem Mitarbeiter am Allgemeinen Preußischen Landrecht, Johann Jakob Engel (17411802) war Professor und Theaterdirektor, und Johann Friedrich Zöllner (1763-1804) Prediger an der Charité sowie Publizist der Aufklärung. All diese Genannten waren auch Mitglieder 
erwähnte Gesellschaft mit Dohm, Klein und Engel, die möglicherweise die Mittwochsgesellschaft meint, versammelte eher etablierte Beamte. Henriette Herz' Teekränzchen hingegen vereinte zwar heute bekannte Namen, aber, wie von Gentz bestätigt, zu diesem Zeitpunkt die eher jüngere Generation von noch nicht festgelegten Karrieren: Bei Friedrich von Gentz, Franz Michael Leuchsenring und Johann Peter Ancillon kann man Anfang der 1790er-Jahre durchaus von einer Karriere im Umbruch sprechen. ${ }^{148}$ In der Lesegesellschaft waren aber sowohl die beiden Brüder Humboldt wie deren Lehrer vertreten. Einen unterschiedlichen Geschmack zwischen den Ehepartnern erwähnte Henriette Herz nicht, sie unterschied die Gastgeber nach ihren Attraktivitätsfaktoren: „Herz zog durch seinen Geist $u$. als berühmter Arzt die Leute an sich, ich durch meine Schönheit $u$. durch den Sinn den ich für alles Wissenschaftliche hatte, denn es gab kaum eine, in der ich mich nicht einigermassen umgesehen hatte u. einige trieb ich ernstlich - so Physic u. später mehrere Sprachen““ ${ }^{149}$

In der Gesamtschau sprechen die überlieferten Quellen für ein vielfältiges geselliges Leben im Haus Herz, dessen Gäste sich in verschiedenen Gruppierungen zusammenfanden und das sich mit anderen Gesellschaften und Kränzchen an anderen Orten überschnitt.

der so genannten Geheimen Mittwochsgesellschaft, die hier auch gemeint sein könnte. Mit dem schon vielfach zitierten Verleger Friedrich Nicolai (1733-1811) war der prominenteste und langjährigste Verfechter der Berliner Aufklärung regelmäßiger Umgang beider Herzens. Klein, Engel und Dohm waren zeitweilig auch Lehrer Wilhelm von Humboldts, was den Eindruck verstärkt, dass es sich bei dessen zunehmender Distanz zum Hause Herz um einen ,Generationskonflikt' handelte.

148 Friedrich von Gentz wechselte als politischer Publizist Anfang der 1790er-Jahre gerade die Fronten vom Revolutionsanhänger zum -gegner. Franz Michael Leuchsenring (1746-1827) war ein Literat von schillerndem Charakter und ebensolchen Zuschreibungen: bekannt als empfindsamer Dichter, später als Illuminat aus Preußen verbannt und Jakobiner in Paris, hatte er schon früh in Berliner Salonkreisen einiges Aufsehen erregt, weil er Adele Ephraim heiraten, aber nicht zulassen wollte, dass sie sich taufen ließ, sodass der Plan aufgegeben wurde. Vgl. Karl August Varnhagen: Leuchsenring, in: ders. 1987-1994, Bd. 4, S. 152-183. Varnhagen ergänzt, „solche Verbindungen waren damals noch höchst selten und für beiderlei Religions-parteien höchst anstößig. [...] In diesem Falle aber würde das Ärgernis um so größer gewesen sein, als Leuchsenring durchaus darauf bestand, dass seine Frau keine Christin werden, sondern Jüdin bleiben sollte.“ Ebd., S. 164 f. Auch Graf Christian von Bernstorff (1769-1835), Sohn des dänischen Außenministers, später selbst Diplomat in dänischen und dann preußischen Diensten, kämpfte Anfang der 1790er-Jahre um seine Heiratspläne mit Marianne Meyer Eybenberg, die sein Vater verbot; der spätere Prinzenerzieher Jean Pierre Frederic -, bzw. je nach Lesart Johann Peter Friedrich Ancillon (1767-1837), preußischer Staatsmann hugenottischen Ursprungs, unterrichtete um 1790 noch an der Militärakademie.

149 Herz 1896, S. 183. 


$$
\begin{aligned}
& \text { Mupiumun }
\end{aligned}
$$

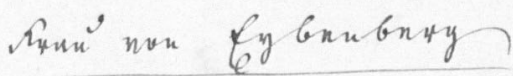

$$
\begin{aligned}
& \text { yab. Mnyou. }
\end{aligned}
$$

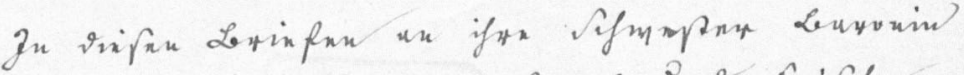

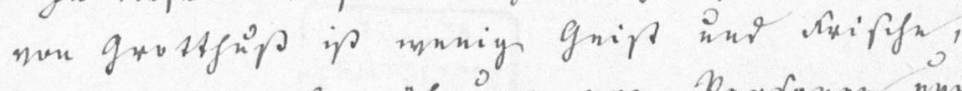

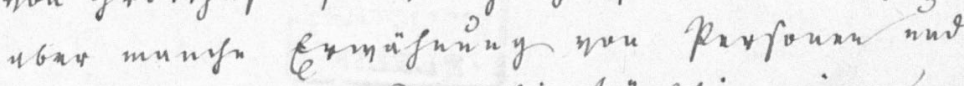

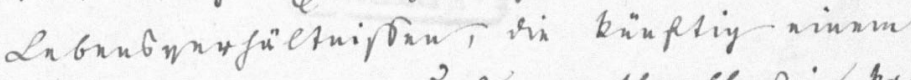

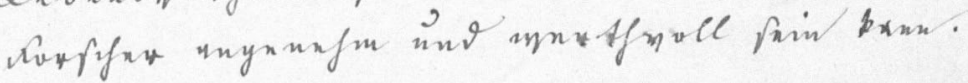

Abb. 10: Karl August Varnhagen über Marianne Meyer Eybenberg.

\section{„Meyers“}

Marianne / Frau von Eybenberg / geb. Meyer.

In diesen Briefen an ihre Schwester Baronin von Grotthuß ist wenig Geist und Frische, aber manche Erwähnung von Personen und Lebensverhältnissen, die künftig einem Forscher angenehm und werthvoll sein kann. Karl August Varnhagen, Arbeitsvermerk (s. o.). 150

Aus den gedruckten Quellen des Jahres 1794/95 wie überhaupt aus den nachgelassenen Papieren der Beteiligten, geschweige denn der Sekundärliteratur, erfährt man wenig über den „Salon“ oder die Salons der Schwestern Meyer, nichts über potentielle Gäste und Inhalte bzw. auch nur darüber, wo der Teetisch gestanden haben könnte. ${ }^{151}$ Die Bibliothek des Vaters und damit vermut-

150 Karl August Varnhagen, auf dem Deckblatt ihrer gesammelten Briefe, ungedruckt, SV 57. 151 Laut Petra Wilhelmy dürfte man Marianne Meyer Eybenberg nicht zu den Gastgeberinnen zählen, sie gehörte zum Kreis ihrer Schwester. Wilhelmy 1989, S. 8. Da sie in den überlieferten Quellen selbstständig einlud oder in beider Namen Billets verfasste, ist diese scharfe Grenze 1794 nicht belegbar oder nicht nötig. Umgekehrt sind die innigen Beziehungen zu Goethe, die Wilhelmy Grotthus attestiert, von ihr vielleicht erwünscht, aber um 1800 nicht wirklich vorhanden, das innigere Verhältnis bestand zu Marianne [s. III.5]. Laut Wilhelmy kehrte Sara Meyer Grotthus in ihr Elternhaus zurück, in das sie dann möglicherweise eingeladen hat. 
lich das Elternhaus wird bei Nicolai als in der Spandauer Straße situiert angegeben.152 Zumindest in den späten 1790er-Jahren hat Marianne Meyer Eybenberg in der Nähe des Gendarmenmarktes gewohnt. ${ }^{153}$

Einladungen der Schwestern Meyer zum Tee sind bereits aus dem Jahr 1793 überliefert und es spricht nichts dagegen, dass sie auch weiter stattfanden. „Bey Meyers war ich Gestern“, hieß es 1794 einmal bei Rahel Levin Varnhagen, die umgekehrt auch ihre Freundinnen als Gäste empfing: „[...] die Schwestern Meyer waren unverhofft bei mir“. ${ }^{154}$ An anderer Stelle erwähnte sie die oben zitierte gemeinsame Einladung von „Sarchen“ an sie und Brinckmann, für den sie gleich mit zusagte, was auf vertrauten Umgang aller drei Personen schließen lässt. Marianne Meyer Eybenberg lud sowohl in ihrem als auch im Namen ihrer Schwester ein, sprach von einem kleinen „Zirkel“, den sie habe, machte für ihre Gäste Tee und Punsch. ${ }^{155}$ Typisch ist folgende Einladung für einen Samstagsnachmittagstee, aus einem Billet an Brinckmann: „Wollen Sie heute Nachmittag Thée mit uns trinken, so sage ich ihnen mündlich, wie es mich freut, Sie wieder in unserem kleinen Zirkel zu sehen“156. Es ist möglich, dass die Bekanntschaften der Schwestern Meyer in vornehmere Kreise reichten als die der anderen Frauen. ${ }^{157}$ Beide Schwestern hatten 1794 bereits adlige Verehrer. Es ist anzunehmen, dass Meyer Eybenberg mit dem österreichischen Diplomaten und Fürsten Heinrich XIV. Reuß, den sie später heimlich heiratete,

152 Nicolai 1786, Bd. 2, S.787. Die meisten Bemerkungen über Marianne Meyer stammen aus späteren Jahren [s. IV], der besonders rege Umgang Rahel Levin Varnhagens mit Sara Meyer Grotthus fällt in die Zeit um 1809, in der die Salongeselligkeit laut traditioneller Lesart ja vorüber war. Die meisten Briefe sind sogar erst aus der Zeit nach 1812 überliefert. Vgl. SV 78 bzw. vgl. die Exemplare in der DV BdA, SV 207.

153 Dies nach einer Randbemerkung Friedrich Schlegels: „Die Levi sagt mir eben, daß man in dem Haus, wo Marianne gewohnt, d. h. in der Mitte der Stadt wenige Schritte vom Theater drey Zimmer und eine Kammer für 3 Ldrs auf einen Monat haben könne.“ Friedrich Schlegel an Caroline Schlegel Schelling, Frühmärz 1799, in: KFSA, Bd. 24, S. 241.

154 „noch eines bey Meyers war ich Gestern denen u der ganzen Welt soll ich sagen wie sie sind, u ,ich weiß es nicht““. Rahel Levin Varnhagen an Gustav von Brinckmann, 27. 9. 1794, ungedruckt, in: BA V; Rahel Levin Varnhagen an David Veit, 18. 2.1794, in: GW VII/I, S. 177. 155 „Zirkel“ nach dem weiter unten zitierten Billet. Marianne Meyer Eybenberg an Gustav von Brinckmann, o. J. (8. 10.), in BA E. Weitere Billets mit Einladungen aus dem Jahr 1793 in BA E. Den Punsch erwähnt Brinckmann in einem Brief an Rahel Levin vom 9. 5. 1794, ungedruckt, BA V.

156 Marianne Meyer Eybenberg an Gustav von Brinckmann, o. D. (8. 10.), ungedruckt, in BA E. 157 So war Marianne Meyer Eybenberg bereits vor Rahel Levin Varnhagen mit der adligen Gastgeberin Frau von Berg bekannt. In einem Brief an Goethe 1795 ließ sie dieser Grüße ausrichten. Marianne Meyer Eybenberg an Johann Wolfgang von Goethe, 27. 10. 1795, ungedruckt, GSA 28/306. 
schon länger eng verbunden war, da er sie in seinem Testament von 1792 schon als erste Erbin eingesetzt hatte. ${ }^{158}$

Aus einer Randbemerkung weiß man, dass zu den frühen Bekannten und Verehrern Sara Meyer Grotthus der Musiker Carl Friedrich von Zelter gehörte. ${ }^{159}$ Die berühmten Bekanntschaften Sara Meyer Grotthus', wie etwa die der Madame Genlis fielen in die Jahre nach 1796, spätestens zu diesem Zeitpunkt verkehrte sie regelmäßig auch im Hause Cohen und schauspielerte in deren Privattheater. ${ }^{160}$ Aus dem Jahr 1795 ist vor allem ein Brief des Baron Friedrich von Grotthus, ihres späteren Ehemanns überliefert, der sich als sehr gefälliger, in der Trauerphase um ihren Vater sehr anteilnehmender Mann präsentierte. ${ }^{161}$ Auch existiert ein Geburtstagsglückwunsch von ihrem inoffiziellen Schwager Fürst Heinrich Reuß, der hier als eines der seltenen Dokumente dieses Mannes zitiert werden soll:

///Glück auf! Glück auf! rufe ich Ihnen zu am heutigen Tage, aus redlich meinendem Herzen; und wünsche Ihnen aus vollem Herzen Gesundheit, und frohen Muth, und Tausend Gutes! Verschmähen Sie nicht die kleine offrande[?], die ich Ihnen anzubiethen

158 Auf einem Feldzug gegen die Franzosen hatte er am 13. 9. 1792 verfügt, dass im Falle seines Todes „die Acht Tausend Thaler in Louisd'or, welche [...] bei Herrn Hof Banquier Itzig in Berlin, auf Interessen stehen, dergestalt der Mademoiselle Mariane Meyer, Tochter des Herrn Aron Meyer zu Berlin, zu ihrer Nutznießung auf Lebenszeit, und [...] vermacht sein sollen“. Zit. nach: Beger 2008, S. 267

159 Der einzige mir bekannte Hinweis darauf ist eine Bemerkung in einem Brief an Goethe 1824, in dem er „Frau von Grotthuß, eine 40jährige Bekanntschaft“ erwähnt und anfügt: „Lieber Gott! sic transeat - Es war ein hübsches Wesen. Unser waren viele, und ich bin davon gelaufen, weil ich das Schmachten nicht aushalte." Carl Friedrich Zelter an Johann Wolfgang von Goethe, 15. 7. 1824, in: Hecker 1987, Bd. 2, S. 325.

160 Die Schriftstellerin und Prinzenerzieherin Stephanie Felicité de Genlis (1746-1830) verbrachte einige Monate ihres Exils in Berlin, wurde unter Spionageverdacht nach Hamburg vertrieben und kehrte noch einmal für einige Monate zurück. In ihren Memoiren, die leider ohne Jahreszahlen arbeiten, erwähnt sie Sara Meyer Grotthus bei ihrem zweiten Aufenthalt als Teilnehmerin an einem Liebhabertheater im Hause Cohen, allerdings nur in einem Satz: „Die Baronesse Grotthus spielte nach meiner Anleitung die Rolle der Galathee zum Entzücken.“ August von Faurat (Hrsg.): Memoiren der Frau Gräfin von Genlis aus dem achtzehnten Jahrhundert und aus der französischen Revolution vom Jahr 1756 bis zur gegenwärtigen Zeit nach dem Französischen frei bearbeitet von August von Faurat, 8 Bde., Leipzig 1826, Bd.5, S. 32. Ob dies ein Hinweis darauf ist, dass die Genlis Gast im Salon Grotthus war, bleibt offen.

161 Hier ist noch ein sehr interessanter und berührender Ehebriefwechsel zu entdecken. Eine Veröffentlichung im Rahmen des Projekts von Silke Schlichtmann ist geplant. Manuskripte in SV 78. 
wage: von rechtswegen sollte es mit Lichtern und Blumen umsteckt seyn, es möchte aber noch so viel schöne Dinge herum stecken, so bliebe es ja dennoch nur ein unendlich schwaches Zeichen des immer gleich lebhaften Andenkens, $u$ der treuen Ergebenheit, die Sie - hoffe ich - mit Zuversicht zutrauen Ihrem getreuen Freund Reuß.162///

Die Schwestern erschienen in den Briefen der anderen, oft gemeinsam als „Meyers“, als gesellschaftliche Größe, deren Tun von allgemeinem Interesse war. 163 „Meyers gehen nach Karlsbad“ war mehreren Schreibenden eine Neuigkeit wert, auch, dass sie mit eigenen Pferden reisten. ${ }^{164}$ Verbindungen zu Rahel Levin Varnhagen waren zunächst Grüße, über gemeinsame Gäste ausgetauscht, und Gefälligkeiten wie Mitbringsel von der Leipziger Messe. Aus den Jahren 1794/95 ist nur ein Brief Marianne Meyer Eybenbergs an das Haus Levin überliefert, eine ebenso empathische wie höfliche Antwort auf ein Beileidsschreiben zum Tod des Vaters. ${ }^{165}$ Wenig später aber, möglicherweise nach dem gemeinsamen Karlsbadaufenthalt, lud man sich ganz unprätentiös gegenseitig zum Tee ein, als Boten fungierte ,ihr` Gesandter Fürst Reuß:

\footnotetext{
///Liebste Levy wollen Sie Donnerstag Mittag mit Brink: bey uns Eßen? und die Liepmann bitten von der parthie zu sein? - ich bitte bitte geben Sie meinem Heinrich ein erfreuliches Ja pour toute repouse mit für Ihre Freundin M. - der Liep: laße ich nichts weiteres sagen und verlaße mich auf Sie, daß Sie es arrangiren, daß sie mitkömmt! Ade Ade///166
}

162 Heinrich XIV. Reuß an Sara Meyer Grotthus, 20. 10. 1795, ungedruckt, SV 78.

163 „Grüße Meyers und sage ihnen [...]“ ist eine typische Formulierung zwischen Liman und Levin Varnhagen, beispielsweise in: Friederike Liman an Rahel Levin Varnhagen, 16. 7. 1795, in: Bosold 1996, S. 25

164 „Diesen Abend gehen die Meyers nach Carlsbad, warum bin ich nicht an dieser Stelle, wahrlich ich fühle daß ich's sehr verdiehne, in Ihrer Nähe zu sein.“ Hitzel Fließ Boye Sparre an Rahel Levin Varnhagen, o. D. [1795], ungedruckt, in SV 34. Und „sie Reisen mit Eigene Pferde, den tag 6 meilen.“ Friderike Liman an Rahel Levin Varnhagen, 13. 6. 1795, in: Bosold 1996, S. 8.

165 Der Text beginnt: „Haben Sie Dank meine Liebe für Ihre tröstenden Worte, Ihre Theilnahme, deren wir in unserer Lage so sehr bedürfen! Ich spreche Ihnen nicht über die schändliche Begebenheit selbst, das vermag ich noch nicht, ohne mir das Herz zu zerreißen, ohne jede [?] von Kraft, und Faßung, die mir noch blieb, und durch die liebevolle Behandlung der Bewohner dieses Schloßes angefacht wird, gänzlich zu zernichten!“ Marianne Meyer Eybenberg an Rahel Levin Varnhagen, 26. 8. [0. J], ungedruckt, SV 57. Dem Inhalt nach ist der Brief kurz nach dem Tod von Aaron Meyer 1795 verfasst. Der Vater war auf der Reise nach Karlsbad verstorben, die Familie war auf dem Gut Schönholz untergekommen.

166 Marianne Meyer Eybenberg an Rahel Levin Varnhagen, o. D., SV 57. 
Wie weiter unten dargestellt, waren für die weniger eng befreundeten Zeitgenossen 1795 an den Schwestern Meyer vorrangig die Bekanntschaft mit Goethe und potentielle erotische Verwicklungen von Interesse. Keine weitere Erwähnung fanden die innerfamiliären Konflikte der Meyers oder die einstmalige Taufe der Schwestern. Tatsächlich hatte die Taufe in der preußischen Verwaltung einiges Geräusch verursacht, der Prediger war wegen übereilten Handelns gerügt worden, der König hatte Aufklärung über diesen Fall verlangt. ${ }^{167}$ Dieser Umstand hat aber anscheinend in der Salongesellschaft keine weiteren Kreise gezogen, da er nicht erwähnt wurde. ${ }^{168}$ Zum Thema wurde die Taufe nur bei Leuten, die den Meyers nicht näher standen. ${ }^{169}$

\section{Wiederzuentdeckende Gastgeberinnen}

Eine gesellschaftliche Größe als Gastgeberin und Besucherin, die in der Sekundärliteratur zu den Salons kaum, in den von mir gesichteten Primärquellen hingegen fortlaufend erwähnt wird, war Hitzel Fließ Boye Sparre (1772/51839) ${ }^{170}$. Sie war die Tochter des Fabrikanten Bern(h)ard, des Arbeitgebers und Kompagnons von Moses Mendelssohn, ${ }^{171}$ und ältere Schwester der als

167 Vgl. die umfängliche Akte zur „Taufe der beiden Töchter des Aaron Meyer durch den Prediger Stein in Welsigkendorf bei Jüterborg und deren Rückkehr zum Judentum 1788/ 1798“. GStA I. HA, Rep. 21, Kurmärkische Städte, Ämter und Kreise, Nr. 215, Fasz. 6. S. a. Hahn 2002(a).

168 Lediglich kurz nach der versuchten Rückkonversion 1788 hatte Alexander von Humboldt einem Freund sachlich gemeldet: „Dass die Mariane Meier wieder Jüdin geworden ist, weißt Du. Es sind schlechterdings keine Zerimonien weder bei uns noch in der Synagoge gewesen: sondern sie hat bloß gemeldet dem Consistorio, dass sie wieder eine Jüdin sein wollte, was alles, wie vernünftig ohne Geräusch vorgegangen ist. Jetzt ist das Kurmärk[ische] Consistorium vom Staatsrath zur Rechenschaft gezogen worden, über den schnellen Übergang vom Christenthum zum Judenthum““““”++.“ Alexander von Humboldt an Gabriel Wagner, 12. 12. 1788, zit. nach: Hahn 2002(a), S. 37 f. Die Zeichen am Ende werden leider nicht entschlüsselt.

169 So fühlte der Verleger Sander sich 1797 veranlasst, das Gerücht zu kolportieren, sie habe sich für schön genug gehalten, um sich auf das bloße Heiratsversprechen eines Grafen Gröben taufen zu lassen. Dieser aber setzte seine „Ausdrücke auf Schrauben, um auch wieder zurück zu können“. Johann Daniel Sander an Carl August Böttiger, 14. 1. 1797, in: Maurach 1990, Bd.1, S. 87.

170 Sie war die Tochter des Moses Zülz, der sich später Moses Bernhardt nannte. Sie hieß nach ihrer Taufe Johanne Hedwig Wilhelmine, unterzeichnete die meisten ihrer Briefe mit $\mathrm{H}$. 171 „Moses Zülz=S. des Issachar Beermann Zülz=Moses Bernhardt“ [Jacobsohn 1968, S. 150] hatte zusammen mit seinem Bruder Abraham und Moses Mendelssohn die Konzession zur 
Salonière bekannt gewordenen Philippine Cohen. ${ }^{172}$ Diese wird ihrerseits in den Primärquellen 1794 nur wenig erwähnt. ${ }^{173}$

„Die Fließ“ hingegen, die eine lebenslange Freundschaft mit Rahel Levin Varnhagen verband, war deren und Friederike Limans regelmäßige Begleitung, ins Theater, auf Ausflügen und zur Kur nach Freienwalde. Wichtiger noch, sie lud die beiden Frauen auch selbst zum Tee, ebenso wie die Herz, Brinckmann oder die Marchetti. ${ }^{174}$ Die Rolle der „Doktorin Fließ“, späterer „Baronin Boye“, noch späterer „Gräfin Sparre“ als Gastgeberin der Salongäste Humboldt, Gentz, Brinckmann und Schlegel wird in Kapitel IV beschrieben. Hier soll vor allem auf das in ihrem Hause veranstaltete „Fließsche Konzert“ hingewiesen werden, einen kommunikativen Ort von Rang, der heute vergessen ist. Das Konzert bei Fließens, wohnhaft in der Spandauer Straße, besaß dabei solches Niveau und Regelmäßigkeit, dass Nicolai es in seinen Stadtführer aufnahm. ${ }^{175}$ Er erwähnt auch, dass man von einem „Abonnirten“, zu denen Rahel Levin Varnhagen jedenfalls gehört haben muss, eingeführt werden sollte.

Auf den Gastgeberstatus der Fließ deutet aus dem Untersuchungszeitraum vor allem folgendes Billet, in dem sowohl mit bekannten als auch unbekannten Gästen gelockt wird:

Fortführung der Seidenfabrik seines Vaters Isaachar Beermann, alias Isaak Bernhardt, erhalten.

172 Pessel Zülz, getauft als Philippine Amalie Henriette Cohen (1776-nach 1833), heiratete am 1. 5. 1794 Ephraim Cohen aus den Niederlanden, der sie und ihre Familie später in den Bankrott führte. Ihr geselliges Engagement ist vor allem in den Werken Karl August Varnhagens überliefert. Zur Nachkommenschaft s. Jacobsohn 1968, S. 362 f., v. a. Fn. 672. 173 Sie wird lediglich als die junge Cohen erwähnt, die jetzt einen Bräutigam habe, und die gelegentlich einen Ausflug mitmache. Rahel Levin Varnhagen an David Veit, 15. 11. 1795, in: GW VII/II, S. 19.

174 Der einzig vorhandene Hinweis auf Hitzel Fließ Boye Sparre und ihre Rolle in der Berliner Salongesellschaft von Albert Leitzmann, der sie ein „,beliebtes mitglied der geistreichen gesellschaftskreise, die in den briefen der zeit viel genannt wird“, verhallte anscheinend ungehört in der Forschung. Leitzmann 1939, S. 208. (Leitzmann schrieb alle Texte ohne Großbuchstaben). Neuerdings hat sie, als Wilhelmine von Sparre, einen umfänglicheren Wikipedia-Eintrag, der sie als typisches Beispiel einer wohlhabenden Berliner Jüdin um 1800, und dezidiert nicht als Gastgeberin beschreibt, unter: http:// de.wikipedia.org/wiki/Wilhelmine_von_Sparre (zuletzt eingesehen am 2. 2. 2010). Die Angaben im Text sind nicht alle korrekt.

175 Nicolai 1793, S. 153; Das Konzert fand wöchentlich mittwochs, im Sommer nur einmal pro Monat statt. Die Adresse wird bestätigt vom Adresskalender 1795: „Hr D. Isaac Flies, w. in der Spandauerstr. im Fliesschen H. “ Der Umstand, dass das Ehepaar Fließ ein eigenes Haus besaß, deutet auf einigen Wohlstand. Adreß-kalender 1795, S. 406. 


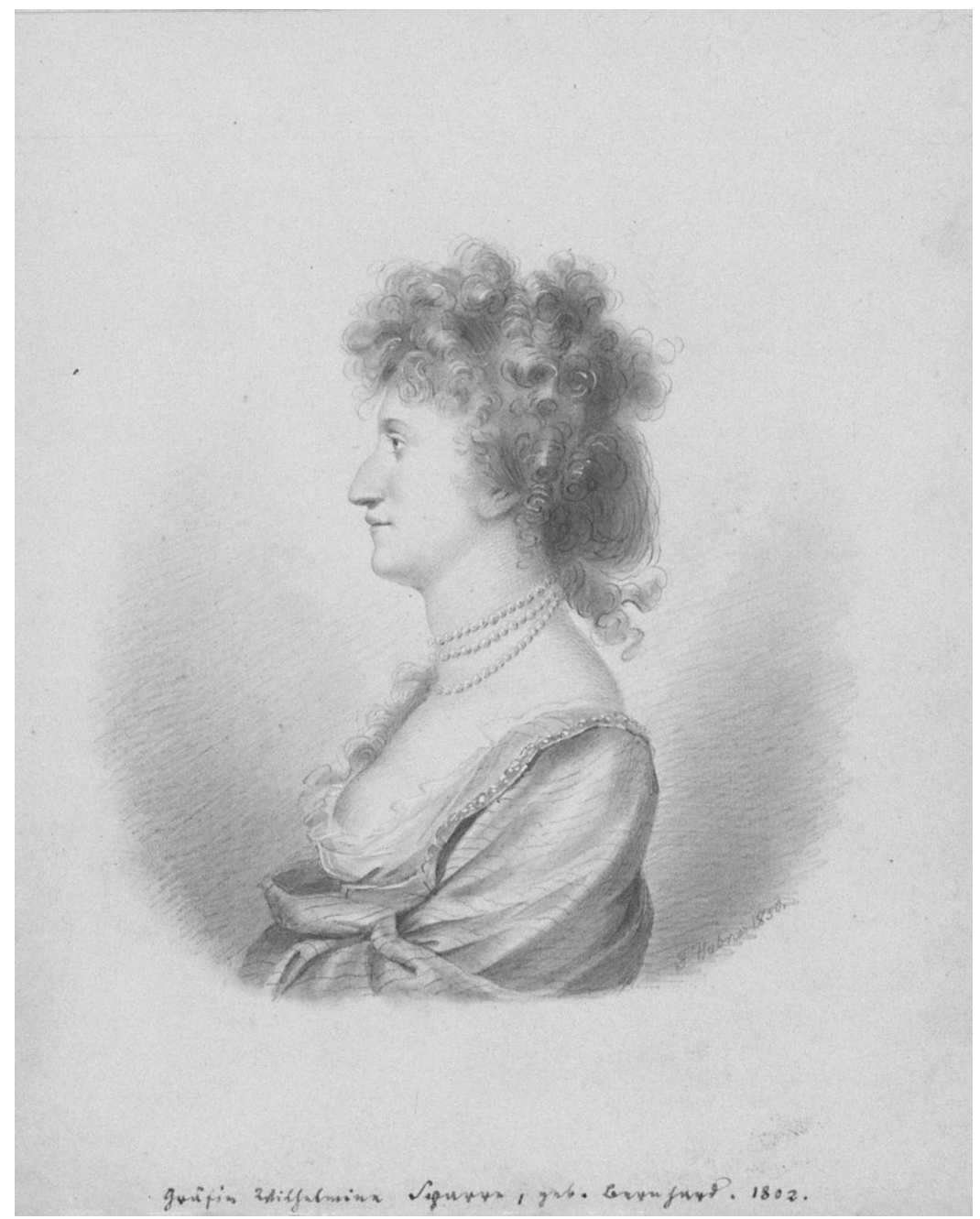

Abb. 11: Eine wiederzuentdeckende Salonière? Hitzel Fließ Boye Sparre (1772/5?-1839).

///,Sie würden mir eine Gefälligkeit erzeugen wenn Sie Morgen zum Thee zu mir kämen, ich habe Thee-Gesellschaft, die U ist freilich nicht dabei, aber die Lev: und noch ein paar nicht uninteressante Menschen. Ich rechne darauf Sie zu sehen. Hflies Mittwoch d 1sten [?] 94“///176

176 Hitzel Fließ Boye Sparre an Gustav von Brinckmann, 1794, ungedruckt, BA F. „U“ steht für Unzelmann, „Lev.“ für Rahel Levin Varnhagen. 
Aus späteren Zeiten ist ihre Gastgeberinnenrolle untere anderem in Briefen Friedrich Schlegels belegt, von denen einer aus dem Jahr 1797 hier angeführt werden soll, da er die Gleichrangigkeit der Gastgeberinnen bzw. ihr Nebeneinander im ,Unterhaltungsangebot“ für Intellektuelle belegt: „Mad Vließ wünscht und bittet Sie hierdurch auf heute Abend zum Thee und zum Essen. Mad Veith bedauert, dass sie nicht zu Hause war, als Sie da waren. Mad. Herz bedauert, dass Sie zu Hause war, als Sie nicht kamen, ungeachtet ich Sie angekündigt hatte“.177

Ebenfalls zumindest gelegentlich eingeladen hat die bereits oben erwähnte Jeannette Ephraim Stieglitz. ${ }^{178}$ Im Brinkmanska Arkivet sind einige undatierte Billets überliefert, die vor ihrem Weggang nach Hannover, also etwa 1794 verfasst sein müssen:

///,Da ein Theil unserer heiligen Familie nicht zu Hause diesen Mittag ißt, u meine Mutter in den elenden Wahn lebt daß Ihr miteßen so was Freudengebendes sey, daß alle ihre Lieben es Theilhaft werden müssten, so bittet sie Sie möchten wo möglich lieber diesen Abend mit uns essen. Mündlich mehr. Jeannette.“///179

An dieser Stelle sei darauf hingewiesen, dass in der zeitgenössischen Memoirenliteratur das Haus ihres Vaters, Benjamin Veitel Ephraim, ebenfalls als gut vernetzter Treffpunkt Gelehrter und Künstler geschildert wird, es aber weder er noch seine Frau oder Töchter zu einer Aufnahme in die Überlieferung der Salongesellschaft, zu der sie deutlich gehörten, geschweige denn Salonièren ,gebracht‘ haben. ${ }^{180}$ Ein möglicher Grund könnte sein, dass in diesem Fall der Initiator der Geselligkeit ein Vater und Kaufmann, nicht dessen Frau oder Tochter gewesen ist, was der in den meisten Salondefinitionen geforderten weibli-

177 Friedrich Schlegel an Gustav von Brinckmann, Oktober 1797, in: KFSA, Bd. 24, S. 23. 178 Geborene Jente Ephraim (1764-1843). Sie war die zweite Tochter von Benjamin Veitel Ephraim und damit Cousine von Sara und Marianne Meyer. Sie nannte sich schon in den 1790er-Jahren Jeannette, nach der Taufe Sophie Jeannette. Sie heiratete 1792 den Mediziner Israel Stieglitz. Stieglitz hatte sich während des Studiums in Göttingen mit Wilhelm von Humboldt angefreundet und ihm einmal das Leben gerettet. Detaillierte biografische Angaben zu Jeannette Ephraim Stieglitz erstmals bei Stieglitz 2001. Zu Israel Stieglitz s. Jacobsohn 1968, S. 349 f.

179 Jeannette Ephraim Stieglitz an Gustav von Brinckmann, undatiert, ungedruckt, BA E. 180 Vgl. beispielsweise Zelters Erinnerungen, dass der Hausherr „Gelehrte, Dichter und Künstler nicht selten in seinem Hause zu sehen“ sich bemühte und er in diesem Hause „zuerst Moses Mendelssohn, Ramler, Engel, Leuchsenring, Stamford, Rode, Chodowiecki, Meil, Brandes und andere“ gesehen habe. Zelter 1931, S.136. Die Familienbiografin Olga Stieglitz spricht ebenso beiläufig wie vermutlich berechtigt vom „Ephraimschen Salon“. Stieglitz 2001, S. 145. 
chen Gastgeberschaft widerspricht. ${ }^{181} \mathrm{Zu}$ fragen ist wiederum, wie sinnvoll und berechtigt diese Unterscheidung wirklich ist, zumindest aus der Perspektive der Gäste, die in beiden Fällen in einer gemischten Runde jüdischer und nichtjüdischer gebildeter Männer und Frauen saßen.

\section{Fürstliche Vergnügungen}

Das mottogebende Zitat des Abschnitts stammt aus einem Brief Friederike Limans, die einen Sommerabend der Salongesellschaft beschrieb: „[...] gestren Abend führte uns dass Ungefähr bei Itzigs vorbey der Fürst Reuss gab Ihnen eine nachtmusic aufs Wasser, [Sie] die grosse Familie mit alle mögliche nezelrodes etc. wahren vor der thüre versamelt wir hielten stille und die Arnstein baht uns auszusteigen und wir blieben noch bis nach 11 da“..182

Bei „Itzigs“, dem großen Stadtpalais des Bankiers Daniel Itzig, Vater zahlreicher Töchter und mehrerer Salonièren, führte die hier genannten Sprecher 1794/95 tatsächlich nur „ein Ungefähr“ vorbei, weitere Erwähnungen gibt es zunächst nicht. Vermutlich fand die Nachtmusik in Itzigs prächtigem Garten statt, eine Sehenswürdigkeit eigenen Ranges, von Nicolai ausführlich beschrieben, in Schönheit und Ausstattung dem Park von Sanssouci verglichen. ${ }^{183}$ Dafür, dass Palais oder Garten des reichsten Manns der Stadt 1794/95 von den Mitgliedern der Salongesellschaft häufiger besucht wurden, findet sich kein Hinweis. Auch mit der Itzigtochter und Wiener Salonière Fanny von Arnstein verband die Berlinerinnen 1794/95 noch eine nur flüchtige Bekanntschaft. Rahel Levin Varnhagen ließ sich in Breslau zwar gern von einem Gast über das Haus Arnstein erzählen und Friederike Liman beschrieb, dass man bei dem zufälligen Treffen sehr liebenswürdig aufgenommen wurde, aber zu einer näheren Bekanntschaft sollte es erst 1798 kommen, als Fanny von Arnstein Berlin besuchte in Begleitung ihrer schönen Tochter Henriette, die von mehreren Salonbesuchern intensiv umworben wurde. Den Briefen 1795 ist noch eine

181 Nur Hilde Spiel zählt das Haus Benjamin Ephraims zu „den ersten Häusern, in denen solche Zirkel sich bilden durften“. Spiel 1992, S. 94. Ihr Hinweis hat aber kaum Nachfolgeforschung ausgelöst.

182 Friederike Liman an Rahel Levin Varnhagen, Frühjahr 1795, in: Bosold 1996, S. 5.

183 Der Garten lag zwischen der Köpenicker Straße und dem Schlesischen Tor, war berühmt für seine Standbilder, Labyrinthe und seine höchst kunstvolle Gesamtanlage. Über die Ausstattung und Bedeutung dieses Gartens berichtet ausführlich auch Hilde Spiel in der Biografie Fanny von Arnsteins, da er die Quelle ihrer Gelassenheit und Selbstverständnisses der Zugehörigkeit zur großen Welt gewesen sei. „Hier gewann sie Vergnügen an reicher Geselligkeit, überwand sie spielend und träumend den Fluch ihres Volkes [...]. Kein furchtbares, in sich gekrümmtes Erschrecken wie bei der Rahel [...]. “ Spiel 1992, S. 41. 
Distanz zur vornehmeren Welt, die man aber mit Leichtigkeit abtat, anzumerken. ${ }^{184}$

Bei dem von Friederike Liman erwähnten Organisator der Nachtmusik für Itzigs handelt es sich um den Fürsten und Diplomaten Heinrich XIV. Reuß (Plauen-Greiz), ${ }^{185}$ Mitglied einer sehr alten deutschen Adelsfamilie mit eigenem Palais in Berlin, und diplomatischer Vertreter des Deutscher Kaiserreiches. Er wurde in den Briefen leider erst aus Anlass seines frühen Todes 1799 ausführlicher thematisiert, als bekannt wurde, dass seine Freundin Marianne Meyer Eybenberg, ihm heimlich angetraut gewesen war und um die Anerkennung dieser Ehe bei seiner Familie kämpfen musste. In den zeitgenössischen Stadtbeschreibungen wird gelegentlich der Reußsche Garten erwähnt, der am Schiffbauerdamm gelegen und prächtig gewesen sein soll. Auch hier ließe sich spekulieren, dass Nachbarschaft das Kennenlernen in der Salongesellschaft erleichtert hat, da der Garten der Familie Reuß gewissermaßen dem ebenso schönen der Familie Ephraim benachbart war, deren Enkelin Marianne Meyer war. ${ }^{186}$

184 In Breslau „sprach ich den Geheimrath Levo der von Wien kam und Wunder! von Frau von Arnstein erzehlte von ihr Haus Prinzen, Minister, Grafen, Gesante, Garten, spät eßen, und alles was wir schon von Wien wissen." Rahel Levin Varnhagen an Markus Levin, 8. 8. 1794, in: ERLV III, S. 23. Friederike Liman an Rahel Levin Varnhagen, Frühjahr 1795, in: Bosold 1996, S. 5. In späteren Jahren, vor allem zu Zeiten des Wiener Kongresses, sind von allen Berliner Salonièren und den meisten Gästen Besuche im Haus Arnstein und Eskeles in Wien überliefert, von beiden Häusern sollte sich Rahel Levin beeindruckt zeigen, allerdings aus bemerkenswert unterschiedlichen Gründen. Im Palais Arnstein lobte sie die Weltläufigkeit, an Bernhard Eskeles genau das Gegenteil, dass er altväterlich geblieben sei und originell. Vgl. den Abschnitt zu Herzens.

185 Fürst Heinrich XIV. Reuß-Plauen-Greiz (1749-1799), ist verglichen mit den anderen Männern dieses Namens (alle Fürsten und Prinzen des Hauses Reuß, in allen Linien, hießen Heinrich) sehr schlecht dokumentiert. Eine wichtige und kaum noch genutzte Quelle ist der Nachlass seiner Familie im Thüringischen Haupt- und Staatsarchiv, besonders die Testamente des früh verstorbenen Fürsten, die ihn als sehr umsichtigen und Marianne Meyer Eybenberg aufrichtig liebenden Mann zeigen. Der Titel Reuß wird ohne „von“ zitiert. 186 Den Ephraimschen Garten beschreibt Julius Rodenberg als „einen prachtvollen Garten am Schiffbauerdamm, in welchem sechs Kolossalstatuen von Schlüter standen [...], ursprünglich dazu bestimmt, die Balustrade des königlichen Schlosses zu schmücken, und ein schönes Landhaus im Barockstil, welches von einer riesigen Platane beschattet ward.“ Zum Zeitpunkt von Rodenbergs Beschreibung war „diese Herrlichkeit lange dahin“, den Neubauten der Friedrich-Wilhelm-Stadt gewichen, auch das Gartenhaus, das noch lange von der S-Bahn aus zu sehen gewesen sei. Julius Rodenberg: Bilder aus dem Berliner Leben hrsg. von Gisela Lüttig, mit einem Nachwort von Heinz Knobloch, Berlin 1987, S. 214; Der Erwerb des Gartens 1761 durch Veitel Heine Ephraim geschah mit königlicher Spezialgenehmigung. Es war das erste Mal, dass ein Jude in Preußen Grund und Boden kaufen durfte. Vgl. dazu Laurenz Demps: Der Schiffbauerdamm, Ein unbekanntes Kapitel Berliner Stadtgeschichte, Berlin 1993, S. 43 ff. Führt man die Spekulation über diese 


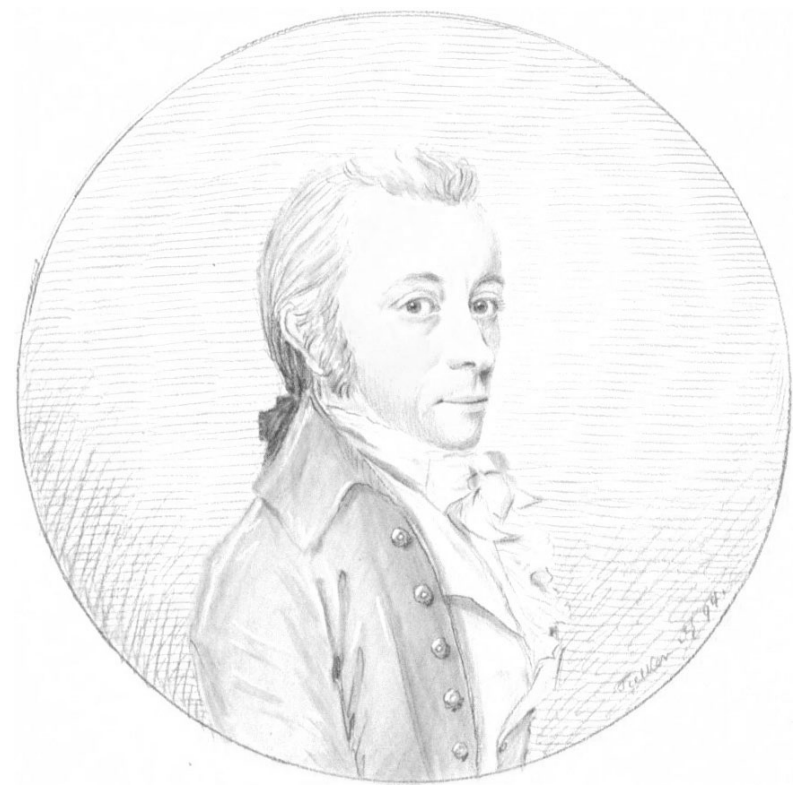

Abb. 12: Fürst Heinrich XIV. Reuß, Ehemann Marianne Meyer Eybenbergs, (1749-1799).

Von Heinrich XIV. Reuß selbst überliefert sind in der Sammlung Varnhagen einige undatierte Billets, die laut Katalog den Jahren 1795-1797 entstammen, sowie ein gezeichnetes Portrait, ein markantes Halbprofil eines Mann mit Uniform und Zopf. Wenngleich keine regelmäßigen Einladungen in sein Haus bekannt sind, kann der Fürst als Katalysator der Geselligkeit gelten. Das Bücherverzeichnis seines Nachlasses zeigt ihn als umfassend interessierten und gebildeten Mann, der mit einer umfänglichen Sammlung, die er gemeinsam mit Marianne Meyer Eybenberg aufbaute, möglicherweise ähnlich wie Brinckmann die Lektürewünsche der Salonfrauen erfüllen konnte. ${ }^{187}$ Die Billets, vor allem an Sara Meyer Grotthus und Rahel Levin Varnhagen, zeigen ihn als ritterlichen Kavalier, der Bücher verlieh, Billets besorgte, Briefe vermittelte und anscheinend bei der Verwaltung des Erbes der Meyers geholfen hat. ${ }^{188}$

Ein fürstlicher Salon, der 1794 trotz andersmeinender Darstellung in der Literatur nicht wirklich existent war, ist der der Herzogin Dorothea von Kur-

Nachbarschaft weiter, rührte die Bekanntschaft spätestens aus den frühen 1780er-Jahren, da die Familie Reuß den Garten später an den Hof verkaufte, der die Tierarzneischule darauf gründete.

187 Vgl. „Catalogus der Bücher zu der Verlassenschaft“, in: ThStA Greiz, Geh. Kab. Greiz I nr. 88a, S. 31-50.

188 Vgl. dazu die wenigen Dokumente in SV 213. 
land. Sie hielt sich zwar gelegentlich auf einem Schloss bei Berlin auf, doch ließ sich aus diesem Jahr kein Kontakt weder zu den hier Genannten noch zu Personen ihres Ranges am Berliner Hof nachweisen. ${ }^{189}$ Auch ihre Schwester, Elisa von der Recke, fand in diesem Jahr in den Briefen der Salongesellschaft keine Erwähnung, obzwar sie sich gelegentlich in Berlin aufhielt. In späteren Jahren gab es einige Zusammentreffen, sowohl Marianne Meyer als auch Rahel Levin erwähnen Begegnungen mit den Prinzessinnen Kurland - dann allerdings als Frau von Eybenberg und Frau von Varnhagen, und in Badeorten. ${ }^{190}$

\subsection{Spaziergänge und andere öffentliche Vergnügungen}

Die Billets und Briefe des Jahre 1794/95 deuten buchstäblich auf ein sehr bewegtes Leben der Salongesellschaft: Neben den Teetischen wurden bereits Gärten oder Konzerte als Treffpunkte erwähnt, auch die Orte dazwischen müssen dazu gerechnet werden. Spaziergänge, Ausfahrten und vor allem Besuche machen und empfangen gehörten zu den alltäglichen Vorhaben der Beteiligten. Daneben prägten Ausflüge, etwa nach „Scharlottenbourg“ oder Potsdam, Theaterbesuche und andere kulturelle Teilhabe den Lebensrhythmus. Kommunikation und Konversation fanden, den Quellen zufolge, nicht nur an all diesen, sondern auch zwischen den einzelnen Orten statt. Die Salonkonversation ließ sich im mehrfachen Sinne nicht auf spezifische Räume begrenzen. Sie erstreckte sich - wie später im Falle des viel zitierten Grillparzerbesuchs ${ }^{191}$ bei

189 Sie lebte im Untersuchungszeitraum gelegentlich in Schloss Friedrichsfelde, wohin sie zuvor bereits einmal Moses Mendelssohn eingeladen hatte. Außer der Gesellschaft ihres Verehrers, ihres Bruders und einer neugeborenen Tochter (Dorothea Prinzessin von Kurland, 1793-1862) ist von Geselligkeit hier aber nichts überliefert. Ihren Salon Unter den Linden soll sie erst nach 1800 geführt haben. Das Gebäude, Unter den Linden 7, wurde nach der Geburt der Tochter Ende 1793 erworben. Wilhelmy verweist darauf, dass die Herzogin erst nach dem Tod ihres Gatten (1800) regelmäßig in Berlin lebte. Wilhelmy 1989, S. 637.

Vermutlich beruft sie sich darin auf Hans Landsberg, der schreibt, dass die Herzogin in dem Palais ihrer Tochter Unter den Linden, der heutigen russischen Botschaft, ab der Jahrhundertwende glänzende Gesellschaften gegeben habe. Landsberg 2000, S. 68 f. 190 Beispielsweise verkehrten Marianne Meyer Eybenberg und kurländische Prinzessinnen 1808 in Teplitz miteinander. Vgl. Johann Wolfgang von Goethe, Tagebucheintrag 3. 7. 1808, zit. nach: Sauer 1904, S.377. Rahel Levin Varnhagen erhielt im österreichischen Baden Schwimmstunden gemeinsam mit der Herzogin von Sagan, Tochter der Herzogin von Kurland. Dabei erinnern sich beide einer früheren Begegnung 1797 oder 1799 in Teplitz. Rahel Levin Varnhagen an Karl August Varnhagen, 27. 6. 1815, in: GW II, S. 298.

191 Franz Grillparzer wurde von Varnhagen am Ende eines langen Tages und „müde bis zum Sterben“ noch zum Haus gebracht, in dem Rahel wohnte. Sie kam ihnen auf der Treppe entgegen, begann die Unterhaltung, „und ich war bezaubert. Meine Müdigkeit verflog. [...] Ich habe nie in meinem Leben interessanter und besser reden gehört.“ Franz Grillparzer: 
der Legationsrätin Varnhagen - bis auf die Treppen des Hauses und begleitete Salonteilnehmer bis vor die Tür bzw. zur nächsten Veranstaltung. Rahel Levin Varnhagen beispielsweise berichtete, wie sie auf einem Nachhauseweg von der Doktorin Lemos, Henriette Herz' Schwiegermutter, mit Isaak Euchel besonders gut gesprochen und Bücher diskutiert hätte. ${ }^{192}$ Ein anderes Mal ließ sie sich von einem Gast des Ehepaars Fließ nach Hause bringen und überzeugte ihn auf dem Wege, auch ihr Gast zu werden. ${ }^{193}$ Im weiter oben zitierten Billet fand Brinckmann einen Professor so „aimable“, dass er einem Herzschen Freitag einen Spaziergang mit ihm anschloss und sogar zweimal die Linden auf und ab marschierte. Auch die langjährige Freundschaft zu Levin Varnhagen verdankte Brinckmann nach eigener Aussage eigentlich einem „Treppengespräch“ nach einem Salonbesuch. ${ }^{194}$

Der Befund vom Gang und Spaziergang als Kommunikationsort, der das Bild vom Salon als einer um einen Teetisch versammelten Gruppe ausweitet, entspricht allerdings dem Empfinden der Zeit, nach dem „Spaziergänge“ unter die Sehenswürdigkeiten einer Stadt gezählt und in Reiseführern erwähnt wurden. ${ }^{195}$ Auch der Weg entlang der 1801 fertig gestellten Stadtmauer Berlins hieß vermutlich nicht zufällig „Communication“.196

Die Vorstellung, dass man die als Salon bekannten geselligen Aktivitäten auch im ganzen Haus und auch auf der Straße wiederfinden kann, wurde bis-

Fragmente einer Selbstbiographie, in: Werke in 2 Bd., hrsg. von P. Stapf, Berlin [u. a.] 1959, S. 852, zit. nach: Strube 1992, S. 218.

192 Rahel Levin Varnhagen an David Veit, 3.1. 1794, in: GW VII/I, S. $107 \mathrm{ff}$. Dass es bei der Schwiegermutter von Henriette Herz auch Teegesellschaften gegeben hat, ist m. W. noch überhaupt nicht untersucht.

193 „Dr. Bote war einmal bei uns, ich will Ihnen sagen, wie das geschah; ich sah ihn in Gesellschaft bei Fließens [...]; Dr Fließ und er brachten mich zu Mad. Liman, unterwegs sagte ich: ,Sie waren so gütig mir das Buch selbst zu bringen, ich war aber nicht zu Hause, und ich habe mir eingebildet, Sie hätten mich dabei besucht; wollen Sie mir das wohl ersetzen?‘ - ,Mit Vergnügen, wenn Sie erlauben.““ Rahel Levin Varnhagen an David Veit, 20. 2. 1794, in: GW VII/I, S. 175 f.

194 „Wir trafen uns in einer ziemlich gemischten Gesellschaft [bei Herzens, H. L. L.], wo Rahel wenig sprach, aber ,geflügelte Worte', die mich um so aufmerksamer machten [...].“ Auf der Treppe habe Rahel dann gesagt: „,Ich sollte Ihre Freundin sein! ganz andre Dinge würden Sie von mir hören müssen!‘ [...] Dieses Treppengespräch war unsere erste, für mich immer gewurzelte Bekanntschaft.“ Gustav von Brinckmann: Rahel. Brief an von Varnhagen, nach dem Tode seiner Gattin. 1834, hier zit. nach dem Original, BA V.

195 Vgl. z. B. Nicolais Wegweiser von 1793, in dem unter „Oeffentliche Spaziergänge, Spazierfahrten und andere Vergnügungen“ der „Thiergarten“, die „Gegend um Berlin“ gleichwertig neben Scheibenschießen und Oper genannt werden. Nicolai 1793, S. $150 \mathrm{ff}$. 196 Mieck 1980, S. 406. 
her nur einmal beschrieben, und nur für Rahel Levin Varnhagen. ${ }^{197}$ Dieses Kapitel ist ein Plädoyer dafür, die Berliner Salongesellschaft der 1790er-Jahre im Modell der offenen Häuser zu denken: offen für Besucher unterschiedlicher Herkunft, offen aber auch im Wortessinne zwischen den Etagen, für eine Beteiligung der Familie. Offen waren die Häuser schließlich auch zur Straße hin, um das Gespräch in ein anderes Haus oder auf den Weg mitzunehmen.

Diese Fortsetzung des Gesprächs auf der Straße und die schnellen Ortswechsel wurden natürlich durch die Nähe der einzelnen Etablissements begünstigt. In einer Zeit, in der man die meisten innerstädtischen Wege noch per pedes zurücklegte, war es für die Salons von Vorteil, in der Nähe des Theaters, der Oper und der Clubs zu liegen, die von ihren potentiellen Gästen aufgesucht wurden. Eine von Petra Wilhelmy erarbeitete Karte ${ }^{198}$ zeigt eine strategisch günstige Lage als Merkmal der Berliner Salons von 1790 bis zum Ende des 19. Jahrhunderts. Der Umstand, dass man vom Haus der Levins zum Nationaltheater auf dem Markt maximal zehn Minuten Fußweg zurücklegen musste, trug sicherlich ebenso zur Attraktivität eines Nachttees bei, wie die Tatsache, dass die Besuche auch nachts stattfinden oder enden konnten, ohne dass ein öffentliches Verkehrsmittel bzw. eine private Kutsche bereit gehalten werden musste. Umgekehrt war bereits die Distanz von Berlin Mitte nach Tegel eine solche Entfernung, dass Wilhelm von Humboldt sich 1795 mehrere Wochen auf seinem Schloss aufhalten konnte, ohne von Freunden spontan aufgesucht zu werden. Auch gab es nahe gelegene Gegenden, die ,man' kaum besuchte: Mit einer Wohnung jenseits der Oranienburger Straße, heute ebenfalls Berlin-Mitte, wurden Friedrich Schlegel und Dorothea Mendelssohn Veit Schlegel 1797 im doppelten Sinne als außerhalb der vornehmen Kreise empfunden.

Wie oben gezeigt, fand neben den bekannten „Salons“ im Hause Herz und Levin ein Großteil der Kommunikation nicht an einem Teetisch, sondern andernorts statt. Auf der Suche nach kommunikativen Orten in Berlin ist festzuhalten, dass jeder Briefwechsel ebenso wie in den intellektuellen Themen auch in der Nennung von Vergnügungen und Orten andere Schwerpunkte setzt, andere Treffpunkte häufiger nennt, je nach den Vorlieben oder gemeinsamen Erinnerungsorten der Briefpartner. Auch die Lektüre zahlreicher Briefwechsel aus demselben Zeitraum kann daher nur eine ungefähre Hochrechnung zu den kommunikativen Orten dieser Zeit, nur einen Näherungswert auf der Beliebtheitsskala der Salongesellschaft ermöglichen. Als besonders illustre Beispiele für kommunikative Orte, die - wie der Salon - eine Mischung der Stände und Geschlechter ermöglichten, und da sie in fast allen Korresponden-

197 Vgl. Roebling 1993.

198 Wilhelmy 1989, S. $966 \mathrm{ff}$. 
zen häufiger erwähnt werden, sollen hier der Tiergarten und das Theater als kommunikative Orte und Treffpunkte der Salongesellschaft vorgestellt werden.

\section{„Thiergartenleben“}

„Einer der angenehmsten Spaziergänge in Berlin, wo vornehmlich des Sonntags alle Stände vereinigt sind, um sich Erholung und Erquickung zu schaffen, ist der Tiergarten“, bemerkte ein zeitgenössischer Reisender. ${ }^{199}$ Ursprünglich als Jagdrevier der Kurfürsten genutzt, war der Park von Friedrichs II. Architekten Knobelsdorff so als Lustgarten umgestaltet worden, dass überschattete Alleen und Gänge, etwa der „Philosophische Gang“, Raum sowohl für aneinander vorbeifahrende Kutschen als auch für Spaziergangsgeplauder boten.200 Der Tiergarten war Treffpunkt, Ziel kurzer Ausflüge und angenehmer Kommunikationsort in dem Sinne, dass er Kommunikation ermöglichte, aber nicht erzwang: „Es giebt hier kein Mensch auf den andern Achtung, jedermann genießt nur die uneingeschränkteste Freiheit, die nur die Beschaffenheit eines solchen Orts mit sich bringen kann". ${ }^{201}$ Gegenüber dieser etwas idealisierten Darstellung beschrieb Friederike Liman 1794 sowohl bewusstes Sehen und Gesehenwerden, wie auch das Darüberhinweg- oder Aneinandervorbeisehen: „Sontag begegnete ich im thiergarten die Elliot mit navarro und noch einer menschpersohn, $[\mathrm{zu}]$ in einem ganzen wagen navarro bückte sich gans hinein um mich nicht zu grüssen, sie konnte meine insolence nicht leiden weil ich sie gradezu ansah und wendete den kopf mit dedain weg“. ${ }^{202}$ Obwohl also der

199 Karl Heinrich Krögen: Freie Bemerkungen über Berlin, Leipzig, Prag [1785], Leipzig und Weimar 1986, S. 28.

200 Der Tiergarten war 1794 und weit darüber hinaus übrigens der einzige heimische Ort, den Berliner mit dem Begriff Salon in Verbindung bringen konnten, da hier gewisse baumumstandene Plätze als so genannte „grüne Salons“ gestaltet wurden. „Links, vom Brandenburger Thore, hat der Park reitzende Alleen, geschlängelte Gänge, Salons von Birken und Weißbüschen, den Apoll- oder Florasalon (von den daselbst befindlichen Statuen also benennet.)“ Nicolai 1793, S. 151. Hervorhebung im Original. Vgl. auch Klaus von Krosigk: Der Berliner Tiergarten (Berliner Ansichten; Bd. 21), Berlin 2001 S. 28 f. Auch 1834, zu einem Zeitpunkt als Salons im Sinne geselliger Phänomene in der Salonforschung als etablierte Berliner Institution gelten, haben sie noch keinen eigenen Eintrag in Reiseführern. Vgl. z. B. das sehr detaillierte Zedlitz-Lexikon, das zwischen Salomons Meierei und Salpeterfabriken eine bezeichnende Leerstelle hat: Leopold Freiher von Zedlitz: Neuestes ConversationsHandbuch für Berlin und Potsdam. Zum täglichen Gebrauch der Einheimischen und Fremde aller Stände, Berlin 1834, reprint Berlin 1979.

201 Krögen 1986, S. 28

202 Friederike Liman an Rahel Levin Varnhagen, 21. oder 22.6. 1795, ungedruckt, in: Bosold 1996, S. 15. Schreibung im Original. 
Tiergarten als Treffpunkt der Stände galt, glaubte Friederike Liman, dass die Gattin des englischen Gesandten es als „Dedain“, also Unverschämtheit empfand, wenn sie von ihr angesehen würde. Der erwähnte Marquis Navarro D’Andrado war zu dieser Zeit Gast bei Levins und daher auch mit Friederike Liman gut bekannt, aber anscheinend nicht immer ...

Das Vergnügen dieses öffentlichen und offenen Orts, als „Sammelplatz von Hohen und Niedern, von Reichen und Armen“ lag vermutlich vor allem in der Mischung seiner Besucher und in der Beobachtung dieser Mischung. „Man kann hier ohne viele Mühe ein reiches Maß von Menschenkenntnissen sammlen, das man oft jahrelang vergeblich zu erreichen sucht“, 203 schrieb ein Buchhändler, und ein Offizier, der sich auf die Galanterien von Berlin spezialisierte, lobte den Tiergarten: „Hier hüpft der Stutzer dem Philosophen vorbey, und dort rauscht eine wollüstige Nymphe hinter der Frau Präsidentin drein“.204 Die Kaffeegärten am Anfang des Tiergartens wurden schließlich explizit als Treffpunkt der Geschlechter erwähnt: „man sieht da [...] eine zahlreiche Gesellschaft beiderlei Geschlechts, die sich bei Kaffe, Wein und Schokolade die Zeit verkürzen. Die Frauenzimmer sitzen ohngeachtet des vielen Tobakrauchens mit unter den Mannspersonen“.205

Eine Attraktion des Tiergartens bestand sicher darin, die Stadtprominenz dort ansehen zu können. ${ }^{206}$ Die gesellschaftliche Offenheit des Ortes muss dann noch dadurch gesteigert worden sein, dass Personen einfacher Herkunft durch prächtige bzw. für ihr Herkommen zu prächtige Kleidung für Personen höheren Standes gehalten werden konnten. Verschiedene Stadtbeschreibungen erwähnen, dass hier eine stadtbekannte Mätresse im gleichen Kleid wie eine Gräfin gegangen sei oder ein Adliger einer Prostituierten solange den Arm geboten habe, bis ein Freund, der sie von dem anderen Ort kannte, ihn aufklärte. ${ }^{207}$

Neben der Funktion als öffentlicher Ort oder Spaziergang verfügte der Tiergarten noch über interessante Lokale bzw. Restaurationen, in denen Mitglieder

203 Krögen 1986, S. 29.

204 [Johann Friedel]: Briefe über die Galanterien von Berlin. Auf einer Reise gesammelt von einem österreichischen Offizier 1782, Berlin 1987, S. 63.

205 Krögen 1986, S. 29. Auch die Berliner Sitte, bei dem geringsten Anschein guten Wetters seinen Kaffee draußen zu trinken, bestand anscheinend schon vor 200 Jahren, denn man sah „die Menschen in leichter Tracht mehrere Stunden in unserm ohnehin feuchten Thiergarten bei dem geliebten Caffee im Freien verweilen“. Formey 1796, S. 82.

2061794 ist z. B. auch in den Briefen der Königin Luise zu lesen, dass sie mit ihrer Schwester im Wagen durch den Tiergarten fuhr, auch begleitet von zwei Ehemännern zu Pferde. Luise von Preußen an Therese von Thurn und Taxis, 19. 2. 1794 und 25. 2. 1794, in: Malve Rothkirch (Hrsg.): Königin Luise von Preußen: Briefe und Aufzeichnungen. Mit einer Einleitung von Hartmut Boockmann, München [u.a.] 1995, S. 52.

207 Vgl. die Anekdoten bei Krögen 1986, S. 29 und Friedel 1782, S. 62. 
der Salongesellschaft speisten. ${ }^{208}$ In diesen Restaurationen, vor allem in großen Gärten, vermischte sich die Grenze von öffentlich und privat insofern, als dass Privatpersonen im öffentlichen Raum ausgewählte Gäste zur Gesellschaft bitten konnten. ${ }^{209}$ In den Briefen der Salonbeteiligten wurden beispielsweise die Gärten der Brüder Boucher und der Ephraimsche Garten als Attraktion verzeichnet. ${ }^{210}$ Weiterhin wird das Areal vielfach erwähnt wegen der Sommerwohnungen, die sich einige Berliner dort nahmen, um die warmen Monate im Grünen zu verbringen. Für Frühjahr und Sommer muss der Tiergarten als einer der wesentlichen Orte der Salongesellschaft zählen. Henriette und Markus Herz zogen sommers in den Tiergarten und empfingen dort auch Gäste. Anfang des 19. Jahrhunderts sollte Familie Beer ihren Wohnsitz ganz in den Tiergarten verlegen und dort gemischte Gesellschaften geben. ${ }^{211}$ Rahel Levin Varnhagen beschwerte sich bei David Veit im März 1795: „Ich war mit der Liman und Unzelmann ausgefahren [...], uns ein Zimmer, bis ich verreist, im Thiergarten zu miethen; aber keins bekommen." Und im August des Jahres schrieben ihr Bruder und Schwägerin, sie wären „alle Tage“ dort.212

Mit einer Bekannten zu einer Bekannten in den Tiergarten fahren und darüber einer anderen Bekannten zu berichten, war eine weitere häufige Verlustierung der Salongesellschaft in dieser Zeit: „ich habe heute ordentlich ein francoisiches Billet an die marchetti geschrieben und sie invitirt, morgen Nachmittag mit mir bey der flies in thiergarten $\mathrm{zu}$ faren“, schrieb Friederike Liman. ${ }^{213}$ Ähnliches berichtete Rahel Levin Varnhagen - ihre Beschreibung eines Frühlingstages ist ein gutes Beispiel dafür, dass Geselligkeit den Charakter eines Staffellaufs annehmen konnte: „[...] die Baranius trat in mein Zimmer,

208 Beispielsweise wurde häufig auf dem Weg nach Charlottenburg, bis wohin sich der Tiergarten erstreckte, in einem Kaffeehaus Rast gemacht.

209 Explizit aus dem Jahr 1795 nennt zum Beispiel der Arzt Heim verschiedene Gastgeber, von denen er „in Gesellschaft mehrerer im Therbuschischen Garten bewirtet worden“. Heim 1989, S. $92 \mathrm{f}$.

210 Vgl. z. B. Rahel Levin Varnhagen an David Veit 1. 4. 1793, in: GW VII/I, S. 10 und Rose Varnhagen an Rahel Levin Varnhagen, 18. 5. 1795, ungedruckt, SV 214. Heim nennt den Therbuschischen und den Georgischen Garten. Diese Nichtüberschneidung kann aber Zufall sein, da die Zahl der Gartenrestaurationen in Berlin verhältnismäßig groß war.

211 Zu der Villa Beer und den Geselligkeiten s. zuletzt: Liliane Weissberg: Von Liepmann Meyer Wulff bis Hans Richter. Eine Berliner Familien- und Stadtgeschichte, in: Sven Kuhrau / Kurt Winkler (Hrsg.): Juden. Bürger. Berliner. Das Gedächtnis der Familie Beer-MeyerbeerRichter, Berlin 2004, S. 15-32, bes. $21 \mathrm{ff}$.

212 Vgl. Rahel Levin Varnhagen an David Veit, 22. 3. 1795, in: GW VII/II, S. 84, sowie den gemeinschaftlichen Brief von Markus und Hendel Levin an Rahel Levin Varnhagen, 29. 8. 1795, SV 214, auch in: ERLV III, S. 55.

213 Friederike Liman an Rahel Levin Varnhagen, 6. 6.1795, in: Bosold 1996, S.6. 
blieb bis Mittag, half mir Heimann versäumen, welcher mich dann mit Fließ zusammen zwang, nach dem Thiergarten zu gehen; [...] ich aß, wurde zur Fließ gebeten, wo eine Frau vom Lande war, die ich sehen wollte“.214

Ein für die Salongesellschaft besonders wichtiger Ort dieser Zeit im Tiergarten war die Restauration „Hofjäger“, 215 die so beliebt war, dass man bei Besuchen mit Sicherheit davon ausgehen konnte, irgend einen Bekannten zufällig zu treffen, bzw. auch davon ausgehen musste. Brinckmann traf dort zufällig Rahel Levin Varnhagens Schwägerin und Eltern, „die Fließ“ suchte dort ihren Ehemann zu vermeiden: „[...] nachher machte ich jedenfalls dass die F mit mir zum Hoffgäger ging: wo es grad den tag sehr hübsch war und Q [traff] traf [ich] mit dem ich mir eigentlich ein rendezvous da gab. die F war aber unausstehlich sie eilte weil sie glaubte ihr caro marito würde komen“. ${ }^{216}$ Entscheidend war nicht nur, wen man dort traf, sondern auch mit wem man dorthin fuhr: „die U wollte nicht dass wir zusammen faren weil sie befürchtet die Marchetti kann es übel nehmen und da hatt sie auch sehr recht".217

Dafür, dass der Tiergarten und die Aufenthalte dort vielleicht kein täglicher, aber wesentlicher Bestandteil des Salonlebens waren ${ }^{218}$ bzw. dass der Tiergarten als offener Ort verschiedenste anregende Mischungen erlaubte, spricht schließlich eine Formulierung des Gastes Burgsdorf, der seine Zeit mit Rahel Levin Varnhagen und ihren Freundinnen als „Thiergartenleben“ bezeichnete. Anders, als Peter Seibert formuliert, ist der Tiergarten nicht eine „Vorstufe“ für die Verkehrsformen der Berliner Salons oder Fluchtpunkt, sondern essentieller Teil davon. ${ }^{219}$

214 Rahel Levin Varnhagen an David Veit, 24. 3. 1795, in: GW VII/II, S. 86.

215 Der Hofjäger war ein Kaffeegarten am Ende der Tiergarten-Straße genannten Häuserreihe, benannt nach der Tatsache, dass in dem Haus früher der königliche Hofjäger gewohnt hatte.

216 Friederike Liman an Rahel Levin Varnhagen, 21. 6. 1795, in: Bosold 1996, S. 15. „F“ steht für Fließ Boye Sparre, der „geliebte Ehemann“ ist Isaac Fließ. „Q“ meint Otto von Quast, Verehrer Friederike Unzelmanns.

217 Friederike Liman an Rahel Levin Varnhagen, 4. 8. 1795, in: Bosold 1996, S. 30. „U“ steht für Unzelmann. Marchetti und Plumer waren beide Sängerinnen, daher möglicherweise die Eifersucht. Schreibung im Original.

218 Der Hofjäger scheint regelmäßiges Vergnügen gewesen zu sein, so schlug Rahel Levin Varnhagen einmal eine Einladung zur Mitfahrt mit den Worten aus „alle Tage ist nicht Sonntag“. Rahel Levin Varnhagen an Gustav von Brinckmann, 10. 9. 1796, ungedruckt, SV 38. 219 Wilhelm von Burgsdorf an Gustav von Brinckmann, 3. 9. 1796, in: Cohn 1907, S. 8. Seibert 1993(a), S. 144. 


\section{Das Theater als Treffpunkt und Thema der Salongesellschaft}

Das Theater stellt sich im Vergleich der Korrespondenzen als einer der wesentlichen Diskussionsgegenstände der Salonbeteiligten dar. Sowohl die Aufführungen wie die Aufführenden waren von großem Interesse. Das ist auch aus dem Grund bemerkenswert, da das Berliner Theater um 1800 keineswegs einen guten Ruf hatte, sondern eher durch Tumulte auf und Missverständnisse hinter der Bühne sowie organisatorische Kleinkriege in jeder Form von sich reden machte.220 1794/95 im speziellen kam es, neben oder infolge von Auseinandersetzungen zwischen Direktion und einzelnen Stars, zu Aufruhr auf der Bühne und Lärm aus dem Publikum. Diese wurden in den Briefen der Salongesellschaft kaum kommentiert, allerdings hielt diese vom allgemeinen Publikum in der Stadt auch nicht unbedingt viel. ${ }^{221}$

Die Anfang der 1790er-Jahre wesentlichen Spielstätten in Berlin waren das Nationaltheater auf dem Gendarmenmarkt ${ }^{222}$ und das Opernhaus Unter den Linden.223 Die 1742 eröffnete Königliche Oper bot italienische Oper. In dem 1775

220 Erst mit der Übernahme der Direktion des Nationaltheaters durch Iffland 1796 wurde die Grundlage für eine „Bühne der „Berliner Klassik“ gelegt. Klaus Gerlach: Einleitung, in: ders. (Hrsg.): Der gesellschaftliche Wandel um 1800 und das Berliner Nationaltheater, Hannover 2009, S.7-18, hier S. 7.

221 „Denn etwas gleichgültigeres gibt's gar nicht, als die Fünfhundert ungefähr, die jenes sein sollten, denn ich behaupte, es giebt hier gar keins, weil ich nur eine urtheilende Menge darunter versteh', unter den Fünfhunderten aber sind nu etwa dreißig, die gar nach dem Orchester sehen [...]; sind auch diese dreißig etwa getheilter Meinung, so kommt's nie zur Sprache, weil's Ihnen nicht so viel werth ist, das Maul drum zu öffnen [...]." Rahel Levin Varnhagen an David Veit, 25.1.1794, in: GW VII/I, S.127. Möglicherweise war die Anspruchslosigkeit ein Grund für die folgenreichen Nebengespräche, die sie im Theater führte.

222 Der Platz ist auf offiziellen Karten zu dieser Zeit als Friedrichstädtischer Markt verzeichnet, war aber bereits auch unter dem Namen Gensd'armenmarkt bekannt. 223 Eine umfassende Theatergeschichte Berlins von den Anfängen bis heute gibt es eigentlich nicht. In der Forschung liegt das Interesse seit Anfang des 20. Jahrhunderts schwerpunktmäßig auf einzelnen Institutionen. Als Einführung: Ruth Freydank: Theater in Berlin. Von den Anfängen bis 1945, Berlin 1988, s. a. Gerlach 2009. Zur Zeit um 1800 s. wegen Detailreichtum und Quellennähe außerdem: Carl Martin Plümicke: Entwurf einer Theatergeschichte von Berlin, nebst allgemeinen Bemerkungen über den Geschmack, hiesige Theaterschriftsteller und Behandlung der Kunst, in den verschiedenen Epochen. Berlin und Stettin 1781; Albert Emil Brachvogel: Geschichte des Königlichen Theaters zu Berlin. Nach Archivalien des Königlichen Geh. Staats=Archivs und des Königl. Theaters, 2 Bde., Berlin 1878 sowie Rudolph Genée: Hundert Jahre des Königlichen Schauspiels in Berlin. Nach Quellen geschildert, Berlin 1886. Alle drei Darstellungen vertreten einen bürgerlichnationalen Interpretationsansatz und betonen den Aufstieg der nationalen deutschen Bühnenkunst im späten 18. Jahrhundert. Zur Oper um 1800 vgl. Christoph Henzel: Die italienische Hofoper in Berlin um 1800. Vincenzo Righini als preußischer Hofkapellmeister. Stuttgart [u. a.] 1994. 
erbauten und seit 1786 deutsch bespielten Nationaltheater wurden Schauspiel und deutschsprachiges Musiktheater geboten. ${ }^{224}$ Dieser Umstand und zahlreiche Doppelverträge von Darstellern, die an beiden Häusern verpflichtet waren, führte seit den 1790er-Jahren zur verschärften Konkurrenz - ein Thema für die Salongesellschaft vor allem wegen der mit mehreren Salonièren befreundeten Schauspielerin Friederike Unzelmann. ${ }^{225}$ Die jüdischen Salonièren besuchten beide Häuser regelmäßig. In den Billets finden zudem noch Theaterausflüge nach Potsdam und „Scharlottenbourg“ Erwähnung, womit die Bühne im Potsdamer Neuen Palais und das 1791 fertiggestellte Theater im Schloß Charlottenburg gemeint sein dürften. ${ }^{226}$

Dass Kulturgenießende noch in den 1780er-Jahren nach gesellschaftlicher Herkunft unterschieden worden waren, ${ }^{227}$ macht eine zeitgenössische Theatergeschichte deutlich, die die „Bürgerschaft“ im Wortessinne auf die hinteren Ränge der Oper verwies: Sogar bei den Redouten, den großen, kostenlosen öffentlichen Maskenbällen zur Zeit des Karnevals, die theoretisch die gesellschaftliche Herkunft zu verschleiern helfen sollten, ${ }^{228}$ wurde zwischen „Herrschaft“ und allgemeinem „Publikum“ unterschieden. Erstere speiste im großen Saal, letzteres schaute, wie noch beim absolutistischen Hof, von der Galerie aus zu. ${ }^{229}$ Zum Ende des Jahrhunderts - ein genaues Datum ist leider nicht überliefert - wurden die Bestimmungen gelockert bzw. das Theater als Treffpunkt populärer. Die Freundinnen Liman und Levin Varnhagen beispielsweise saßen mal oben, mal unten im Theater. Mal zeigte sich Liman im Parkett als Kritikerin nicht nur der Bühnen-, sondern auch der adligen Selbstdarsteller, mal machte Levin Varnhagen in der Loge eine für ihr Leben bedeutsame

224 Berlin hatte später als andere deutsche Theaterstädte, wie etwa Hamburg oder Leipzig, erst 1742 die Grundlagen für einen regelmäßigen Theater- und Opernaufführungsbetrieb gelegt. In diesem Jahr bekam nicht nur das gehobene Publikum mit der königlichen Oper eine neue Kulturstätte, auch wurde erstmals eine Konzession für regelmäßige Theateraufführungen im Berliner Rathaus vergeben.

225 Die Unzelmann, „deren Aeußeres schon Alles bezauberte, war ebenso in Tragödie und Lustspiel wie in der Oper gefeiert", erst nachdem sie die Singstimme verlor, zog sie sich auf das Theater zurück. Genee 1886, S. 42.

226 Beispielsweise: „[...] wir werden schon morgen eine Partie zu samen nach Scharlottenburg machen, wo probe sein wird, von der operette die Sontag da aufgeführt wird.“ Friederike Liman an Rahel Levin Varnhagen, Mitte Juni 1795, in: Bosold 1996, S. 11. Und: „Es wird einen Monat Komödie in Potsdam sein, und da werde ich eigenmächtig - mit der Eigensatz hin." Rahel Levin Varnhagen an David Veit, 7. 5. 1795, in: GW VII/II, S. 116. 227 Die Oper war gemäß ihrer Gründung anfänglich eine Einrichtung des Hofes, ein Ort mit eingeschränkter Öffentlichkeit, sodass Friedrich II. gelegentlich auch ganze Regimenter abkommandiert hatte, um Reihen zu füllen.

228 Zu diesem Zweck wurde unter anderem das Parkett auf Bühnenhöhe heraufgeschraubt. 229 Plümicke 1781, S. 119. 
Bekanntschaft, wie im Winter 1795 die des Baron Karl Finck von Finckenstein, ihres späteren Verlobten.

Mit den großen Logen, die im Theater bis zu sechs, in der Oper laut zeitgenössischem Preisaushang bis zu 20 Personen fassten, sowie weitläufigen Säulengängen und Foyers boten Oper und Theater zahlreiche Plätze der oberflächlichen wie auch der persönlichen Konversation.230 Immerhin gelang es Rahel Levin Varnhagen, den als schüchtern geltenden Baron mit einem Gespräch in der Theaterloge so für sich einzunehmen, dass er Gast in ihrem Hause wurde. Die Logen können quasi als halböffentliche Orte betrachtet werden, insofern man ausgewählte Freunde dorthin vorher einladen konnte, sofern es einem zuvor gelungen war, eine Loge $\mathrm{zu}$ reservieren. ${ }^{231} \mathrm{Im}$ ersten Rang hatte der Hof bzw. die verschiedenen Hofstaaten ihre Logen, im zweiten und dritten die Spitzen der Regierungsbehörden sowie „Fremde Residenten u: Leg:[ations] Sekr.[ekretäre]“, also auch die Diplomaten, die in den Salons verkehrten. Im Parterre gab es Logen für Staatsbedienstete der Departements sowie Künstler und Gelehrte, zum Beispiel die „Opern Acteur Loge“. Offiziell konnte zwar jeder Bürger, wie bei Nicolai erwähnt, um ein Eintrittsbillet einkommen, aber die Anzahl der zu verteilenden Tickets war nach dem Urteil einer Tageszeitung viel zu klein: „Für Fremde, denen ihr Stand nicht erlaubt, am Hofe zu erscheinen [...] und für die ganze achtungswürdige Klasse der Fabrikanten, Kaufleute, Künstler [...] ist kein Raum vorhanden“.232

Die Damen Liman, Fließ, Levin und Meyer, die ihrem Stand zufolge zu keiner der vergabefähigen Gruppen gehörten, konnten ihre Theaterkontakte nutzen und kamen so häufig in den exklusiven Genuß eines Logenplatzes. Oder sie gebrauchten ihre Bekanntschaft mit den Diplomaten wie Brinckmann oder Reuß, die in ihrem Beruf als Hofmitglieder galten, um Billets zu bekommen. Reuß besorgte Logen und machte sich zum Sprachrohr der Damen untereinander:

///Mademoiselle Meyer erkundigt sich bey Ihnen, ob Sie heute mit ihr das Schauspiel besuchen wollen, $u$ bittet Sie durch mich um Antwort, ich füge meinen herzlichen Gruß

230 Ein möglicher Grund für viele Gespräche in der Oper könnte auch gewesen sein, dass die Sicht auf vielen Plätzen nicht gut war. Auch nach dem Umbau unter Friedrich Wilhelm II. konnten von den 3.500 Personen, die das Opernhaus fasste, nach zeitgenössischen Kritiken, 2.000 nicht gut sehen. Vgl. Neue Berlinische Monatsschrift 44, 1801, zit. nach: Henzel 1994, S. 30, Fn 6.

231 „Personen die die Oper sehen wollen und nicht zum Hofe gehören ersuchen den Königlichen Direktor der Lustbarkeiten [...] um ein Billet oder gehen mit Personen vom Königlichen Hofe oder von den Landeskollegien in die denselben bestimmten Logen." Nicolai 1993, S. 152.

232 Neue Berlinische Monatsschrift I, 1799, S. 248 f., zit. nach: Henzel 1994, S. 34. 
an, $\mathrm{u}$ bitte gehorsamst - aber alles nur mündlich - mir sagen zu lassen, ob Sie vielleicht schon eine Loge haben, oder ob ich eine bestellen soll. auf französisch sagt man agrezz [?] mes homages, warum wollten Sie Sich nicht auch huldigen laßen // von Reuß // Mittwoch///233

Der Zugang zum Nationaltheater ${ }^{234}$ war allgemeiner, allerdings im Untersuchungszeitraum nicht wenig umkämpft. Sitzplätze waren hier für Einzelpersonen oder logenweise für jedermann erwerbbar, zum bemerkenswerten Preis von etwa zwei Reichsthalern pro Loge.235 Zwei bis heute gängige Zugangsformen zum Theater lösten seit den 1780er- Jahren immer wieder Debatten bei den Betreibern aus, da sie über die Maßen vergeben wurden und die Einnahmen schwächten: so genannte Freibillets und Abonnements. In einem interessanten Fall war 1787 der Antrag eines jüdischen Ehepaars auf zwei reservierte Plätze gemeinsam mit dem Antrag von Berlins bekanntester Bordellbesitzerin diskutiert worden. Das betreffende amtliche „Promemoria“ wird hier zitiert, um den Billets den Tonfall eines offiziellen, halböffentlichen Schriftstücks entgegenzusetzen:

Es hat sich der zum Christenthum übergegangene Jude Ferdinand Wilhelm Fließ gemeldet, [...] wie er gesonnen sey, für sich und seine Frau auf zwei Plätze im Parkett zu aboniren und 2 Friedrichsdor monatlich zu geben. Meiner unvorgreiflichen Meinung nach dürfte dem Gesuch des p. Fließ zu deferiren seyn, jedoch überlaße ich solches [...] Euer Königl. Hochlöblichen General Direction, welche ich auch hierdurch ganz gehorsamst ersuchen muß, das bereits mündlich vorgetragene Abonnement der Schubitzen auf die Pfeilerloge im zweiten Range rechter Hand für 3 Friedrichsdor monatlich genehmigen zu wollen. ${ }^{236}$

233 Heinrich XIV. Reuß an Rahel Levin Varnhagen, undatiert, ungedruckt, SV 213.

234 Entgegen seinem Namen hat man sich unter dem Nationaltheater 1794 keinen repräsentativen Bau, sondern ein schmales schlichtes Gebäude vorzustellen, das auch noch nicht den zentralen Platz des heutigen Schauspielhauses einnahm. Es wird berichtet, dass es im Parkett etwa 300, in den Logen etwa 700 Personen fasste. Vgl. Aldabert Behr / Alfred Hoffmann: Das Schauspielhaus in Berlin, Berlin 1984, S. 30.

235 „Logen werden bey der Cassirerin Mad. Bredow, wohnhaft in der Mohrenstraße, ohnweit der Friedrichstraßen=Ecke, Parterre, von Morgens bis Mittags um 1 Uhr bestellt.“ Vgl. „Die Zauberflöte“, Programm der Berliner Erstaufführung vom 12. 5. 1794, in: Freydank 1988, S. 133. Im Mai 1794 konnte man ein Ticket für die Zauberflöte lösen für 4 Groschen in der Galerie und 16 Groschen im ersten Rang. „Eine ganze Loge auf vier Personen 2 Rthlr. 16 Gr.“ Bei einem Jahresgehalt eines Schauspielers von 1.200 Reichsthalern kostete die Miete einer Loge damit einen stattlichen Preis.

236 Kriegsrath Bertram, zu dieser Zeit Leiter der ökonomischen und Kassenangelegenheiten an die Generaldirektion des Nationaltheaters, 29. 7. 1787, zit. nach: Brachvogel 1878, S. 68 f. Ferdinand Wilhelm Fließ ist nicht der Ehemann (Carl Eduard, geb. Isaac) der hier mehrfach erwähnten Hitzel Fließ Boye Sparre. 
Theaterhistoriker des 19. Jahrhunderts empörten sich darüber, dass dies Gesuch der Bordellbesitzerin Schubitz angenommen wurde und beklagten eine unziemliche Verbindung zweier öffentlicher Orte.237 1794 selbst wurde das Problem, das Theater als Treffpunkt zur Aushandlung verschiedener öffentlicher und privater Interessen zu nutzen, praktischer angegangen: Die Interessen wurden ,sortiert‘, nach dem Vorschlag eines Kontrolleurs, dass „es zur Bewürkung mehrere Ruhe und Ordnung nicht wenig beitragen [würde], wenn der Logensteher Plötz auf der linken Seite des zweiten Ranges angewiesen würde, [...] Freudenmädchen [...] alle nach der rechten Seite zu verweisen“, in Richtung besagter Pfeilerloge der Madame Schubitz nämlich. ${ }^{238}$

In den besonders dicht überlieferten Briefwechseln Rahel Levin Varnhagens mit David Veit und Friederike Liman lässt sich erkennen, dass das Theater einen hohen Stellenwert als gemeinsames Interesse neben oder sogar gleichauf mit der Literatur einnahm. ${ }^{239}$ Auch hier galt, wie explizit betont wurde: „Wenn Sie etwas Interessantes sehen oder kennen lernen, muß ich's gleich wissen. Einer für beide und beide für Einen hierin ist nicht übel, noch dazu in schlechten Zeiten“.240

Nicht nur in den Diskussionen von Theateraufführungen verband sich oft Klatsch mit kenntnisreicher Kritik, ähnliches galt für die Wahrnehmung des Theaters als Treffpunkt. Mitglieder der Salongesellschaft berichteten ausführlich, wen sie im Theater gesehen und gesprochen hatten und wer sie angesprochen hatte. Auch die Fahrten zum und vom Theater waren Orte der Begegnung. Rahel Levin Varnhagen berichtete stolz, mit der Marchetti in einem königlichen Wagen gefahren zu sein, und David Veit, dass er Wilhelm von Burgsdorf auf einer Rückfahrt kennengelernt habe. ${ }^{241}$ Ähnlich berichtete Friederike Liman, wer sie ,gesehen habe' und wer nicht und revanchierte sich für das Übersehen mit Spott: „es war eine schreckliche Brilliance im theater; so viel perlen und

237 Empörend schien dass „die Dame durch ihn [den Direktor] [...] Gelegenheit erhielt, ihre - Abendbörse in's Theater zu verlegen!“ Dass die Direktion und Professor Engel „von der Qualität der Dame so ganz und gar keine Ahnung gehabt haben sollten, [war] kaum zu glauben.“ Brachvogel 1878, S. 69. Nicht wenige Theater- und Salonbesucher hatten diese Ahnung durchaus, zumindest von Humboldt, Gentz und Brinckmann sind Besuche im Etablissement der Schubitz überliefert. Vgl. V.

238 Kontrolleur Lampe an die Generaldirektion, 26. 9. 1794, zit. nach: Brachvogel 1878, S. 361 .

239 Veit kommentierte so gleich in dem ersten Brief aus Weimar die dortige Theatersituation, Friederike Liman berichtete ihrer Freundin wesentlich mehr von aktuellen Aufführungen als von ihrer internationalen Lektüre, die sie eingestreuten Zitaten zufolge durchaus unternahm.

240 Rahel Levin Varnhagen an David Veit, 2. 11. 1793, in: GW VII/I, S. 47.

241 David Veit an Rahel Levin Varnhagen, 1. 10. 1796, in: GW VII/II, S. 230. 
Brillianten wie die Radsewill aufhatte habe ich nie zusamen gesehen“. ${ }^{242}$ Und nicht ohne Ironie beschrieb sie ein zufälliges Zusammentreffen mit dem Gesandten Navarro, dem sie ihre Lorgnette geliehen habe, damit er die Unzelmann besser betrachten könne - derselbe Navarro, der sie im Tiergarten nicht erkennen wollte. ${ }^{243}$

\section{,Hintergrundwissen` und Öffentlichkeiten im Theater}

Nicht selten waren die Kommentare zum Theater in eine Anspielung verpackt, die nur Zeitgenossen als ,Insider‘ erschließen konnten, wie zum Beispiel Rahel Levin Varnhagen die Kritik an einer Mozartoper in einem Witz ihrer Freundin Rebecca Ephraim kolportierte:

Die Ephraim [...] war schon seit einiger Zeit mit vielen Stücken unzufrieden, den Tag vorher aber hatte sie die Entführung gesehen [...] und da sagte sie mir mit ihrem einzigen Ton und Art: „Ich hab mich auch gestern nicht amüsirt, Reinwald aus der portechaise steigen zu sehen, kann doch auch keine Befriedigung sein.“ Nun müssten Sie aber Reinwald, die Entführung, die Scene, und unser gällerndes Publikum kennen, Mich dünkt, Sie kennen alles. ${ }^{244}$

Aber auch nicht selten, wie im Falle der Rosamonda von Reichardt, findet sich eine kenntnisreiche umfängliche „recension“, wie Friederike Liman es selbst einmal nannte. ${ }^{245}$ Liman und Levin Varnhagen haben genug gesehen, um die Qualität und Details verschiedener Inszenierungen gegeneinander abwägen zu

242 Friederike Liman an Rahel Levin Varnhagen, 23. 6. 1795, in: Bosold 1996, S. 16. Gemeint ist Friederike Luise von Radziwill (1770-1836), geborene Prinzessin von Preußen, die sich laut Wilhelmy seit 1796 auch als Gastgeberin eines „fürstlichen Salons“ einen Namen machte. Wilhelmy 2000, S. 86 ff. Hertz zählt Radziwill nicht unter die nichtjüdischen Salonièren. Der Satz von Liman ist anno 1794 der einzige Hinweis einer Begegnung wenn auch nur auf Sichtweite von der Prinzessin mit den jüdischen Salonfrauen. Sonst belegen Briefe Brinckmanns aus diesem Jahr, der in ihrem Hause verkehrte, dass die „Prinzeß Radziwill“ ihnen ein Begriff war. Vgl. Gustav von Brinckmann an Rahel Levin Varnhagen, 27. 8. 1795, ungedruckt, SV 38. Später wird ihr Bruder, Prinz Louis Ferdinand, zumindest den Namen seiner Schwester mit in die Salons genommen haben. Der vielzitierte Bericht des Grafen Salm, der u. a. einen Besuch des Fürsten Radziwill bei Rahel Levin Varnhagen beschreibt, gilt als nicht authentisch. Vgl. [anon.]: Rahel Levin und ihre Gesellschaft. Aus den Papieren des Grafen $S^{\star \star \star}$. In: Die Grenzboten. Zeitschrift für Politik und Literatur, Jg. 3 (1844), Bd. 2 (1. Semester), S. 709-720, 735-746.

243 Friederike Liman an Rahel Levin Varnhagen, 28. 8. 1795, in: Bosold 1996, S. 34 f.

244 Vgl. Rahel Levin Varnhagen an David Veit, 26.1.1794, in: GW VII/I, S. 131.

245 Friederike Liman an Rahel Levin Varnhagen, 12. bis 28. 2. 1801, in: Bosold 1996, S. 52 Vgl. auch die prägnante Rezension Rahel Levin Varnhagens zu den „Witzlingen“ vom 1. 11. 1793, in: GW VII/I, S. 44. 
können. Auch an den Theaterkritiken zeigt sich, dass Briefe in erster Linie als Gemeingut verstanden werden und, durften sie einmal nicht öffentlich gemacht werden, dies explizit vermerkt wurde: „ich bitte dich lese niemand meine recension über Reichardts oper vor man könnte es hierher schreiben ich sehe ihn itzt zuweilen; und da wäre es mir unangenehm“.246

Diese Vorsicht scheint angemessen, waren doch die Berichte über das Theater, ähnlich denen der Gesellschaften, neben denen sie unverbunden standen, reich an Respektlosigkeiten. Beispielsweise verglich Friederike Liman einen Schauspieler: „Liverati als chineser [...] sah so natürlich aus wie dein Vater wen er in Schlafrock ein Balet tanzte“.247

Für die 1790er-Jahren ist bekannt, dass mehrere Schauspielerinnen als Gast zumindest bei Rahel Levin Varnhagen verkehrten. Wie der Briefwechsel mit Friederike Liman zeigte, empfing auch Hitzel Fließ Boye Sparre Künstlerinnen bei sich. Bereits in den späten 1780er-Jahren aber gab es einen noch kaum beleuchteten engen Bezug zwischen Theater und Salon, da zumindest ein Mitglied der Theaterleitung, Johann Jakob Engel, regelmäßiger Gast im Hause Herz war. Seine umfänglichen Schwierigkeiten, eine verbesserte Aufführungsqualität zu erreichen, mag er zumindest angedeutet haben. Mitglieder der Salongesellschaft hielten ihn, anders als der König, für einen Verbesserer und verglichen in den Briefen seine Rolle etwa mit der Goethes in Weimar. ${ }^{248}$ Seine Entlassung - er hatte 1794 in Abwesenheit des Königs die Zauberflöte auf die Bühne gebracht - wurde in den Briefen nicht kommentiert, dafür aber die Qualität des neuen Direktors Iffland ausführlich diskutiert.249

Künstlerinnen wie Friederike Unzelmann und Maria Marchetti müssen 1794/1795 nicht nur als Thema und Stammgäste im Hause Levin gelten, ${ }^{250}$ sie baten oft selbst, nicht nur in die Loge, sondern ebenfalls zum Tee oder zu Privatvorstellungen. ${ }^{251}$ Strukturell betrachtet luden damit Vertreterinnen der

246 Friederike Liman an Rahel Levin Varnhagen, 12. bis 28. 2. 1801, in: Bosold 1996, S. 52. Rahel Levin Varnhagen war zu diesem Zeitpunkt in Paris, d. h. dass Liman befürchtete, dass ihre Kritik selbst aus Frankreich den Weg zurück nach Berlin finden könnte.

247 Friederike Liman an Rahel Levin Varnhagen, 23. 6. 1795, in: Bosold 1996, S. 16.

248 David Veit an Rahel Levin Varnhagen, 20. 3. 1793, in: GW VII/I, S. 5.

249 Lediglich Wilhelm von Humboldt fragt nach den Gründen von Engels Entlassung. An Brinckmann, 3. 11. 1794, in: Leitzmann 1939, S. 80.

250 Wie selbstverständlich schrieb Rahel Levin Varnhagen im November 1793, dass sie „die Marchetti“ gestern kennengelernt habe und morgen besuchen werde. Von da an ist Frau Marchetti eine der am meisten erwähnten Personen in dem Briefwechsel. „Ich bin viel bei der Marchetti, die mir zum Weinen vorsingt." Rahel Levin Varnhagen an David Veit, 2. 11. 1793 bzw. 7. 5. 1795, in: GW VII/I, S. 46 und GW VII/II, S. 116.

251 „Heute sind wir bey der marchetti dass heist F: etc. Wessely auch und sie wird uns ein oratorium von Bertoni vorsingen“, schrieb Friederike Liman an Rahel Levin Varnhagen. Sie luden auch nicht nur Rahel, sondern deren Mutter und Schwägerin ebenfalls und auch ohne 
künstlerischen Öffentlichkeit selbst als Privatiers ein. Die Rolle des Gastes und der Gastgeberin konnte auch zwischen diesen Partien täglich wechseln. Daneben waren es auch oft die als Schönheiten oder Talente bekannten Schauspielerinnen, über die ihre jüdischen Freundinnen neue und „vornehme“ Bekanntschaften machten. So kam Rahel Levin Varnhagen bei einem Besuch in Dresden in den Vorzug, von einem Bekannten der Unzelmann die Stadt gezeigt zu bekommen und konnte, wie David Veit versicherte, in Karlsbad mit Sicherheit davon ausgehen, dass Goethe ihre Reisegefährtin Unzelmann würde kennenlernen wollen. ${ }^{252}$

Rahel Levin Varnhagen verpflichtete sich zwei ihrer späteren Freunde auch - dadurch, dass sie ihnen in ihren Räumlichkeiten die Möglichkeit bot, sich mit unstandesgemäßen Geliebten zu treffen: Für Prinz Louis Ferdinand war Pauline Wiesel nicht der einzige, aber ein wichtiger Grund, deren Freundin aufzusuchen, ebenso gewann Levin Varnhagen Gentz' dauernde Freundschaft durch freundlichen Umgang mit der Schauspielerin Christel Eigensatz. ${ }^{253}$ Umgekehrte Verhältnisse, dass eine bürgerliche oder aristokratische Frau sich mit einem Schauspieler liierte, innerhalb oder außerhalb des Salons, sind in den Briefen nicht überliefert, wie überhaupt fast keine Frau christlich bürgerlicher Herkunft in den Briefen genannt wird und die später bei Rahel Levin verkehrenden adligen Frauen als Exzentrikerinnen galten.

Für die Salonfrauen waren Theaterbesuche eine Selbstverständlichkeit, aber eine zu verteidigende. Solange Programm geboten wurde - die Opern spielten nur im Winter -, nutzten die Frauen die Gelegenheit so häufig wie möglich, auch bei schlechteren Stücken. Viel kolportiert wurde in diesem Zusammenhang das Geständnis Rahel Levin Varnhagens an David Veit, sie ginge sogar am Sabbat ins Theater: „Auch geh ich nicht selten zur Marchetti; et, imaginez, ich bin gestern mit ihr am hellen lichten Sabbath in einem König-

Rahel ein, so erwähnt Friederike Liman eine „Fete“ bei der Eigensatz, bei der sie mit „mama und röschen" [Chaie und Rose Levin] war. Friederike Liman an Rahel Levin Varnhagen, 23. 6. 1795, in: Bosold 1996, S. 16 u. 17.

252 David Veit an Rahel Levin Varnhagen, 5. 6. 1795, GW VII/II, S. 152. 25 Jahre später machte endlich Friederike Liman aus ähnlichem Anlass die Bekanntschaft des Dichters im Bade, weil sie dorthin mit der berühmten Sängerin Anna Milder gereist war und gemeinsam mit ihr Goethe vorgestellt wurde. Friederike Liman an Rahel Levin Varnhagen, 16. 8. 1823, in: Bosold 1996, S. 113.

253 Pauline Wiesel (1778-1848), in der Salongesellschaft viel verehrte Persönlichkeit, bekannt geworden in der Literatur als Freundin Rahel Levin Varnhagens und Lebensgefährtin des Prinzen. Zur Biografie s. Hahn / Bosold / Isselstein 1998. Christel (eigentlich Christiane Dorothea) Eigensa(t)z, spätere Pedrillo (1781-1850), Schauspielerin. 
lichen Wagen um halb drei Uhr nach der Opernprobe gefahren“. ${ }^{254}$ In der Sekundärliteratur wird dieses Zitat, als gebrochenes Gebot der Sabbatruhe, oft als Ausdruck gelungener, oder vorschneller Akkulturation gelesen. ${ }^{255}$ Tatsächlich, in der langen Version gelesen, deutete Rahel Levin Varnhagen durchaus Skrupel gegenüber diesem Traditionsbruch an, da sie nahtlos fortsetzte: „[...] es hat mich niemand gesehen, ich hätt's, und würd', und werd' es jedem abstreiten - und der mir aus dem Wagen geholfen hätte! mich dünkt, so kann und muß man’s in meiner Lage machen“.256 David Veit ging auf diese Stelle nur am Rande ein und bestätigte die Übergangssituation, in der sich beide befanden, in dem für die Salongesellschaft üblichen spöttischen Ton: „Wenn Sie am Sabbath fahren, müssen Sie es nicht abläugnen, sonst werde ich glauben, dass Sie zu der Reformation der Juden nichts beitragen wollen“. ${ }^{257}$ Auch muss diese Stelle m. E. im Zusammenhang des Gesamtbriefwechsels gelesen werden, dem zufolge die Theaterleidenschaft wie die Spöttelei, gemeinsam mit der bisweilen wütend verteidigten Hochachtung vor Moses Mendelssohn, zur geistigen Ausstattung dieser Generation gehört.

\subsection{Mischung der Stände und Geschlechter - Der „jüdische Salon“ im Geselligkeitsgewebe Berlins}

Vergleicht man die in den hier untersuchten Quellen erwähnten Unterhaltungsformen und Treffpunkte mit denen anderer Berliner und Berlinbesuchenden derselben Zeit, ergeben sich einige interessante Besonderheiten. Als exemplarische Vergleichszeugen werden hier die Tagebücher Elisa von der Reckes und Ernst Ludwig Heims herangezogen, die beide mit Personen verschiedener Stände verkehrten und mit einigen Mitgliedern der Salongesellschaft bekannt waren.

Als beliebte und leicht zugängliche Unterhaltungsform, bei der verschiedene Stände zusammentrafen, die sowohl in den gedruckten Stadtbeschreibun-

254 Rahel Levin Varnhagen an David Veit, 15. 12. 1793, in: GW VII/I, S.76. Manchen Opernsängerinnen wurde als Teil ihres Vertrages ein königlicher Wagen zur Verfügung gestellt.

255 Zuletzt sieht Amos Elon in dieser Stelle einen Beweis für den Abscheu, den Rahel Levin Varnhagen, „diese außerordentlich assimilierte Jüdin“, gegenüber ihrer Herkunft empfindet. Vgl. Elon 2002, S. 83. Meiner Meinung nach lässt sich diese Stelle aber durchaus als Beleg für ein Unbehagen lesen, zumindest dafür, dass es 1794 für sie nicht selbstverständlich war, das Gesetz des Feiertags derart offensichtlich zu brechen.

256 Rahel Levin Varnhagen an David Veit, 15. 12. 1793, in: GW VII/I, S. 76.

257 David Veit an Rahel Levin Varnhagen, 24. 12. 1793, in: GW VII/I, S. 90. 
gen, Tagebüchern, als auch in den Briefwechseln der Salongesellschaft angeführt werden, können neben Ausfahrten und Spaziergängen verschiedene Restaurationen wie öffentliche Gärten gelten. Vergleicht man aber die ,Bühnenfrequenz' der Salonbeteiligten mit der anderer Intellektueller im Zeitraum 1794/95, lässt sich sagen: regelmäßige Theater- und Opernbesuche wie sie etwa Levin Varnhagen oder Liman unternahmen, lagen dem bürgerlichen Arzt Heim und der Freifrau von der Recke fern. ${ }^{258}$ Eine zeitgenössische Quelle, der bisher kaum nachgegangen wurde, besagt, dass im Untersuchungszeitraum das Berliner Theater immer zur Hälfte mit Juden besetzt gewesen sei, und begründet dies damit, dass es das einzige ihnen offenstehende öffentliche Vergnügen sei. ${ }^{259}$ Diese Aussage ist in ihrer Absolutheit nicht haltbar, aber schon die Tendenz ist bemerkenswert, die Hälfte des Theaters bezöge sich auf etwa 400 Personen, das wäre ein Achtel der gesamten jüdischen Bevölkerung Berlins als Theatergänger! Wie eine Arbeit Markus Herz' belegt, äusserten sich dabei nicht nur jüdische männliche Intellektuelle, sondern auch jüdische Frauen beim „Kaffeegespräch“ schon 1771 selbstbewusst als Theaterkritikerinnen. ${ }^{260}$ Festzuhalten bleibt natürlich auch, dass das Theater um 1800 einer der wenigen Emanzipationsorte in dem Sinne war, dass es Frauen und Juden Möglichkeit bot, sich beruflich ein Auskommen und eine Karriere zu schaffen. Wenn auch der Schritt in die Öffentlichkeit der Bühne mit Risiken für den gesellschaftlichen Status und Ruf verbunden war.

258 Allerdings könnte dies auch an Heims geringem Zeitetat und an seinem Geschmack liegen. Wie Gustav Parthey berichtet, war Heim früher aus Zeitgründen nicht ins Theater gekommen und konnte später weder den ihm von seiner Familie spendierten „fatalen“ Schillerdramen noch dem Ballet mit den „unanständigen Bewegungen“ etwas abgewinnen. Vgl. Parthey 1907,1, S. 224 f. Der beruflich viel kommunizierende Arzt - „an Gesellschaften finde ich keinen Gefallen, da ich den ganzen Tag mit den Kranken beschäftigt bin und immer reden muss“ - wurde gesellig nur dann initiativ, wenn er fachlichen Rat suchte. Heim gründete 1799 einen „medizinischen Klub“, später nahm er teil an der „medizinischchrirurgischen Gesellschaft“. Wolfgang Geschorek: Ernst Ludwig Heim. Das Leben eines Volksarztes, Leipzig 1982, S.127 und $139 \mathrm{f}$.

259 Formey 1796, S. 93. Er fährt in dem für ihn typischen, Juden gegenüber vorurteilsbehafteten, Tonfall fort: „Ich will nicht glauben, dass Müssiggang die Ursache davon sei; aber eine Hauptursache ist wohl diese dass sie weniger häussliches Glück haben, weniger in Gesellschaft kommen, und ihnen der Eintritt in alle Ressourcen versagt ist.“ Ebd. 260 Das „Freymüthige Kaffeegespräch“ ist im weiteren Sinne eine Kritik Herz' an einer Berliner Theateraufführung, und daran, dass eine jüdische Figur darin, jüdischen Dialekt sprechend, komisch dargestellt wird. [Markus Herz]: Freymüthiges Kaffeegespräch zwoer Zuschauerinnen über den Juden Pinkus, oder der Geschmack eines gewissen Parterrs, hrsg. von Otchkustes, Berlin 1771. Wichtig ist dabei, dass Herz seine Kritik zwei jüdischen „Madames“ in den Mund legt. 
Eine Geselligkeitsform, an der umgekehrt (jüdische) Frauen wenig teilnahmen oder teilnehmen konnten, fand nach anderen Quellen auch in den 1790erJahren in Berlin häufig statt, das halböffentliche Mittagessen unter gelehrten Männern. Als halb- oder teilöffentlich müssen diese Zusammentreffen gelten, sofern die Tatsache der Mittagstafel über Berlin hinaus bekannt war und durchreisende Gelehrte durchaus hoffen konnten, zu dem Kreis Berliner Bekannter zugeladen zu werden. Ernst Ludwig Heim zum Beispiel war gelegentlicher Gast bei Nicolais Mittagessen, $\mathrm{zu}$ denen nach den vorhandenen Quellen keine der hier genannten Personen der Salongesellschaft zugezogen wurde. Dass bei diesen gelehrten Mittagessen auch Frauen anwesend sein konnten, könnten Tagebucheinträge von der Reckes belegen, die in den 1790ern im Hause Nicolai wohnte und sich regelmäßig mit ihm und seinen gelehrten Freunden traf. Allerdings war sie eine enge Freundin des Hauses und erwähnt auch keine anderen weiblichen Namen. Die Ausnahme galt vermutlich mehr ihr als Vertreterin des Ranges oder der speziellen Geisteshaltung als der des weiblichen Geschlechts.

Heim hatte im Rahmen anderer Privateinladungen auch verschiedentlich Kontakt zu Mitgliedern der Salongesellschaft, wie etwa $\mathrm{zu}$ dem Ehepaar Schlabrendorf oder den Brüdern Humboldt, die er schon als „Junkers“ in Botanik unterrichtet hatte. ${ }^{261}$ Aus dem Jahr 1796 etwa ist ein gemeinsames Mittagessen erwähnt, nach dem gemeinschaftliche Experimente veranstaltet wurden. ${ }^{262}$ Weitere Vergnügungen bzw. öffentliche Orte, die in den hier untersuchten Salonbriefwechseln nicht vorkommen, im Tagebuch des in ähnlichen Kreisen verkehrenden Arztes Heim aber sehr wohl genannt sind, sind neben naturbegeisterten Ausflügen auch stadtöffentliche Ereignisse wie Hinrichtungen sowie

261 Vgl. z. B. den Tagebucheintrag aus dem Untersuchungszeitraum: „Mittags beim Buchdrukker Unger in Gesellschaft des Grafen v. Schlabbrendorff nebst dessen Fr. Gemahlin gespeist“. 3. 10. 1795, Heim 1989, S. 93.

262 An dieser Stelle muss leider angefügt werden, dass trotz der bekannten Blitzableitervorlesung im Hause Herz keine weiteren Quellen gefunden wurden, die auf naturwissenschaftliche Experimente in anderen Salons schließen lassen. Auch Ausflüge aus primär wissenschaftlichem Erkenntnisinteresse, z. B. in Privatkabinette mit naturwissenschaftlichen Sammlungen oder in die Charité, wie der Arzt Heim sie häufig unternahm, konnten im Jahr 1794/95 bei den Salonbeteiligten nicht nachgewiesen werden. Heim fuhr beispielsweise mit seiner Familie 1794 zur Sternwarte und zum Scharfrichter, aus pädagogischem Interesse. Er hielt seinen Besuch bei letzterem für nützlicher als einen Ausflug in die Kirche. 22. 4. 1794, Heim 1989, S. 86. Aus späterer Zeit ist aber bekannt, dass z. B. Marianne Meyer Eybenberg sich mit Steinsammlungen beschäftigte, u. a. für Goethes Kollektionen tätig wurde. Auch die Begeisterung für die Natur, die in den Briefen verschiedener Salonfrauen zum Ausdruck kommt, besonders bei Rahel Levin Varnhagen, wäre eine eigene Untersuchung wert. 
solche höfische Vergnügungen wie die Jagd, bei denen Bürger als Zuschauer zugelassen waren. Ebenfalls von den Billetschreibenden 1794/95 wenig erwähnt - und möglicherweise von ihnen weniger genutzt - wurden die bei Nicolai erwähnten zahlreichen öffentlichen und privaten Bibliotheken und Galerien Berlins. ${ }^{263}$ Auch wenn bekannt ist, dass Henriette Herz in ihrer Jugend Leihbibliotheken genutzt hat, scheinen sich die Mitglieder der Salongesellschaft sich in den Jahren intensiven geselligen Verkehrs primär ihres eigenen Netzwerkes bedient zu haben. Bücher und Manuskripte erhielt man bei Freunden und besuchenden Autoren, ein wesentlicher Teil des Briefwechsels und vermutlich des Salonnetzes überhaupt diente der Literaturbeschaffung.

Dieses Netz bzw. als seine Knotenpunkte die offenen Häuser einiger jüdischer Gastgeberinnen, wurden, in der Gegenperspektive, nicht in der offiziellen Literatur erwähnt, anders als beispielsweise Freimaurerlogen, Kaffeehäuser und Privatkonzerte, was für einen de facto informellen Charakter der ,berühmten Salons“ um 1800 spricht. Dabei waren die Adressen dem Stadtführer durchaus bekannt: Markus Herz wurde unter den Privatvorlesungen genannt, seine Frau nicht erwähnt. ${ }^{264}$ Aaron Meyer zählte zu den bekannten Besitzern umfassender Privatbibliotheken, die Teerunden seiner heute als Salonièren bekannten Töchter, die für ihre Bildung sicher viel von dieser Bibliothek profitierten, findet man nicht. 265

Mitglieder und Bekannte der Salonteilnehmer werden hingegen gelegentlich als Gäste der Kaffeehäuser erwähnt, so zum Beispiel ist Salomon Maimon dafür bekannt, im Triestschen Kaffeehaus zu verkehren, sodass Rahel Levin Varnhagen ihm ein ausgeliehenes Buch dorthin zurückbringen soll. ${ }^{266}$ Dass ganze Salongesellschaften sich allerdings in ein Kaffeehaus vertagt haben, wie es aus Paris bekannt ist, ist aus den Briefen nicht ablesbar. Vielmehr warnte Levin Varnhagen an einer Stelle einen Freund vor unkontrolliertem Kaffeehausbesuch. In Berlin sei dies zwar ungefährlich, aber in anderen Städten führe es zu einem schlechten Ruf. ${ }^{267} \mathrm{Zu}$ den von Nicolai zahlreichen erwähnten Frei-

263 „Bibliotheken von Privatpersonen“ und „Gemäldesammlungen einiger Privatpersonen“ sind zu dieser Zeit eine eigene Rubrik. Nicolai 1793, S. 141f. bzw. 147 f. Brinckmanns Privatsammlung von Büchern, die zu dieser Zeit schon mehrere Tausend umfasste, ist hier allerdings nicht erwähnt.

264 „Hr. Hofrath Herz (in der neuen Friedrichstraße) Physik und philosophisch-medicinische Vorlesungen.“ Nicolai 1793, S. 133.

265 „Aaron Meyer, in der Spandauerstraße, neuere Geschichte und Literatur“. Nicolai 1793, S. 142. In der ausführlicheren Ausgabe von 1786 werden als Besonderheit noch die französischen Übersetzungen klassischer Texte und zahlreiche zeitgenössische fremdsprachige Dichter erwähnt. Nicolai 1786, Bd.11, S. 787.

266 David Veit an Rahel Levin Varnhagen, 5. 10. 1793, in: GW VII/I, S. 20.

267 Aus nicht ganz geklärten Gründen hielt Rahel Levin Varnhagen es für schädlich, wenn ihr Freund Veit in einer ständisch geprägten Gesellschaft wie der Hannovers, „wo man 
maurerlogen Berlins, in deren Nähe Salons in pamphletischer und antisemitischer Literatur oft gerückt wurden, besteht, nach den Briefen der Salonteilnehmer 1794/95 zu urteilen, kein Zusammenhang.

Grundsätzlich lässt sich sagen, dass nicht nur das Wort „Salon“ in der ganzen zeitgenössischen Sachliteratur nicht vorkommt, sondern auch das Phänomen als solches darin fehlt. Abgesehen von einzelnen Namensnennungen wie obigen gibt es keine Hinweise auf, um die eingangs erarbeitete Minimaldefinition zu zitieren, „halböffentliche Treffen, bei den Personen verschiedener Stände, Religionen und Geschlechter zum gebildeten Gespräch zusammenfanden“, in den Räumen der heute als Salonièren bekannten Frauen. Hingegen sprechen die Quellen auch und gerade in Bezug auf Berlin von einem sehr variantenreichen geselligen Leben, was in der Forschung dazu geführt hat, den „mächtigen Geist der Assoziation“ um 1800 wirken zu sehen. ${ }^{268}$ Zeitgenössische Beschreibungen der Stadt verwenden als Begriff für eine idealerweise gemischte bildende Geselligkeitsform häufig das Wort „Gesellschaft“: „Diese Institute, wenn sie nicht bloß unbedeutende Kränzchen oder bloß Gelegenheit zum Spiel und Schmausereien sind, haben großen Einfluß auf Bildung und Sitten der Berliner“. ${ }^{269}$

Krögens Beschreibung dieser Gesellschaften liest sich sehr ähnlich wie das Ideal eines Salons. Demnach gab es regelmäßige und unregelmäßige Zusammentreffen, und

in vielen sind verheiratete und unverheiratete Frauenzimmer zugegen. Man ist hier nicht gezwungen, [...] man kann über eine jede Sache frei sprechen [...], zu solchen Gesellschaften werden nur die Mitglieder aus verschiedenen Familien, Ämtern und Beschäftigungen gewählt, durch deren Umgang man zur Bildung des Verstandes nichts Bessers wünschen kann als die Mitteilung der Ideen. ${ }^{270}$

Diese Texte, die Frauen in öffentlichen Räumen mitdebattieren sahen, weisen auf eine Situation, in der Grenzen zwischen öffentlich und privat und die Rollen der Geschlechter in der Geselligkeit noch keineswegs so festgelegt waren wie in den Abendgesellschaften des späteren 19. Jahrhunderts, in denen Frauen als Damen des Hauses überwiegend darum bemüht schienen, die Karri-

respektirt oder verachtet wird“, ins Kaffeehaus ginge. Rahel Levin Varnhagen an David Veit, 26. 1. 1794, in: GW VII/I, S. 140.

268 Vgl. dazu die sehr erhellende Forschungskritik von Ulrike Weckel: Der „mächtige Geist der Assoziation“. Ein- und Ausgrenzungen bei der Geselligkeit der Geschlechter im späten 18. und frühen 19. Jahrhundert, in: Archiv für Sozialgeschichte 38, 1998, S.57-77.

269 Krögen 1986, S. 32. Unter diesen unspezifischen Begriff fasst ein Berlinreisender Klubs, Ressourcen und sogar manche Tabagien.

270 Krögen 1986, S. 32. 
eren der Männer zu befördern. Sinnvoller als die Hervorhebung der Salons als den geselligen Ort um 1800 scheint es, das Nebeneinander verschiedener Geselligkeitsformen zu betonen und die damit verbundene Offenheit. Aus dem Vergleich der zeitgenössisch beschriebenen „Gesellschaften“ und hier untersuchten Teetische ergäben sich dann drei besondere Merkmale der letzteren, die sich vielleicht als Salonqualifikation eignen: die Gastgeberrolle einer Frau, die ausgesprochene Beteiligung Personen jüdischer Herkunft beiderlei Geschlechts sowie die Tatsache, dass diese Teetische informell, vielleicht nur Eingeweihten bekannt waren.

Ohne die individuelle Leistung und Attraktivität der als „Salonièren“ bekannten einzelnen Frauen ansatzweise in Frage stellen zu wollen, darf nicht verschwiegen werden, dass erstens die Lage und Ausstattung der Häuser wohlhabender jüdischer Familien Geselligkeit zu haben erleichtert haben wird und die Geselligkeiten der Töchter oft aus den Traditionen des Hauses erwuchsen. Zweitens ist wichtig zu erinnern, dass die Bildung der Frauen von den Familien, i. e. vor allem Vätern und Ehegatten, gefördert oder finanziert wurde. Drittens ist festzuhalten, dass, wie oben beschrieben, dass die Pflege des kommunikativen Netzes wirkliche Familienarbeit war. Nicht nur alle Levins waren als Gastgeber aktiv, auch Itzigs werden als Gruppe wahrgenommen, die Mütter von Lilla Salomon und der Salonière Cohen sind als Gastgeberinnen bekannt. ${ }^{271}$

Wenn von „Berliner Salons“ um 1800 gesprochen wird, sollte dabei nicht übersehen werden, dass die Salonbeteiligten mit dieser wie auch mit anderen geselligen Formen und Orten experimentierten, dass zahlreiche gesellige Formen nebeneinander bestanden und von denselben Personen gelebt wurden, dass auch nichtjüdische Männer ähnliche Gruppen zum Tee einluden und dieselben Gästegruppen der Salons sich auch an öffentlichen Orten zusammenfanden. Das Besondere an der Initiative der gebildeten jüdischen Frauen ist die Leistung, so hochrangige und verschiedene Personen an sich $\mathrm{zu}$ binden, was bei ihnen ganz andere Talente und Grenzüberschreitungen (oder -mißachtung) voraussetzt als bei bürgerlich oder adlig voll etablierten Männern.

Diese Leistung wird im Vergleich mit den Verhältnissen, die 20 Jahre später zwischen den Personen herrschen sollten, besonders deutlich. Aus dem Jahr 1815, vom Wiener Kongress, ist von Wilhelm von Humboldt Rahel Levin Varn-

271 Sie sei bei „Mad. Salomon engagirt“ schrieb Rahel Levin Varnhagen an Gustav von Brinckmann, 21. 6. 1794, ungedruckt, SV 38. (Hier bleibt allerdings auch die Möglichkeit, dass es sich um Vögelchen Salomon, spätere Solmar handelt, Schwester der Hendel Levin, s. die Anmerkungen in ERLV III, S. 1464.) Friderike Liman nahm an einem Mittagessen teil, dass „die Bernhard“ in Freienwalde gab. Friederike Liman an Rahel Levin Varnhagen, 5. 7. 1795, in: Bosold 1996, S. 21. 
hagen gegenüber folgende Haltung überliefert: „Er liebe mich immer: sehen könne er mich nur nicht, weil ich immer alles thäte, was er nicht leiden könne: er will mir ein dîner geben (dîner! Ihr seht, ich bin tot und nicht im Himmel). ich soll die Personen nennen; also als Königin." Die vermeintliche Ehre, ihm Gäste nennen zu dürfen, die er einladen würde, macht zugleich deutlich, dass ihre selbst ausgesprochenen Einladungen nicht mehr von Bedeutung waren. Humboldt konnte ihr sogar, wenn auch scherzhaft, andeuten, dass ihr Benehmen seinen Besuch verhindere. Beeindruckend, wenn auch folgenlos, war ihre Antwort: „Ich sagte, er soll mich weniger lieben, und mich besuchen: dann wolle ich die Personen nennen. Ich mußte fort. So blieb’s“. ${ }^{272}$

\subsection{Frankreich, Juden, Frauenrechte? - Emanzipation als Thema im Salon 1794/95}

Die Welt sieht damals anders aus, jugendlicher, trotz des Puders und der Zöpfe, trotz der Perücken und der ehrsamen Bibelfestigkeit. Sie ähnelt noch immer mehr dem buntgewirkten Bilde, das der Grieche hatte, als unserer heutigen schnellen Sachlichkeit. Arno Schmidt 273

Vor dem Hintergrund des ebenso politisch-gesellschaftlich wie literaturhistorisch bewegten Jahres 1794/95 stellt sich die Frage, welche der kulturellen und politischen Ereignisse dieser Zeit - die Epoche des Terreurs in der Französischen Revolution, die Koalitionskriege, der Beginn der Freundschaft zwischen Goethe und Schiller oder die Veröffentlichung des neuen Allgemeinen Preußischen Landrechts, ${ }^{274}$ um nur einige der ,Epochenmarken` zu nennen - in die Briefgespräche der Salongesellschaft Einzug hielten. In Bezug auf die unter II. geschilderten zeitgenössischen Emanzipationsdiskurse ist vor allem zu fragen,

272 Rahel Levin Varnhagen an Markus Levin Robert, 16. 3. 1815, in: ERLV III, S. 530 f. 273 Arno Schmidt: Fouqué und einige seiner Zeitgenossen. Biographischer Versuch, Darmstadt 1958, S. 20. Der Versuch, den Zeitraum Sommer 1794 bis Sommer 1795 kurz umfassend zu charakterisieren, käme akademisch und literarisch einem Selbstmord gleich. Vertreter zu vieler literarischer und politischer Strömungen könnten sich zu kurz gekommen fühlen und die Autorin vor die imaginierte Guillotine zitieren - womit sie noch Zeitgefühl genug bewiesen hätten. Als anregende Einführung in diese Zeit sei stattdessen der oben zitierte Epochenumriss in der Fouquébiografie Arno Schmidts nachdrücklich empfohlen, bemerkenswert auch wegen seiner Beschreibung einer relativen Humanität.

274 Das Allgemeine Landrecht (ALR) als Ergebnis einer bereits von Friedrich II. initiierten Justizreform, in seiner „Janusköpfigkeit“ ein Abbild des Ständestaats im Umbruch, sollte bis 
inwieweit auf Texte der Geschlechterdebatte bzw. der Debatte über die Gleichstellung der Juden Bezug genommen wurde, die beide Mitte der 1790er-Jahre einen Höhepunkt erreichten. War Emanzipation Thema am Teetisch?

\section{Thümmels Reisen - Weltliteratur im Salon}

Wie anders das war, „was die Deutschen lasen, während ihre Klassiker schrieben“, als man rückblickend erwarten könnte, hat Walter Benjamin idealtypisch beschrieben ${ }^{275}$ und ließe sich auch hier wieder bestätigen, für nationale wie für internationale „Klassiker“. Zum Beispiel kann hier summierend festgehalten werden, dass Goethe - allem vielerwähnten „Goethekult“ der Salons zum Trotz [s. III.5] - 1794/95 nicht der meistdiskutierte Autor der Berliner Salons war. Allein am Beispiel des Briefwechsels Rahel Levin Varnhagens mit David Veit lässt sich zeigen, dass er zwar umfängliche, aber keineswegs schwerpunktmäßig Auseinandersetzungen mit Goethes Leben und Werk enthält. Intensiv debattiert wurden ebenso Moses Mendelssohn und Salomon Maimon sowie nur wenig später Jean Paul und Johann Gottlieb Fichte, sodass eine Verortung des geistigen Standpunktes Veits und Levin Varnhagens aus diesem Briefwechsel heraus höchstens als ,auf der Höhe der Zeit‘ möglich wäre. Jean Paul wurde in den Briefen der Salongesellschaft beinahe ebenso häufig und rühmend erwähnt wie Goethe, wenn auch ohne den hymnischen Unterton.

Vor dem Hintergrund der Lektüreintensität und -variabilität ${ }^{276}$ fällt besonders auf, dass die in dieser Zeit erschienenen, heute als Wendepunkte im Diskurs gewerteten politischen Streitschriften von Johann Gottlieb Fichte und Saul Ascher nicht erwähnt wurden. Gleichermaßen auffällig ist, dass Mary Woll-

1900 Grundlage der preußischen Sozialverfassung bleiben. Obzwar Gesetzesbücher zu kaum einer Zeit den Rang literarischer Bestseller erreichen, hätte das ALR einer kritischen Intelligenz wie den Besuchern der Salons durch viele einzelne Punkte diskussionswert werden müssen, an denen es in die Gesellschaftsstruktur eingriff - oder eben gerade nicht. Daß Moses Mendelssohn mit den Bearbeitern des Gesetzes in Kontakt stand und gelegentlich dazu konsultiert wurde, bedeutete nicht, dass die die Juden betreffenden Einschränkungen und Sonderrechte aufgehoben oder in Frage gestellt wurden. Vgl. zur Stellung der Juden im ALR und zur Rolle Mendelssohns: Anke Breitenborn: Randgruppen im Allgemeinen Landrecht für die Preußischen Staaten von 1794 (Quellen und Forschungen zur Brandenburgischen und Preußischen Geschichte, Bd.6), Berlin 1994.

275 Walter Benjamin: Was die Deutschen lasen, während ihre Klassiker schrieben, in: ders.: Gesammelte Schriften, Bd. IV/2, Frankfurt/M. 1991, S. 641-673.

276 Für eine beispielhafte Beschreibung des Spektrums an Autoren und Werken, das allein Rahel Levin Varnhagen mit David Veit und Friederike Liman, von Fichte und Hume bis Shakespeare und Homer insgesamt, durchbuchstabierte', siehe die Liste im Nachwort bei Bosold 1996, S. 183. 
stonecrafts Verteidigung der Rechte der Frau und William Godwins Prinzip der politischen Gerechtigkeit ${ }^{277}$ - zwei heute als Wegmarken der internationalen politischen Literatur geltenden Texte der Zeit, denen, gemessen am Leserprotest, auch die Zeitgenossen schon emanzipatorischen Inhalt zugestanden, und die einem mehrsprachig lesenden und aktuell informierten Salonpublikum unter die Augen gekommen sein müssten - dem überlieferten Material nach nicht rezipiert wurden. Gelesen wurden stattdessen zum Beispiel Berichte internationaler Reisender, der erwähnte Stolberg oder „Tummels reisen“, das heißt damals aktuelle, mit Moritz August von Thümmel heute auch gänzlich vergessene Autoren. ${ }^{278}$

Hinweise auf eine saloninterne Diskussion von Wollstonecrafts Forderungen, nach verbesserter Mädchenerziehung, der Revision Rousseauscher Maximen und schließlich einem gleichberechtigteren Verhältnis der Geschlechter, wären auch daher besonders interessant, da in der Sekundärliteratur zum Berliner Salon immer wieder die Behauptung auftaucht, dass Henriette Herz eine Übersetzung des Wollstonecrafttextes angefertigt habe. ${ }^{279}$ Dafür dass Herz, die sprachlich dazu durchaus in der Lage gewesen wäre, an einer Übersetzung gearbeitet hat, gibt es aber in den hinterlassenen Quellen nicht nur dieses Jahres keinen Hinweis. ${ }^{280}$ Dass die Berliner Salongesellschaft überhaupt mit Wollstonecrafts Gedankengut in Kontakt gekommen ist, lässt sich nur aus verstreuten Randbemerkungen belegen: Wegen seiner Bekanntschaft mit Graf Gustav von Schlabrendorf, einem aristokratischen Freigeist, der in Paris mit Mary Wollstonecraft Umgang hatte, ließ sich annehmen, dass Wilhelm von Humboldt deren Namen kannte. Schlabrendorf hat später ihre Lebensbeschrei-

277 William Godwin: An Enquiry Concerning Political Justice, and it’s Influence on General Virtue and Happiness, London 1793.

278 Gemeint ist: Moritz August von Thümmel: Reise in die mittäglichen Provinzen von Frankreich im Jahr 1785-1786, Leipzig, 1791-1805, ein Buch auch politischen Inhalts. 1794 war der 3. Teil erschienen. So erwähnt im Brief Friederike Liman an Rahel Levin Varnhagen, 13. 6. 1795, in: Bosold 1996, S. 7 ff. Auch David Veit diskutierte das Buch mit Rahel Levin Varnhagen.

279 Diese Übersetzung wird zuletzt von Petra Wilhelmy angeführt, als nicht erschienenes Werk 1832. Wilhelmy 1989, S.682. Wilhelmy beruft sich dabei auf einen Aufsatz, der noch einen Schritt weitergeht und ohne Quellenhinweis die These formuliert, Henriette Herz „trug indirekt durch ihre Übersetzung von Mary Wollstonecrafts 1792 erschienene[n] Traktat[s] [...] zur Entstehung der Frauenbewegung bei“. Manfred Schlösser: Gestalten, Ideen und Formen des literarischen Lebens um 1800, in: Berlin zwischen 1789 und 1848. Facetten einer Epoche, Ausstellung. (Akademie-Katalog 131) Berlin 1981 S. 195-242, hier S. 220.

280 Auch die beste Kennerin der Sammlung Varnhagen, Barbara Hahn, und die Pionierin der Romantikforschung, Barbara Becker Cantarino, haben keinen Hinweis auf so einen Übersetzungsplan gefunden und sehen dies Gerücht als eine der zahlreichen berüchtigten „Leichen im Salonkeller“. Mündliche Bestätigung mir gegenüber in Sheffield, 19. 4. 2006. 
bung aus der Hand ihres Ehemanns Godwin gelesen. Ein gemeinsamer dritter Bekannter erwähnt in einer Fußnote: „Humboldt hat es auch in den Händen gehabt“ “. ${ }^{281}$ Allerdings bewirkte dies keinen nachweislich verändernden Effekt auf dessen Einstellung in Geschlechterfragen. ${ }^{282}$ Der einzige mir bekannte Nachweis, dass Wollstonecrafts Buch über die Frauenrechte von den Salonfrauen Berlins wahrgenommen wurde, ist in einem ungedruckten Brief Elisa von der Reckes zu finden, die das Buch der ganzen Familie Nicolai und auch dem Hausherren empfahl. ${ }^{283}$ Seine Reaktion ist leider nicht überliefert.

$\mathrm{Zu}$ den Salons als potentiellen Foren der Emanzipationsdiskurse ist insgesamt festzuhalten: Die Emanzipation der Frau war kein eigenes Thema der Salonbillets und -briefe, wurde aber implizit diskutiert in den Reflexionen über die eigene Situation, das eigene Schreiben oder das Schicksal gemeinsamer Bekannter. ${ }^{284}$ Wie in den folgenden Abschnitten zu zeigen sein wird, wurde Humboldts Beitrag zur Geschlechterdebatte rezipiert, aber unter ganz anderem Vorzeichen gelesen. Vergleichbar auch kein selbstständiger Diskurs war die Situation der jüdischen Bevölkerung in den Korrespondenzen, stattdessen können zahlreiche kleine Hinweise auf die Meinungen dazu gefunden werden, etwa in ironischen Wendungen, Beschreibungen anderer Städte, und wieder gemeinsamer Bekannter. Sachliche Kommentare geschweige eine ausführliche Reflektion darüber, wie es war, ,zwischen den Religionen` Umgang zu haben, findet man in den Briefen der Beteiligten nicht, ebenso wenig wie sachliche oder politische Diskussionen über Stand und Rechte.

281 Gustav Graf von Schlabrendorf (1750-1824). Das Zitat seines Freundes Jochmann nach: Werner Kraft: Carl Gustav Jochmann und sein Kreis. Zur deutschen Geistesgeschichte zwischen Aufklärung und Vormärz, München 1972, S. 37. Vgl. zu dieser faszinierenden Gestalt vgl. v. a. das Porträt von Karl August Varnhagens unter dem bezeichnenden Titel: Graf von Schlabrendorf, amtlos Staatsmann, heimatfremd Bürger, begütert arm, in: ders. 1987-1994, Bd. 4, S. 62-77.

282 Zumindest lehnte er ihre politischen Forderungen und vermutlich ihre Lebensweise ab. 1829 rechnete es Humboldt seinem Freund Georg Forster als negativ an, dass er für jemanden wie die Wollstonecraft Leidenschaft empfunden habe. Wilhelm von Humboldt an Charlotte Diede, 30. 7. 1829, in: Wilhelm von Humboldts Briefe an eine Freundin. Zum ersten Male nach den Originalen herausgegeben von Albert Leitzmann, 2 Bde., Berlin 1949, Bd.2, S. 43.

283 „Liebste Minna![...] Ich habe in diesen Tagen ein Buch gelesen, welches mir zuviel[?] Vergnügen gemacht hat, und welches ich Dir, Deiner Schwägerin und in der Folge auch Lotten empfehle. Es heißt Rettung der Rechte des Weibes von Marie Wollstonecraft. Frage Deinen guten Vater, ob inm dies Buch auch so gut als mir gefällt.“ Elisa von der Recke an Wilhelmine Parthey, 29. 9. 1793, ungedruckt, Nachlass Nicolai-Parthey, LAB E 200-02, Bd. 2, Brief 16.

284 Vgl. dazu auch die Diskussionen des Frauenbildes in V. 
An dieser Stelle soll, auch wegen der Seltenheit der Überlieferung, ein anderes Dokument mit den Briefen parallel gelesen werden, das über mögliche Themen am Teetisch Aussagen machen kann, der Bibliothekskatalog des Diplomaten Fürst Heinrich XIV. Reuß.285 Sein Catalogus der Verlassenschaft ist aus dem Grund besonders interessant, da sein Sekretär darauf hinwies, dass es sich eigentlich um eine mit der Salonière Meyer Eybenberg gemeinsam besessene und genutzte Bibliothek handelte.286 Die Sammlung umfasste nicht nur aktuelle Literatur in verschiedenen Sprachen (deutsch, englisch, französisch), sondern auffallend verschiedene Gattungen wie Lyrik, Zeitungschriften, Karten- und Notenmaterial. Während politische Fachliteratur und Wörterbücher auch dem Berufstand Diplomat geschuldet sein können, deuten die literarischen Bände auf breit gefächertes Interesse - und auf nachhaltige Rezeption der Emanzipationsdiskurse, im Beispieljahr und davor. Die komplette Sammlung der Horen-Bände gehörte ebenso dazu wie Gentz politische Monatsschrift. ${ }^{287}$ Mit Rousseaus Heloise und Richardsons Pamela waren zwei Klassiker des empfindsamen Frauenbildes vertreten, daneben finden sich mit Lessings Hamburgischer Dramaturgie ein Grundlagendwerk der Aufklärung, Werke Friedrichs II., aber auch fast alle Werke Schillers. ${ }^{288}$ Besonders interessant sind Bücher von und über Moses Mendelssohn, Markus Herz und Lazarus Bendavid, Werke zur jüdischen Geschichte und ein Lehrbuch zur Erlernung der jüdisch deutschen Sprache, das Marianne Meyer Eybenberg sicher nicht benötigte. ${ }^{289}$ Abschließend ist bemerkenswert, dass, auch wenn sich kein Hinweis auf Mary

285 Vgl. zu den folgenden Angaben „Catalogus der Bücher zu der Verlassenschaft“, in: ThStA Greiz, Geh. Kab. Greiz I nr. 88a, S. 31-50.

286 Die Bibliothek, „die einige hundert Bände betragen mag“, sei nicht taxiert worden, da sie gröstentheils aus „abgerippenen“ [abgegriffenen?] Werken bestand, die nicht viel Wert haben würden „und weil wenigstens die Hälfte davon der Demoiselle Meyer gehört, deren Chiffre auf dem Einband abgedruckt ist, und welche diese Bücher dem holdseligen Prinzen in Verehrung gegeben hat, weil sie sehr oft von Berlin abwesend war, wie dieses allen Leuten im Hause bekannt ist“, ThStA Greiz, Geh. Kab. Greiz I nr. 88a, S.74 r.

287 Friedrich von Gentz: Neue Deutsche Monatsschrift, Berlin 1795. Die Zeitschrift enthielt u. a. eine vom Herausgeber verfasste „Histor. polit. Uebersicht der Hauptbegebenheiten des Jahres 1794 “. Ebd.

288 Samuel Richardson: Pamela. Or Virtue Rewarded, London 1767, und Jean Jacques Rousseau: Julie ou la nouvelle Héloise, Paris o. J., waren beide in Originalsprache in der Sammlung vorhanden.

289 Beispielsweise stehen auf der Liste das Buch des Grafen Mirabeau: „Sur Moses Mendelssohn, Sur La Reforme Politique des Juifs“, London 1787, und von Lazarus Bendavid zwar nicht die erwähnte „Charakteristick der Juden“, aber seine Vorlesungen über die „Critik der reinen Vernunft“ aus dem Jahr 1795. Da 1792 als Erscheinung des Lehrbuches angegeben ist, handelt es sich vermutlich um Gottfried Selig: Lehrbuch zur gründlichen Erlernung der jüdisch deutschen Sprache: für Beamte, Gerichtsverwandte, Advocaten [...] Leipzig 1792. 
Wollstonecraft findet, Werke aus den Salons anderer Städte durchaus enthalten sind. ${ }^{290}$ Die Bücherliste macht deutlich, wie schwer es ist, generalisierende Aussagen über das Leseverhalten der Berliner Salons auch in nur einem Beispieljahr zu treffen. Auch wenn nicht mehr festzuhalten ist, was der Diplomat und was die befreundete Salonière las, deutet ein Buch über die Ungerechtigkeit der polnischen Teilung in ihrer Sammlung zumindest darauf hin, dass das Thema zur Kenntnis gelangte. Es ist nicht zu hoch gegriffen, diese Liste als Dokument eines interkulturellen Austausches auf hohem literarischen und politischem Niveau zu lesen.

\section{„Juditäsfeinheit“ - Das Beispiel Rahel Levin Varnhagen - David Veit}

Wären nicht die paar Juden hier, man sähe gar nichts Schmutziges.

David Veit an Rahel Levin Varnhagen, 1794291

Konkrete Hinweise darauf, ob und wie ,das Jüdische‘ Thema in Briefen der Salongesellschaft wurde, sind uns nur aus Briefen von Personen jüdischer Herkunft untereinander überliefert. Im Briefwechsel Rahel Levin Varnhagens mit David Veit beispielsweise erweist sich die Frage, inwieweit man über seine Herkunft „hinaus kann“, zwar nicht als Leitmotiv, aber als immer wieder durchscheinendes ungelöstes Problem, auf das oft ohne Zusammenhang wieder zurückgekommen wird, denn ,woran ich jetzt entsetzlich oft denke, daß man nämlich, und schlimmlich, weder über sein Zeitalter hinaus kann noch über sein Alter, Geschlecht, noch sogar - Stand, noch Temperament“. 292 Wegen dieser Reihung der Kategorien verdient der Briefwechsel an dieser Stelle eine exemplarische Betrachtung. Ganz am Anfang dieses Briefwechsels war Rahel Levin Varnhagens berühmtes Wort gefallen, „dass ich ein Schlemihl und eine Jüdin bin“.293 Es ist oft mottogebend verwendet worden für Biografien einer Salonière, die mit ihrer Herkunft rang. Liest man es aber im Kontext einer langen Antwort auf den Eröffnungsbrief Veits, war es ein begeistert aufgenommenes Diskussionsthema unter vielen, und hieß außerdem in voller Länge: „Es wird mir nie einkommen, dass ich ein Schlemihl und eine Jüdin bin, da

290 So besaßen Reuß und Meyer Eybenberg die Schrift Elisas von der Recke, mit der diese Cagliostro als Schwindler entlarvte, die Arbeit des Hamburger Philosophen Hermann Samuel Reimarus über die natürliche Religion und das Dictionary of the English Language von Samuel Johnson, Gast des Bluestocking Circle.

291 Aus Hannover. David Veit an Rahel Levin Varnhagen, 16. 1. 1794, in: GW VII/I, S.117.

292 Rahel Levin Varnhagen an David Veit, 13. 12. 1793, in: GW VII/I, S. 75.

293 Rahel Levin Varnhagen an David Veit, 1. 4. 1793, in: GW VII/I, S. 13. 
es mir nach den langen Jahren und dem vielen Denken darüber nicht bekannt wurd, so werd ich's allerdings auch nie recht wissen“. ${ }^{294}$ Interessanterweise war dies auch der Brief, in dem sie eine zweite grundlegende, in der Frauenund Rahelforschung viel zitierte Frage stellte: „[...] kann ein Frauenzimmer dafür, wenn es auch ein Mensch ist?" Aber nicht nur das Geschlecht wurde als beengend empfunden, auch die Stadt, oder „ist es einem ordentlichen Menschen möglich, Berlins Pflaster sich für die Welt ausgeben zu lassen“.295 Der Brief kann als Zeugnis dafür gelesen werden, dass die Salongesellschaft die in den zeitgenössischen Debatten in Frage gestellten Kategorien debattierte. Genau betrachtet sind es aber zwei enge Freunde jüdischer Herkunft, die sich über ihre Situation verständigen. Möglicherweise begriff sich Rahel Levin Varnhagen, durch Geschlecht, Religion und örtliche Anbindung, als dreifach begrenzt. Der Brief war jedenfalls ein Appell an den reisenden Veit, sie durch seine Briefe die Welt sehen zu lassen und sie nutzte die Kategorien gebündelt als überzeugende Argumente.

Im weiteren Verlauf der Korrespondenz gaben manchmal der Aufenthaltsort oder bestimmte Lektüren das Stichwort, ,Jüdisches' zu diskutieren, beispielsweise hieß es nach einem Besuch in Hannover: „Mit den Juden sieht es, in Ansehung des ersten Rangs, den ich ganz gesehen habe, Berlin=ähnlich aus. Einige Frauenzimmer sind comme il faut; alle Herren unter jeder Kritik, und lange nicht so gut wie in Berlin“.296 Diese Beobachtung einer schnelleren Akkulturation der jüdischen „Frauenzimmer“ seitens Veits ist insofern interessant, als in der Forschung meistens nichtjüdische Gäste mit ähnlichen Beobachtungen zitiert werden. Während Veit einen Bildungsvorsprung der Frauen aus Berlin kannte, war ausgeprägte Klassengesellschaft spezifisch für Hannover: „Selbst die Juden unter sich beobachten Rang. Der erste Rang Juden zählt sich zu dem zweiten unter den Christen“.297 Veit rapportierte dies eindeutig als Unterschied zu dem, was er aus Berlin gewohnt war. Bezeichnend war auch sein Kompliment an den einzigen Juden, der ihm in Hannover wirklich gefallen habe, Israel Stieglitz: „Es ist als ob man Humboldt hörte. Ein solcher Jude ist mir doch noch nicht vorgekommen“.298 Über ihre eigene ,jüdische

294 Ebd. Neben dieser Frage nahm sie in ihrem ersten Brief als Diskussionsfäden außerdem folgende Themen auf: Goethes Erscheinen und unverheiratetes Zusammenleben, andere zeitgenössische Dichter sowie ihre eigenen Berliner Vergnügungen bis hin zu den Hyazinthen im Ausflugsgarten, und ihre Familie.

295 Rahel Levin Varnhagen an David Veit, 1. 4.1793, in: GW VII/I, S. 12.

296 David Veit an Rahel Levin Varnhagen, 16.1.1794, in: GWVII/I, S. 114. Hervorhebung im Original.

297 David Veit an Rahel Levin Varnhagen, 16. 1. 1794, in: GWVII/I, S. 114.

298 David Veit an Rahel Levin Varnhagen, 16.1.1794, in: GWVII/I, S. 116. 
Situation' sprachen Veit und Levin Varnhagen fast nur in Metaphern und Bildern: In demselben Brief, indem sie das berühmte Bild vom Judentum als dauerhaft schmerzende Wunde beschrieb, nannte Levin Varnhagen sich durch ihre Herkunft „lahm“: „Ja, würde der Lahme sagen, wenn ich nicht zu gehen nöthig hätte, ich habe aber nicht zu leben, und jeder Schritt, den ich machen will, und nicht kann, erinnert mich nicht an die allgemeinen Uebel der Menschen [...], sondern ich fühle mein besonder Unglück noch, und doppelt und zehnfach“. ${ }^{299}$ Und während sie selbstironisch schloss mit: „Hab ich je ein lahmes Gleichniß gesehen, so ist es dieses; es hinkt so, daß man mein Unglück nicht im geringsten daraus ersehen würde, wenn man's nicht kennt“, 300 so antwortete Veit im selben Bild: „Wohl sind wir lahm und müssen gehen, und darum will ich jetzt nach Frankreich, weil nur dort jetzt gute hölzerne Beine gemacht werden“. ${ }^{301}$ Zugleich attestierte er ihr, „schwerlich hat je ein Mensch kläglicher und wahrer über die Juden geschrieben, als Sie“.302

Wünschenswert wäre in diesem Zusammenhang die Möglichkeit eine Analyse der Lektüren jüdischer Autoren der Aufklärung im Salon, die in den Briefwechseln oft nur namentlich erwähnt werden: Salomon Maimon, Isaak Euchel, und vor allem Moses Mendelssohn, im Zusammenhang mit welchem das noch ungedeutete Stichwort „Juditätsfeinheit“ geprägt wird. ${ }^{303}$ Man achtete und diskutierte Mendelssohn - 1795 war die Lessingbiografie mit seinem Vorwort Gegenstand in den Briefwechseln -, kritisierte an seinen Texten den Hauch „morgenländischen Moralgeschichtchens“304 und erörterte seine Mittlerposition zwischen den Religionen:

„[...] allerdings hat Mendelssohn orientalische Tornüre; nur vergessen sie nicht, dass er diese Tournüre aus guten Gründen beibehalten, vielleicht affektirt hat. Er wollte zeigen, dass ein Jude mit dem Geist seiner Väter, und ganz nach dem Muster des Orients gebildet, die höchste Freiheit erreichen kann; er wollte durch sein Beispiel zeigen, was der Jude als Christ und Jude leistet; er hat sich immer bemühet, zwischen beiden Partheien durchzuschwimmen, und manchmal stehtauch dem geübtesten Schwimmer [...] der Angtsschweiß auf der Stirn. Wieviel Lob und Tadel in diesem Urtheil liegt, darf ich Ihnen nicht erst noch auseinandersetzen“.305

Ein weiterer viel erwähnter Dichter, über dessen Bedeutung sich alle einig waren, ist Gotthold Ephraim Lessing. Veit wollte ihn gewissermaßen zum ,Stoff

299 Rahel Levin Varnhagen an David Veit, 21. 3. 1795, in: GW VII/II, S. 80.

300 Rahel Levin Varnhagen an David Veit, 21. 3.1795, in: GW VII/II, S. 81.

301 David Veit an Rahel Levin Varnhagen, 23. 4. 1795, in: GW VII/II, S. 99.

302 Ebd.

303 Rahel Levin Varnhagen an David Veit, 3. 1. 1794, in: GW VII/I, S. 103.

304 Rahel Levin Varnhagen an David Veit, 13. 12. 1793, in: GW VII/I, S. 80.

305 David Veit an Rahel Levin Varnhagen, 24. 12. 1793, in: GW VII/I, S. 80. 
im Fernstudium erheben, indem er Rahel Levin Varnhagen vorschlug, die Theorie der Fabel zu diskutieren. ${ }^{306}$ Rahel Levin Varnhagen aber wehrte sich nicht nur gegen Veits Vorschlag, ihr Lessingzitate abzuschreiben mit der vielsagenden Formulierung: „Den Lessing hat doch jeder Jude“, sie hatte ,ihren Lessing' so gut im Kopf, dass sie Schillers Ideen mit denen Lessings ohne Textgrundlage vergleichen konnte..$^{307}$

Raum für Interpretation des Selbstbildes entsteht, wenn man dies LessingZitat mit dem folgenden, aus dem Antwortbrief, konfrontiert: „Wieland und Goethe muß jeder Deutsche haben (nicht aus Stolz, sondern weil man nur in der Muttersprache vollkommen goutirt)“.308 Über Sprache oder Kultur wurden Zugehörigkeiten definiert. Aus dem Briefwechsel Veit-Levin Varnhagen spricht eine seltsame Mischung aus Distanz zu „den“ Juden (mit denen anscheinend die ältere, traditionsbewahrende Generation, auch die der ersten Maskilim gemeint war) und Stolz auf den Beitrag Mendelssohns zur deutschen Kultur. ${ }^{309}$

Festzuhalten ist für die Diskussion der Literatur und anderer Themen, dass sich Veit und Levin Varnhagen, ebenso wie etwa Levin Varnhagen und Brinckmann, als gleichberechtigte Gesprächspartner behandelten und erwiesen. Zwar konnte David Veit, vor Ort' sein und mehr Informationen über Weimarer Dichter oder ihre Projekte liefern, und Brinckmann hatte die größere Bibliothek, oft genug aber konnte Rahel Levin zurückschreiben, sie habe beider Empfehlungen schon längst gelesen. Veit und Levin Varnhagen agierten jeweils als Ratgeber auf verschiedenen Gebieten, er verbesserte ihr Deutsch und Französisch, sie wurde um Rat gebeten, wie er sich höhergestellten Personen gegenüber verhalten solle, um sich zu „emanzipiren“310 [vgl. III.4].

Die ausgesuchten Briefwechsel überblickend lässt sich zusammenfassend festhalten, dass sowohl die Rolle der Frau als auch der Status der Juden in der Gesellschaft implizit und explizit mehrfach vermerkt und beklagt wurden, nicht selten auch in Kombination. Das emanzipatorische Element lag aber vor allem im Selbstverständnis der Debattierenden: Die persönlichen Fragen und Interessen, die den Großteil des Briefwechsels ausmachten, diskutieren Brinckmann, Levin und Veit aber dezidiert als Menschen, nicht als Mann und Frau und nicht als Juden. Allerdings auch nicht als politische Existenzen.

306 David Veit an Rahel Levin Varnhagen, 27. 11. 1793, in: GW VII/I, S. 67.

307 Rahel Levin Varnhagen an David Veit, 7.5. 1795 und 15. 11. 1794, in: GW VII/II, S. 112 und S. 1.

308 David Veit an Rahel Levin Varnhagen, 16.1.1794, in: GW VII/I, S. 114.

309 „Wenn man bedenkt, daß es ein Jude war, der die deutsche Philosphie zur Sprache brachte, muß man wahrhaft erstaunen." David Veit an Rahel Levin Varnhagen, 16. 1. 1794, in: GW VII/I, S. 121.

310 Rahel Levin Varnhagen an David Veit, 25.1. 1794, in: GW VII/I, S. 126. 


\section{„Das Schicksal der guillotinirten Olympia Gouges eröffnet den weiblichen Schöngeistern [...] nicht die frohesten Aussichten.“ - Zur Politik in Briefen} Politik findet in den hier untersuchten Briefwechseln des Jahres 1794/95 so gut wie nicht statt. ${ }^{311}$ Politische Ereignisse aus Preußen oder dem revolutionären Frankreich werden, mit der deutlichen Ausnahme des politisch publizierenden Gentz und seiner Briefwechsel, einfach nicht thematisiert. Fragen wie „Was sagen Sie zu den Vorfällen am Rhein?“ waren dabei zwischen den hier ausgesuchten Protagonisten durchaus aufgeworfen worden, allerdings nicht oft, und eher zu Beginn der Revolution. ${ }^{312}$ Argumente pro und contra französische Politik wurden 1794 nicht ausgetauscht, auch Begriffe wie „Revolution“ oder „Guillotine“ wurden 1794 in der Berliner Salongesellschaft selten und überwiegend metaphorisch benutzt. Beispielsweise wenn Brinckmann schrieb, dass er unter heftigem Zahnschmerz litt und sich mit einem Artikel von Gentz tröstete, nach dem „Revolution gegen den Oberherrn“ keinen Sinn habe und er also seinen Zähnen kein Recht zum Aufstand zubilligen wolle. ${ }^{313}$ Lediglich in dem Brief David Veits an Rahel Levin Varnhagen, in dem auch der Status der jüdischen Bevölkerung thematisiert wurde, kam es zu einer wenn auch leicht resignativen Einschätzung der Revolution. Veit imaginiert sich nach Frankreich, „wo ich von meinem Taufschein nicht Gebrauch zu machen nöthig habe“ - mehr als das erwähnte Holzbein für die Lahmenden aber „wird wohl die Revolution nicht für die Juden sein“. ${ }^{314}$

311 Das Zitat im Titel aus der Rezension der „Rettung der Rechte des Weibes“ im Journal des Luxus und der Moden, 1794, zitiert nach: Gibbels 2004, S. 84. Ein möglicher Grund für die Politikferne innerhalb der Briefe der Salongesellschaft kann dabei darin liegen, dass, wie in einem Brief Humboldts an Brinckmann angedeutet, eine Diskussion über ein politisches Buch, wie das erwähnte von Edmund Burke, zu einer tatsächlichen Meinungsverschiedenheit und tiefergehenden Verstimmung führen könnte. Die unterschiedliche Bewertung dieses Buches scheint ein Grund der länger währenden Entfremdung zwischen Humboldt und Brinckmann um 1794 gewesen zu sein, wird aber nicht explifiziert. Vgl. Wilhelm von Humboldt an Gustav von Brinckmann, 14. 7. 1794, in: Leitzmann 1939, S.74 f.

312 Wilhelm von Humboldt an Friedrich von Schiller, 7. 12. 1792, in: Leitzmann 1900, S. 48. Humboldt schlug seinem Freund Schiller damit eine Reise nach Paris vor, positionierte allerdings sich zugleich als tendenziell Konservativer, der es seinem Jugendfreund Georg Forster nicht verzeihen konnte, dass dieser „auf einmal ganz öffentlich zur französischen Partei übergegangen ist“. Er nahm es Forster vor allem übel, dass dieser sich gegen seinen Dienstherrn, den Kurfürsten von Mainz, undankbar zeigte. Hier bezeichnet Humboldt seine politische Position als unentschieden: „Mein eignes Interesse, d. h. das ich als Zuschauer an dem Ausgange nehme, weiß kaum recht, wohin es sich schlagen soll." Ebd. Wichtig fand Humboldt die französischen Ereignisse nicht wegen einer „freien Konstitution“, sondern wegen des Enthusiasmus des Volkes. Ebd. S. 49.

313 Gustav von Brinckmann an Rahel Levin Varnhagen, undatiertes Billet, 1794 einsortiert, SV 38.

314 David Veit an Rahel Levin Varnhagen, 23. 4. 1795, in: GW VII/II, S. 99. 
Nur zwei lokale politische Begebenheiten wurden 1794/95 ausführlich thematisiert und sollen daher hier erwähnt werden. Rahel Levin Varnhagen berichtete mehreren abwesenden Freunden über Handwerker-„,Aufläufe“. Sie erwähnte auch einen möglichen Grund für die Seltenheit solcher Berichte ihr Haus war im Wortessinne politikfern, i. e. weitab von dem Geschehen: „Wir Friedrichstädter erfuhren den Lärm erst anderthalb Tage später. In unsrer schönen Straße wohnt niemand, der unter zweitausend Thaler zu verzehren hätte“.315

Ein zweites Ereignis, bei dem aktuelle Politik 1794 sicht- und hörbar wurde, war der Durchmarsch französischer Kriegsgefangener durch Bernau bei Berlin. Dieser wurde $\mathrm{zu}$ einem quasi gesellschaftlichen Ereignis, $\mathrm{zu}$ dem man eine Ausfahrt verabredete. Friederike Liman berichtete verärgert von einem Nachmittag bei Frau Fließ, wo der Ausflug das bestimmende Thema gewesen sei: „[...] für mich ohne übertreibung eine Tortur, denn um dir nur eine Ide zu machen die Koch sprach von nichts andrem als von eine partie nach Bernau wo sie den andren tag zusamen hinfahren würden um die gefangnen Franzosen durchkomen zu sehen; dencke dir also was sie da alles sprach um sich bey Wessely zu acreditiren“. 316

Hitzel Fließ Boye Sparre berichtete ihrer Freundin kurz darauf selbst von dem Ausflug nach Bernau und schwärmte von ihren Gesprächen mit Kriegsgefangenen und deren französischem Wesen: „Es herrscht ein ganz anderes Leben unter diesen Wesen, eine solche plie, solche Leichtigkeit, vom gemeinsten Soldaten bis zum General, den Nachmittag tanzten die Gemeinen, da hättest Du französicke (!?) pas sehen wollen, welche ohne Schue und mit unter, ohne Strümpfe getanzt wurden, und die eloquence von allen diesen Menschen, die ist wahrlich einzig“..317

Noch andere Berliner nahmen durchziehende Kriegsgefangene als Anlass, einen Ausflug zu machen. Der Arzt Heim beschreibt in seinem Tagebuch, wie er sich extra schnelle Pferde auslieh, um rechtzeitig in Oranienburg zu sein. Allerdings löste der Ausflug bei ihm eher Nachdenklichkeit aus: „Der Anblik der Gefangenen Franzosen machte mir aber kein Vergnügen. Ein solcher Anblik muß immer den Krieg gehässig machen $u$. wehe den Menschen die Preußen zu einem Krieg mit Frankreich geraten haben“.318 Wie „die Fließ“

315 Rahel Levin Varnhagen an David Veit, 2. 6. 1795, in: GW VII/II, S. 141

316 Friederike Liman an Rahel Levin Varnhagen, 21. 6. 1795, in: Bosold 1996, S. $14 \mathrm{f}$.

317 Hitzel Fließ Boye Sparre an Rahel Levin Varnhagen, o. D., nach dem Briefwechsel Rahel Levin-Friederike Liman datierbar, SV 34, „Mad. Boye“. Schreibung im Original.

318 Tagebucheintrag 25. 8. 1794, Heim 1989, S. 87. 
hatte Heim sich selbst an die Franzosen gewandt, vermerkte aber vor allem seinen Ärger über deren schlechte Behandlung durch die Preußen. ${ }^{319}$

Es ist anzunehmen, dass politische Ereignisse in und um Frankreich auch politische Betrachtungen bei einigen Teilnehmern der Salongesellschaft ausgelöst haben, überliefert ist es 1794/95 kaum. Heim ähnliche Überlegungen zum Krieg oder zum Verhältnis zwischen Preußen und Frankreich wurden in den von mir gesichteten Briefwechseln der Salongesellschaft nicht geäußert, obwohl politischen Schriften, wie Gentz' Arbeit über die Revolution, durchaus gelesen wurden. Äußerungen anderer gesellschaftlich engagierter Frauen und Männer aus der Zeit, das Tagebuch Elisa von der Reckes oder Ernst Ludwig Heims zum Beispiel, belegen dabei, dass Politik anno 1794 durchaus ein beherrschendes Thema bei Tischgesellschaften sein konnte. ${ }^{320}$ Es stellt sich daher die Frage, ob die Nichterwähnung zwischen den Repräsentanten der Salongesellschaft ein Quellenproblem oder eine bewusste Ausklammerung eines Themas reflektiert. Auch sozialkritische Betrachtungen wie die Reckes, dass die Festbeleuchtung eines Palais' mit dem Leben eines vom Gerüst gefallenen Arbeiters erkauft sei, finden sich hier nicht. ${ }^{321}$ Ergänzend ist aber eine Äußerung Dorothea Mendelssohn Veit Schlegels anzuführen, die zwei Jahre vor dem Untersuchungszeitraum nach einem Opernbesuch in Rheinsberg,revolutionäre‘ Gedanken äußerte: „[...] gehen Sie nun um ein Haus weiter, nur die Ekke herum, und sie finden kein ganzes Dach, keine reine Straße, kein ganz angezogenes Kind. Dürftigkeit und Elend allenthalben [...]. Verdammte Aristorkratie! konnte ich mir nicht erwehren auszurufen [...] So eine Oper, kostet mehr, als es kosten würde, ein eingefallnes Häuschen wieder aufbauen zu

319 „Die Franzosen selbst waren noch munter genug. Mit mehreren gesprochen [...]. Abends ritt ich wieder zurük, mehr mit den Franzosen als den Unsrigen zufrieden, welches nicht hübsch ist.“ 25. 8. 1794, Heim 1989, S. 87 und 90.

320 Sie überliefert einen Dialog zweier Tischgäste, eines Arztes und eines Schauspielers, über die Freiheit: „Wer sollte sich die Freiheit wünsche, durch die jetzt in Frankreich so vieles Blut mit leichtsinniger Grausamkeit vergossen wird?!“ Elisa von der Recke, Tagebucheintrag 19. 2. 1794, in: Johannes Werner (Hrsg.): Elisa von der Recke. Mein Journal. Elisas neu aufgefundene Tagebücher aus den Jahren 1791 und 1793/95, Leipzig 1927, S. 150. Heim kam 1794 mit einem Patienten und Minister ins Gespräch über die aktuelle preußische Staatsverfassung und notierte seine Besorgnis darüber in seinem Tagebuch. Heim 1989, S. 90 .

321 Recke fügte empört hinzu: „Diese Nachricht erzählte mir eine Dame [...] mit dem Ausdrucke, als wenn dieser Unglücksfall die Pracht des Festes vergrößerte.“ Elisa von der Recke, Tagebucheintrag 27.9.1791, in: Werner 1927, S.62. Allerdings muss hinzugefügt werden, dass ihr Tagebuch über weite Strecke genau ihrem Konflikt als zwischen den Ständen stehend und mit den Bürgern mitfühlend gewidmet ist. 
laßen.“ Interessant ist ihr Abschlussgruß an Rahel Levin Varnhagen: „Verzeihen Sie meinen Eifer, liebe Aristocratin - Sie sollten nur Rheinsberg sehen“.322

Für die Briefe, die in der Salongesellschaft und nicht zwischen engen Jugenfreunden gewechselt wurden, gilt, dass erst 1797, als mit Wilhelm von Humboldt und Brinckmann zwei Habitués der Berliner Salon nach Paris übersiedelten, vergleichende Betrachtungen zwischen den Städten, ihren Bewohnern und deren prä- und postrevolutionäre Kultur zum Thema in den Briefwechseln wurde. Für die Perspektive Berliner Salonteilnehmer 1794 könnte man überspitzt sagen: Hier wurde Politik zum Event. Oder aber: die Revolution musste auf Ausfahrtslänge an Berlin heranrücken, um von den hier vorgestellten Sprechern wahrgenommen zu werden. Allerdings befanden sich die potentiellen Politikabstinenzler damit in bester Gesellschaft. Symptomatisch für den Umgang mit Politik durch bürgerliche Intelligenz der Zeit in diesem Moment mag Goethes Vorschlag an seine Mutter gelten, seinem Sohn zu Weihnachten eine Miniguillotine $\mathrm{zu}$ schenken. ${ }^{323}$

\section{Kein Ort der Salongesellschaft - Breslau und „die Böhmen“}

Ich bin hier. Weiter kein Wort; auch das verdienen Sie nicht. R. L. An David Veit aus Breslau, 3. 9. $1794^{324}$

An dieser Stelle wird eine Stadt erwähnt, obwohl und weil sie in den Auseinandersetzungen in der Salongesellschaft 1794/95 nicht zum Thema wurde und im doppelten Sinne als Unort der Salongesellschaft gelten muss. Im Sommer 1794 unternahm Rahel Levin Varnhagen mit ihrer Mutter Chaie und ihrer Schwester Rose eine gemeinsame Reise zu Verwandten nach Breslau. ${ }^{325}$ Dieser Aufenthalt

322 Dorothea Mendelssohn Veit Schlegel und Henriette Mendelssohn an Rahel Levin Varnhagen, 13. 9. 1792, in: KFSA, Bd.23, S.64. Hervorhebung im Original.

323 Ein Vorschlag, den seine Mutter vehement ablehnte: „Alles was ich Dir zu gefallen thun kann, geschieht gern und macht mir selbst Freude - aber eine solche infame Mordmaschine zu kaufen - das thue ich um keinen preiß - wäre ich Obrigkeit, die Verfertiger hätten an ein Halseisen gemusst." Catharina Elisabeth Goethe an Johann Wolfgang von Goethe, 23. 11. 1793, in: Albert Köster (Hrsg.): Briefe von Goethes Mutter, Leipzig 1908, S. 119. 324 Rahel Levin Varnhagen an David Veit, 3. 9. 1794 in: GW VII/I, S. 223. „das verdienen“ im Druck gesperrt.

325 In Breslau wohnte der wohlhabende Kaufmann Lipmann Meyer, ein Neffe von Levin Markus, und damit Vetter von Rahel, der wegen des großen Altersunterschiedes „Onkel“ genannt wurde. Er war u. a. Ober-Gemeindeältester der Breslauer jüdischen Gemeinde. Vgl. die genealogischen Recherchen von Paul Jacobi in einem Brief an Carola Stern 1992, zit. nach: ERLV II, S. 607, Anm. 1. 
fand in den Briefen an ihre Salonbekannten kaum Niederschlag. Eben dieser Umstand aber bzw. die Tatsache, dass Rahel Levin Varnhagen ihre Eindrücke von der jüdischen Bevölkerung Breslaus ihren Bekannten gegenüber nicht, ihrer Familie gegenüber aber ausführlich und mit merkbarer Distanz berichtete, ist für das Selbstverständnis einer Berliner Jüdin um 1800 bemerkenswert. 326

Im Folgenden soll kurz skizziert werden, welchem ihrer Briefpartner gegenüber Rahel Levin Varnhagen was thematisierte und was nicht. An David Veit ist aus dieser Zeit nur obiger Einzeiler[!] überliefert, der kürzeste Brief der gesamten Korrespondenz und einziger seiner Art. Allerdings haftet ihm noch ein eigenwilliger Nachsatz an: „N. S. Nun hör ich’s Sie haben doch einen schlesischen Accent. Ich bin acht Tage hier, vierzehn im Gebirge und wiederum vierzehn hier; den achtzehnten reis’ ich nach Hause. Verdienen Sie’s“?327 Veit stammte aus Breslau, weshalb sie seinen Akzent dort wiederzuerkennen vermochte, und weshalb sie vielleicht auch davon ausging, ihm aus dieser Stadt nichts berichten zu müssen. Warum er es aber nicht „verdient“ haben könnte, bleibt, wie Bosold zu recht anmerkt, reine Spekulation. In den Briefen, die sie ihm nach der Rückkehr aus Breslau schrieb, nahm sie keinen Bezug auf ihre dortigen Erlebnisse, sondern wechselte gleich wieder zu ihren gemeinsamen Themen. An Gustav von Brinckmann schrieb sie in dieser Zeit zwar „Lassen Sie sich immer meine Briefe mitteilen, sie sind auch für Sie“, auch mit Navarro D’Andrado wurde die Korrespondenz fortgesetzt, aber eigene, persönliche Kommentare aus Breslau sind weder an diese beiden noch an irgendwelche anderen Bekannten überliefert. ${ }^{328}$ Auffällig ist noch, dass Brinckmann seine Billets nach Breslau, die auch nur kleine Neuigkeiten aus Berlin enthielten, durchweg auf französisch schrieb, ebenso wie Rahel Levin Varnhagen Kommentare zu ihrer Gastfamilie oft ins Französische setzte, mit der expliziten Begründung, dass sie deren Neugier fürchtete: „[...] j’ecris les horreurs en franç: parceque je crains les curieux“. 329

326 Im BdA erschienen nur stark gekürzte und veränderte Fassungen. Der erste vollständige Abdruck eines schlesischen Briefes bei Isselstein 1993, S.54-59. Eine ausführliche Analyse der „Schlesischen Reise“ für das Selbstverständnis Rahel Levin Varnhagens bietet Bosold 1996, S. 178-194. Dass die Briefe eigentlich undruckbar seien, wie Bosold meint, kann ich nicht bestätigen, vielmehr macht der jetzt erfolgte Druck, die zahlreichen Unterstreichungen und Ausrufezeichen, die Aufregung(en) dieser Reise sinnfällig, vgl. ERLV III, S. 16-43.

327 Rahel Levin Varnhagen an David Veit, 3. 9.1794 in: GW VII/I, S. 223.

328 Rahel Levin Varnhagen an Gustav von Brinckmann, 26. 8. 1794, in: GW I, S. 98. Nach den überlieferten Briefen Navarros ging es in Levin Varnhagens Briefen an ihn nicht um Reiseerfahrungen. Bosold 1996, S. 180.

329 Rahel Levin Varnhagen an Markus Levin, 8. 8. 1794, in: ERLV III, S. 16. 
Als Quelle für diese Reise bleiben neun Briefe an ihren Bruder Markus Theodor, die bei genauerem Hinsehen zugleich auch an andere Familienmitglieder gerichtet waren, zu denen hier auch Friederike Liman zählte. ${ }^{330}$ Diese Briefe können ihrem Detailreichtum und Umfang nach als kleine Reiseberichte oder besser Reisetagebücher gelesen werden, wie auch die Verfasserin selbst sie als „Jurnale“ sah und darum bat, diese aufzuheben. ${ }^{331}$ Bereits der erste Brief an die Familie vom 8. 8.1794 enthielt Bemerkungen zu Reisewegen und Gesellschaft, zur freundlichen Aufnahme im Haus ihres Onkels und - von Varnhagen im Buch des Andenkens um ganze Seiten gekürzt - ihr Erstaunen oder Entsetzen über das Leben in der Stadt: „Denk dir Hans eine prolongirte Probesgaße aber die heuser nach dem Himel zu spitzig und millonarden Böhmen, und welche'?! wie man sie bey uns nie siht.“ Im selben Brief findet sich eine Beschreibung der Geräuschkulisse, ebenfalls von Varnhagen nicht gedruckt: „[...] dass sich eine Menge Böhmen zanken [...]“ und der Hinweis, „dass die Böhmen alle Morgen in Mistischer Sprache die sie heilige nenen ihm bis in sein Wolkenpalais hinein schreien; denk nicht dass es übertrieben ist“.332 Der Begriff „Böhmen“ war nicht auf eine geografische Herkunft bezogen, sondern auf traditionell lebende Juden. ${ }^{333}$ In der Korrespondenz Rahel Levin Varnhagens aus Breslau wurde er stereotyp für die dort lebenden Juden verwandt, immer in Assoziation mit "geschrey“ und Menschenmasse. Die etymologische Erklärung des Begriffs ist in der Forschung nicht ganz geklärt. Carola Stern vermutet eine Ableitung vom hebräischen behema, Tier oder Ochse. Birgit Bosold verweist auf den jiddischen Begriff „a wilde B’heime“, worunter ein primitiver Mensch $\mathrm{zu}$ verstehen sei. ${ }^{334}$ Entsprechend diesen

330 Die Zählungen sind unterschiedlich, die ERLV III zählt sieben Briefe aus Breslau. 331 „[...] verwart meine Briefe den daß sind meine Jurnale [...]. Franz thu Du's.“ Rahel Levin Varnhagen an Markus Levin - und eben Friederike Liman (Franz), 11. 8. 1794, in: ERLV III, S. 28.

332 Rahel Levin Varnhagen an Markus Levin, 8. 8. 1794, in: ERLV III, S. 16, 18.

333 Ein „Ghetto“ bzw. ein vorgeschriebenes Wohngebiet gab es, wie in Berlin, auch in Breslau nicht, wohl aber eine Wohngegend, die Juden vornehmlich besiedelten, in der Altstadt, vor allem um den ehemaligen Karlsplatz, der im Volksmund auch „Judenplatz“ hieß. Gegen Ende der Regierungszeiten Friedrichs II. lebten etwa 2.500 Juden in Breslau, in absoluten Zahlen also Berlin vergleichbar, im Verhältnis zur Gesamtbevölkerung Breslaus aber eine viel größere jüdische Gemeinde. Auch nach einer neuen Judenordnung von 1790 war die jüdische Gemeinde von internen Kämpfen zwischen liberalen und traditionellen Gruppierungen geprägt. Gerhard Scheuermann: Die jüdische Gemeinde, in ders.: Das Breslau-Lexikon, Dülmen 1994, o. S.

334 Stern 1994, S. 21, Bosold 1996, S. 186. Dabei fügt Bosold hinzu, dass der jiddische Begriff über verschiedene etymologische Zwischenstufen aus dem hebräischen entstanden 
abwertenden Konnotationen finden sich in den Briefen aus Breslau Hinweise auf den „böhmenhaß“ einer vornehmeren Jüdin in Breslau, beziehungsweise auf ,antiböhmen“.335

Sicher nicht ohne Grund wählt Carola Stern die Reise nach Breslau als Einstieg in ihre berühmte romanhafte Biografie Rahel Levin Varnhagens: An dem Kontrast zwischen einem „orthodoxen, sinnlichen, schmutzigen“ Breslau zum „gradlinigen, aufgeklärten“ Berlin lässt sich sinnfällig darstellen, wie groß die Distanz zwischen einer modernen Jüdin und dem strenggläubigen Judentum um 1800 gewesen sein muss. ${ }^{336}$ Anders als Bosold, die zwischen den Zeilen der Familienbriefe vor allem Abscheu zu lesen glaubt, sieht Stern ihre Protagonistin aber auch fasziniert von dieser fremden Lebenswelt. Nicht die Befolgung der Religionsgesetze habe sie gestört, sondern nur die unmoderne Lebensart. 337 Dafür sprechen die sehr lobenden Äußerungen im zweiten Brief aus Breslau, in dem sie schöne Gärten und schöne Häuser pries. Zu ihrer positiven Stimmung mag auch eine französische Konversation mit einem Soldaten oder ein Besuch bei einer ehemaligen Berliner Bekannten beigetragen haben, die ähnlich wie in Berlin „,in einer guten Straße“ „recht gut meublirt“ und „ganz modern und simpel“ wohnte, sogar „in einem Hause so groß wie Herzens“. Allerdings zeichnete sich eben diese Freundin durch „böhmenhaß“ aus. 338

Neben dem Lärm war es vor allem der Schmutz, der Rahel Levin irritiert zu haben scheint. Bereits an ihrem Reisegefährten, dem jüdischen Gelehrten Haltern, hatte sie seine unkultivierten Umgangsformen beklagt, wie „dieses Bepatsche aller Lebensmittel“. 339 Die im Buch des Andenkens überlieferte Version der Reise, die allgemein als Ausdruck von Stress nach vier Tagen geteilter Postkutsche deutbar wäre, liest sich im Original verschärfter, denn Varnhagen hatte das allzu Eklige (im folgenden kursiv) gekürzt: „[...] dies ewige Gerede,

ist. Vgl. auch die Deutungen zu „behéjme“ (als 1. Haustier, 2. Dummer Mann oder Dumme Frau und 3. Arbeitstier) in: Leo Rosten: Jiddisch. Eine kleine Enzyklopädie, München 2003, S. $80 \mathrm{f}$.

335 Allerdings ist der Böhmenhass aus der Druckfassung des BdA gekürzt. Rahel Levin Varnhagen an Markus Levin, 11. 8.1794 und 26. 8. 1794, in: ERLV III, S. 25 und S. 35. 336 Stern 1994, S. 17-25. Ähnlich beginnt auch Hilde Spiel ihre Biografie Fanny von Arnsteins mit der Reise der Braut von Berlin in das reichere, aber wenig aufgeklärte Wien. Vgl. Spiel 1962, S. 9 ff.

337 „Mögen dem ,Onkel‘ die jüdischen Religionsgesetze ungleich mehr bedeuten als den Verwandten in Berlin - daran stört sich Rahel nicht. [...] Sie nimmt Anstoß an der Lebensart. Nichts im Haus lässt etwas von dem modernen Lebenszuschnitt des Berliner jüdischen Bürgertums erkennen.“ Stern 1994, S. 21.

338 Rahel Levin Varnhagen an Markus Levin, 11. 8. 1794, in: ERLV III, S. 25.

339 Rahel Levin Varnhagen an Markus Levin, 8. 8. 1794, in: ERLV III, S. 20. 
dies Nahsitzen, dieses Gestinke nach Schweiß, und Schmuhls Schnupftuch dieses Rotz in die Hände reiben, (als wünsche man sich) dieses Bewundern, dass man so wenig Schnupftücher braucht [...]““.340 Ebenso wie sie an Haltern „diese triviale entsetzliche Moral“ und seine mangelnden Umgangsformen ablehnt, irritieren sie am Haus ihres Onkels die - akustische - Nähe zu traditionellen Gesängen, die Flöhe und unkultiviertes Betragen der Mitwohnenden. ${ }^{341}$

Mit Bildern einer engen Gasse, spitzen Giebeln und handelnden Juden scheint die Atmosphäre des Schtetls heraufbeschworen bzw. womöglich, wie Bosold argumentiert, das Bild des „Ostjuden“ vorweggenommen. ${ }^{342}$ Dazu passt die ablehnende Haltung gegenüber den baulichen und hygienischen Verhältnissen im Hause des Onkels, in dem auch das Fehlen eines Klaviers bedauert wurde, als Symbol des kultivierten Lebens. Andererseits betonte die Besucherin immer wieder ihre Hochachtung vor der Person des Onkels, seiner Gastfreiheit und seinem Bemühen, ihr den Aufenthalt so angenehm wie möglich zu machen. ${ }^{343}$ Die beiden überlieferten Briefe ihres Bruders Liepmann, später Ludwig Robert, der 1794/95 bei dem Vetter in Breslau in die kaufmännische Lehre ging, klangen, im Vergleich, auch nicht wirklich entsetzt, eher amüsiert. Er sei sehr gut aufgenommen worden und habe gute Gespräche mit dem Onkel geführt, auch über die Religion. Zwar werde in Breslau ,überhaupt viel davon gesprochen“, aber man konnte auch mit dem Onkel darüber scherzen, dass der Berliner Lehrling die „Schuhl“ direkt gegenüber seinem Zimmer hatte, gemeint war die Privatsynagoge im Hause. ${ }^{344}$ Die Tante sei gut frisiert und höflich. Anscheinend hatte er anderes erwartet, denn er fügte hinzu: „[...] ob dieses zuvorkommende und höfliche nur schein ist kann ich in dieser kurzen Zeit nicht beurteilen“. ${ }^{345}$

Die Irritation blieb. Als Rahel Levin Varnhagen nach 14 Tagen Rundfahrt in schöner Landschaft wieder in Breslau ankam, überfielen sie Beklemmungen:

340 Rahel Levin Varnhagen an Markus Levin, 8. 8. 1794, in: ERLV III, S. 20, im Vgl. mit BdA I, S. 82. In der BdA-Version fehlen auch die Unterstreichungen.

341, „[...] dabey war eine colonie flöhe auf meinem leibe glüklich, die sich ihn seit voriger Nacht zur Insul ihrer freiheit und gleichheit ausgesucht haben." Rahel Levin Varnhagen an Markus Levin, 8. 8. 1794, in: ERLV III, S.17; und über den Reisebegleiter Haltern, den sie nur das „Biest“ nannte: „[...] was meint ihr dazu wenn einer immer in Geselschaft sitzt und sich mit einen Ohrlöffell die Ohren reine macht es zu Kloß wirbelt und dan in die Hände schmiert?“ Rahel Levin Varnhagen an Markus Levin, 23. 8. 1794, in ERLV III, S. 33.

342 Bosold 1996, S. $188 \mathrm{ff}$.

$343, \ldots[.$.$] indessen muß ich weiter treumen und nach mein clavir fragen dahieß es wäre$ keins zu haben [...] Der oncle versichert ich würde eins bekomen, indeßen hab ich keins.“ Rahel Levin Varnhagen an Marcus Levin, 8. 8. 1794, in: ERLV III, S. 17.

344 Ludwig Robert an Rahel Levin Varnhagen, vor August 1794, in: ERLV II, S. 9. 345 Ludwig Robert an Rahel Levin Varnhagen, vor August 1794, in: ERLV II, S. 9. 
[...] wie ward mir aber, wieder in dieser engen Straße ein zu kriechen und in dieses Hause [...]. Mir wurde so angst und bange daß ich mich eine Stunde lang vor der Thür aufhielt [...]. vor Böhmen schäm ich mich nicht, man sich nicht, nun die sind so einen Abend in der engen Gaße, und in solcher Menge, daß ich diese Straße ohne Ubertreibung und auf meiner Ehre mit keiner von den unsrigen in der Art vergleichen kann, Sieber u NagelGaße sind zwar enger aber nicht so Volkreich, nicht so ausschließend Böhmen reich. ${ }^{346}$

Wenn es auch „Böhmen“ in Berlin gab, hatte man mit diesen keinen Kontakt. Hannah Arendt sieht in der Reaktion Rahel Levin Varnhagens auf ihre „obligaten jüdischen Provinzverwandten“ vor allem Scham wirken, die sie zugleich als absoluten Verzicht auf Zugehörigkeit deutet. „Keine Taufe, keine Assimilation, keine noch so reiche und adlige Heirat hätte eine so radikale Wirkung haben können wie diese Scham“. 347

Ob Scham, ${ }^{348}$ Ekel oder Faszination die wesentliche Reaktion der Berliner Levins auf die Lebensverhältnisse der Juden in Breslau war, bleibt letztendlich eine Frage der Interpretation. Es scheint aber bezeichnend, dass, wie hier im speziellen Fall aus und nach Breslau, in den meisten Briefen zwischen der jüdischen Gastgeberin und ihren nichtjüdischen Salonbekannten allgemein „das Jüdische“, die jüdische Herkunft oder die jüdische Emanzipation nicht thematisiert wurde. Anders als Bosold scheint mir kein absichtsvolles Verschweigen vor ihren Gästen am Werk, da zwei gut vernetzte Diplomaten die Reise zumindest in vermittelter Form kennenlernten: „[...] theile ihm in auszug mein Unglück mit ich will es haben“. ${ }^{349}$ Die grundsätzliche Abwesenheit des Themas, die sich für die meisten Briefe zwischen jüdischen und nichtjüdischen Salonbeteiligten zumindest in den frühen 1790er-Jahren konstatieren lässt, deutet womöglich auf mangelndes Interesse an der Herkunft als Unterscheidungsmerkmal. Man sah sich nicht in Bezug zu den „Böhmen“, sondern zählte sich zu den aufgeklärten Berlinern. Umgekehrt ist der spätere Wiedereinzug der Kategorie „jüdisch“ in die Briefwechsel um 1800 ein Zeichen dafür, dass in der Gesellschaft vermehrt unsichtbare Schranken wieder hochgezogen wurden. Und die Thematisierung „des Jüdischen“ in den Briefen einiger nichtjüdischer Gäste untereinander deutet daraufhin, dass die jüdische Herkunft einiger Salonbeteiligter nicht so irrelevant war, wie diese es sich vielleicht gewünscht hätten.

346 Rahel Levin Varnhagen an Markus Levin, 30. 8. 1794, in: ERLV III, S. 34.

347 Arendt 2001, S. 227.

348 Inwieweit Scham auch progressive im Sinne von befreiende Konsequenzen haben kann, diskutiert, auch am Beispiel von Hannah Arendts Rahel-Biografie, Jill Locke: Shame and the Future of Feminism, in: Hypatia, 22/F, Herbst 2007, S. 146-162.

349 Rahel Levin Varnhagen an Marcus Levin, 8. 8. 1794, in: ERLV III, S. 21. 
Was zählt, ist die erschriebene und in diesem Falle erschwiegene Nähe zu den „modernen“ Menschen in Berlin. Nicht nur in preußischen Meilen gemessen, lag 1794 Weimar dichter an der Jägerstraße als Breslau.

\section{Zwischen Berlin und Weimar-Jena}

In Weimar möchte ich wohl eine geraume Zeit hindurch - ein Fremder sein.

David Veit an Rahel Levin Varnhagen, erster Brief

(Weimar=Jena, wie schon gesagt worden).

Karl August Varnhagen 350

Zum Verhältnis zwischen Weimar-Jena und Berlin gibt es aus und seit der hier interessierenden Zeit zahllose Kontroversen zwischen Intellektuellen beider Städte, ${ }^{351} \mathrm{zu}$ denen jedes Jubiläum zahlreiche neue, biografische, essayistische und wissenschaftliche Beiträge beisteuert. ${ }^{352}$ Seit kurzem haben der Berliner Salon und Weimar die Gemeinsamkeit, als bedeutende deutsche Erinnerungsorte zu gelten, wobei in beiden Fällen der Forschung „ästhetisierende Topogra-

350 David Veit an Rahel Levin Varnhagen, 20. 3. 1793, in: GW VII/I, S. 6. Karl August Varnhagen an Johann Peter Eckermann, Oktober 1829, in: Carl. F. Schreiber: Sieben Briefe Varnhagens an J. P. Eckermann, in: The Journal of English and Germanic Philology, Vol 21, No. 3 (July 1922), S. 411-430, hier S. 414.

351 Statt eines Forschungsüberblicks sei hier exemplarisch auf den Sonderforschungsbereich verwiesen, der eigens der Erforschung der „ereignishaften Kommunikationsverdichtung“ gewidmet ist: Vgl.: „Ereignis Weimar-Jena. Kultur um 1800“ unter: http:// www2.uni-jena.de/ereignis/ (zuletzt eingesehen am 17. 2. 2010). Dem Konzept einer Doppelstadt wurde hier insoweit gefolgt, als dass Weimar und Jena zusammenhängend betrachtet werden. (Vergleichbare Konzepte lassen sich schon bei Zeitgenossen finden, Karl August Varnhagen plante ein Lexikon Weimars unter Einbeziehung Jenas.) Für diese Arbeit besonders interessant ist das Teilprojekt A4 zu Geschlechterbeziehungen, das nicht nur die Großzahl der an dem „Ereignis“ beteiligten Frauen aus den Quellen herausarbeitet, sondern nach den Geschlechterverhältnissen in Praxis und im Diskurs fragt.

352 Einen besonders guten Überblick über die verschiedenen Forschungsansätze zum Thema bietet der Sammelband von Ernst Osterkamp (Hrsg.): Wechselwirkungen. Kunst und Wissenschaft in Berlin und Weimar im Zeichen Goethes (Publikationen zur Zeitschrift für Germanistik, Bd. 5), Bern [u. a.] 2002. Auch das jüngste Weimarer Jubiläumsjahr zum 200. Todestag der Herzogin Anna Amalia und zum 250. Geburtstag ihres Sohnes stellte sich u.a. dem Vergleich der Städte im Rahmen einer Tagung: „Weimar-Jena 1800 - Das Ereignis im Kontext“. Demgegenüber hat die Berlin Brandenburgische Akademie der Wissenschaften ein Forschungsforum „Berliner Klassik“ geschaffen, welches die „ungewöhnliche Kulturblüte“ in der preußischen Hauptstadt zwischen 1786 und 1815 untersucht. Conrad Wiedemann: Über das Projekt Berliner Klassik, unter: http://www.berliner-klassik.de/projekt/conradwiedemann [vom 19. 2. 2010]. 
phie“ attestiert werden könnte. ${ }^{353}$ Der viel bearbeitete und immer noch schiefe Vergleich des Kulturangebots zwischen Haupt- und Residenzstadt interessiert hier allerdings nur insofern, als er 1794 dazu führte, dass zwei Habitués der Berliner Salons, Wilhelm von Humboldt und David Veit, ihren Lebensmittelpunkt zeitweilig nach Jena und Weimar verlegten ${ }^{354}$ und von dort über Berlin und seine Kultur vergleichend räsonierten: Die Frage, der in diesem Abschnitt nachgegangen werden soll, ist, welcherart Verbindungen die Berliner Salongesellschaft im Untersuchungszeitraum nach Weimar-Jena aufbaute, wie und worüber kommuniziert wurde. Das Kapitel beruht im Wesentlichen auf einer Lektüre verschiedener Briefwechsel der zwei Mitglieder der Berliner Salongesellschaft, die sich im Beispieljahr überwiegend in Weimar-Jena aufhielten und ihre Eindrücke nach Berlin korrespondierten. ${ }^{355}$ Ihre Briefe werden vergleichend gelesen mit anderen diese Städte verbindenden Korrespondenzen, ${ }^{356}$ vor

353 Dies in Abwandlung der Deutung von Georg Bollenbeck, dass Weimar eine „ästhetisierte Topographie“ hervorgebracht habe, da die Stadt selbst schon zu Goethes Zeiten enttäuschend gewesen sein muss. Georg Bollenbeck: Weimar, in: Etienne Francois / Hagen Schulze (Hrsg.): Deutsche Erinnerungsorte, 3 Bde., München 2001, Bd.1, S. 207-224, hier S. 213. Noch 2006 gilt die „komparatistische Erkundigung des Kräftefeldes“ zwischen Berlin und Weimar als „Desiderat“. Robert Charlier: Die Muse von Weimar. Vom Philosophenhof zur Musenstadt der deutschen Klassik, in: Günter Lottes/Iwan d’Aprile: Hofkultur und aufgeklärte Öffentlichkeit. Potsdam im 18. Jahrhundert im europäischen Kontext, Berlin 2006, S. 169-183, hier S. 183.

354 David Veit ging nach Jena zum Studium. Umstritten ist, wann genau Wilhelm von Humboldt realisierte, in Schiller den „Leitstern seines Lebens entdeckt zu haben“, sicher ist, dass sein Motiv für den Umzug nach Jena die erwünschte Nähe zu Schiller war, den er Ende 1789 kennengelernt hatte. Heinz Steinberg: Wilhelm von Humboldt (Preußische Köpfe, 32), Berlin 2001, S. 18.

355 Veit nutzte seine Studienzeit in Jena für mehrere Aufenthalte in Weimar, und wurde von seiner Freundin zu detailreichen kritischen Schilderungen seiner Reisen ermuntert; ebenso legte er Wert darauf, über das gesellschaftliche und intellektuelle Geschehen in Berlin auf dem Laufenden gehalten zu werden. Das macht den Briefwechsel zu einer hervorragenden Quelle für die Ideen und Kommentare, die zwischen Berlin und Weimar hin- und hergingen. Vgl. GW VII. Wesentliche Quellen für die Beschäftigungen Humboldts der Jahre 1794/95 sind Humboldts Briefwechsel mit Gustav von Brinckmann in Berlin, die Briefe aus Berlin und Tegel an Friedrich von Schiller und seine jetzt entstehenden Arbeiten, die Aufsätze zur Geschlechtertheorie sowie eine viel gelesene Rezension zu Friedrich Heinrich Jacobis Roman „Woldemar".

356 Die Kommentare von und über Goethe sowie das besondere Verhältnis der jüdischen Salonièren zu Goethe werden im nachfolgenden Abschnitt zu Karlsbad und Teplitz separat charakterisiert. Der Quellenbestand, der für die allgemeingesellschaftlichen Beziehungen Berlins zu Weimar um 1800 und umgekehrt als besonders aufschlussreich gilt, der berühmtberüchtigte Briefwechsel Goethes mit dem Direktor der Berliner Singakademie Zelter setzte erst 1796 ein und intensivierte sich erst ab 1799. Die Salongesellschaft betreffend, lässt sich aus Andeutungen entnehmen, dass Zelter, zumindest kurz, mit Markus und Henriette Herz 
allem mit den Briefen des Berliner Verlegers Johann Daniel Sander ${ }^{357}$ an seinen Weimarer Kollegen Carl August Böttiger. 358

Die Präsentation des kommunikativen ,Ereignisses Weimar-Jena‘ als Ort der Berliner Salongesellschaft ist in drei große Abschnitte unterteilt: Es wird, nach einer kurzen Charakterisierung der Schauplätze [4.1], zunächst untersucht, inwiefern sich die Beziehungen dreier Berliner Salonteilnehmer, Wilhelm von Humboldts, Rahel Levin Varnhagens und David Veits, über die Entfernung nach Weimar untereinander neu gestalteten [4.2]. Zweitens will das Unterkapitel den Berliner Blick auf Weimar und Jena, deren Bewohner und ihre Projekte einfangen - am Beispiel der in diesem Zeitabschnitt begonnenen Zeitschrift Die Horen. Da Die Horen als solche sowohl als publizistisches Projekt der Weimarer Klassik als auch als Forum der literarischen Fehde um 1800 detailliert analysiert worden sind, ${ }^{359}$ konzentriert sich diese Untersuchung auf die Rezeption

verkehrte und dass er Sara Meyer Grotthus kannte, über deren jeweilige Teetische oder Geselligkeiten fällt aber kein Wort. Vgl. Hecker 1987, Bd.1, S.39, Bd.2, S. 325 und Bd. 3 , S. 508.

357 Dabei sind leider nur die Briefe Sanders überliefert. Vgl. Maurach $1990 \mathrm{ff}$. Der kommentarreich edierte Briefkorpus ist von der Forschung noch wenig genutzt. Wirklich bekannt geworden sind lediglich Auszüge, die, Goethe betreffend, bereits von Ludwig Geiger herausgegeben worden sind. Vgl. ders.: Berlin und die Xenien (Aus den Briefen Sanders an Böttiger), in: GJB XVII (1896), S. 230-234. Zugleich ist auf eine Forschungslücke hinzuweisen - Johann Daniel und seine Frau Sophie Sander (1768-1828) waren gesellschaftlich sehr engagiert; die vielen engen Beziehungen zu Personen, die auch in jüdischen Salons verkehrten, wie Ende der 1790er-Jahre Isaak Euchel oder Gustav von Brinckmann, könnten zum Ausgangspunkt werden für einen Vergleich der Geselligkeiten in Häusern des jüdischen und nichtjüdischen Bürgertums Berlins.

358 Allerdings darf, abgesehen von seinen Verkaufszahlen, nicht vieles von Sanders Angaben als aufrichtiges Bild der Berliner Gesellschaft betrachtet werden, dem Vergnügen an der Assoziation werden die Fakten hier oft deutlich nachgeordnet. Welchen schädlichen Einfluss die Veröffentlichung solcher privat genossenen Details haben konnte, wird am posthumen Schicksal eben des Verlegers Böttiger sichtbar. Er hatte während seiner Weimarer Jahre Tageshefte geführt und später darauf einen Text über „Literarische Zustände und Zeitgenossen“ verfasst, der von seinem Sohn veröffentlicht wurde und seinen Ruf als Meister des Klatsches bis heute begründet, den des Autors und Verlegers weit in den Schatten stellt. Als jüngste Ausgabe: Carl August Böttiger: Literarische Zustände und Zeitgenossen. Begegnungen und Gespräche im klassischen Weimar, hrsg. von Klaus Gerlach, Berlin 1998.

359 Bereits im Briefwechsel der beteiligten Autoren finden sich zahlreiche Erörterungen zur Strategie und Verbesserungsmöglichkeiten der Zeitschrift. Eine erste ausführliche Analyse, die in den Details noch immer sehr brauchbar ist, in ihrer Interpretation aber als überholt gelten muss, stammt aus dem Jahr 1960. Günter Schulz: Schillers „Horen“. Politik und Erziehung. Analyse einer deutschen Zeitschrift (Deutsche Presseforschung, Bd. 2) Heidelberg 1960. Michael Gross wertet in seiner umfänglichen Dissertation alle Werke und Debatten im Hinblick auf das Ideal der,,ästhetisierten Öffentlichkeit“, das Goethe und Schiller mit ihren 
dieses Projekts durch die Berliner Salongesellschaft, von der Idee bis zum ersten Jahrgang der Zeitschrift, sowie auf die Frage, ob sich die Wahrnehmung des Projektes im Salon von der allgemeinen Rezeption unterschied [4.3]. Abschließend geht es um die Diskussion zweier in den Horen publizierter Texte eines der Mitglieder der Salongesellschaft: die geschlechtertheoretischen Aufsätze Wilhelm von Humboldts [4.4].360 Wie in II. dargelegt, sind die HorenAufsätze Humboldts ein wichtiges Element der zeitgenössischen Geschlechtscharakterdebatte und darüber hinaus ein Beispiel für die diskursive und personelle Überschneidung der Berliner Salons und der Emanzipationsdiskurse. Die abschließende Frage dieses Abschnittes lautet daher: Wie wurde Wilhelm von Humboldts Geschlechtermodell und die Tatsache, dass es von einem Salongast entworfen wurde, im Salon wahrgenommen?

\subsection{Familie und Freundschaft - topografische und persönliche Nähe und Distanz in Jena und Weimar}

Kein Ort in Deutschland würde mir das sein, was Jena und seine Nachbarschaft mir ist, denn ich bin überzeugt, dass man nirgends eine so wahre und vernünftige Freiheit genießt und in einem so kleinen Umfang so viele vorzügliche Menschen findet.

Friedrich von Schiller an Christian Gottlob Voigt, 5. 4. $1795^{361}$

Jena war zur fraglichen Zeit der engen Kooperation Humboldts mit Schiller eine Stadt der Wissenschaft, eine Stadt der Zeitschriften und eine kleine Stadt von 4.500 Personen, unter denen ca. 800 Studenten eine stadtbildprägende Gruppe ausmachten. Arbeitswege müssen als in jeder Richtung kurz gelten. Die persönliche Nähe der beiden Autoren in Jena spiegelt sich dennoch in besonderer räumlicher Nähe: Schiller vermittelte Humboldt zunächst sein altes

Projekten verfolgt hätten. Michael Gross: Ästhetik und Öffentlichkeit. Die Publizistik der Weimarer Klassik, Hildesheim [u. a.] 1994; Die jüngste Monografie zu den „Horen“ diskutiert sie als typischen Fall der streitreichen Zeitschriftenkultur um 1800, in der die einzelnen Medien oft zum Austragungsort grundsätzlicher literarischer Parteiungen wurden. Sylvia Kall: „Wir leben jetzt recht in Zeiten der Fehde“. Zeitschriften am Ende des 18. Jahrhunderts als Medien und Kristallisationspunkte literarischer Auseinandersetzung (Bochumer Schriften zur deutschen Literatur, Bd.62), Frankfurt/M. [u. a.] 2004. Einen publizistisch wie ideologisch interessanten Aspekt beleuchtet Holmgren 2007: Vom Redakteur der Horen, der weiblichem Schreiben in Übereinstimmung mit Goethe grundsätzlich Dilettantismus attestiert hatte, wurden sechs Autorinnen explizit zur Mitarbeit eingeladen, um dem zentralen Zeitschriftenprojekt der Klassik aus dem Tal des Leser- und Leserinnenschwunds zu helfen. 360 Humboldt 1903(a) und 1903(b).

361 Friedrich von Schiller an Christian Gottlob Voigt, 6. 4. 1795, zit. nach: Schillers Jena. 1789-1799. Wohnorte, Wirken und Weggefährten (literarischer Stadtplan), Jena 2006, o. S. 
Quartier, ab Oktober 1794 wohnten die Familien sich am zentralen Markt so gegenüber, dass sie einander winken konnten. ${ }^{362}$ Wenn Alexander von Humboldt seinen Bruder besuchte, nahm auch er an den Arbeitsgesprächen teil. ${ }^{363}$

Wo David Veit wohnte, ist nicht dokumentiert, außer dass es ein Gartenhaus war, vermutlich das eines Professors oder Universitätsangestellten, denn er erwähnt, dass Humboldt alle anderen in seinem Haus kenne und gelegentlich besuche. ${ }^{364}$ Als traditionell leben wollender Jude bzw. auf der Suche nach einem jüdischen Umfeld hätte Veit es in Jena schwer gehabt, da die Stadt die Ansiedlung von Juden verbot und erst 1792 Juden ein Aufenthalt ohne Handelstätigkeit erlaubt wurde, wovon nur sehr wenige Studenten Gebrauch machten. ${ }^{365}$

Hier muss auch angemerkt sein, dass einerseits der „kleine Umfang“ Jenas zwar viele „vorzügliche Leute“ zusammenbrachte - mit Karl Ludwig Woltmann und Johann Gottlieb Fichte lagen die Wohnungen mindestens zweier weiterer Horen-Autoren sozusagen in ,Teedistanz ${ }^{*}$-, dass aber andererseits die räumliche Nähe der Arbeitsorte einer Kooperation nicht notwendigerweise förderlich war: Auch das spätere Wohnhaus der Schlegels lag nur eine Parallelstraße weiter von denen Schillers und Humboldts, ${ }^{366}$ dennoch nahmen, nach dem Bruch zwischen Schiller und Friedrich Schlegel, 367 beide Kreise einander nur über das Medium Papier wahr. Zeigten sich die Begegnungen verschiedener

362 Friedrich von Schiller wohnte mit seiner Familie vom 14. Mai 1794 bis 12. April 1795 im Jagemannschen Haus, Unterm Markt 1 (heute zerstört). Dies Haus wurde dann zugleich Geburts- und Redaktionsort der „Horen“. Die Humboldts wohnten in der Zwätzgengasse 9, an derselben Ecke des Marktplatzes. Die Entfernung der beiden Häuser lässt sich mit zehn Schritt angeben.

363 Das berühmte Verdammungsurteil Schillers über Alexander von Humboldt, dieser sei ein „viel zu beschränkter Verstandesmensch“ und sein Unterfangen, die erhabene Natur ausmessen zu wollen, eine „Frecheit“, fiel erst drei Jahre später. Friedrich von Schiller an Christian Gottfried Körner, 6. 8. 1797, in: Karl Heinz Hahn (Hrsg.): Schillers Briefe, 2 Bde., Berlin [u. a.] 1968, Bd. 2, S. 143. Nach dem ersten Kennenlernen 1794 war Schiller noch sehr beeindruckt von Alexander von Humboldts Kenntnissen.

364 David Veit an Rahel Levin Varnhagen, 4. 6. 1795, in: GW VII/II, S. 145.

365 Ulrike Schramm-Häder: Jeder erfreuet sich der Gleichheit vor dem Gesetze, nur nicht der Jude. Die Emanzipation der Juden in Sachsen-Weimar-Eisenach (1823-1850), München [u. a.] 2001, S. 239. Die Zahl der jüdischen Studierenden lässt sich nicht ermitteln, da das Matrikelbuch die Religion nicht aufweist. Ebd. S. 240.

366 In der Leutragasse 5, das Haus wurde 1945 zerstört.

367 August Wilhelm Schlegel war zur Mitarbeit an den Horen 1795 eingeladen worden und steuerte zahlreiche Übersetzungen bei. Als sein Bruder Friedrich aber die Horen öffentlich kritisierte, empörte sich Schiller und löste die Verbindung zu seinem Autor 1797. 
Parteiungen, Stände und Geschlechter in Jena im größeren Rahmen „spannungsreich und freudevoll““,368 waren auch innerhalb des Kosmos Universität die Jahre um 1800 geprägt von Unruhen, vor allem der Auseinandersetzung um den 1794 neu ernannten Professor Fichte, der sich die Studentenorden durch fortwährende Provokationen so zum Feind machte, dass sie ihm die Scheiben einschlagen wollten und ihn damit zeitweilig aus Jena verjagten. ${ }^{369}$

Von den zahllosen Beschreibungen der Stadt Weimar um 1800 sei hier die wohl berühmteste zitiert, die die Verwunderung der Zeitgenossen über das Nebeneinander von ,großen Geistern' und überschaubarer Provinzialität in Weimar prägnant zum Ausdruck brachte: Madame de Staël fasste ihren Besuch 1803 in die Worte: „Weimar war keine kleine Stadt, es war ein großes Schloß, wo eine ausgesuchte Gesellschaft sich interessiert über jedes neue Kunstprojekt unterhielt“. 370 Zahlreiche Zeitgenossen machten auch die Diskrepanz zwischen ihren Erwartungen und dem tatsächlichen Eindruck der Stadt deutlich, einer fasste es in das Bild vom „poetischen“ Weimar einer- und dem „körperlichen“ Weimar andererseits. ${ }^{371}$ Neben den prächtigen fürstlichen Neubauten prägte auch hier der mittelalterliche Stadtkern, inklusive einiger Scheunen, das Stadtbild wesentlich. Beleuchtung erfolgte noch mittels Handlaterne und erst im Jahr vor dem hier geschilderten, 1793, war es verboten worden, sein Nachtgeschirr auf die Straße zu entleeren. Die zugleich rohe und reizvolle Stadt verdiente den von Zeitgenossen verliehenen Titel „Bücherfabrik“372 dadurch, dass sie in ihren ca. 750 Häusern und unter den 7.200 Einwohner um 1800 auffal-

368 So der Titel einer umfänglichen Untersuchung der Feste in Jena als öffentliche Orte, worunter akademische Rituale ebenso wie kirchliche Feiern zu rechnen sind: Johanna Sänger / Lars Delle (Hrsg.): Spannungsreich und Freudevoll. Jenaer Festkultur um 1800, Köln 2005. Zum „Ereignis“ Jena, v. a. zur Konzentration der hier arbeitenden Intellektuellen vgl. auch: Friedrich Strack: Evolution des Geistes: Jena um 1800. Natur und Kunst, Philosophie und Wissenschaft im Spannungsfeld der Geschichte, (Deutscher Idealismus, 17) Stuttgart 1994.

369 Fichte zog sich im Sommer 1795 nach Ossmannstedt zurück und nahm erst im Winter seine Vorlesungen wieder auf. Er lehrte in Jena bis er in Folge des Atheismusstreits entlassen wurde und 1799 nach Berlin ging.

370 Anne Germaine de Staël: Über Deutschland. Vollständige und neu durchgesehene Fassung der deutschen Erstausgabe von 1814, hrsg. von Monika Bosse, Frankfurt/M. 1985, S. 98.

371 Rückert 1970, S. 46.

372 Thomas Kopfermann / Dietrich Steinbach: Weimar-Jena. Epochenzentrum 1800, Stuttgart 1992, S. 4, bzw.: [Joseph Rückert]: Bemerkungen über Weimar 1799, hrsg. und mit einem Nachwort versehen von Eberhard Haufe, Weimar 1970, S. 10. 
lend viele Bücherproduzenten, Autoren, Autorinnen und Verleger, beherbergte. 373

Der Begriff und die Institution „Salon“ waren im Weimar vor 1800 ungebräuchlich, lediglich ein Parkgebäude trug diesen Namen. ${ }^{374}$ Das Interesse des Weimarer Hofs an intellektuell inspirierter Geselligkeit ist durch die Herzogin Anna-Amalia sprichwörtlich geworden. An ihren oft so genannten „Musenhof“ hatte sie bereits in den 1770er-Jahren die Dichter Musäus und Wieland als Prinzenerzieher engagiert. Seit 1787 fand einmal in der Woche bei ihr eine gemischte Tafelrunde statt. Aus dem Jahr 1795 selbst stammt das berühmte Gemälde von dieser Tafelrunde im Wittumspalais, von eben dem hier ansässigen Melchior Kraus. Es zeigt Mitglieder der Hofgesellschaft in bürgerlichem Ambiente, mit Lesen oder Zeichnen, die Frauen auch mit Handarbeiten beschäftigt. ${ }^{375}$ Die Hofdame Luise von Göchhausen lud im Mansardenzimmer des Palais im Winter ausgesuchte, auch bürgerliche Freunde zum Frühstück, zu dem „Freundschaftsbrötchen“ und „Freundschaftsmokka“ gereicht wurden. ${ }^{376}$ Die bekannteren thematisch gebundenen Gesellschaften in Weimar und Jena neben der Hofgeselligkeit können als „teilöffentliche Geselligkeit“ betrachtet werden, da sich alle auf bestimmte Personengruppen bezogen,

373 Hans Henning: Vorwort, in: Friedrich Albrecht Klebe: Historisch-statistische Nachrichten von der berühmten Residenzstadt Weimar. Fotomechanischer Neudr. der Originalausgabe Elberfeld 1800, Leipzig 1975, o. S. 1794 lebten hier als Attraktionen des deutschen Geisteslebens vor allem Goethe, seit 1775 in der Stadt und vom Herzog mit verschiedensten Funktionen betraut, u. a. als Theaterdirektor und Mitglied des Geheimen Consiliums, daneben der Theologe Johann Gottfried Herder als Oberhofprediger, der Unternehmer und Verleger Friedrich Johann Justin Bertuch, der unter anderem das berühmte „Journal des Luxus und der Moden“ herausgab, als Dichter und Herausgeber des „Teutschen Merkurs“ Christoph Martin Wieland sowie der Autor und ,Klatschreporter ' Carl August Böttiger. Unter den hier lebendenden bildenden Künstlern hebt eine zeitgenössische Stadtbeschreibung vor allem den Maler Georg Melchior Kraus hervor.

374 „Der Salon“ von Weimar war um 1800 ein in gothischem Stil gehaltenes einfaches Gebäude, versteckt im Park, das im Wesentlichen aus einem Saal für Konzertaufführungen bestand. Klebe 1975, S. $133 \mathrm{ff}$.

375 Georg Melchior Kraus: „Abendgesellschaft (Tafelrunde) bei Herzogin Anna Amalia“, um 1795, Goethe Nationalmuseum, Weimar. Im Umfeld des Weimarer Jubiläumsjahrs 2007 erschienen zahlreiche Biografien und Einzeluntersuchungen zu Anna Amalia. Vgl. exemplarisch: Leonie und Joachim Berger: Anna Amalia von Weimar. Eine Biographie, München 2006. Die erfolgreiche Anwerbepolitik der Herzogin führt noch 200 Jahre nach ihrem Tod zu reißerischen Fragestellungen. Vgl. Ettore Ghibelino: Goethe und Anna Amalia. Eine verbotene Liebe? Weimar 2007.

376 Vgl. den Eintrag „Geselligkeit in Weimar“ in: Effi Biedrynski: Goethes Weimar. Das Lexikon der Personen und Schauplätze, Zürich 1993, S. 107-120, hier S. 108. 
meistens dies sogar in Statuten festhielten. ${ }^{377}$ Ein eigentlicher Weimarer Salon ${ }^{378}$ wird der Stadt erst nach dem Zusammenbruch 1806 und dem Zuzug Johanna von Schopenhauers attestiert. ${ }^{379}$ Die gebildete Kaufmannswitwe hatte ihr Haus geschickt vor Plünderungen bewahren können und sammelte dort die an geistigem Austausch Interessierten aller Parteien. ${ }^{380}$ Ihr geselliges Engagement konnte aber den bald wieder erstarkenden Vorurteilen der Stände gegeneinander auf Dauer nicht standhalten. ${ }^{381}$

In dem hier untersuchten Jahr und für die zwei Berliner Salonmitglieder war Weimar ebenfalls deutlich ein Ort mit ausgesprochenen Ständeschranken,

377 Diese Zuordnung treffen Kopfermann / Steinbach 1992, S. 66. Am berühmtesten ist Goethes Freitagsgesellschaft, die von 1791-1797 existierte, von Goethe als ein „Reunionspunkt“ ausgewählter Gelehrter gedacht. Biedrynski 1993, S.108. In Jena sind als Vereinigungen aus dem Untersuchungszeitraum die Naturforschende Gesellschaft (gegründet 1793) zu nennen sowie die Literarische Gesellschaft der freien Männer [sic!], die am 1. 6.1794 ins Leben gerufen wurde. Letztere mietete einen kleinen Garten, in dem jeweils Mittwochs selbst verfasste Aufsätze gelesen und diskutiert wurden. Diese Gesellschaft ist besonders interessant durch ihre umfänglichen und außergewöhnlichen Statuten, die u.a. vorsahen, die Aufsätze nach getaner Arbeit öffentlich zu verbrennen. Vgl. zum Kampf dieser Gesellschaft um öffentliche Anerkennung Felicitas Marwinski: Lesen und Geselligkeit, Jena 1991, S. 20-27.

378 Wegen der Zentrierung um den einzigen ,Fixstern' Goethe ist in der Forschung umstritten, ob Johanna Schopenhauers Kreis zu den „echten Salons“ zu zählen sei. Unabhängig davon kam die sich um sie versammelnde Gruppe aus adligen und bürgerlichen, deutschen und französischen Männern und Frauen dem Ideal einer Salon-Geselligkeit näher als alle Weimarer Gruppierungen zuvor. Astrid Köhler vertritt die These, dass Johanna Schopenhauer sich dezidiert mit ihrem Engagement auf die Berliner Salons bezog bzw. für ihr geselliges Projekt Weimar wählte, weil in dieser Stadt noch keine etablierten geselligen Zirkel existierten. Mündliche Aussage mir gegenüber auf der Konferenz „Berlin 1800-1830. Die Emanzipation einer Kulturmetropole“, 12.-14. 10. 2007 in Potsdam.

379 Zum Geselligkeitsprojekt der Johanna Schopenhauer (1766-1838) vgl. ausführlich Köhler 1996. Zu anderen geselligen Formaten in Weimar s. Freyer / Horn / Grochowina 2009.

380 Sie hatte u. a. hochrangige Militärs bei sich einquartiert und vermittelte zwischen französischen und deutschen Interessen. Vgl. dazu auch Astrid Köhler: Welt und Weimar. Geselligkeitskonzeptionen im Salon der Johanna Schopenhauer (1806-1829), in:

Simanowski / Turk / Schmidt 1999, S. 147-160. Ihr Plan war, „mit wenig Mühe und noch weniger Unkosten [...] wenigstens einmahl in der Woche die ersten Köpfe in Weimar und vielleicht in Deutschland um meinen Theetisch zu versammeln“, Johanna an Arthur Schopenhauer, 26. 5. 1806, zit. nach: Köhler 1999, S. 154. Dies ist eine der wenigen expliziten Gründungsabsichtserklärungen einer Salonière.

381 Zeitgenossen beschrieben, wie der Hass des Großherzogs auf die „bürgerliche Canaille“ dazu führte, dass Johanna Schopenhauer in den 1820er-Jahren nicht mehr überall eingeladen wurde. Johann Diederich Gries an Johann Heinrich Abeken, 12. 6. 1829, zitiert nach: Köhler 1999, S. 158. Köhler spricht von „sozialen Platzanweisungen“ von Seiten des Hofes, die sich auf die Gesellschaft auswirkten. Ebd. S. 160. 
die allerdings auf den verschiedenen gesellschaftlichen Ebenen unterschiedlich reflektiert, bzw. von dem Adligen nicht thematisiert wurden: Wilhelm von Humboldt erwähnte gesellschaftliche Ausschließungen in Weimar oder Jena gar nicht, David Veit hingegen mehrfach. So bemerkte er gleich bei seinem ersten Besuch der Stadt, den er Goethes wegen unternahm, dass selbst dieser nicht zur herzoglichen Tafel geladen werde, wenn der „hohe Adel“ dort sitze. Die Forschung spricht von Weimars „bürgerlich-höfischen Kompromissen“, nach denen der Adel zwar bürgerliche Beamte einstellte, sich aber gesellschaftlich umso deutlicher abgrenzte. ${ }^{382}$ Auch Veit fand in Weimar noch das absolutistische Prinzip vom Volk als fernen Betrachter des Adels: „Diesen hohen Adel habe ich gestern bei der Herzogin in einem Saale speisen sehen, über welchem eine Galerie für die Zuschauer erbaut ist“"383. Wesentlich schärfer und ironischer fasste es fast zur gleichen Zeit der Student Joseph Rückert: „Es wecket und nähret eine günstige Stimmung unter den niedern Klassen, die [...] bei dem Anblick der unter ihren Augen schleppenden Pracht und des schwülen, umgebenden Hofglanzes ihren bequemern Zustand von der freien Galerie des Lebens herab nicht anders als gesegnet und glücklich finden können“. ${ }^{384}$ Rückert stellte überrascht fest, dass die scharfen Gegensätze in Weimar nicht zu Aufruhr führten, wie andernorts. Allerdings fügte er sachlich hinzu: „Auf der Galerie [...] sind, um Unordnungen zu vermeiden, Wachen aufgestellt und die Geschlechter getrennt“. .385

Auch der Ort, der für die Berliner Salongesellschaft immer wieder als Thema und Attraktion wesentlich wurde, das Goethe-Haus am Frauenplan, 386 war unterschiedlich leicht zugänglich: Für einen jüdischen Studenten aus Berlin, wie David Veit, war Goethe durch ein Empfehlungsschreiben für einen Besuch in seinem eigenen Haus erreichbar, wobei Veits weitläufige Verwandtschaft mit Moses Mendelssohn und die Bekanntschaft mit Salomon Maimon das ihre dazu tat und ein Brief des Letzteren sein ,Eintritssbillet‘ in das Goethehaus wurde. ${ }^{387}$ Daneben erwies es sich als möglich, Goethe an ausgewählten

382 Kopfermann / Steinbach 1992, S. 18.

383 David Veit an Rahel Levin Varnhagen, 20. 3.1793, in: GW VII/I, S.7. Hervorhebung H. L. L. 384 Rückert 1970. S. 91. Joseph Rückert war 1794 als Student nach Jena gekommen und dann Hauslehrer in der Nähe Weimars. Seine Bemerkungen erschienen erstmals 1799.

385 Rückert 1970, S. 93.

386 Das jetzige Goethe-Nationalmuseum in Weimar zeigt noch zahlreiche Räume in der Originalausstattung auch aus dieser Zeit. Goethe hatte das Haus 1782 bezogen, erhielt es 1792 als Dienstwohnung zur Miete, 1794 geschenkt und ließ es bis 1795 nach italienischem Vorbild umbauen.

387 David und sein Onkel Simon Veit besuchten Goethe im März 1793 mit einem Empfehlungsschreiben von Karl Philipp Moritz, den Goethe aus Italien kannte. Simon Veit war der Gatte Dorotheas, der Tochter Mendelssohns. Im weiteren Verlauf der Bekanntschaft wurde er mehrfach von Goethe auf Maimon angesprochen. 
öffentlichen Orten zu treffen, zum Beispiel in den Anatomievorlesungen (in Jena) oder vor allem im Theater. Während in Berlin für solche ,erwünschten Zufälle، das Theater ein potentieller Treffpunkt unter mehreren war, war es in Weimar der einzige öffentliche Ort, der beiläufige Bekanntschaften und Unterhaltungen zwischen Personen verschiedenen Standes erlaubte. ${ }^{388}$

Als adligem Schweden sollte sich einem anderen Freund Levin Varnhagens, dem Salongast von Brinckmann, zwei Jahre später die Möglichkeit bieten, Goethe bei Hofe oder bei Mitgliedern des Hofes zum Diner zu begegnen. Er konnte sich auch selbst im Goethehaus einladen bzw. sich ankündigen, indem er sich auf die Freundschaft zu Humboldt berief. ${ }^{389}$ Humboldt selbst war als Schillerfreund und hervorragender Kenner antiker Dichtung schnell zum begehrten Arbeitspartner Goethes geworden und wurde über diesen auch bei der Herzogin zu Tisch gebeten. 390 Die räumliche und inhaltliche Nähe zwischen Goethe, Schiller und auch Wilhelm von Humboldt lässt sich aus jedem Brief des Goethe-Schiller-Briefwechsels dieser Zeit ablesen. ${ }^{391}$ Die Weimarer Gesellschaft wurde schließlich gelegentlich als Testpublikum der Horen-Texte genutzt, zum Beispiel, indem Goethe der von ihm installierten Freitagsgesellschaft aus den Manuskripten vorlas, ohne den Autor zu verraten; auch dem Hof muss er Vorabveröffentlichungen mündlich oder schriftlich zukommen lassen haben, denn er berichtete Schiller mit Vergnügen, welchen „Rumor“ die Horen bei Hofe gemacht hätten. 392

388 Veit, der noch bei seinem ersten Besuch in Weimar seiner Freundin erzählte, dass die Bekanntschaft Goethes sehr schwer zu machen sei, berichtete später von mehreren kurzen Gesprächen mit Goethe im Theater, der dort „auf dem Platz des Adels“ saß, aber gelegentlich auch zu Personen, die ihn interessierten, in die Loge kam, auch einmal zu David Veit. David Veit an Rahel Levin Varnhagen, 20.10. 1794, in: GW VII/I, S. 244 f.

389 Am 17. 2. 1798 kündigte Brinckmann sein Kommen an und bat um Besuchsmöglichkeit, er rechne dabei auf „Güte gegen die gemeinschaftlichen Freunde“. Geiger 1896(a), S. 43. Bis 1804 folgten gelegentliche Briefe, die sowohl literarische Themen, als auch Klatsch über Berlin und gemeinsame Bekannte enthielten.

390 Vgl. zu dieser Beziehung zuletzt: Ernst Osterkamp: Gesamtbildung und freier Genuß. Wechselwirkungen zwischen Goethe und Wilhelm von Humboldt, in: Osterkamp 2002, S. 133-154.

391 Die Distanz zwischen Weimar und Jena ließ sich von der Post in einem Tag überwinden, sodass ein morgens abgesandtes Manuskript abends schon ausgelesen sein konnte. Oft genug wurde ein noch schnellerer Kontakt hergestellt, in dem ein Dichter zu dem anderen herüberritt oder -wanderte. Schließlich fielen in diese Zeit mehrere gemeinsame Arbeitsaufenthalte.

392 Vgl. z. B.: „[...] ich las ein Stückchen davon in meiner gestrigen Gesellschaft vor, ohne zu sagen woher es komme noch wohin es gehe. Man gab ihm viel Beifall.“ Johann Wolfgang von Goethe an Friedrich von Schiller, 28. 2. 1795, in: Manfred Beetz (Hrsg.): Briefwechsel 


\section{2, „[...] mit Humboldt au niveau stehen“ - David Veit, Rahel Levin Varnhagen, Wilhelm von Humboldt und Kommunikation über „ein Drittes“}

Ich weiß nämlich den Ton nicht zu bestimmen, aus welchem der Brief klingen muss; ich weiß eigentlich gar nicht recht, wie ich mit ihm stehe.

David Veit über Wilhelm von Humboldt 393

Das Verhältnis zwischen den beiden Salongästen David Veit und Wilhelm von Humboldt in Jena wirft ein bezeichnendes Licht auf die tatsächlich möglichen Kontaktebenen zwischen einem jüdischen Studenten und einem adligen Privatgelehrten.

Aus Berliner Kreisen flüchtig mit ihm bekannt, hatte David Veit Humboldt um ein Empfehlungsschreiben für Professoren an dessen ehemaliger Universität Göttingen gebeten und bekommen. Mehrere Briefe zwischen Veit und Levin Varnhagen wurden der Überlegung gewidmet, wie Veit sich bei Humboldt dafür bedanken könne, welche Formulierungen und Anreden zu brauchen seien. ${ }^{394}$ David Veit betrachtete seine Freundin hier eindeutig als Mentorin in Umgangsformen, die ihm dann auch empfahl: „Sie emanzipiren sich“.395 Zugleich aber mahnte sie die gesellschaftliche Verpflichtung an: Humboldt eventuell nicht zu schreiben sei „himmelschreiend, denn es kann Ihnen nebenher von reellem Schaden sein“. 396

Die Einschätzung Humboldts durch seine ehemalige Gastgeberin war zugleich abgewogen und pragmatisch: „so unsicher nun einmal seine Passion ist, sich durch sein Gespräch auszugeben, so sicher und gewiß thut er Ihnen gewiß immer alles zum Vortheil was er kann, und dass er oft viel kann, werden Sie wissen“. ${ }^{397}$ Mit der berechtigten Überlegung, dass Humboldt die Empfeh-

zwischen Schiller und Goethe in den Jahren 1794 bis 1805. Die Münchener Ausgabe erstmals im Taschenbuch, 2 Bde., München [u. a.] 2005, Bd.1, S. 66. Der weiter unten zitierte Brief vom 18. 3. 1795, ebd., Bd.1, S. 70.

393 David Veit an Rahel Levin Vanrhagen, 16. 1. 1794, in: GW VII/I, S. 112; Das Zitat in der Überschrift: David Veit an Rahel Levin Varnhagen, 5. 1. 1795, in: GW VII/II, S. 61.

394 Die briefliche Beratung ist ebenso detailliert wie offenherzig: „Humboldt hat mir Empfehlungen mitgegeben, die mir hier sehr nützlich waren.“ David Veit an Rahel Levin Varnhagen, 27. 11. 1793, in: GW VII/I, S.64. Und: „[...] besonders da er verheirathet ist und sich, trotz aller vorgefallenen Vorfallenheiten, seine Titel eben so ungern nehmen lässt als jeder andere; und dennnoch muß der Brief selbst ein ungezwungenes, freundschaftliches, und subalternes Ansehen haben." David Veit an Rahel Levin Varnhagen, 16 .1. 1794, in: GW VII/I: 112 .

395 Rahel Levin Varnhagen an David Veit, 26.1.1795, in: GW VII/I, S. 126.

396 Rahel Levin Varnhagen an David Veit, 31. 12. 1793, in: GW VII/I, S. 77.

397 Rahel Levin Varnhagen an David Veit, 31. 12. 1793, in: GW VII/I, S. 77. 
lung auch aus Eigeninteresse geschrieben habe, um Kontakte in Göttingen wieder neu zu knüpfen, empfahl Rahel Levin Varnhagen schließlich einen Dankesbrief mit voller Titulatur, einfachem Stil und den gewünschten Informationen. Ihre ausführliche Anweisung liest sich wie ein Briefsteller zum natürlichen Freundschaftsbrief, dem Anlass, nicht dem Adressaten entsprechend zu schreiben, und endete mit dem bemerkenswerten: „[...] wie Sie mit ihm stehen wollen, bestimmen Sie“.398 Damit wurde der Brief eindeutig zum Werkzeug, zum Mittel, eine (neue) Kontaktebene zu schaffen.

Mit dem Brief, den Veit ihr schließlich in Abschrift beilegte, zeigte sie sich nicht ganz zufrieden. Veit aber wollte Humboldt nicht devoter als nötig entgegenkommen, denn er „habe wichtigere Empfehlungen gehabt“.399

Als Veit seinen Studienort von Göttingen nach Jena verlegte, kam es dann zu einem regelmäßigen Umgang mit Humboldt, den Veit seiner Freundin gegenüber zunächst als rein pragmatisch begründet erklärte. Humboldt besuchte medizinische Kollegien der Universität aus Privatinteresse, sodass es zu fachlichen Gesprächen und gelegentlichen Einladungen zu ihm nach Hause gekommen sei. Nicht ganz ohne Stolz berichtet Veit wenig später: „Bei Humboldt genieße ich alle mögliche Freundschaft".400 Dass Veit aber bei Humboldts nur erschien, wenn er gebeten wurde, und auch dann nicht immer, billigte Levin Varnhagen als die beste Umgangsform, denn man solle solche Freundschaften nicht überstrapazieren: „[...] verlassen Sie sich nicht zu sehr auf sich, und das Verhältniß, was zwischen Ihnen sein kann, und sein Sie immer fein, zurückhaltend, artig (im Systemsinne, lieber Jünger), und was er sich erlaubt (im Urtheil hauptsächlich), erlauben Sie sich nicht“. 401 Bei dieser Gelegenheit formulierte sie eine gesellige Einsicht, die als Motto ihres eignen Kreises gelten könnte: „[...] dass nur mit Menschen häufig umgehen Freud bringt, wo man immer sich zeigen kann wie man ist, wenigstens ohne alle Gefahr, große und kleine“.402

Veit stellte mehrfach fest, dass er nicht Humboldts Lebensart besäße, nichtsdestotrotz erhielt er persönliche Einblicke in dessen literarische und wissenschaftliche Pläne, die er nach Berlin korrespondierte. Auch mit Alexander

398 Rahel Levin Varnhagen an David Veit, 26. 1. 1794, in: GW VII/I, S.125. „So kann man in einem gelehrten oder freundschaftlichen Briefwechsel an einen König schreiben.“ Ebd.

399 David Veit an Rahel Levin Varnhagen, 4. 3. 1794, in: GW VII/I, S. 191.

400 David Veit an Rahel Levin Varnhagen, 21. 10. 1794, in: GW VII/I, S. 246.

401 Rahel Levin Varnhagen an David Veit, 16. 11. 1794, in: GW VII/II, S. 13. Schreibung im Original.

402 Rahel Levin Varnhagen an David Veit, 26. 12. 1794, in: GW VII/II, S. 50. Hervorhebung im Original. 
von Humboldt hat Veit vermutlich wissenschaftliche Gespräche geführt, da er ihm seine Dissertation widmete. 403

Wilhelm von Humboldt zeigte sich David Veit gegenüber ausgesprochen interessiert und höflich, hieß ihn als seinen Tischgast häufig willkommen, denn „Veit ist ein sehr guter Kopf und ich thue für ihn, was ich kann“.404 Allerdings konnte er sich, wie in Kapitel IV näher ausgeführt, nicht zurückhalten, konsequent die jüdische Identität seines Gastes zu betonen.

Bezeichnend für Berliner Verhältnisse ist die Reaktion im Hause Herz, dessen Gäste, wie Rahel Levin Varnhagen berichtete, die Nachricht über den Umgang zwischen Veit und Humboldt „ehrerbietig“ und zum Teil „schafig“ aufnahmen. ${ }^{405}$ Erhellend für die Verhältnisse in Weimar und Jena ist hingegen vor allem die Selbstpositionierung Veits zu Humboldt und Goethe. Er schrieb, nachdem Goethe ihn mitten im Gespräch hatte stehen lassen: „Sie können gar nicht glauben, wie ich noch immer geängstigt bin, ohngeachtet ich schon von Humboldt, der ihn jetzt genau kennt, die Versicherung habe, dass er oft so schnell weggeht, da Humboldt es schon auf sich genommen hat, noch einmal mit ihm von mir zu sprechen“.406 Und zur Tatsache, dass Goethe sich zu ihm in die Loge gesetzt hatte, schrieb Veit: „Die Menschen in Weimar sagen alle, ich müsse Eindruck auf ihn gemacht haben; so etwas thäte er nur seinen Lieblingen: Humboldt schreibt es einer ungewöhnlichen Laune und seiner Liebe für Maimon zu. Denken Sie nun - erst das Vergnügen und nun die Angst“!407

Das Verhältnis Rahel Levin Varnhagens zu diesen beiden Männern macht deutlich, dass ,Salonkommunikation' auf direkten und indirekten Wegen erfolgen konnte: Selbst standen sie und Humboldt aus nicht bekannten Gründen nicht im Briefkontakt, 408 über Veit aber gelangten ihre Urteile unmittelbar und oft in direkter Rede an den jeweiligen anderen. Beispielsweise kommunizierte

403 Vgl. die Widmung „Illustrissimo Domino F. A. de Humboldt [...] viro de scientia naturali optime merito" auf dem Vorblatt der gedruckten Dissertationsschrift von David Veit:

Dissertatio Inauguralis Medica [...] Examini Subjicit Auctor David Veit Vratislaviensis, Halle 1797.

404 Wilhelm von Humboldt an Gustav von Brinckmann, 3. 11. 1794, in: Leitzmann 1939, S. 80 .

405 Der Buchhändler Michaelis habe von Veit berichtet: „,Er sieht aber niemand, und studirt fleißig [...] außer Hrn. von Humboldt besucht er niemanden. ' Nun wurden alle Gesichter ehrerbietig und approbirend.“ Und: „Hr. Michaelis sah zu schafig aus“, Rahel Levin Varnhagen an David Veit, 1. 11. 1794, in: GW VII/I, S. 266.

406 David Veit an Rahel Levin Varnhagen, 20. 10. 1794, in: GW VII/I, S. 245

407 David Veit an Rahel Levin Varnhagen, 20. 10. 1794, in: GW VII/I, S. 245

408 In der Sammlung Varnhagen sind neben vielen anderen Manuskripten von Wilhelm von Humboldt nur je ein Brief an Rahel Levin Varnhagen vom 20.1. 1797, und einer anno 1809 überliefert, SV 89. 
Levin Varnhagen 1794 mit Humboldt via Veit über Jacobis Woldemar, ein damals vielgelesenes Buch. ${ }^{409}$ Humboldt hatte eine Rezension zu dem Roman verfasst, die Levin Varnhagen weitaus geistreicher fand als das Buch selbst. Die Rezension war ihr von Veit und Brinckmann gleichzeitig empfohlen worden. Dass ihr dabei manches zu „dunkel“ sein könnte, wie Veit vermutet hatte, wies sie strikt zurück. Sie habe es gleich verstanden, Humboldt dadurch erst kennengelernt, und ihn gegenüber ihren Bekannten verteidigt. ${ }^{410}$ Von Veit wie üblich um ihre Meinung zu aktuellen Werken gebeten, schrieb sie darüber hinaus über mehrere Tage an einem ausführlichen Kommentar in ihrem Antwortbrief, sozusagen eine Rezension der Rezension. ${ }^{411}$ Diesen Brief hatte Veit, vermutlich nicht zufällig, in der Tasche, als er Humboldt das nächste Mal besuchte und machte ihn auf eine Art neugierig, dass Humboldt um auszugsweises Vorlesen bitten musste. ${ }^{412}$ So erfuhr Humboldt, dass Rahel Levin Varnhagen seinen Text schätze, weil er darin bestimmt habe, was Menschenkenntnis eigentlich sei. Wiederum über Veit ließ Humboldt der Verfasserin ausrichten, dass er ihr Urteil höchst zutreffend fände - was bei ihrer rein positiven Wertung nicht verwundern muss - und dass er ihr ein richtiges Urteil schon zugetraut habe, obwohl sich ihr als Frau dabei Schwierigkeiten in den Weg stellten. Rahel Levin Varnhagen, die zunächst vorgab, dass ihr dies Vorgehen, das Vorlesen und Diskutieren ihres Textes, völlig gleichgültig sei, „denn auf nichts in der Welt hab' ich weniger Anspruch zu machen, als auf ein litterarisches [Urteil]“", drängte Veit dann doch zu mehr Details dieser Begegnung. ${ }^{413}$ So musste sie lesen, dass Veit ihren Brief deswegen vorgelesen, damit Humboldt ihre Literaturkenntnis erführe und „schon darum, damit er Sie nicht, wie es mir schiene, für bloß witzig halte“. ${ }^{414}$ Sie erfuhr auch, dass der Anwalt ihrer Bildung, um den Eindruck noch zu verbessern, während des Vorlesens ihre

409 Friedrich Heinrich Jacobi: Woldemar. Königsberg 1794. Eine erste Ausgabe war 1779 erschienen.

410 „Weh mir, mit was für Menschen ist man umgeben! [...] für so dumm habe ich sie Alle doch nicht gehalten. [...] die Menschenkenntnis wollten sie ihm absprechen. Hat er denn mit ihnen nie gesprochen, wie er in dieser Rezension geschrieben hat?“ Rahel Levin Varnhagen an David Veit, 15. 11. 1794, in: GW VII/II, S. 6.

411 Vgl. Rahel Levin Varnhagen an David Veit, 15. 11. 1794, in: GW VII/II, S. $1 \mathrm{ff}$. 412 „Ich war einen Abend bei Humboldt, eben da ich Ihren Brief in der Tasche, oder vielmehr, expreß mitgenommen hatte, und sagte ihm, ich hätte einen Brief, der ihn interessierte." David Veit an Rahel Levin Varnhagen, 20. 12. 1794, in: GW VII/II, S. 40. 413 Rahel Levin Varnhagen an David Veit, 10. 12. 1794, in: GW VII/II, S. 28. 414 David Veit an Rahel Levin Varnhagen, 20.12. 1794, in: GW VII/II, S. 40. 
„Exklamationen“ weggelassen und das Deutsch korrigiert habe.415 Damit gab Veit bereits bei dieser allerersten Veröffentlichung eines ,Raheltextes“ das paradoxe Muster vor, das spätere Herausgeber befolgen würden: Um die Originalität des Inhalts zur Geltung zu bringen, wurde die Form ,standardisiert‘. Allerdings gab er als Begleitmotiv zugleich an, sie solle „niemals tief unter Humboldt zu stehen scheinen; und das schienen Sie allerdings, wie Sie ihn so sehr bewunderten“.416 Auch Humboldt hatte zunächst den Schicklichkeitsvorstellungen der Zeit entsprechend reagiert und gefürchtet, wenn Levin Varnhagen von dieser „Veröffentlichung“ erführe, würde sie keine solchen Briefe mehr schreiben - womit er sich irrte. Rahel Levin Varnhagen selbst fand beider Bedenken zwar unnötig, ging aber dann nicht weiter darauf ein. Sie betonte, es sei ihr das Wichtigste, auf diesem Wege Humboldt wirklich kennengelernt zu haben.417

Mehrfach im Briefwechsel mit Veit war sie auf den scheinbaren Widerspruch eingegangen, dass ein gewisser Abstand Menschenkenntnis erst möglich mache und man sich im Brief oft persönlicher begegnen könne als im Gespräch. Im Zusammenhang mit Wilhelm von Humboldt bekam diese Feststellung noch eine besondere Note. Sie fasste es in den Vergleich: „Ein Wald von Freunden, die unter ihren Schatten mich hielten, hinderten mich gutmeinend, mich an den Strahlen seiner Sonne auch zu beleben“. ${ }^{418}$ Dies klingt wie eine Ahnung, dass solche Sonne auch brennen kann - wie die Aussagen ihrer Freunde Brinckmann und Gentz belegten, die nur wenig später Rahel Levin Varnhagen vor dem „Hass“ ihres gemeinsamen Freundes Humboldt schützen zu müssen glaubten. ${ }^{419}$

1794 blieb es in beiden Richtungen bei Bewunderung auf Distanz, vermittelt über David Veit, den man hier durchaus als Medium der Kommunikation bezeichnen kann.

Zusammenfassend lässt sich sagen, dass sowohl Rahel Levin als auch David Veit der Unterschied ihrer Lebenswelt zu der eines Humboldt, trotz zahlreicher gemeinsamer Berührungspunkte, durchweg sehr bewusst war. Das hin-

415, ,...] ich habe alle Exklamationen weggelasen und alles unrichtige Deutsch in richtiges verwandelt, wiewohl ich Sie versichern kann, dass Ihnen selbst zum richtig Schreiben nicht viel mehr fehlt.“ David Veit an Rahel Levin Varnhagen, 1. 12. 1794, in: GW VII/II, S. 22. Hervorhebung im Original.

416 David Veit an Rahel Levin Varnhagen, 20.12. 1794, in: GW VII/II, S. 42.

417 „Warum glauben Sie mir nicht, wenn ich Ihnen sage, dass ich Humboldt nie gekannt habe, und ihn erst aus dieser Zeitung habe kennen lernen." Rahel Levin Varnhagen an David Veit, in: GW VII/II, S. 51.

418 Rahel Levin Varnhagen an David Veit, 26.12. 1794, in: GW VII/II, S. 51.

419 Humboldt sollte sich unter anderem von der Mischung der Gäste bei Levins irritiert zeigen, vgl. Kapitel V. 
derte sie nicht daran, diesen Kontakt zu nutzen und, im Falle Veits, gelegentlich den Umgang Humboldts $\mathrm{zu}$ genießen. Es hinderte sie ebenfalls nicht daran, den Charakter und die Lebensweise Humboldts gleichberechtigt neben den näherer Freunde ausführlich zu diskutieren. Im Wortlaut des Briefwechsels gesprochen, ließe sich sagen, dass sich die Briefpartner menschlich und in ihren sozialen Fähigkeiten durchaus als Humboldt gleichberechtigt, wenn nicht ihm voraus betrachteten, dass gerade die Person Wilhelm von Humboldts ihnen aber 1795 den gesellschaftlichen Unterschied der Stände und der sozialen Möglichkeiten sehr bewusst machte. Dieses Bewusstsein sprach Rahel Levin Varnhagen an, wenn sie David Veit ermahnt, er müsse sich davon „emanzipiren“, um Humboldt einen guten Brief schreiben zu können.

\section{3 „Ich werde die Horen schon bekommen; und wenn auch für ... mein Taschengeld." - Die Rezeption der „Horen“ durch die Berliner Salongesellschaft}

Die Horen, 420 das erste und vielleicht umstrittenste publizistische Projekt der Weimarer Klassik, wurden im Juni 1794 entworfen und erschienen bis 1798. In den hier interessierenden Zeitabschnitt fallen intensive Diskussionen zwischen Schiller, Goethe und Humboldt, ob und wie auf die spezielle Rezeption der ersten Hefte zu reagieren sei. Das Konzept der Zeitschrift, philosophische und poetische Texte in einer Schreibart zu vereinigen, die sowohl das Interesse der Gelehrten als auch des nicht gelehrten Publikums wecken sollte, die programmatische Absage an die Behandlung politischer Themen, und die Ankündigung, dass hier ,die vorzüglichsten Schriftsteller der Nation in eine literarische Assoziation“ zusammenfanden, hatten für anfänglich großen Absatz gesorgt. ${ }^{421}$ Zugleich boten die vollmundige Ankündigung der Zeitschrift, „die politisch geteilte Welt unter der Fahne der Wahrheit und Schönheit wieder zu vereini-

420 Die Zeitschrift wurde benannt nach den drei Töchtern des Zeus Eunomia, Dike und Irene, Vergöttlichungen der gesetzlichen Ordnung, der Gerechtigkeit und des Friedens. „Taschengeld“ nach: Rahel Levin Varnhagen an David Veit, 15. 11. 1794, in: GW VII/II, S. 18. 421, ,...] !vorzüglich aber und unbedingt wird sie sich alles verbieten, was sich auf Staatsreligion und politische Verfassung bezieht.“ Friedrich von Schiller: „Einladung zur Mitarbeit“, 13. 6. 1794, in: Schulz 1960, S. 211 ff., hier S. 211. Für eine kritische Zusammenfassung des Forschungsstandes zur Politik-Abstinenz der Klassik vgl. Kall 2004, S. $146 \mathrm{ff}$. Die poetischste Verteidigung für Schillers Entscheidung findet sich bei Thomas Mann: „[...] das ist nicht Flucht aus der Wirklichkeit ins Müßig-Schöne, es ist bewahrender Dienst am Leben, der Wille es zu heilen von Angst und Haß durch seelische Befreiung.“ Thomas Mann: Versuch über Schiller. Seinem Andenken zum 150. Todestag in Liebe gewidmet, Berlin [u. a.] 1955, S. 100. 
gen“, und die Liste der angefragten Autoren Kritikern einen guten Ausgangspunkt und Maßstab für ihre Verbesserungsvorschläge. Das Interesse am Projekt konzentrierte sich bald mehr auf die Urheber bzw. die Tatsache, dass sich Goethe, Schiller und andere bekannte Autoren in einem Projekt vereinigt hatten, als auf das Ergebnis. Bereits im März berichtete Goethe, dass es „im Weimarischen Publico“ gewaltig rumore, „mir ist aber weder ein reines pro noch contra vorgekommen, man ist eigentlich nur dahinter her".422

Die untersuchten Briefwechsel bieten zahlreiche Hinweise darauf, dass die Horen von Teilnehmern der Berliner Salongesellschaft sehr zeitnah rezipiert wurden. Bereits in der Entstehungsphase wurde das Projekt mit großem Interesse verfolgt. Es gab vielfältige personelle Verbindungen zu diesem Projekt, von den um Mitarbeit gebetenen Berliner Schriftstellern verkehrten zumindest Maimon und Gentz gelegentlich im Hause Herz und waren Rahel Levin Varnhagen von Person bekannt. In der Person Wilhelm von Humboldts war ein ehemaliger Salongast nicht nur als Autor beteiligt, sondern die Berliner hatten mit ihm durch die intime Nähe zu Schiller buchstäblich ein Ohr und Auge am Schreibtisch des Herausgebers. Genauer gesagt: hätten haben können, denn tatsächlich berichtete Humboldt in seiner Jenaer Zeit nur wenig und nur ausgewählten Freunden über seine Arbeiten nach Berlin, vor allem an Brinckmann, der so als guter Kenner der Weimarer Verhältnisse galt. ${ }^{423}$ Neben Brinckmann, und mehr als dieser, wurde David Veit zum Informationskanal. Anfang Juli hatte Schiller Voranfragen an potentielle Autoren geschickt, bereits im Oktober machte Veit seine Freundin auf das Projekt aufmerksam: „Habe ich Ihnen nicht geschrieben, daß Schiller ein Journal herausgiebt, woran Goethe und alle Menschen arbeiten?"“24 Veit regte an, sich rechtzeitig um ein Abonnement zu kümmern, obwohl er den Preis zu hoch fand, und Rahel Levin Varnhagen beschloss noch bevor das Journal auf den Markt kam, es unbedingt zu erwerben, und sei es für ihr „Taschengeld““ ${ }^{425}$ Wohl in dem Bewusstsein, dass seine Briefe zum

422 Johann Wolfgang von Goethe an Friedrich von Schiller, 18. 3. 1795, in: Beetz 2005, Bd.1, S.70, Hervorhebung im Original.

423 So ging Veit davon aus, dass Brinckmann seine Freundin über die Anonyma in den „Horen“ bzw. „Xenien“ aufklären könne. David Veit an Rahel Levin Varnhagen, 1. 10. 1796, in: GW VII/II, S. 231.

424 David Veit an Rahel Levin Varnhagen, 23. 10. 1794, in: GW VII/I, S. 254. Dass Goethes Mitarbeit, über den jede noch so kleine Information zu berichten Rahel Levin Varnhagen ihren Freund ausdrücklich gebeten hatte, besonders attraktiv für die potentielle Leserin sein würde, konnte Veit als wahrscheinlich annehmen. Im weiteren Verlauf sollten die Freunde allerdings an ganz verschiedenen Aufsätzen der Zeitschrift Interesse zeigen.

425 „Wo werd' ich Schiller’s Journal herkriegen, ich bin von Gott und Menschen verlassen.“, Rahel Levin Varnhagen an David Veit, 31. 10. 1795, in: GW VII/I, S. 263. 
Teil auch der Familie Levin zur Kenntnis gelangten, baute Veit eine indirekte Mahnung an den Haushaltsvorstand und Bruder ein:

Schiller’s Journal wird „Die „Horen“ heißen und jeder Mensch wird es haben. Goethe arbeitet rasend viel mit daran; wenn ich Ihres Bruders Schwester wäre, oder auch nur ich Veit in Berlin, sollte es Markus wohl von Anfang an halten, besonders da die Thalia eingeht, der Merkur schlecht wird, und dieses Journal gewiß lange gut bleiben wird“.426

Der ,Trick، wirkte, einen Monat später konnte Rahel Levin Varnhagen melden, dass ihr Bruder die Horen halte. Es kann als typisch für die gesamte briefliche Beziehung zwischen Rahel Levin Varnhagen und David Veit gelten, dass er sich auf verschiedenen Wegen für ihre Lektüre engagierte. Die Anschaffung der Horen war aber eine der wenigen Gelegenheiten, bei denen sich Veit nicht nur für seine Freundin einsetzte, sondern an ihrem weniger textinteressierten Umfeld deutlich Kritik übte: „Vielleicht kommt er darauf dass man trotz der Vatersorgen noch Zeit hat, für seine eigene Bildung zu arbeiten, dass die Faulheit an einem Menschen, dem der Zufall gute Ideen gegeben hat, hart an das Unanständige gränzt“. 427

Hier sprach sowohl der jüdische Aufklärer, der es nicht verstand, wenn Bildungschancen vernachlässigt wurden, als auch der Anwalt der weiblichen intellektuellen Freunde.

Nach Erscheinen wurden die jeweiligen Nummern im Kreis der Rahel Levin Varnhagen gleich gelesen, herumgereicht und diskutiert. Sie selbst war so neugierig auf manche Stücke, dass sie sie noch bei ihrem zweiten treuen Literaturlieferanten Brinckmann anfragen ließ, bevor ihre eigene Ausgabe kam. ${ }^{428}$

Als Ausdruck besonderer Qualität oder besonderer Neugierde lässt sich deuten, dass Rahel Levin Varnhagen sich die Zeitschrift von Brinckmann sogar

426 David Veit an Rahel Levin Varnhagen, 10. 11. 1794, in: GW VII/I, S. 273.

427 David Veit an Rahel Levin Varnhagen, 5. 1. 1795, in: GW VII/II, S. 62.

428 „Es würde niemand die „Horen“ genießen, wie es mit vielen Dingen geht, wenn ich auch Edelsinn hätte. Sie werden gewiß zufrieden sein, mir ein so großes Vergnügen zu machen; denn ich habe ein unbeschreibliches, sie schon heute Abend zu lesen. Sobald - es wird morgen seyn - wir unsre haben, schick ich Sie Ihnen zurück: Heute sind Sie ja beym König und lesen diesen Abend nicht.“ Ihr Lesetempo bezeugen zwei andere Kurznachrichten, die im Abstand von zwei Tagen verfasst wurden. Am Mittwoch fasste das Billet die Bitte: ///,Haben Sie die Güte, mir die „Horen“ zu schicken, wo Benvenuto Cellini darin steht. Ich will Sie Ihnen halten, als ob Sie sie in Ihrem Bücherschrank hätten. Wie haben Sie Ihre Kopfweh schlafen lassen?“/// Und zwei Tage später hieß es: ///,Freitag. Ich sage Ihnen den besten Dank für die „Horen“; und bitte zugleich um Vergebung, dass ich sie solange behalten habe. Für die künftigen bedanke ich mich, weil ich sie bis zum Stück, wo die Agnes anfängt, aus meines Bruders Sammlung gelesen habe. Bon jour. RL.“/// An Gustav von Brinckmann, Berlin, undatiert [20., 22. u.23. 3. 95, einsortiert nach dem 19. 3., datierbar wegen der Erwähnung des Cellini], ungedruckt, SV 38. 
ins Bad nachsenden ließ, und dies, obwohl David Veit scherzhaft gemeint hatte, die Horen seien „kaum für eine Badekur“.429

Allgemein war Schillers Ankündigung in Berlin auf großes Interesse gestoßen, die Zahl von 133 Abonnenten wurde nur von 150 in Leipzig übertroffen. Besonders bemerkenswert am Subscribentenverzeichnis ist die einzige bürgerliche Frau unter den selbstständigen Abonnenten, mit Lieferadresse in Neustrelitz: Dorothea Veit, geborene Mendelssohn aus Berlin. Leider sind aus dieser Zeit keine Kommentare zu der Zeitschrift von ihr überliefert.

Das Interesse des Publikums wurde auch unter den ausgesuchten Sprechern anscheinend besonders angeregt durch die angekündigte Anonymität der Autoren. Rahel Levin Varnhagen nutzte ihren ,guten Draht‘ zur Redaktion aus, wenn sie Veit bat: „Haben Sie doch die Güte, mich immer bei Gelegenheit wissen zu lassen, von welchen Meistern die Sachen in den ,Horen“ sind; Sie werden das gewiß erfahren, die Leser aber, wie man sagt, erst am Ende jedes Jahrgangs“. ${ }^{430}$ Veit entsprach der Bitte, allerdings mit dem Hinweis: „Sagen Sie es keinem der sie nicht recht versteht; überhaupt nicht, dass Sie diese Namen mit Gewißheit und von mir wissen; es ist mir zwar nicht recht verboten, und wird eben nicht als Geheimnis behandelt; aber außer Ihrem Zirkel möchte man sich nicht erklären können u.s. w. [...]““431

So blieben die Berliner Leser mit den Weimarer Autoren in enger Verbindung. Nicht nur ließ sich die Berliner Salongesellschaft gern mit Hintergrundinformationen auf dem Laufenden halten, auch waren die Autoren besonders an der Rezeption in den Salons interessiert. Bereits im Vorfeld hatten einige Salonbeteiligte in privater Korrespondenz Anzeige von dem Projekt bekommen, mit der Bitte die Ankündigungen der Horen ,gelegentlich Ihren Bekannten auszuteilen“.432 Nach Erscheinen der ersten Hefte wurde Marianne Meyer Eybenberg von Goethe selbst um einen Kommentar gebeten, Humboldt fuhr regelmäßig von Tegel nach Berlin, um den Eindruck der jeweiligen Stücke zu erfahren und an Schiller melden zu können - niemals ohne Hinweis auf das seiner Meinung nach Beschränkte des hauptstädtischen Publikums: „Ich war indeß Einen Tag in Berlin und melde Ihnen doch einige possierliche Dinge. Zuerst über die ,Horen'. Nichts als was wir längst hörten. Die ,Unterhaltungen“ mißfallen durchaus und total, auch der Prokurator. Man klagt im Ganzen über Mangel an Leichtigkeit [...]““.433 Rahel Levin Varnhagen muss der Bitte nach Geheimhal-

429 David Veit an Rahel Levin Varnhagen, 15. 6. 1795, in: GW VII/II, S. 157.

430 Rahel Levin Varnhagen an David Veit, 26. 12. 1794, in: GW VII/II, S. 56.

431 David Veit an Rahel Levin Varnhagen, 28.1.1795, in: GW VII/II, S. 67.

432 Wilhelm von Humboldt an Gustav von Brinckmann, 22. 12. 1794, in: Leitzmann 1939, S. 81 .

433 Dies und die zwei folgenden Zitate: Wilhelm von Humboldt an Friedrich von Schiller, 17. 7. 1795, in: Leitzmann 1900, S. $60 \mathrm{f}$. 
tung nachgekommen sein, denn zumindest im Hause Herz war man „über die Verfasser [...] in der größesten Verwirrung gewesen.“ Auch ohne Kenntnis der Autoren wurde Kritik deutlich formuliert: „Herz hat über Ihre Briefe und über Anmuth und Würde ein eignes Gleichnis gebraucht. Man soll ein Gericht haben, wo Bambusrohr in Zucker und Gewürz eingemacht wird. Diesem gleichen Ihre philosophischen Schriften. Erst schmecken sie süß und zart, aber endlich bleibt etwas zurück, mit dem nun freilich nichts weiter anzufangen ist, weil es das bloße Holz ist.“ Humboldt berichtet dem Herausgeber Schiller mehrfach und ausführlich von Kommentaren aus dem Hause Herz zu den Horen. Es scheint ihm dieser Ort besonders wichtig oder vielleicht sogar repräsentativ für das anspruchsvollere Berliner Publikum gewesen zu sein. Zugleich aber nahm er Markus Herz als personifizierten Beleg dafür, dass hier noch der Geschmack einer anderen, der Aufklärergeneration, vorherrschend war, die für neue literarische Strömungen, als deren Teil sich Humboldt durchaus begriff, kein Verständnis hatte: „Herz sagte mir, nach dem gewöhnlichen Tribut des Lobes, er verstehe sie [Schillers Briefe, H. L. L.] nicht, und es sey eine schlimmere Undeutlichkeit als z. B. in Kant. [...] Im Grunde halte ich das Urtheil für sehr wahr, nur dass es mehr ein Urtheil über den Leser als über Sie ist“.434 Bezeichnend für Herz' Geschmack schien ihm, bei vergleichbarer Gelegenheit, das größte Kompliment, das dieser über einen Horen-Artikel machte, „den er mit recht großem Vergnügen gelesen und ganz verstanden habe. Er setzte, woraus Sie die Art dieses Urteils erkennen, hinzu, er habe in ihm die Art zu philosophieren wiedergefunden, an die man sonst durch Lessing, Mendelssohn usw. gewöhnt gewesen sei““435 Es scheint sich hier ein Generationskonflikt oder zumindest eine literarische Parteiung deutlich abzuzeichnen. ${ }^{436}$ Als denkenden Kopf akzeptierte Humboldt in dieser Hinsicht nur Friedrich von Gentz, der auf Schillers Briefe enthusiastisch reagiert habe. ${ }^{437}$ Das Urteil von Markus Herz ähnelte dem von Friedrich Nicolai über Schillers Briefe in Tendenz und Formulierung, auch dieser hatte ,die Deduktion derselben in der dunkelsten Schreibart vorgetragen“ gefunden, die nicht nur triviale Dinge hervorhebe,

434 Wilhelm von Humboldt an Friedrich von Schiller, 15. 8. 1795, in: Leitzmann 1900, S.75. 435 Wilhelm von Humboldt an Friedrich von Schiller, 20. 11. 1795, in: Leitzmann 1900, S. 224 .

436 Viele dieser Aufklärer und Besucher des Hauses Herz waren Humboldts Lehrer und Mentoren gewesen, die ihn u. a. mit Empfehlungsschreiben für seine Deutschlandreisen ausgestattet hatten und denen er eine grundlegende Kenntnis (spät)aufklärerischer Ideen verdankte, von denen er sich allerdings seit seinen Studienjahren zunehmend distanziert hatte. Vgl. zu diesem Thema Sauter 1989, bes. S. 39 ff.

437 Wilhelm von Humboldt an Friedrich von Schiller, 20. 11. 1795, in: Leitzmann 1900, S. 224 . 
sondern „beständig Missverständnisse veranlasst“.438 An anderer Stelle stand Herz für Humboldt symbolisch für die Naivität der altmodischen Berliner Intellektuellen: „Indeß sind auch die Berliner Gelehrten über diesen Punkt in einer ganz eignen wahren, oder affectirten Unschuld. So fragte mich Herz neulich in ganzem Ernst, ob denn Göthe in der That Geld nehme"?439 Dass Goethe doppelt so viel wie alle anderen Autoren der Horen bekam, hätten sich die Berliner Aufklärer vielleicht wirklich nicht denken können. Daß die Berliner jüdischen Salons, wie oft dargestellt, Goethe „als Clique seiner Anhänger“440 eine unumschränkte Verehrung entgegenbrachten, muss mit Blick auf die Horen-Rezeption differenzierter betrachtet werden. Markus Herz äußerte sich ironisch-kritisch, über Henriette Herz' Reaktion gibt es leider keine Quelle. Die Meinungen anderer Salonièren waren nicht einhellig: Wohl nannte Marianne Meyer Eybenberg an Goethe auf dessen Anfrage, was ihr in den Horen gefallen habe, das Märchen. ${ }^{441} \mathrm{Ob}$ sie von Goethes Autorschaft wusste, ihm hier wissentlich oder unwissentlich ein Kompliment machte, ist nicht mehr herauszufinden. 442 Ganz anders erging es Rahel Levin Varnhagen, die an ihrer grundsätzlichen Begeisterung für Goethe nichts ändern, aber nicht glauben mochte, dass die Unterhaltungen von ihm seien, weil sie ihn nicht wiedererkennen könne. ${ }^{443}$

438 Friedrich Nicolai: Beschreibung einer Reise durch Deutschland und die Schweiz im Jahre 1781. Nebst Bemerkungen über Gelehrsamkeit, Industrie, Religion und Sitten, Bd. 11, Berlin [u. a.] 1796, S. 279 f. Ähnlich abgeschmackt wie Herzens und vermutlich Nicolais Meinung fand Humboldt die des Aufklärers Daniel Jenisch zu einem parallel entstehenden GoetheProjekt: „Jenisch über den „Meister“: „[...] ich habe den „Meister“ auf meiner Frau ihrer Toilette liegen sehn, stellen Sie sich vor, der Mensch, der Goethe, spricht 5 Seiten lang von Puppenspielen." Wilhelm von Humboldt an Friedrich von Schiller, S.17.

7. 1795, in: Leitzmann 1900, S. 61.

439 Wilhelm von Humboldt an Friedrich von Schiller, 25. 8. 1795, in: Leitzmann 1900, S. 98. 440 Johann Daniel Sander an Carl August Böttiger, 15. 10. 1796, in: Wilhelm Bode: Goethe in vertraulichen Briefen seiner Zeitgenossen, 3 Bde., Berlin 1999, Bd. 2, S. 77.

441 Marianne Meyer Eybenberg an Johann Wolfgang von Goethe, 2. 2. 1796, dies ungedruckt, GSA 28/306.

442 Daher rührt möglicherweise Sanders Einschätzung, dass hier - und innerhalb Berlins nur hier - Goethes „Unterhaltungen“ mit dem dort verarbeiteten „Märchen“ geschätzt wurden: „Man fällt hier über Goethe ziemlich allgemein (nur die Clique seiner Anbeter ausgenommen, die sogar sein ,Märchen“ in den ,Horen“ himmlisch finden) das Urteil, der viele Weihrauch habe inn schwindlig gemacht und er erlaube sich nun Dinge, die man auch nicht ungeahndet sollte hingehen lassen. “ Johann Daniel Sander an Carl August Böttiger, 15. 10. 1796, in: Bode 1999, Bd.2, S. 77.

443 Während David Veit sie „vortrefflich“ fand, schrieb seine Freundin, dass sie die „Unterhaltungen“ anfangs mochte, aber durch eine Geschichte gänzlich „dekontenancirt“ sei; sie habe anfangs geglaubt, Goethe darin zu erkennen, dann nicht mehr. Allerdings fand sie noch eine Entschuldigung für die Qualität: „[...] dass der Leser immer verliert, wenn man 
Die Redakteure der Horen nahmen die Kritiken anfänglich mit wenn auch sarkastischem Humor zur Kenntnis. Schiller nannte sich „amüsiert“ über die Berichte aus Berlin. Humboldt schickte ihm sogar eine Persiflage, die im Berliner Satireblatt Camera Obscura erschienen war, und die „de Horen“ plattdeutsch verstehen wollte und sie so von den göttlichen Töchtern zu den Huren herunterbrachte. ${ }^{444}$ Amüsierter Leser dieser Camera Obscura war unter anderem Brinckmann, der im selben Jahr Levin Varnhagen hieraus eine andere Satire auf Schiller empfahl, die dessen Lied an die Freude im wahrsten Sinne zum Gassenhauer machte, vorgetragen von Madame Schubitz' Bordellangestellten:

\begin{abstract}
Es ist Gottlob wieder ein neuer Moqueur erschienen, der Camera obskura von Berlin heißt. Eins der schönsten poetischen Stücke darin ist; eine Parodie von Schillers Gedicht an die Freude, zum Morgengebet für die Mad. Schul. u ihre Kleinen. Die beiden ganz unveränderten Zeilen: „Wir umarmen Millionen, unsern Kuß der ganzen Welt!“ als ein Chor von den Kindern gesungen machen doch einen sehr guten Effekt; und gefallen doppelt durch ihre naïve Wahrheit. 445
\end{abstract}

Die oben erwähnte positive Rezeption der Horen seitens zumindest einiger Mitglieder der Berliner Salongesellschaft war damit keineswegs selbstverständlich für das Berliner Publikum, auch nicht für die intellektuellen Kreise der Stadt. Nicht nur amüsierte sich die Allgemeinheit über die Geschichte des plattdeutschen Zugereisten, auch „Leute, die von jeher als fein passirt haben“, verstünden nicht alle Inhalte der Zeitung. ${ }^{446}$ Rahel Levin Varnhagen beschloss, um

ihm ein Werk bissenweise zusteckt!“ David Veit und Rahel Levin Varnhagen, 20. 5. 1795 bzw. 1. 6. 1795, in: GW VII/II, S. 129 bzw. 133.

444 Die Anekdote war folgende: Ein Mecklenburger findet bei einem Berliner Freund das 2. Stück der Horen; Über den Titel ensetzt er sich, da er ihn plattdeutsch liest: „Gott bewahre uns, für de Horen [= Huren] en Schornal [= Journal].“ Als er über den wahren Hintergrund der Zeitung aufgeklärt wird, liest er’s doch, u. a. Humboldts Aufsatz über den Geschlechtsunterschied, und erklärt dann, er habe zwar wenig verstanden, aber was er verstanden habe, wäre eben doch „Horenkram“. „Die Horen, eine Anekdote“, in: Camera Obscura von Berlin, 20. Heft, Berlin 1795, S. 315-317.

445 Gustav von Brinckmann an Rahel Levin Varnhagen, 30. 7. 1795, ungedruckt, SV 38. Karl August Varnhagen löste „Schul“ als “Schubitz ???“ auf, was die oben erwähnte Bordellbesitzerin meint. Im Original lautet der Titel „Morgengebet der Madam S... und ihrer Kleinen. Eine Parodie auf Schillers „Lied an die Freude“, in: Camera Obscura von Berlin, 1. Heft, Berlin 1795, S. 25.

446 „Ich versteh' sie ganz; mit den Menschen muß man nicht darüber reden; und auch geradezu sage ich, wie sie, ich versteh' oder lese sie nicht. [...] Leute, die von jeher für fein passirt haben, verstehen sie auch nicht." Rahel Levin Varnhagen an David Veit, 21. 3.1795, in: GW VII/II, S. 81 . 
sinnlose Diskussionen zu meiden, den meisten Leuten gegenüber zu behaupten, sie läse die Horen gar nicht.

Schiller und Humboldt erörterten die Probleme der Horen ausführlich, beendeten die Debatte schließlich aber mit der Überzeugung, dass das Publikum nicht klug genug für ihre Aufsätze gewesen sei; besonders die Berliner zeigten nur oberflächlichen Lektüreverhalten: „,...] es wird entsetzlich wenig gelesen, das meiste nur angegafft und durchblättert. eigentlich lesen tut jeder fast nur das, was er zu seinem eigenen Geschreibsel braucht“. 447 Dass Humboldt so pauschal keineswegs Recht hatte, zeigt sich daran, dass alle Nummern der Horen in Berlin noch wahrgenommen wurden, und daneben oder gemeinsam mit ihnen umfängliche Diskussionen anderer Werke, vor allem des Wilhelm Meister und Fichtescher Texte stattfanden. ${ }^{448}$ Auch die immer noch verbreitete These, dass es in den Berliner Salons „eher geistreiche, leichter geschürzte Gespräche“ gegeben habe, in denen „statt der neueste Recension in den Horen die heiße und begehrliche Leidenschaft aufzog“, ist mit dieser Rezeptionsanalyse widerlegt. ${ }^{449}$ Allerdings zeigte sich das Berliner Publikum wie das allgemeine, und wie die Herausgeber selbst, nach anfänglicher Begeisterung mit fortlaufendem Projekt an den Horen immer weniger interessiert. Die brieflichen Diskussionen wurden weniger, schließlich nur noch die Autoren nach Berlin gemeldet und Wilhelm von Burgsdorf schrieb schon 1796: „Von Schiller haben wir in den Horen nichts mehr zu erwarten“. 450

447 Wilhelm von Humboldt an Friedrich von Schiller, 4. 12. 1795, in: Leitzmann 1900, S. 249. 448 So lobten Veit und Levin Varnhagen etwa die Qualität von Schillers „Horen“-Beiträgen und diskutierten, ob Fichte Schillers Ideen verträte. Vgl. David Veit an Rahel Levin Varnhagen, 8. 2. 1795 und 23. 4. 1795, in: GW VII/II, S. 74 und 99. Fortlaufend bis 1797 meldete Veit Autoren und Gerüchte über Autorschaft nach Berlin, aber zunehmend weniger inhaltliche Details. Ende des Jahres 1795 verdrängten vor allem briefliche Diskussionen über Goethes „Wilhelm Meister“ andere Themen. Erst im Oktober 1796 kündigte Veit mit den „Xenien“ das Nachfolgeprojekt an und versprach auch hierüber spezielle Informationen. David Veit an Rahel Levin Varnhagen, 1. 10. 1796, in: GW VII/II, S.231. Auch nannte Rahel Levin Varnhagen Fichte den „Pflug“, der sie für die „Horen“ erst „urbar“ gemacht habe. Dies. an David Veit, 21. 3.1795, in: GW VII/II, S. 81.

449 So z. B. Peter Gradenwitz, der den Berliner Konversationston der Weimarer Nachdenklichkeit kontrastiert. Vgl. Gradenwitz 1991, S. 129 u. 157. Einer seiner Belege (2. Zitat) ist Karl Gutzkows Reminiszenz an den Berliner Salon, die aus der Verteidigungsrede für Schlegels „Lucinde“ stammt, und als ein Plädoyer für Sinnlichkeit bekannt ist. Gutzkow selber wurde 1811 geboren und hat nicht an dem Salongeschehen teilgenommen, das er schwärmend - „Aspasien gaben reizende Toilettenstunden“- beschrieb. Tatsächlich wurde in den Berliner Salons beides gelesen, die „Horen“ und die „Lucinde“. Karl Gutzkow:

Schleiermachers Vertraute Brife über die Lucinde. Mit einer Vorrede von Karl Gutzkow, Hamburg 1835, S. XXVII.

450 Wilhelm von Burgsdorf an Gustav von Brinckmann, 12. 12. 1796, in: Cohn 1907, S. 60. 


\section{4 „Über den Geschlechtsunterschied“ und dessen Auswirkung auf die Berliner Salongesellschaft - Wilhelm von Humboldts Beitrag zur Geschlechtscharakterdebatte}

Wilhelm von Humboldts Horen-Beiträge zur „männlichen und weiblichen Form“ bzw. dem „Geschlechtsunterschied und seine Auswirkung auf die organische Natur“ gehörten zur philosophisch-anthropologischen oder ästhetischen Sparte der Zeitschrift. Dass darin eine Geschlechtertheorie entwickelt wurde, die zur Grundlage des bürgerlichen Frauenbildes wurde und damit durchaus (gesellschafts)politische Relevanz bekam, war 1795 in keiner Weise absehbar. Diesen langfristigen pädagogischen Effekt hätten sich Autor und Herausgeber vielleicht allgemein ,erträumt', sicherlich aber nicht mit diesen Texten träumen lassen. Bei der umfänglichen Diskussion, die Humboldts Texte in der Frauenforschung, später der feministischen Literaturwissenschaft und den Gender Studies erfahren haben, ${ }^{451}$ kann sich die Analyse hier auf eine Wiedergabe der wesentlichen Argumentationsstränge beschränken. Das Haupt-

451 Vgl. ausführlich III.3. Exemplarisch seien zwei Klassiker genannt: Als erste, bis heute immer wieder zitierte, Analyse der Begrifflichkeit der getrennten Sphären von Humboldt bis ins 19. Jahrhundert s. Hausen 1976. Zum Niederschlag des Humboldtschen Modells in der Literatur um 1800: Hannelore Scholz: Widersprüche im bürgerlichen Frauenbild. Zur ästhetischen Reflexion und poetischen Praxis bei Lessing, Friedrich Schlegel und Schiller (Ergebnisse der Frauenforschung, Bd. 26), Weinheim 1992. Drei andere Interpretationsansätze sollen hier erwähnt werden, die die Horen-Aufsätze nicht primär als Geschlechtertheorie betrachten. Irina König untersucht die Texte, etwas einseitig, als rein ästhetische Theorie; Marion Heinz setzt sie in Bezug zur Staatstheorie Humboldts und kommt zu dem Schluss, dass Humboldt vom Staat keine Einmischung in die häusliche Welt, sondern nur Toleranz für die eigenständige Entwicklung der Geschlechter erwarte. Dabei übersieht Heinz allerdings, dass Humboldt mit der „Höherbewertung“ des Weiblichen - im Trend der Zeit - zugleich dessen Ausschluss aus der Öffentlichkeit begründet. Helmut Müller-Sievers knüpft eine Verbindung zwischen den Horen-Aufsätzen und der Sprachphilosophie Humboldts über den Begriff der Zeugung. Irina König: Vom Ursprung des Geistes aus der Geschlechtlichkeit. Zur chronologischen und systematischen Entwicklung der Ästhetik Wilhelm von Humboldts, (Deutsche Hochschulschriften 413) Egelsbach [u. a.] 1992; Marion Heinz: Die Idealisierung des Weiblichen und der liberale Staat. Zum Verhältnis von Geschlechtertheorie und Staatskonzeption bei Wilhelm von Humboldt, in: dies. / Klaus Hammacher (Hrsg.): Recht-Moral-Selbst. Gedenkschrift für Wolfgang H. Schrader (Europea Memoria 29), Hildesheim [u.a.] 2004, S.69-78. Helmut Müller-Sievers: Über Zeugungskraft. Biologische, philosophische und sprachliche Generativität, in: Hans-Jörg Rheinberger / Michael Hagner / Bettina Wahrig-Schmidt: Räume des Wissens. Repräsentationen, Codierung, Spur, Berlin 1997, S. 145-164. Der weitergehenden Erforschung von Humboldts Auffassung menschlicher Geschlechtlichkeit, besonders dem „Zusammenhang von ,physischer Natur und ,moralischer Natur“" des Menschen widmet sich die Wilhelm-von-Humboldt-Stiftung. http://www.humboldtstiftung.de (1. 5. 2010). 
interesse besteht dabei weniger in einer Hinterfragung des polaren Geschlechterbildes als solchem, so nötig sie immer noch ist, sondern darin, die Äußerungen Humboldts in Beziehung zu den Salons zu setzen.

Die Aufsätze über den Geschlechtsunterschied lagen dem Herausgeber spätestens zum Jahreswechsel 1794/95 im Manuskript vor. Gedanklich skizziert worden sind sie aller Wahrscheinlichkeit nach noch in Berlin, zu Zeiten, als Wilhelm von Humboldt regelmäßiger Salongast war. ${ }^{452}$ Ein polares Liebes- und Geschlechtermodell hatte Humboldt zumindest bereits im Kopf, als er ständiger Gast in den Berliner Salons war: Aus Anlass einer unernsten Liebelei seines Freundes Gentz fasste er sein eigenes Liebesideal in folgende Worte: „Daher verlange ich von beiden Subjekten einen solchen Grad der Vollendung [...], dass keiner dem anderen mehr zu geben hofft als er selbst zurück empfängt; überhaupt liegt gerade aller Reiz der Liebe in der höchsten Eigenheit beider Wesen, und dann in der höchsten engen Verbindung des in sich Eignen" ".53 Ganz ähnlich definierte er später in den Horen-Aufsätzen den „Geschlechtsbegriff“ „als eine so eigenthümliche Ungleichartigkeit verschiedener Kräfte, dass sie nur verbunden ein Ganzes ausmachen, und ein gegenseitiges Bedürfniß, dieß Ganze durch Wechselwirkung in der That herzustellen“.454 Das Wortfeld „Eigen-“ wurde das in seinem Aufsatz am meisten zur Charakterisierung der beiden Geschlechter verwendete, womit Humboldt auch hier seine Forderung unterstrich, dass Mann und Frau ihre jeweilige geschlechtsspezifische Eigenheit entwickeln sollen, für ein perfektes Ganzes. 455

„Von der Wichtigkeit des Endzwecks erfüllt, welchem der Unterschied der Geschlechter zunächst gewidmet ist“, nahm Humboldt in seinem Aufsatz den Prozess der Zeugung als Ausgangspunkt der Untersuchung und Interpretationsansatz für alle Vorgänge der Natur. ${ }^{456}$ Das grundlegende Prinzip der Natur bestand nach Humboldt darin, dass zwei gegensätzliche Kräfte sich zu etwas

452 Diese Verbindung wurde bisher in der Forschung zu Humboldts Werk noch nicht in Betracht gezogen. Lediglich im Zusammenhang einer möglichen Wechselwirkung zwischen Humboldts Ehe-Erfahrung und seinem Schaffen wurde die Frage gestreift. Vgl. Peter Weisz: Beziehungserfahrung und Bildungstheorie. Die klassische Bildungstheorie im Lichte der Briefe Caroline und Wilhelm von Humboldts (Europäische Hochschulschriften, Reihe XI: Pädagogik, Bd. 924), Frankfurt/M. 2005, bes. S. 34 ff.

453 Wilhelm von Humboldt an Gustav von Brinckmann, 14. 9. 1792, in: Leitzmann 1939, S. 24 f. Hervorhebung H. L. L.

454 Humboldt 1903(a), S. 312. Hervorhebung H. L. L.

455 Humboldts Wortfeld des ersten Aufsatzes kreist um die zentralen Begriffe Natur, Kraft, Geschlecht, Zeugung, im zweiten Aufsatz sind die primären Begriffe Schönheit und Genie. Beide Male arbeitet er auf abstrakter Ebene mit Kategorien oder „Prinzipien“: männlich und weiblich.

456 Humboldt 1903(a), S. 311. 
Neuem verbinden und so, in Unendlichkeit fortgesetzt, das Leben erhalten: „Die Natur, welche mit endlichen Mitteln unendliche Zwecke verfolgt, gründet ihr Gebäude auf den Widerstreit der Kräfte“.457 So sei „auch jede Zeugung eine Verbindung zweier verschiedener ungleichartiger Principien, die man, da die einen mehr thätig, die andern mehr leidend sind, die zeugenden (im engern Verstand des Worts) und die empfangenden nennt“. 458

Das Neue und für die Nachwirkung Fatale an diesem grundsätzlich dialektischen Gedanken war, dass Humboldt diese gegensätzlichen Kräfte mit dem Begriffspaar männlich / weiblich verband:

Hier nun beginnt der Unterschied der Geschlechter. Die zeugende Kraft ist mehr zur Einwirkung, die empfangende mehr zur Rückwirkung gestimmt. Was von der erstern belebt wird, nennen wir männlich, was die letztere beseelt, weiblich. Alles Männliche zeigt mehr Selbstthätigkeit, alles Weibliche mehr leidende Empfänglichkeit. Indeß besteht dieser Unterschied nur in der Richtung, nicht in dem Vermögen.459

Trotz dieses letzten Satzes, der nur die Richtung, keine Wertung implizieren wollte, und trotz Humboldts Versicherung, mit der männlichen und weiblichen Kraft seien nicht notwendig männliche und weibliche Personen gemeint, lässt sich der anschließende Text als bild- und metaphernreicher Entwurf eines Zwei-Sphären-Modells lesen. Dazu trägt bei, dass Humboldt selbst in seinem Text schließlich doch „das männliche Prinzip“ und „der Mann“ synonym verwandte. 460

Der zweite für die Rezeption folgrenreiche Gedankenschritt in Humboldts Text war der Analogieschluss von der körperlichen zur moralischen Natur des Menschen:461

457 Humboldt 1903(a), S. 322.

458 Humboldt 1903(a), S. 316. Wie im Aufsatz über den Geschlechtsunterschied sah Humboldt auch in dem über die körperlichen Erscheinungsformen vor allem Gegensätze zwischen der männlichen und weiblichen Ausprägung, die einander zu einem Ganzen aber erst ergänzten: „Der Ausdruck von Kraft in der einen [Gestalt] wird durch den Ausdruck von Schwäche in der andern gemildert, und die weibliche Zartheit richtet sich an der männlichen Festigkeit auf." Humboldt, 1903(b), S. 335.

459 Humboldt 1903(a), S. 319. Hervorhebung H. L. L.

460 Ein Beispiel für die synonyme Verwendung ist Humboldts Definition des Männlichen: „Die männliche Kraft, zu beleben bestimmt, sammelt sich von selbst, und durch eigne Bewegung. [...] Der Mann, dessen Brust ein thatenkühner Muth begeistert, fühlt sich in sich verengt. [...] Uneigennützig und fern von jedem Gedanken an eignen Genuß, befruchtet er sie mit der Fülle seiner Kraft. Die neue Schöpfung steht da, und freudig ruht er aus im Anblicke seiner Kinder.“ Humboldt 1903, S. 323 f. u. 326 f. Hervorhebung H. L. L.

461 „Diesem gegenseitigen Zeugen und Empfangen ist nicht bloß die Fortdauer der Gattungen in der Körperwelt anvertraut. Auch die reinste und geistige Empfindung geht auf 
Schon in dem bloß körperlichen Theil seines Wesens findet er mit unverkennbarer Schrift dasjenige ausgedrückt, was er in seinem moralischen zum Daseyn zu bringen streben soll. 462

Damit wurde ein genereller Zusammenhang zwischen physischer und moralischer Natur des Menschen behauptet und so eine reine Definition des so genannten Geschlechtscharakters gegeben.

Wie bereits erwähnt, beabsichtigte Humboldt mit den Horen-Aufsätzen kaum eine, ihm in der Forschung später gelegentlich zugeschriebene, Etablierung eines neuen Geschlechterbildes, da er ja seines als das naturgegebene ansah. Stattdessen war die Arbeit am Geschlechtscharakter Teil eines größeren wissenschaftlichen Projektes, des Studiums der vergleichenden Anthropologie. $\mathrm{Zu}$ Beförderung dieser „Menschenkunde“, als einer sich im 18. Jahrhundert aus verschiedenen Disziplinen etablierenden Forschungsrichtung, wollte Humboldt einen Ansatz entwickeln, der „zugleich naturhistorisch, historisch und philosophisch“ sein sollte, und schlug als Arbeitsbegriffe „Geschlechts-, Temperaments- und Nationalcharaktere" vor. 463

Bemerkenswert an dem von Humboldt abgesteckten Forschungsfeld ist die von ihm vorzüglich geforderte Methode des Studiums der Menschen in Geselligkeit. Humboldt war überzeugt davon, dass, mehr als Religion oder Geschäfte, „auf die eigenthümliche Charakterbildung der freie und alltägliche Umgang in engeren und weitern Verbindungen [wirke]: in der Ehe, der Freundschaft, kleineren und grösseren gesellschaftlichen Cirkeln“. Er empfahl daher zur Menschenkenntnis Beobachtung in Geselligkeit. ${ }^{464}$ Wenn man die HorenAufsätze als erste Teilstudie seiner Anthropologie betrachtet, muss man der zeitlichen Reihenfolge wegen annehmen, dass die Feldforschung für diese Studie in Humboldts Berliner Zeit und unter anderem bei seinen Salonbesuchen stattgefunden hat.

In dem vermutlich 1797 entstandenen Plan einer vergleichenden Anthropologie umriss Humboldt das Forschungsfeld im Großen und kam dabei auf die in den Horen entwickelte Theorie noch einmal zurück. ${ }^{465}$ Der letzte Abschnitt

demselben Wege hervor, und selbst der Gedanke, dieser feinste und letzte Sprössling der Sinnlichkeit, verleugnet diesen Ursprung nicht. Die geistige Zeugungskraft ist das Genie.“ Humboldt 1903(a), S. 316.

462 Humboldt 1903(a), S. 314.

463 Humboldt 1903(c), hier S. 395 bzw. 391.

464 Humboldt 1903(c), S. 382.

465 Die Entstehung des Aufsatzes wird von Leitzmann auf 1795, in der jüngeren Forschung auf 1797 datiert. Vgl. die Anmerkungen von Flitner und Giel in: Wilhelm von Humboldt. Werke in fünf Bänden, hrsg. von Andreas Flitner und Klaus Giel, 4. Auflage, Darmstadt 2002, Bd. 5: Kleine Schriften: Autobiographisches, Dichtungen, Briefe, Kommentare und Anmerkungen zu Band I-V, S. 334-336. 
des „Plans“ bietet sozusagen eine prägnante Kurzfassung des polaren Geschlechterbildes, eine Auflistung der „naturgegebenen“ weiblichen Eigenschaften, hier aber bar jeder philosophischen Herleitung. ${ }^{466}$ Bei wiederholtem Lob der „Innigkeit“ und „Phantasie“ der Frauen, wurde ihnen hier deutlich das Vermögen zu dichterischen Produktionen jenseits der Lyrik und das Interesse an abstraktem Denken abgesprochen. ${ }^{467}$ Ein Hinweis auf die Tatsache, dass den meisten Frauen bis dato die notwendige Ausbildung für diese Gattungen, etwa in Dramentheorie oder Latein, vorenthalten war, fehlt in dieser ,natürlichen“ Herleitung, ebenso wie in Schillers Preisung, die Frau sei „freier in ihrem gebundenen Wirken, reicher als er in des Wissens Bezirken“.468 Diese Zitate werden in der Zusammenschau der Ereignisse 1794 konterkariert: In der Zeit, als Humboldt an seinen anthropologischen Thesen arbeitete, erreichte ihn die erwähnte Rezension eines seiner anderen Texte, verfasst von Rahel Levin Varnhagen, die sich damit durchaus im männlichen Bereich der Kritik tätig zeigte, und er sah sich genötigt, ihr Komplimente an ihre Urteilskraft zu machen.

\section{Zur Rezeption der Aufsätze durch die Kritik und im Salon}

Humboldts Aufsätze weckten bei Publikum und Rezensenten gleichermaßen Interesse und Lust an bildreicher Kritik. Bereits vor der Zusammenarbeit an den Horen hatte Schiller den etwas trockenen Schreibstil Humboldts bemerkt, der diesem selbst im Weg stünde. Als ihm aber der Text Humboldts im Manuskript vorlag, äußerte sich der Herausgeber zuversichtlich, dass noch „nichts so zusammenhängendes über diesen Gegenstand geschrieben“ sei. In summa befand Schiller: „Humboldts Aufsätze über die Weiber [sic!] (denn es werden mehr) sind kein unbedeutender Beytrag für die ,Horen““.469 Als sein Freund und Horen-Mitarbeiter Körner vorsichtig einwandte, „das Abstrakte was in dem Aufsatz herrscht, ist für den bequemen Leser ermüdend“, machte Schiller sei-

466 Anhänger eines polaren Geschlechterbildes geben dieser Darstellung den Vorzug, zum Beispiel die Herausgeber der fünfbändigen Humboldt-Ausgabe von $1980 \mathrm{ff}$., die den Text noch in der Ausgabe von 2002 unreflektiert als „geistvoll und dicht geschriebene Charakteristik des weiblichen Geschlechts“ bezeichnen. S. Humboldt 2002, Bd. 5, S. 335. 467 „Nur lehrt die Erfahrung soviel, dass Frauen sich nicht leicht an denjenigen Gattungen versuchen, deren Gelingen vorzugsweise auf ihrer künstlerischen, nur durch Genie möglichen Form beruht, wie die epische und dramatische Poesie und die plastische Kunst ist.“ Humboldt 1903(c), S. 406.

468 Friedrich von Schiller: Würde der Frauen [1796], in: ders: Werke und Briefe, hrsg. von Otto Dann u. a., 12 Bde., Frankfurt/M. 1992-2002, Bd.1, S. 186.

469 Friedrich von Schiller an Christain Gottfried Körner, alle Zitate vom 29. 12. 1794, in: Schiller 1992-2002, Bd.11, S. 775. 
nen Standpunkt deutlicher: Auf den bequemen Leser dürfe man keine Rücksicht nehmen, denn „Geschmack verzeyht schon einigen Mangel an Form, und wer diesen nicht hat, muß sich einige Anstrengung gefallen lassen, weil die Form hier immer der Sache nachstehen muß“. 470 Zwei spätere Entscheidungen Schillers klingen hier bereits an, erstens, sich dem Publikumsgeschmack nicht $\mathrm{zu}$ beugen und zweitens, des wichtigen Inhalts wegen, seinem Freund Humboldt in der Form zu sekundieren.

Der Unterschied zwischen Form und Inhalt der Humboldtschen Aufsätze wurde auch außerhalb der Horen-Redaktion diskutiert. Nicolai nannte den Aufsatz über den Geschlechtsunterschied einen „philosophischen Traum voll feiner Empfindung, [...] freylich nun in einer ziemlich gezierten Schreibart vorgetragen“.471 Mackensen empfand ihn als Anmaßung: „Die Weisheit des Verfassers scheint die Weisheit des Korans zu seyn, welcher die ganze Natur in eine männliche und eine weibliche Hälfte theilt“".472 Dabei, und das ist bezeichnend, nahm er Humboldt aber besonders übel, dass er das männliche und weibliche Prinzip als gleichwertig schilderte, denn nach Mackensens Meinung sei das Weib nur Geschlecht, in allem was es tue, der Mann hingegen die Welt zu erkennen fähig. ${ }^{473}$ Dass öffentliche und private Kritiken in diesem Kreis ineinander übergingen, zeigt der Einfluss einer Äußerung Immanuel Kants, die, obzwar in einem Brief an Schiller geäußert, in der lesenden Welt die Runde machte. Kant hatte zugegeben, dass er den Text, „so ein guter Kopf mir auch der Verfasser zu seyn scheint, doch nicht enträtseln könne“.474 Der Brief wurde von Schiller Humboldt offenbar zur Kenntnis gegeben, der ihn an Körner weiterreichte mit dem Kommentar, dass ihn Kants Kritik besonders beschäftige. ${ }^{475}$ Der Text scheint auch in größerem Kreise kursiert zu haben,

470 Christian Gottfried Körner an Friedrich von Schiller, 16. 1. 1795, ders. an Christian Gottfried Körner, 19. 1. 1795, zit. nach: Schulz 1960, S. 98 f.

471 Nicolai 1796, S. 264.

472 August Mackensen, Ende 1795, zit. nach: Schulz 1960, S. 76.

473 Humboldt fand denn auch, Mackensens Kritik „übertrifft an Unverschämtheit und Plattheit alles, was man je gesehn hat. Indeß sind einige Einfälle nicht übel und die Wendung des Ganzen hämisch genug. “ Wilhelm von Humboldt an Friedrich von Schiller, 20. 11. 1795, in: Leitzmann 1900, S. 208.

474 Immanuel Kant an Friedrich von Schiller, 30. 3. 1795, zit. nach: Schulz 1960, S. 99. Zugleich nahm er den Aufsatz aber zum Anlass, über die „Natureinrichtung: dass alle Besaamung in beyden organischen Reichen zwey Geschlechter bedarf“ zu philosophieren, konnte sich schließlich mit der Idee doch nicht anfreunden, dass dies ein Grundprinzip der gesamten Natur sein solle. Ebd.

475 „Kants Urtheil geht mir sehr durch den Kopf. Zwar sucht mich Schiller zu trösten, aber besser ists immer, keinen Trost zu bedürfen.“ Wilhelm von Humboldt an Christian Gottfried Körner, 7. 5. 1795, zit. nach: Schulz 1960, S. 100. 
wurde dort aber leicht entstellt zitiert: Friedrich Schlegel schrieb seinem Bruder: „Humboldt grämt sich, weil Kant geschrieben hat, sein Aufsatz über die Geschlechter, welchen man nun wirklich nicht wohl verstehen kann, möge wohl von einem sehr scharfsinnigen Kopf sein, es sey ihm auch wohl dergleichen durch den Sinn gefahren, aber es lasse sich nichts damit machen. Das wurmt ihn“, und David Veit übertrieb ähnlich, gegenüber Rahel Levin Varnhagen: „Von dem Aufsatz ,über die männliche und weibliche Form` - von W. von Humboldt - soll, wie Leute versichern, die glaubwürdig sein sollen, Kant gesagt haben: ,ich habe mir Mühe gegeben; aber ich verstehe diesen Aufsatz nicht; auch zweifle ich sehr; ob der Verfasser ihn versteht“"? ${ }^{476}$

Die angestrebte Anonymität der Autoren, wurde durch die zahlreichen eingeweihten Briefschreiber konterkariert. Über oben geschildertes Weitergeben der Autorennamen oder ganzer Briefe wurde Humboldt bald erkannt und die Polarität hatte einen Namen.

Dass es auch prominente Zeitgenossen gegeben hat, die sich öffentlich gegen das polare Geschlechtermodells wehrten, ist in der feministischen Forschung weitgehend außer Acht gelassen worden, dabei hatte unter anderen der Aufklärer Nicolai sich verwehrt gegen ideelle und ideologische Setzungen, die ,ludendo in umbra scientiae vanae sich nicht die Betrachtung der wirklichen Welt zur Hülfe nehmen“, denn „daß stark und sanft immmer den äußersten Grad dem Männlichen und Weiblichen bezeichnen, soll neu seyn und ist grundfalsch“. 477

Dass Humboldts Text ein Kerntext der Geschlechtscharakterdebatte wurde, hatte schließlich vor allem damit zu tun, dass er durch Schillers Verteidigung eine Verschiebung und Poetisierung erfuhr. David Veit hatte die Aufsätze noch neutral angekündigt als „einen Aufsatz über die moralische Verschiedenheit der Geschlechter“.478 Schiller verkürzte das zu „Humboldts Aufsätze über die Weiber“ - ein kurzer, aber prägnanter Hinweis darauf, dass Schiller zeittypischer Verfechter einer weiblichen Sonderanthropologie war. Während die allgemeine Kritik an den Horen, gemeinsam mit den organisatorischen und finanziellen Schwierigkeiten, das Redaktionskomitee dazu bewog, das Projekt still sterben zu lassen, war man/n in punkto Geschlechtertheorie keineswegs gesonnen, die Ideen unverteidigt verhallen $\mathrm{zu}$ lassen. Aus dem Briefwechsel zwischen Schiller und Humboldt lässt sich ein inhaltlicher und arbeitstechni-

476 Friedrich Schlegel an August Wilhelm Schlegel, 17. 8. 1795, in: KFSA, Bd. 23, S. 248. David Veit an Rahel Levin Varnhagen, 11. 10. 1796, in GW VII/II, S. 232. Hervorhebung im Original. Veit bezog sich mit dem entstellten Kantkommentar auch auf den falschen Aufsatz. 477 Nicolai 1796, S. 271 bzw. 269. Hervorhebung im Original, durch andere Typografie. „Ludendo“: herum spielend im Schatten der eitlen Wissenschaft.

478 David Veit an Rahel Levin Varnhagen, 8. 2. 1795, in: GW VII/I, S. 74. 
scher Zusammenhang bei der Fortentwicklung des Modells genau ablesen: Humboldt, nicht davon überzeugt, dass sein Modell in seiner Schreibart viel Anhänger gewinnen würde, schrieb - am eingangs zitierten Freitag, 21. August 1795 -: „Man wird meinen Productionen schwerlich je viel Geschmack abgewinnen können, und dieß macht mich auch kälter für Dinge, die doch am Ende mehr schriftstellerische Ausführungen als große wissenschaftliche Erweiterungen sind“. ${ }^{479}$ Schiller überzeugte Humboldt davon, dass seine Gedanken in anderer Form sich durchsetzen würden und entwarf 1795 das Gedicht Würde der Frauen, das die Welt in zwei „Herrschgebiete“ teilte. ${ }^{480}$ Humboldt und seine Frau Caroline waren Erstleser des Entwurfs und begeistert von der Würde, „die ein göttliches Stück ist, für die wir innigst danken“. ${ }^{481}$ Humboldt stellte fest, dass sich sein Weltbildentwurf in Poesie besser mache als in Prosa und schrieb beinahe prophetisch: „Die Zeichnung der beiden Charakter ist Ihnen gleich gut als die Entgegenstellung beider gelungen; das Silbenmaß ist äußerst glücklich gewählt, und es wird nur sehr wenig Gedichte geben, die so rechnen können, ihre Wirkung so voll als diese zu tun“.482

Wie erwähnt, ist der Umfang der Beteiligung von Frauen an der Geschlechterdebatte noch detailliert $\mathrm{zu}$ erforschen. Trotz der intensiven und zeitnahen Beschäftigung mit den Horen seitens der Salongesellschaft fand sich aber keine inhaltliche Äußerung der Salonbeteiligten zu Humboldts Text und Schillerscher Poetisierung. ${ }^{483}$ Möglicherweise ist der Brief David Veits, der nur Spott Immanuel Kants kolportierte, bezeichnend dafür, dass den Humboldtschen Aufsätzen nicht die Bedeutung zugemessen wurde, die ihnen heute attestiert werden.

Nachstehend, sowie in Kapitel VI, wird zunächst als implizite Form der Kritik der nachweisbare spielerisch ironische Umgang mit Polaritäten disku-

\footnotetext{
479 Wilhelm von Humboldt an Friedrich von Schiller 21. 8. 1795, in: Leitzmann 1900, S. 89. 480 Das Gedicht malt weiterhin in gegensätzlichen Metaphern und für Männer und Frauen unterschiedlichem Versmaß bildlich und rhythmisch die Geschlechtersphären aus, z. B. „In der Männer Herrschgebiete / Gilt der Stärke trotzig Recht, [...] Aber mit sanft überredender Bitte / Führen die Frauen den Szepter der Sitte.“ Schiller 1992-2002, Bd.1, S. 186.

481 Wilhelm von Humboldt an Friedrich von Schiller, 8. 9. 1795, in: Leitzmann 1900, S. 124. 482 Wilhelm von Humboldt an Friedrich von Schiller, 11. 9. 1795, in: Leitzmann 1900, S. $127 \mathrm{f}$. Und: „Mir war es in der Tat ein unbeschreibliches Gefühl, Dinge, über die ich so oft nachgedacht habe, die vielleicht noch mehr, als Sie bemerkt haben, mit mir und meinem ganzen Wesen verwebt sind, in einer so schönen und angemessnen Diktion ausgeprägt zu finden." Ebd.

483 Dass sie im Briefwechsel Veit-Levin „ausführlich diskutiert“ würden, wie Bosold behauptet, kann ich nicht finden. Während die „Horen“ ausführlich debattiert werden, findet sich zu Humboldts Texten nur die Aussagen Veits, keine von Levin Varnhagen. Bosold 1996, S. 183.
} 
tiert. Stellvertretend für die weibliche Rezeption der Humboldtschen Polarität stehen hier die Kommentare zweier intellektueller Frauen aus dem weiteren Umfeld der Salons, in deren gegensätzlicher Einstellung eine deutliche Warnung davor liegt, von einer nachhaltigen oder gar einheitlichen Rezeption durch weibliche Leser auszugehen: Caroline von Humboldt teilte die positive Meinung ihres Mannes zu Schillers Gedicht und machte noch Vorschläge, die Gegensätze besser zur Geltung zu bringen. ${ }^{484}$ Caroline Schlegel Schelling hingegen wollte ihr bekannte Autoren zur ,Gegendarstellung‘ gewinnen: gegen die „hochfahrenden Poesien [...], die gereimten Metaphysiken und Moralen, und die versifizierten Humboldeschen Weiblichkeiten. Schillern hängt das Ideal [sic] gar zu sehr nach - er meint, es ist schon gut, wenn ers nur ausspricht“. 485 Wenige Jahre später, nach der Veröffentlichung von Schillers Lied von der Glocke, sollte sie bekanntlich schreiben, sie sei vor Lachen darüber vom Stuhle gefallen. 486

Wenn Humboldts polares Modell in den Worten Schillers, oder besser: ihr gemeinsam entwickeltes und von Schiller poetisiertes Modell heute oft zitiert wird, bedeutet das daher keineswegs, dass es bei Zeitgenossen auf Begeisterung stieß. Nur am bekanntesten, nicht alleinstehend, ist die Parodie August Wilhelm Schlegels, der die praktische Seite der Polarität in seiner Formulierung „Ehret die Frauen, sie stricken die Strümpfe ...“ verewigte.

„Wenn die Musen wie Fischweiber schimpfen, was bleibt dann den Fischweibern?“ (Friedrich Nicolai über Goethe ${ }^{487}$ )

Wenn es um Geschlechterbilder in den Horen und deren zeitgenössische Rezeption geht, muss abschließend festgehalten werden, dass den größten Effekt im ersten Jahr der Horen weder politische noch theoretische Texte machten, sondern Goethes Römische Elegien. Die Überlegung des Herausge-

484 Wilhelm von Humboldt an Friedrich von Schiller, 11. 9. 1795, in: Leitzmann 1900, S. 127 f. 485 Caroline Schlegel Schelling an Luise Gotter, 10. 2. 1796 in: Reinhard Buchwald (Hrsg.): Carolinens Leben in ihren Briefen. Aufgrund der von Erich Schmidt besorgten Gesamtausgabe in Auswahl herausgegeben von Reinhard Buchwald, eingeleitet von Ricarda Huch, Leipzig 1923, S. $135 \mathrm{f}$.

486 „Über ein Gedicht von Schiller, das Lied von der Glocke, sind wir gestern Mittag fast von den Stühlen gefallen vor Lachen, es ist a la Voss, a la Tiek, à la Teufel, wenigstens um des Teufels zu werden.“ Caroline Schlegel Schelling an ihre Tochter Auguste Böhmer, 21. 10. 1799, in: dies.: Begegnung mit Caroline. Briefe von Caroline Schlegel-Schelling. Herausgegeben und eingeleitet von Sigrid Damm, Leipzig 1989, S. 230. Spottverse von Friedrich Schlegel über dieses Gedicht gingen an Rahel Levin Varnhagen, 1. 4. 1802, ihre Reaktion ist aber leider nicht überliefert. KFSA, Bd. 25, S. 346.

487 Friedrich Nicolai: Anhang zu Friedrich von Schillers Musen-Almanach für das Jahr 1797, Berlin [u. a.] 1797, S. 4. 
ber Schiller, dass diese Versfassung von Goethes italienischen Erlebnissen „zwar schlüpfrig und nicht sehr dezent sind, aber zu den besten Sachen gehören die er gemacht hat",488 spiegelte sich vor allem in der Empörung der Weimarer Gesellschaft über die „bordellmäßige Nacktheit“ wider, die in einer Abmahnung Goethes durch den Herzog gipfelte. Charlotte von Stein drückte ihr Unverständnis zurückhaltender aus, sie glaube, dass solche Gedichte schön seien, aber täten ihr „nicht wohl“. ${ }^{489}$ Im Vergleich regte sich die hauptstädtische Leserschaft Berlins deutlich weniger auf. Wilhelm von Humboldt selbst nannte den Brief des Herzogs schlicht „drollig“ und fügte hinzu: „Hier findet, wie gesagt, soviel ich bis jetzt hörte, niemand an den ,Elegien“ Anstoß“.490 Danach nahm das Interesse an den Horen erst wieder bei der Veröffentlichung des Romans Agnes von der Lilien zu, einer von mehreren Horen-Texten einer weiblichen Autorin, und einer, der universell positiv aufgenommen wurde. Damit erlosch in den Briefwechseln der Salongesellschaft scheinbar das Interesse an dem Projekt, parallel zu der Ernüchterung des Herausgebers Schiller.

\section{Exkurs: Gefährtin und Erlöserin - \\ Bekannte und unbekannte Langzeitwirkungen der Humboldtschen Aufsätze}

Obwohl keine zeitlich unmittelbare Kritik an Humbolts Polaritätsmodell aus den Salons überliefert ist, lässt sich an einem Briefwechsel wenige Jahre später aufzeigen, dass und wie Beteiligte der Salongesellschaft die Polarität möglicherweise spielerisch und ironisch abwehrten. 1803 schrieb Friedrich von Gentz an Rahel Levin Varnhagen eine viel zitierte Charakterisierung ihrer beider Verhältnis zueinander. Nicht diskutiert wurde bisher, dass er dabei, bewusst oder unbewusst, das Vokabular seines Freundes Humboldt verwendete - allerdings in neuer Konnotation. Während dieser unter anderem postuliert hatte, „alles Männliche zeigt mehr Selbstthätigkeit, alles Weibliche mehr leidende Empfänglichkeit“, schrieb Gentz: „Wissen Sie, Liebe, warum unser Verhältniß so groß und so vollkommen geworden ist? Indeß will ich es Ihnen

488 Friedrich von Schiller an Charlotte von Schiller, 20. 9. 1794, in: Bode 1999, Bd. 2, S. 17. 489 Auch Herder habe gesagt, die „Horen“ müssten mit -u geschrieben werden. Carl August Böttiger an Joachim Christian Friedrich Schulz, 27. 7. 1795, in: Bode 1999, Bd. 2, S. 41.

Charlotte von Stein an Charlotte von Schiller, 27.7.1795, Ebd., S. 42. Nur August Wilhelm Schlegel schrieb begeistert: „In Goethes Elegien herrscht Römischer Geist: Man glaubt italienische Luft zu atmen, wenn man sie liest“, August Wilhelm Schlegel an Friedrich Schlegel, 13. 10. 1795, ebd., S. 47.

490 Wilhelm von Humboldt an Friedrich von Schiller, 4. 8. 1795 in: Leitzmann 1900, S.67. Wenig später hört er von den Elegien „mit großer Achtung sprechen“, 15. 8. 1795, ebd., S. 75. 
sagen. Sie sind ein unendlich produzierendes, ich ein unendlich empfangendes Wesen: Sie sind ein großer Mann, ich bin das erste aller Weiber, die je gelebt haben“. 491

Mit dieser Formulierung hatte Gentz die Bezüge Humboldts genau umgedreht und erklärt, dass ein physischer Mann auch die Rolle der empfangenen Kraft übernehmen, und, nach seiner Auffassung, zumindest das Verhältnis dennoch ein „vollkommenes“ sein könne. Dies ist in erster Linie bemerkenswert für das Selbstverständnis dieses Salongastes, der, anders als Humboldt, nicht anstand, einer Gastgeberin Einfluss auf sein Denken zuzugestehen. Möglich ist es auch, diesen Satz als Hinweis auf eher spielerischen Umgang mit den Geschlechterstereotypen der Zeit in den Salons zu sehen. Es muss hinzugefügt werden, dass Gentz, der diesen Umgang eingestandermaßen genoss, dem Genuss keinerlei publizistischen Konsequenzen folgen ließ.492

Dennoch hatte diese Spielerei in zweiter Instanz geschlechterpolitische Konsequenz. Während das polare Vokabular und Modell nach 1800 Einzug in Konversationslexika und Belletristik hielten, ${ }^{493}$ erfuhr Gentz' spielerische Umkehrung dieses Modells eine genau gegenteilige, progressive Rezeption. In der ,umgedrehten' Version wurde Humboldts bzw. Gentz' Bild, weit entfernt vom Berliner Salon, zum Auslöser einer innovativen Geschlechtertheorie: Die Kombination von geschlechterpolitischer Elektrizität und jüdischer Weiblichkeit (in der Person Rahel Levin Varnhagens) inspirierte den französischen

491 Friedrich von Gentz an Rahel Levin Varnhagen, o. D. 1803, in: Kemp 1979, Bd. III, S. 122. Hervorhebung im Original.

492 Gentz hatte seine Idee weiter ausgeführt: „Das weiß ich: wäre ich ein physisches Weib geworden, ich hätte den Erdkreis vor meine Füße gebracht. Nie habe ich etwas erfunden, nie etwas gedichtet, nie etwas gemacht; bemerken Sie diese Sonderbarkeit: aus mir allein ziehe ich nicht den lumpigsten Funken heraus; ich bin unelektrischer als Metall: aber eben darum ein Ableiter der Elektrizität, wie kein andrer.“ Ebd. Hervorhebung im Original. Der einzige Salongast, der zumindest zeitweise Forderungen nach erweiterterten Handlungsräumen von Frauen jenseits der „Empfänglichkeit“ veröffentlichte, war Friedrich Schleiermacher.

493 Allen Parodien und kantischen Kopfschütteln zum Trotz soll hier nochmals betont sein, dass Humboldt, anders als heute vielfach dargestellt, keineswegs der einzige oder erste Vertreter eines polaren Modells war. Im selben Jahr als Humboldts Aufsätze erschienen, 1794, wurde Karoline Wobesers populärer Roman veröffentlicht, der mit seiner Titelheldin „Elisa“ für zwei deutliche getrennte Sphären warb. Wenige Jahre später erschien eine Fortschreibung dieses Romans, die deutlich mit Humboldtschen (und Rousseauschen) Begriffen operierte: „Der Mann ist zur That, das Weib ist zur Ruhe bestimmt [...]. Der Mann ist der Erzeuger, das Weib ist bloß Gebährerin.“ [Christian August Fischer]: Über den Umgang der Weiber mit Männern. Ein notwendiger Anhang zu der bekannten Schrift „Elisa oder das Weib, wie es seyn sollte“, Leipzig 1800, S. 13. 
Saint-Simonisten Gustav d'Eichthal zu seiner Geschlechtertheorie. ${ }^{494}$ Einem Freund gegenüber bekannte er:

\begin{abstract}
Als ich Dir die Extrakte der Briefe von Gentz schickte, in denen er zu Mme. de Varnhagen sagte, dass in ihrer Beziehung sie der Mann und er die Frau gewesen sei; als ich hinzufügte, dass eine Beziehung dieser Art auch zwischen zwei Männern oder zwischen zwei Frauen existieren könnte, hatte ich unsere eigene Beziehung im Sinn; Gentz’ Denken hatte mir das zum ersten Mal zu Bewusstsein gebracht. ${ }^{495}$
\end{abstract}

Die gesellschaftliche Vision der Saint-Simonisten, die unter anderem die weibliche Emanzipation bis zum Bild einer messianischen Rolle der Frau in der Gesellschaft der Zukunft steigerte, sollte $1832 \mathrm{zu}$ einem Skandal in der französischen und deutschen Presse führen. Gustav d'Eichthal entwarf das Bild eines weiblich-jüdischen Messias:

Die jüdische Frau besitzt eine Natürlichkeit, eine Kraft, eine Wahrheit, die die Christin nicht besitzt, sie wurde nicht wie letztere durch die trügerischen Hommagen der kavalierhaften Galanterie verdorben. Zweifellos ist ihre religiöse und zivile Emanzipation weniger fortgeschritten als die der Christin; [...] aber dieselbe Religion, die die Frau in der Gegenwart erniedrigt, erhebt sie wunderbar für die Zukunft. [...] Ich konnte das Antlitz einer Priesterin nur in dieser Rasse konzipieren. 496

Paola Ferruta vermutet, dass die reale Entsprechung dieses Bildes Rahel Levin Varnhagen gewesen ist, die begeisterte Saint-Simonistin war und die d'Eichthal zumindest über Gespräche mit ihrem Mann und durch dessen Veröffentlichungen gut bekannt war. In jedem Fall gibt es einen zeitlichen Zusammenhang zwischen der Bekanntschaft und brieflichen Auseinandersetzung mit Karl

494 Gustave d'Eichthal (1804-1886), aus einer international vernetzten Bankiersfamilie stammend, hatte nach eigener Aussage, zunächst seinen angeborenen jüdischen, dann den katholischen, dann den Saint-Simonsistischen Glauben „umarmt“. Gustave d'Eichthal, in:, Claude-Henri de Saint-Simon: Oeuvres completes de Saint-Simon et d'Enfantin, 47 Bde., Paris 1865-1878 (OSSE), II Enseignement, 16. Dezember 1831, XIV. Band, II. Teil, S. 112-113, zit. nach: Paola Ferruta: Gustave d'Eichthal und seine Beziehungen zu Rahel und Karl August Varnhagen: Ein deutsch-französischer „transfer culturel“ in den 30er Jahren des 19. Jahrhunderts, Vortrag auf der Konferenz der Varnhagengesellschaft „In Europäisch so ausdrücken“, Oktober 2004, in Kleve. Ich danke Paola Ferruta für die Überlassung des Manuskripts. D’Eichthal hatte einige Monate in der Familie Joseph Mendelssohns in Berlin verbracht. „Für die Jahre 1831 und 32 dokumentieren die Briefzeugnisse des Varnhagenschen Kreises in Berlin eine enthusiastische Rezeption der neuen Lehre, zu deren Verbreitung d'Eichthal kräftig beigetragen hatte." Ferruta 2004, o. S.

495 Gustave d'Eichthal, Arsenal Paris, Fonds d'Eichthal, Ms. 13759 f 7, Brief an Charles Duveyrier aus Montpellier vom 3. Mai 1837., zit. nach: Ferruta 2004, o. S.

496 Zit. nach: Ferruta 2004, o. S. 
August Varnhagen Mitte der 1830er-Jahre und dem Zeitraum, in dem sich d'Eichthal mit der Figur einer jüdischen Erlöserin beschäftigte.

Im Zusammenhang dieses Kapitels ist vor allem d'Eichthals Einschätzung des Rollentausches der Geschlechter von Interesse, wie er sie im Salon verwirklicht sah: „Ich glaube, dass die Frau sich Gentz ewig dankbar zeigen muss, da dieser sich gegenüber Mme. Varnhagen selbst als die größte aller Frauen proklamiert hat". 497

Unabhängig von der Frage, wer wem dankbar zu sein hätte, bleibt festzuhalten, dass die kritische Verkehrung des Humboldtschen Modells durch den Salon fortlebte - wenn auch nur im Bereich der Utopie.

\title{
„Xenien“ und „Mücken“ - \\ der Kampf der Weimarer Klassik gegen die (Berliner) Rezeption der Horen
}

\author{
Horen. Erster Jahrgang. \\ Einige wandeln $\mathrm{zu}$ ernst, die andern schreiten verwegen \\ wenige gehen den Schritt, wie ihn das Publikum hält. \\ Die Xenien über das Publikum \\ Er ist mit einer Fliegenklappe einhergegangen, \\ und wo es zuklappte, da wurde ein Epigramm. \\ Das ,Publikum‘ über die Xenien ${ }^{498}$
}

Schiller und Goethe ersannen, als Ausgleich für ihre schlechten Erfahrungen mit den Horen, schließlich ein neues Gemeinschaftsprojekt, das zwar der Form, nicht aber der Intention nach dem Bild von am antiken Vorbild geschulten Klassikern entspricht. Walter Benjamin zufolge hatte Schiller zuvor erwogen, einen umstürzlerischen Artikel in die Horen zu setzen, um sie mit Furor zu Ende zu bringen. ${ }^{499}$ Schließlich wählte man eine klassische Waffe im Duell mit dem Publikum: Die Xenien, 500 mehrere hundert Verspaare, die in klassischen

497 Gustave d'Eichthal, Arsenal Paris, Fonds d'Eichthal, Ms. 13759 f 7, Brief an Charles Duveyrier aus Montpellier vom 3. Mai 1837, zit. nach: Ferruta 2004, 0. S.

498 Johann Wolfgang von Goethe: Xenien. Xenien von Schiller und Goethe, Frankfurt/M. 1992, S.59; Caroline Schlegel Schelling an Luise Gotter, 4. 9. 1795, in: Bode 1999, Bd.2, S. 74 .

499 Mehrere berühmte Dichter in ihrer Funktion als Zeitungsmacher des 18. Jahrhunderts ersannen ,Knalleffekte‘, um ihre Grundlagenwerke der Klassik und Romantik an den Mann zu bringen, Friedrich Schlegel etwa wollte dem „Athenäum“ Pfefferkuchen beilegen lassen. Vgl. Benjamin 1991, S. 667.

500 Xenien, eigentlich „Gastgeschenke“, haben seit den Xenien des Dichters Martial, den sich Goethe und Schiller hier zum Vorbild nahmen, den Nebensinn: Gastgeschenke unerfreulichen Inhalts. 
Distichen mit dem undankbaren Publikum abrechnen sollten, sind eigentlich rhythmisierter Klatsch. Als solcher, als spezielle Kommunikationsform in der literarischen Auseinandersetzung um 1795, und als Reaktion auf die schlechte Rezeption der Horen auch und gerade in Berlin, bilden sie den Abschluss der Betrachtung.

Bereits nach den ersten, zum Teil hämischen Kritiken überlegte Goethe, die Stimmen zu sammeln und darüber „Gericht“ zu halten, denn „wenn man dergleichen Dinge im Bündlein bindet brennen sie besser“". ${ }^{501}$ Ende 1795 hatten er und Schiller, dem die Idee sofort zusagte, zahlreiche spöttische Zweizeiler zusammengetragen und beschlossen, ihre Namen nur gemeinsam über die ganze Sammlung zu setzen, damit niemand der Angegriffenen wisse, wer ihm den Schlag wirklich beigefügt habe. Damit ist das Charakteristikum der anonymisierten Herkunft des Klatsches erfüllt. Auch das zweite Merkmal, dass Klatsch die Klatscher untereinander verbinde, findet sich in Goethes Formulierung: „Es ist sehr leicht, die unsinnige Unbildung dieses bornierten Volks anschaulich zu machen, man hat dabei das vernünftige Publikum auf seiner Seite, und es gibt eine Art Kriegserklärung gegen die Halbheit“..502

Nach umfangreicher Redaktion ihrer Munition erschienen über 400 Verse in Schillers Musenalmanach für das Jahr 1797 und lösten außergewöhnliches Publikumsinteresse aus. ${ }^{503}$ Dabei bestand das größte Lesevergnügen wiederum darin, zu raten, wer wen verspottete..$^{04}$

Nicht wenige der Getroffenen fühlten sich zu Anti-Xenien bzw. Gegengeschenke an die Sudelköche von Weimar veranlasst, sodass es tatsächlich in langer Nachfolge der Horen zu einem Krieg der Verse kam. ${ }^{505}$ Eine zeitgenössi-

501 Johann Wolfgang von Goethe an Friedrich von Schiller, 28. 10. 1795, in: Beetz 2005, Bd. 1, S. 121.

502 Johann Wolfgang von Goethe an Friedrich von Schiller, 21. 11. 1795, in: Beetz 2005, Bd.1, S.126. Merkmale des Klatsches nach: Jörg Bergmann: Klatsch. Zur Sozialform der diskreten Indiskretion, Berlin 1987. S. dazu auch Punkt 6 dieses Kapitels.

503 Der ersten Auflage des Almanachs im September 1796 folgte eine zweite im November und eine dritte im Januar 1797.

504 Goethe und Schiller teilten ihre Hiebe gegen aktuell mit innen verfeindete Personen, wie den Komponisten Reichardt, und gegen literarische Strömungen, die Berliner Aufklärung ebenso wie die Romantik aus. Friedrich Schlegels Kritik an Schillers Gedichten wurde damit erklärt, dass er sie rückwärts gelesen haben müsse: „Schillers Würde der Frauen: Vorn herein liest sich das Lied nicht zum besten; ich les es von hinten / Strophe für Strophe, und so nimmt es ganz artig sich aus." Goethe 1992, S.67. Tatsächlich kann die Lektüre dieses Gedichts durch das Rückwärtslesen vielleicht gewinnen.

505 So der Titel eines Beispiels dieser Gegenwehr: Johann Gottfried Dyck / Johann Caspar Friedrich Manso: Gegengeschenke an die Sudelköche von Weimar. Von einigen dankbaren Gästen, Leipzig 1797. Die jüngste Dissertation zum Thema nennt die Xenien „einen in der Geschichte der deutschen Literatur beispiellosen Skandal“. Frieder von Ammon: Ungastliche 
sche Karikatur bildete diesen mit einem Handgemenge ab, welches Herder am Boden liegend und Goethe sich vornehm im Hintergrund haltend zeigt, während Schiller und Nicolai boxten. ${ }^{506}$ Der Berliner Aufklärer äußerte sich getroffen, wehrte sich aber zugleich fachlich, indem er den Versen literarische Schwächen vorwarf, sowie den Machern charakterliche. ${ }^{507}$ Rahel Levin Varnhagen bekam den Almanach mit den Xenien von Humboldt geliehen, ein Kommentar ist leider nicht überliefert. Durch die Polemik der Xenien wurde das Publikum nochmals daran erinnert, dass es ein publizistisches Projekt der Weimarer Klassik gegeben hatte, deren Herausgeber nun alle „guillotinierten“, die „ihre Knie nicht vor den göttlichen Horen gebeugt haben“.508 Ob dieser Knalleffekt in Versform zum Abschluss, der sich nach Schillers Voraussage und Absicht gut verkaufte, nicht eher das Scheitern der Horen betonte als ihre Ambitionen, wäre noch zu fragen. ${ }^{509}$ Die nachfolgende Forschung zog es überwiegend vor, die Position Goethes und Schillers als eine rein inhaltliche und kritiklos zu übernehmen. 510

„Diese Geistesgesellschaft ist eine Orgel / wovon Goethe den Blasebalg tritt“ Salon-Kritik in einer Satire auf die Xenien ${ }^{511}$

Interessant für die Rezeption der Berliner Salons sind die Xenien als HorenNachfolger insofern, als eine ihrer Gegenschriften sich nicht nur gegen die Verfasser, sondern explizit gegen die Berliner Goethefreunde richtete. In einer heute vergessenen Satire wird die Rezeption der Goethetexte in den Berliner Salons selbst Gegenstand der Kritik. Der so genannte Mücken-Almanach von

Gaben. Die ,Xenien“ Goethes und Schillers und ihre literarische Rezeption von 1796 bis in die Gegenwart, Tübingen 2005, S. I.

506 Christian Schule: Die Xenienritter, nach einer Zeichnung von Johann August Rossmaßler, 1797, Klassik Stiftung Weimar, Museen.

507 Vgl. Nicolai 1797.

508 Carl August Böttiger an Joachim Christoph Friedrich Schulz, 30. 10. 1796, in: Bode 1999, Bd. 2, S. 81.

509 „Man wird schrecklich darauf schimpfen, aber man wird sehr gierig danach greifen [...].“ Friedrich von Schiller an Wilhelm von Humboldt, 4. 1. 1796, in: Schiller 1992-2002, Bd.12, S. 129

$510 \mathrm{Zu}$ Recht weist Jost Hermand darauf hin, dass es leicht ist, im Nachhinein die Perspektive der literaturgeschichtlichen „Sieger“ einzunehmen, dass es Goethe und Schiller aber mehr ausgezeichnet hätte, wenn sie nicht so auffällig zugleich mit ihren Werken ihre Klassenprivilegien verteidigt hätten, gegen progressivere Autoren. Jost Hermand: Mit scharfer Klinge. Der Xenien-Krieg von 1796, in: ders.: Pro und Contra Goethe. Dichterische und germanistische Stellungnahmen zu seinen Werken. Bern [u. a.] 2005, S. 33-48, hier S. 37 u. 45.

511 [anon.:] Mücken-Almanach für das Jahr 1797, Pest 1797, S. 120. 
1797 ließ die Xenien als Mücken durch Deutschland reisen und ihre Erfahrungen beschreiben. Besonders warm und als Werk Goethes per se positiv aufgenommen wurden sie demnach in der Hauptstadt, und hier besonders bei den „Judengenossen“.512 Die Satire imaginiert als Höhepunkt der Xenien-Rezeption eine persönliche Einladung an die Xenien von seiten einer Berliner „GötheGesellschaft“ bzw. eines „Göthischen Clubs“, der vor übertriebener Gefühligkeit überfließt. Namen werden nicht genannt, aber die Zusammensetzung dieser Geselligkeit wird bezeichnend charaktierisiert: „Plötzlich stürmet auf uns ein eine schreibende Haufe von Damen/Adlicher Referendärs, Juden und Gensd'armerie." So ist es nicht unerklärlich, dass zeitgenössischen Leser diesen Goethe-Club als jüdischen Salon identifizierten: „Hat man bei Ihnen keine Vermutung von wem der Mücken-Almanach sein kann? Hier tut er dem GoetheKlub sehr weh. Alles zusammengenommen, sehe ich nun, dass die Ausfälle einer Gesellschaft gelten, die Madame Herz, Frau des jüdischen Arztes und Philosophen, noch vor Jahr und Tag alle Mittwoch regelmäßig hielt“. ${ }^{513}$ Sander, der dies nach Weimar kolportierte, behauptete im selben Brief allerdings auch und fälschlich, dass Goethe bei seinem Berlinbesuch im Hause Herz vorbeigeschaut und Interesse für ihren „nicht unförmlichen Rumpf“ gezeigt hätte. Der Mücken-Almanach ist also nicht als Quelle für eine tatsächliche Goetherezeption in Berlin zu lesen, sondern als Hinweis darauf, dass man 1797 Berliner Juden mit zuviel Begeisterung für Goethe in Verbindung brachte, fälschlicherweise annahm, dass gewisse Salons pauschal alles von Goethe verehrten, und dass man Goethe mit seinen - vorgeblich exaltierten - jüdischen Verehrern verunglimpfen konnte.

Zusammenfassend lässt sich sagen, dass die Horen, entsprechend ihrem Status als erstem publizistischem Großprojekt der Klassik, von der Berliner Salongesellschaft zeitnah und mit großem Interesse rezipiert wurden. Es gab mehrere personifizierte Kommunikationskanäle zwischen Berlin und Weimar, über die ,Insiderinformationen' angefragt und gesendet wurden, oft waren die Berliner noch vor Erscheinen einer Ausgabe und vor öffentlichem Bekanntwerden der Entschlüsse der Herausgeber darüber informiert. Umgekehrt bestand seitens der Herausgeber großes Interesse an der Rezeption in Berlin und speziell der Salons, wobei negative Kritik zumeist dem veralteten oder schlechten Geschmack der Leser angelastet wurde. Die Horen im Ganzen hatten kaum

512 Der Almanach ist, ohne erkennbaren inhaltlichen Zusammenhang, relativ antijüdisch: Berlin wird eingeleitet mit dem Vers: „Jude und Christ: Dort in den Strassen schreitet in gleichen Spondeen der Christe; Aber als Prosa läuft, hüpfet und kriechet der Jud.“ Und unter dem Vers „Judengenossen: Einigt sich Jude und Christ, da gibt es poetische Prose. Solch ein närrisches Ding kroch uns auch bald in den Weg." Mücken-Almanach 1797, S. 98.

513 Johann Daniel Sander an Carl August Böttiger, 25. 3. 1797, in: Bode 1999, Bd. 2, S. 103. 
den gewünschten pädagogischen Effekt auf den Geschmack einzelner Berliner Leser: Markus Herz blieb bei seiner persönlichen Achtung vor Schiller und ebenso bei seiner Kritik an dessen Schreibart in den Horen, Rahel Levin Varnhagen ließ sich in ihrer Wertschätzung Goethes durch ihre Enttäuschung über dessen Unterhaltungen nicht erschüttern, aber auch nicht abhalten von Kritik im Detail.

Humboldts Horen-Aufsätzen wurde vom zeitgenössischen Publikum nicht die Bedeutung zugemessen, die ihnen post factum in der Geschlechterdebatte eingeräumt wurde. Sein Entwurf eines polaren Geschlechtermodells scheint zu der Zeit keine größere Diskussion ausgelöst zu haben, stattdessen lassen sich vermehrtes briefliches Kopfschütteln, ironische und spielerische Brechungen des Modells nachweisen. Humboldt, Schiller und Goethe fühlten sich mit diesem Projekt wie im Allgemeinen so besonders in Berlin unverstanden. Humboldt nahm infolgedessen lange Zeit davon Abstand, seine anthropologischen Theorien weiter zu bearbeiten. Schiller und Goethe revanchierten sich bei ihren literarischen Gegnern und dem uneinsichtigen Publikum mit ihren Xenien.

Ein Unterschied zwischen der Berliner und der allgemeinen Rezeption bestand am ehesten darin, dass sich in den hier untersuchten Briefwechseln kaum (sittliche) Empörung finden lässt, wie zum Beispiel in der Weimarer Reaktion auf Goethes Elegien. ${ }^{514}$ Satirisierungen der klassischen Texte, wie etwa Schillers Ode an die Freude durch einen Chor der Berliner Freudenmädchen, nahmen die an den Salons Beteiligten überwiegend amüsiert zur Kenntnis: diesen Kuss der ganzen Welt.

\section{Salons und Badeorte}

Es ist kein Zufall, dass in einem Überblick zu den Orten der Salonkommunikation, also zu Orten, die stände-, berufs-, konfessions- und geschlechterübergreifende Begegnungen erlauben, drei Badeorte erwähnt werden. Nicht nur die Forschung hat lange Zeit Kur- und Badeorte als besonders kommunikative Orte definiert, da sie über eine ungewöhnliche Fülle an Kontaktmöglichkeiten verfügten. Bereits die zeitgenössischen Beobachter des geselligen Treibens in den

514 Ähnlich verhält es sich bei den „Xenien“. Wohl nahmen einige Berliner den Fehdehandschuh auf, aber die in Weimarer Kreisen geäußerte Befürchtung, dass „das Maß des Schicklichen und Honetten“ überschritten sei und ein „gar zu übler, grober Ton in unserer literarischen Welt eingeführt" werde, fand sich in Berliner Salonkreisen nicht, womöglich weil die spöttische Haltung Friedrich Nicolai gegenüber eher geteilt wurde. Vgl. Friedrich Schlichtegroll an Carl August Böttiger, 3. 10. 1796, in: Bode 1999, Bd. 2, S. 76. 
Badeorten, die Gäste und ihre Besucher, berichteten von einer „Brunnen-Freyheit“. ${ }^{515}$ Diese und ähnliche Wortschöpfungen ${ }^{516}$ bezogen sich sowohl auf die mögliche Frequenz der Bekanntschaften als auch auf das Interesse der Beteiligten, außerhalb ihrer üblichen Gesellschaftskreise Kontakte zu knüpfen. Es ist anzunehmen, dass in dem Maße, wie im Laufe des 18. Jahrhundert das gesellschaftliche Kur-Leben den reinen medizinischen Effekt als Hauptattraktion eines Badeaufenthaltes ablöste, potentielle neue Kontakte zunehmend ein Motiv wurden, „ins Bad zu fahren“. Im Zusammenhang mit den jüdischen Salonièren ist zu fragen, bis zu welchem Grad diese „Brunnenfreyheit“ auch für sie galt und ihnen dazu dienen konnte, neue Bekanntschaften zu schließen. Welchen Effekt hatte der Besuch dieser „Laboratorien bürgerlicher Gesellschaft" für die Berliner Salonièren?517

Um den Laborcharakter zu ermessen, ist zwischen den ideellen Erwartungen und Vorgaben einerseits - dem Bild der Badeorte als soziale Treffpunkte, wie es bereits in zeitgenössischen Werbeschriften für Badereisen und in der

515 „Brunnen-Freyheit. Herr Lessing ist hier und ich befinde mich wohl.“ Justus Möser an Thomas Abbt, 5. 7. 1766, in: ders.: Briefwechsel. Neu bearbeitet von William F. Sheldon in Zusammenarbeit mit Horst-Rüdiger Jarck, Theodor Penners und Gisela Wagner, Hannover 1992, S. 409. Der hier auf Pyrmont bezogene Begriff wurde zwar nicht einhellig verwendet, das Thema war aber in Briefen aus Kurorten im späteren 18. Jahrhundert kontinuierlich präsent. Vgl. Brigitte Erker: „Brunnenfreiheit“ in Pyrmont. Gesundheit und Geselligkeit im letzten Drittel des 18. Jahrhunderts. in: Raingard Eßer / Thomas Fuchs (Hrsg.): Bäder und Kuren in der Aufklärung. Medizinaldiskurs und Freizeitvergnügen (Aufklärung und Europa, Bd. 11), Berlin 2003, S. 53-98.

516 Es wurde u. a. auch von „Brunnenprivilegium“ und „Brunnengesundheit“ gesprochen. Vgl. als aufschlussreichen ,Originalton‘: Alfred Schröcker (Hrsg.): Die wahre Brunnenfreiheit. Das Kurtagebuch des Johann Christian Kestner vom 9. bis 30. Juli 1765 in Bad Rehburg, Hannover-Laatzen 2005, bes. S.16, 20, 30.

517 Dabei muss man einen Unterschied machen zwischen den Anfangsjahren der Salons, in denen Badeaufenthalte dazu nützen konnten, den Bekanntenkreis zu erweitern, und den Badeaufenthalten von Frauen, die in der Gesellschaft bereits etabliert waren und sich hier womöglich von ihren Verpflichtungen erholen wollten. Kaum in diesem Zusammenhang betrachtet wurde ein Traum Rahel Levin Varnhagens, die 1825 schrieb: „Es kann uns nie in Verlegenheit setzen, wenn wir nur wir sein sollen; aber wohl, wenn wir unsere Maske vorstellen müssen! [...] Das fiel mir von neuem bei der Vorstellung ein, wie ich mich in einem Orte, zum Beispiel in einem fremden Bade, ganz getrost befinden könnte, mit dem geringsten Anzuge, [...] nur auf dem Umgang der Leute beschränkt, mit denen man wahrhaft zu tun hat, oder Bauersleute oder dergleichen. [...] es müsste kein Bekannter dort sein. Der wollte doch schon, daß ich ferner nach meiner vorigem ihm bekannten Maske leben soll.“ Rahel Levin Varnhagen, Tagebucheintrag 19. 6. 1825, in: Kemp 1979, Bd. IV, S. 274. Der Begriff Laboratorium nach: Ute Lotz-Heumann: Kurorte im Reich des 18. Jahrhunderts - ein Typus urbanen Lebens und Laboratorium der bürgerlichen Gesellschaft: Eine Problemskizze, in: Eßer / Fuchs 2003, S. 15-36, bes. S. 25 ff. 
diesen folgenden Sekundärliteratur bis heute entworfen wurde - und der tatsächlichen Infrastruktur andererseits, den Treffpunkten und Ritualen der jeweiligen Kurorte, zu unterscheiden. ${ }^{518}$ Das Verhältnis zwischen beidem wird im Folgenden an den drei Badeorten untersucht, die 1794/95 von den Berliner Jüdinnen aufgesucht wurden: Bad Freienwalde (5.1.) sowie Teplitz und Karlsbad (5.2). Nach einer topografischen und inhaltlichen Rekonstruktion des als einschneidend geltenen Zusammentreffens mit Goethe (5.3.) wird nach den Konsequenzen dieser Begegnung (5.4.) und abschließen nach den Analogien zwischen Salon und Badeort (5.5.) gefragt.

Obwohl verschiedene Disziplinen sich des Themas „Kurort“ und besonders „Kurgesellschaft“ angenommen haben und Arbeiten aus der Sozial-, Kur- und

518 Bereits in der zweiten Hälfte des 18. Jahrhunderts formierte sich in Briefen, Reiseberichten und Zeitschriften ein Diskurs über die Frage, an welchem Kurort die Kurgesellschaft dem Ideal, Kontakte zwischen Adel und Bürgertum zu befördern, überhaupt nahekam. Beispielsweise war Pyrmont „verschrien“ wegen seiner „Distinction“.

S. ausführlich Erker 2003, bes. S. 87-9. Die Frage, inwieweit der Umgang zwischen Gästen jüdischer und christlicher Herkunft durch Badeorte befördert wurde, wurde hingegen kaum öffentlich diskutiert und, abgesehen von biografischen Einzeluntersuchungen, wenig in der Forschung bearbeitet. Zur Perversion dieser Zusammentreffen, dem so genannten „BäderAntisemitismus“ als Phänomen des späten 19. und 20. Jahrhunderts s. Frank Bajohr: „Unser Hotel ist judenfrei“. Bäder-Antisemitismus im 19. und 20. Jahrhundert, Frankfurt/M. 2003. In dem aktuellsten Forschungsüberblick zum Thema Badeorte in der Neuzeit werden Überlegungen wie „Inwieweit hatten Kurorte ,Emanzipationsfunktionen“ für Frauen und Juden?“ als aktuelle Forschungsfrage formuliert. Lotz-Heumann 2003, S. 27. Bis heute kaum untersucht ist der ,Ort' bedürftiger Kranker im Badewesen. Mit einem Blick auf die Kosten schon ist nicht zu bestreiten, dass die Kur um 1800 ein elitäres Phänomen war. So zeigt ein zeitgenössischer Bericht aus England, dass der wöchentliche Verbrauch von Mehl zum Haarepudern in Bath 600 städtische Arme hätte ernähren können. Bath Chronicle, 20. 1. 1790, in: Erker 2003, S. 98. In der Forschung ist der Grad, bis zu dem Kurorte gesellschaftliche Freiräume schufen, heute umstritten. Die Umsetzung der „BrunnenFreyheit“ wird zunehmend hinterfragt. Es gibt euphorische Werbesätze wie „Der Mensch wird im Bad gereinigt [...], seine Glieder lösen sich, im Bade löst sich aber auch seine Zunge, er wird dort zum homo socialis. Badgeschichte ist also im weitesten Sinne auch Kulturgeschichte, oft mit definitiver politischer Konsequenz!“ Otfrid Pustejovsky, Politik und Badeleben, in: Große Welt reist ins Bad. 1800-1914. Baden bei Wien, Badgastein, Bad Ischl, Franzensbad, Karlsbad, Marienbad, Teplitz, München 1980, S. 18-23, hier S.18. LotzHeumann hingegen nennt das Bild von der „gelockerten Moral und der nachlässig praktizierten Religiosität“ in Kurorten „ein häufig wiederholtes Klischee, das es zu prüfen gilt.“ Lotz-Heumann 2003, S. 27. Einen kaum beachteten, aber sehr interessanten Ansatz bietet der Aufsatz von György Sebestyen über Unnatur in der Kur, versinnbildlicht in der Kurpromenade. György Sebestyen: Die Kurpromenade oder die Erfindung der Kunstnatur, in: Große Welt reist ins Bad, S.36-43. Demnach entwickelten Kurgäste „eine ganze Reihe an Kunstgriffen, um natürlich zu erscheinen“. Die Kur wird eine „theatralische Darbietung“, der Kurort ein künstlicher Raum. Ebd., S. 36 ff. 


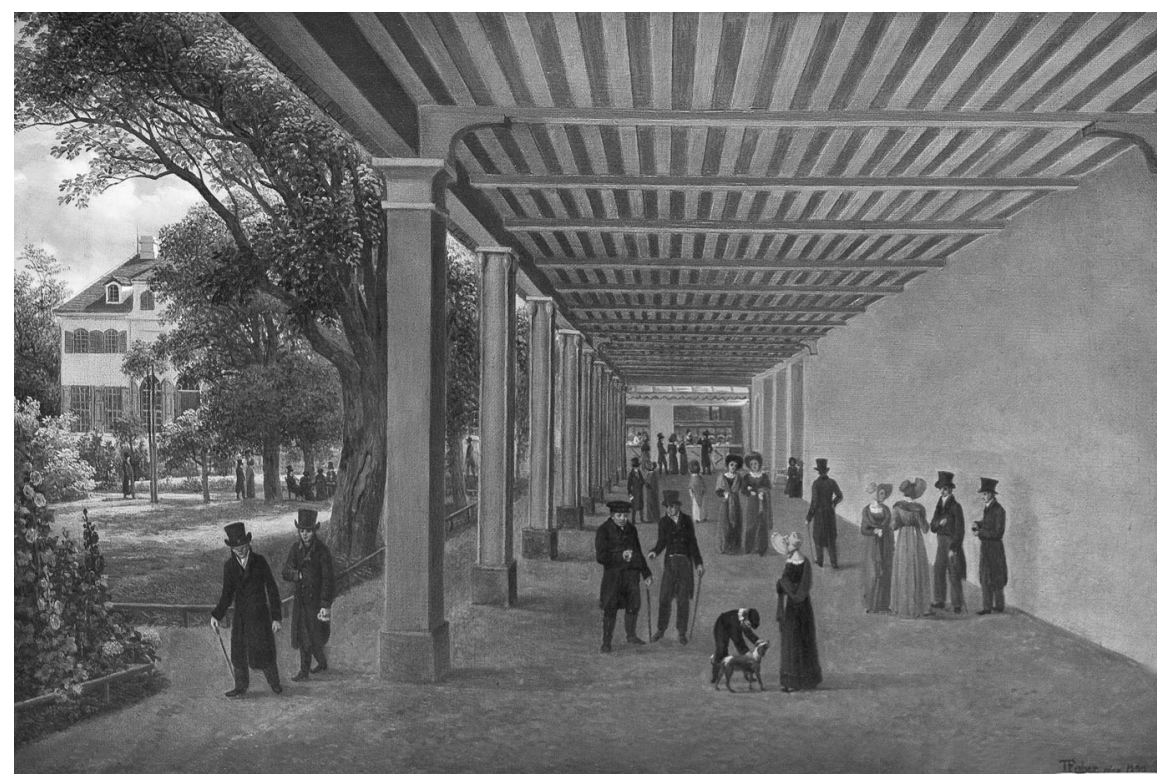

Abb. 13: Treffpunkt Badeort - Trinkhalle in Teplitz (K.G.T Faber, 1822).

Stadtgeschichte vorliegen, ist die Kurstadt im deutschen Sprachraum anders als in der englischen Forschung die „spa town“ noch nicht zum eigenständigen Untersuchungsgegenstand geworden. ${ }^{519}$ Der Badeort teilt mit dem Salon neben potentiellen strukturellen Ähnlichkeiten das Schicksal des „multidisziplinärem Zugriffs“ bei „unübersichtlicher Forschungslage“. 520 Noch im jüngsten Forschungsüberblick zum Thema charakterisiert Ute Lotz-Heumann die Literaturlage zu Badeorten um 1800 als überwiegend von lokalgeschichtlichen oder populärwissenschaftlichen Arbeiten geprägt. ${ }^{521}$ Für Detailfragen zum Kurleben

519 Insbesondere Badereisen(de) des 18. Jahrhunderts werden in Gesamtdarstellungen zur Badegeschichte wie auch zur Bürgertumsgeschichte nur am Rande thematisiert. Bezeichnend sind Periodisierung und Begrifflichkeit: Die meisten Arbeiten gehen davon aus, dass im 18. und 19. Jahrhundert die Funktion des Badeorts als gesellschaftlicher Treffpunkt die des Heilbades zunehmend in den Schatten stellte; die Datierung dieser Wende ist höchst unterschiedlich und kaum belegt.

520 Reinhold P. Kuhnert: Urbanität auf dem Lande. Badereisen nach Pyrmont im 18. Jahrhundert, Göttingen 1984, S. 20. Die Bibliografie zur Geschichte des Badewesens, die Kuhnert einklagte, existierte 2010 immer noch nicht.

521 Während Pyrmont auch für die Aufklärungszeit als gut erforscht gelten kann, gibt es zu Karlsbad oder Teplitz im 18. Jahrhundert keine neueren Arbeiten. Zur Badepraxis um 1800 allgemein vgl. Christina Kröll / Hartmut Schmidt: Bäderkunde und Badepraxis in der Goethezeit, in: Jörn Göres (Hrsg.): „Was ich dort gelebt, genossen ...“. Goethes 
in Karlsbad, Teplitz und Freienwalde sind immer noch die Primärquellen aus der Zeit um 1800 am verläßlichsten, Stadtführer ebenso wie Texte der expandierenden Balneologie, Badekunde, und nicht zuletzt Tagebücher und Reiseberichte von Kurenden, wie zum Beispiel die Schriften der Zeitgenossin Elisa von der Recke.522 Für die hier interessierenden Badeaufenthalte der Berliner Salonièren und $\mathrm{zu}$ ihrer Begegnung mit Goethe können mehrere, allerdings überwiegend berichtende und ausmalende Darstellungen der ,Badebiografie“ des Dichters herangezogen werden. Erinnerungen der Salonièren an diesen Aufenthalt gibt es leider kaum. Wesentliche Quellen sind daher auch hier Primärquellen Dabeigewesesener. ${ }^{523}$

\subsection{Freyenwalde}

Bad Freienwalde, im 18. Jahrhundert noch als Freyenwald(e) bekannt, gilt als das älteste Bad in der Mark Brandenburg.524 Zugleich war es zu dieser Zeit die Berlin nächstgelegene Kurmöglichkeit, $50 \mathrm{~km}$ oder sieben preußische Meilen nordöstlich der Hauptstadt im Oderbruch gelegen, in einem Tagesritt oder einer Tagesfahrt zu erreichen. Markus Herz berichtete beispielsweise seiner Mutter 1800 von seiner Fahrt ins Bad: „[...] in der Landsberger Straße schlug es Zehn, und um halb 7 war ich vor meiner Thüre hier“. 525

Als Treffpunkt war die Stadt als solche, nur zehn Straßen groß, für Berliner Besucher weniger interessant. Auch von der jüdischen Gemeinde Freienwaldes lassen sich keine nachweisbaren Verbindungen zur Berliner Salongesellschaft

Badeaufenthalte 1785-1823. Geselligkeit, Werkentwicklung, Zeitereignisse, Königstein 1982, S. $13-53$.

522 Besonders anschaulich für den Badebetrieb sind beispielsweise: Konrad Anton Zwierlein / Karl Gottlob Kühn: Taschenbuch für Brunnen- und Badegäste 1794, Leipzig 1794, sowie David Becher: Neue Abhandlung über das Karlsbad. Von David Becher, der Arzneikunst Doktor. Leipzig: 1789. Vgl. Werner 1927.

523 Vgl. zum Beispiel Göres 1982. Arbeiten aus dem 19. und beginnenden 20. Jahrhundert dienen oft vor allem dazu, die Bindung des „Großen“ an die Stadt zu dokumentieren. Vgl. Eduard Hlawacek: Goethe in Karlsbad. Zweite vermehrte und verbesserte Auflage von Dr. Viktor Ruß, Karlsbad [u. a.] 1883; Victor Karell: Goethe im Egerland. Sein Leben, Forschen und Dichten in den Egerländer Weltbädern. 1785-1823 (Bücher der Heimat, Bd. 34), Altötting 1949. Zum Forschungsstand die Badeaufenthalte der Salonièren betreffend vgl. 5.3.

524 Noch heute nennt sich die Stadt selbst auch „bedeutendster märkischer Badeort“. 1316 wurde „Vrienwalde“ erstmals urkundlich erwähnt. Eine Heilung durch hiesiges Quellwasser wird 1683 erstmals nachgewiesen. Seit 1924 darf sich die Stadt Bad nennen.

525 Markus Herz an „die Frau Doctorin de Lemos“, 1. 7. 1800, in: Landsberg 2000, S. 158. Eine solche Reise war nicht wenig anstrengend. Herz fuhr fort: „[...] ich habe gefroren wie ein Hund, geträuft wie eine Katze und nur Toback geraucht wie ein Mensch.“ Ebd. 
ziehen. ${ }^{526}$ Vielmehr sind es zwei höchst unterschiedliche Bauwerke Freienwaldes, die als für die Salongesellschaft wesentliche Orte benannt werden müssen: der Gesundbrunnen und das Alaunwerk. ${ }^{527}$ Da sowohl diese Sehenswürdigkeiten als auch die Stadt selbst in Arbeiten zu der Zeit wenig, in Biografien Rahel Levin Varnhagens überhaupt nicht erwähnt werden, wird der für Salonkommunikation nicht unwesentliche Badebetrieb in dieser Arbeit am Beispiel Freienwaldes erläutert.

\title{
Im „schönsten Bade-Schwindel“ - Gemischte Gesellschaft im Kurort?
}

\author{
Doch leb' ich recht artig mit den Leuten hier, denn sie sind sehr gütig gegen mich; \\ und Sie wissen, wie ich auf antworten halte, \\ und was ich für ein geselliger Hund neben meiner Tadelsucht bin. \\ Rahel Levin Varnhagen aus Freienwalde, $1794^{528}$
}

Auf den Kurreisen berühmter oder besonders wohlhabender Reisender um 1800 wurde Bad Freienwalde nicht eingeplant. Es ist anzunehmen, dass der Ort Ende des 18. Jahrhunderts das war, als das ihn Theodor Fontane noch 70 Jahre später beschrieb: ein „märkisches Bad“, dessen Gäste überwiegend „märkische Nachbarn, Fremde aus nächster Nähe“ waren. ${ }^{229}$ Die Materiallage zum Kur- und Gästebetrieb Freienwaldes in der zweiten Hälfte des 18. Jahrhunderts ist dürftig und besteht für diesen Zeitabschnitt aus überwiegend thesenartigen Texten. Stadthistoriker halten es zum Beispiel für unwahrscheinlich,

526 In Bad Freienwalde lässt sich jüdisches Leben spätestens seit 1674 nachweisen. 1786 berichtet Nicolai von 1.863 Einwohnern, darunter 187 Juden. Nicolai 1786, Bd. 3, S. 1066. Zur jüdischen Gemeinde vgl. Reinhard Schmook: Bad Freienwalde, in: Irene Dieckmann / Julius H. Schoeps: Wegweiser durch das jüdische Brandenburg, Berlin 1995, S. 16-21.

527 Mit Gesundbrunnen wurden, im Gegensatz zu den Thermen, die so genannten kalten Quellen bezeichnet, die etwa ab dem 16./17. Jahrhundert genutzt wurden. Alaun, chemisch Kalium-Aluminumsulfat, wurde als Gerbstoff und zum Fixieren von Farbstoffen auf Gewebe verwendet. Es wurde aus Alaunschiefer gewonnen und seit 1717 in Freienwalde in Stollen abgebaut.

528 Rahel Levin Varnhagen an Gustav von Brinckmann, 15. 7. 1794, zit.: nach BdA I, S. 76. „Bade-Schwindel“ im selben Brief, ebd., S.73.

529 Theodor Fontane: Wanderungen durch die Mark Brandenburg, Zweiter Teil: Das Oderland. Barnim-Lebus, hrsg. von Gotthard Erler und Rudolf Mingau (Theodor Fontane. Große Brandenburger Ausgabe. Wanderungen durch die Mark Brandenburg, 2), Berlin 1997 S. 51. „Freienwalde ist kein Roulette- oder Equipagenbad, [...] am wenigsten ein Bad der fünfmal gewechselten Toilette. [...] hier wird noch gefrühstückt, hier sucht noch kein grüner oder schwarzer Tee die alte Herrschaft des Morgenkaffes zu untergraben.“ Ebd. Hervorhebung im Original. 
dass sich zu dieser Zeit bereits Juden unter den Badegästen befanden, was jedoch schon durch die Kuraufenthalte Rahel Levin Varnhagens 1793 und 1794 belegt ist, im letzten Jahr begleitet von ihrem Bruder, besucht von Sophie Meyer Fränkel. 1795 kamen Friederike Liman, Hitzel Fließ Boye Sparre und Henriette Mendelssohn zum Baden in die Stadt. ${ }^{530}$ Allerdings ist die Vermutung, dass Personen nach ihrer Herkunft ausgeschlossen gewesen sein könnten, nicht unberechtigt, da die Polizeiordnung von Pyrmont zur selben Zeit Juden und Christen gemeinen Standes von den Hauptorten des Badens abhielt. 531

Um einen Eindruck vom Badebetrieb der 1790er-Jahre zu gewinnen, muss man die Bade-Reglements, zeitgenössische Stadtbeschreibungen, die überwiegend im aufklärerisch-sachlichen Stil gehalten sind, und die Briefe der Gäste nebeneinander lesen. ${ }^{532}$ Welche Formen und Orte der Kommunikation, welche Ansätze einer gemischten Gesellschaft waren in Freienwalde 1793 und 1794 möglich?

Der Gesundbrunnen, bestehend aus mehreren namhaften Quellen, „2302 Schritt oder 4604 preußische Fuß“ vom Stadtzentrum entfernt, war über eine Allee zu Fuß zu erreichen, ein Spaziergang, der Gästen aller Stände und Schichten nahegelegt wurde. ${ }^{533}$ Den Ablauf des Kuraufenthaltes und die Vorschriften für das Miteinander „auf“ dem Brunnen waren in Brunnenreglements niedergelegt. ${ }^{534}$ Als weitere öffentliche Lustbarkeiten neben dem Gang zum Brunnen werden die Promenaden oder unter freiem Himmel dargebotene Musik erwähnt. „Da zur Aufmunterung der Brunnen- und Badegäste die

530 Briefe Rahel Levin Varnhagens mit Bezug zum Kurbetrieb und dem Absender Freyenwalde wurden bereits 1834 gedruckt. Vgl. GW I, S. 58-60 und 73-81. Die Information zu Ludwig Robert nach: Consolina Vigliero, „Setzen sich da Polonius und Pilades und Iphigenie (Vater Freund und Schwester) hin und schreiben an Ludwig Robert.“ Der Briefwechsel von Rahel Levin Varnhagen und Ludwig Robert, in: ERLV II, S. 911-942, hier S. 939. Alle anderen nach Bosold 1996, S. 21-29. Der Hinweis auf Sophie Meyer Fränkel nach: Rahel Levin Varnhagen an Gustav von Brinckmann, 25. 7. 1794, ungedruckt, BA V. 531 Die „Polizeyordnung“ von 1795 regulierte die Zeiten für Arme, Juden und Christen gemeinen Standes und hielt sie von den gesellschaftlichen Hauptorten fern. Erker 2003, S. 70 .

532 Die in den Jahren von Rahel Levin Varnhagens Aufenthalt günstigen Bestimmungen lassen sich aus dem Brunnenreglement von 1792 ablesen. Gästelisten, wie sie aus anderen Orten und vor allem aus dem späteren 19. Jahrhundert überliefert sind, gab es noch nicht. 533 Thomas Philipp von der Hagen: Beschreibung der Stadt Freyenwalde, des dasigen Gesundbrunnnens und Alaun=Werks. Aus Urkunden und glaubhaften Nachrichten zusammengetragen. Mit vielen Kupfern, Berlin 1784, S. 56.

534 Reglement für den Gesundbrunnen zu Freienwalde. De dato Berlin, den 24. April. 1792, Berlin 1792. Ich danke dem Oderlandmuseum Bad Freienwalde für das Zusenden des Dokuments als Bilddatei. 
Musik gut beitragen kann“, wurde eine „Musikeinrichtung“ installiert, für die - aus nicht näher bezeichnetem Grund - jeder Mann acht und jede Frau vier Groschen zu zahlen hatte. Dafür wurden von der Stadt Musikanten bezahlt, die auf dem Platz vor dem Brunnen und bei der Mittagstafel aufspielten. 535

Im Vordergrund des Kuraufenthaltes standen auf Empfehlung der Badedirektion jedoch das Baden und die Ruhe. Für die Gemütsruhe der Gäste wurden das „Tobackrauchen“ und ein Seitengewehr zu tragen bei Strafe verboten. (Mit dem Seitengewehr wurde zugleich ein Adelsprivileg aus diesem Kurort entfernt.) Zänkereien anzufangen oder sich darauf einzulassen, wurde mit Geldstrafe belegt, Feuerwerke und Schoßhündchen brauchten Genehmigungen. Als Unterkunftsmöglichkeiten werden, in dem Reiseführer, der Rahel Levin Varnhagens Aufenthalt zeitlich am nächsten liegt, für Gäste unterschiedliche Möglichkeiten erwähnt. Nachdem die Gäste sich beim Brunnen-OekonomieInspector gemeldet und ihren Gesundheitszustand beim Brunnen-Medicus „angezeigt“ hatten, konnten sie in einem der beim Brunnen gelegenen GästeHäuser, dem Kurhaus oder dem so genannten Fürstenhaus, in Privatquartieren in den Bergen oder in der Stadt Wohnung nehmen. ${ }^{536}$

\section{Schichten und Stände im märkischen Badebetrieb}

Theoretisch waren alle der Kur Bedürftigen, unabhängig von der Herkunft, zum Badebetrieb zugelassen. Tatsächlich war aber bis zum Jahr 1794 die 1706 erstmals eingeführte Badeordnung durch Reglements mehrfach differenziert und verschärft worden. Hatte der Große Kurfürst Arme noch in beschränktem Maße beim Gesundbrunnen eingeplant, 537 wurden sie später von den Anlagen überwiegend ferngehalten und nur mit Attest zugelassen, für dieses Arrangement zahlten die wohlhabenderen Gäste eine Abgabe. ${ }^{538}$ Eine 1792 einge-

535 Reglement für den Gesundbrunnen 1792, §3. Sofern nicht anders erwähnt, sind die Regelungen für Freienwalde diesem Text entnommen.

536 Von der Hagen 1784, S. 59. Eine hier angefügte Statistik zeigt, dass Freienwalde anno 1779 z. B. 239 Gäste hatte, „als in der Stadt logiret 59, beym Brunnen 180.“ Ebd., S. 62. Leider macht Rahel Levin Varnhagen weder für sich noch für ihre Freundinnen eine Angabe zur Unterkunft.

537 Ein Kupferstich aus dem Jahr 1785 zeigt noch ein „Armenhaus oder Lazareth“ in der Nähe des Gesundbrunnnens. G. F. Schleuen: „Prospect des Gesund Brunnenes Bei Freienwalde an der Oder“, Sammlung Dr. Denk, Verlag Rainer Schönbach, Bad Pyrmont. 538 Fontane berichtet, dass die Gegenwart des Kurfürsten und zu erwartende Wohltaten anfangs große Anziehungsfaktoren für den Gesundbrunnen gewesen seien. Im Jahr 1685, ein 
führte Kurtaxe, das so genannten „Ökonomie-Geld“ von drei Reichstalern pro Person wird den Kreis der Badbesucher weiter eingeschränkt haben. Die Differenzierung des Badereglements wurde allerdings von der Lockerung der religiösen Vorschriften begleitet. ${ }^{539}$

Für den Badebetrieb als solchen wird keine strikte Trennung nach Stand und Schicht, wohl aber unterschiedliche Badegewohnheiten überliefert, etwa dass die „Vornehmeren“ ihr Bad in ihrem Zimmer nähmen und dass Leute vom „gewöhnlichen Stand“ das Bad am Brunnen nutzten. ${ }^{540}$ Rahel Levin Varnhagen spricht in den Briefen davon, ,auf den Brunnen“ $\mathrm{zu}$ gehen, sie scheint also das Gemeinschaftsbad genutzt zu haben. ${ }^{541}$ Während des Bades selbst war die Kommunikation aber eingeschränkt, da die Gäste zwar im selben Gebäude, aber in 16 einzelnen hölzernen Kabinen kurten. Eher wird der Gang zum Brunnen selbst Gelegenheit zur Kommunikation gegeben haben.

Wenn es Rahel Levin Varnhagen und Friederike Liman, wohlhabenden jüdischen Kaufmannstöchtern, möglich war, zahlreiche neue Bekanntschaften, darunter einige adliger Herkunft, $\mathrm{zu}$ machen, lag es vermutlich, neben der baulichen Dichte der Stadt, an einer spezifischen Bade-Ort-Einrichtung, der Gast-Tafel oder ,allgemeinen Tafel“. Dabei handelte es sich um eine Art öffentlicher Mittags- und Abendtafel, für die sich jedermann anmelden konnte bzw. sollte, denn selber kochen zu lassen war nicht gestattet.542 Ein „Oekonom“ nahm die Anmeldungen entgegen und reservierte die Plätze in der Reihenfolge der Meldung. Je früher man anreiste, desto weiter oben saß man. Es wurde nicht nach Rang und Titel platziert. Ein „Tafeldecker“ legte Namenszettelchen auf die Plätze und sorgte dafür, dass die Sitzordnung eingehalten wurde. Diese

Jahr nach der offiziellen Anerkennung als Badeort, seien 1.500 Gäste in Freienwalde gewesen, für die ein eigener Brunnenkoch engagiert worden sei. „Was diesen letzteren angeht, so hatte er die Verpflichtung, für anderthalbe Silbergroschen ein ,gutes Mittagbrot" zu liefern. Freilich nur für die Armen. Der Kurfürst tat in allem, was er konnte.“ Fontane 1997, S. 70

539 Das Brunnen-Reglement von 1706 hatte noch regelmäßige Betstunden vorgeschrieben und verfügt: „Keiner soll wegreisen, bevor er angedeutet, wie er sich befinde, was für Besserung er vermerke, und Gott danken lasse.“ Brunnen-Reglement 1706, in: Hagen 1784, S. 123 f., hier: 123. Spätere Reglements enthalten keine Bezüge zum Kirchenbesuch. 1792 ist von einem öffentlichen Gottesdienst am Brunnen die Rede.

540 Hagen 1784, S. 61.

541 Rahel Levin Varnhagen an Gustav von Brinckmann, 23. 7. 1793, in: GW I, S. 58.

542 Die „Vorschriften für diejenigen welche auf dem Gesundbrunnen zu Freienwalde an der allgemeinen Gasttafel speisen, und für ihre Bedienung “ wurden von der Königlich Preußischen Regierung erlassen und ausgehängt. Ein gleichnamiger Aushang, aus dem Jahr 1825, ist im Archiv des Oderlandmuseums überliefert. Ende des 18. Jahrhunderts wurde die Ordnung für die Tafel im Brunnenreglement festgelegt. 
Maßnahme diente explizit der Lockerung der gesellschaftlichen Umgangsformen, denn, so formulierte die Direktion: „Keinem billigen Brunnengast kann die Bemerkung entgehen, dass, wenn er auf die Vorrechte seines Ranges und Standes strenge besteht, ihm dadurch das gesellschaftliche ungezwungene Leben auf dem Brunnen selbst entzogen wird“. 543

Rahel Levin Varnhagen schrieb mehrfach davon, „bei Tische“ jemanden gesprochen, oder auch nur „gesehen“ $z u$ haben, was für einen Platz an dieser großen Gast-Tafel spricht. ${ }^{544}$ Die Möglichkeit, öffentlich an einer Tafel zu essen, gab es zwar auch in anderen Badeorten, allerdings war der Zugang keineswegs immer allgemein, die Gäste nicht notwendig gemischt. Johanna Schopenhauer berichtete beispielsweise aus Pyrmont von der Möglichkeit, sich eine Frühstückstafel im Freien „etablieren“ zu lassen. Hier saßen aber die Bürgerlichen und die Hofgesellschaft an getrennten Tischen, konnten einander nur beobachten. ${ }^{545}$

Generell vermitteln die Briefe der Berliner jüdischen Frauen einen Eindruck davon, dass es in Freienwalde besonders unkompliziert war, Personen höheren Standes kennenzulernen und gemeinsame gesellige oder gesellschaftliche Ereignisse zu planen. ${ }^{546}$ In der überschaubaren Stadt lernte man viele als

543 Reglement für den Gesundbrunnen 1792, § 16.

544 Vgl. Rahel Levin Varnhagen an Gustav von Brinckmann, 25. 7. 1794, dies ungedruckt, SV 38. Sie habe eine Marie noch nicht kennengelernt, obwohl sie einmal bei Tisch neben ihr saß, denn „sie schien mir ein bischen ängstlich an ihre coterie gefesselt.“ Auch am Spieltisch konnte man sehen oder übersehen, so heißt es im selben Brief „l'abé Hatzfeld wie ihn viele nenen war Gestern, mit Fr: v: Wolff Mam Beisson Zezar Pauline und Hr: v: Kat hier, er spielte aber so l'ombre daß er uns neben sich nicht sah." Diese Stelle in: Hahn / Bosold / Isselstein 1998, S. 170.

545 Sie saß mit ihren Bekannten an einer Tafel, in Sichtweite einer anderen, der die Herzogin von Braunschweig präsidierte: Sie „ergötzte es nicht wenig, das, was in jener uns ganz neuen Hofatmosphäre vorging, wie ein Schauspiel zu betrachten.“ Eine gemeinsame adlige Bekannte bot sich als Vermittlerin an, mit dem Hinweis, „dass an Orten wie diesem auf Hofetikette nicht so strenge gehalten werde, [...] wir hätten nichts weiter zu tun“, setzte sie hinzu, ,als nach dem Rock oder der Hand der Herzogin uns zu bücken, um sie zu küssen“. Schopenhauer, Kaufmannstochter aus der Freistadt Danzig, berichtet, dass diese Bedingung ihr „republikanisches Blut“ in Wallung gebracht hätte: „[...] mit blitzenden Augen und zornbewegter Stimme erklärte ich, dass ich für meine Person unter solchen Bedingungen der mir zugedachten Ehre entsagen müsste.“Johanna Schopenhauer: Im Gedränge der Zeiten, im Gedränge der Welt. Jugenderinnerungen, Tagebücher, Briefe, Husum 2000, S. 198 f. Der Besuch in Pyrmont fand 1787 statt.

546 Wobei diese Details allerdings in den gedruckten Versionen nicht immer überliefert sind So ist z. B. der oben erwähnte Brief, in dem Rahel Pauline Cesar oder Hatzfeld erwähnt, im BdA auszugsweise gedruckt, ohne die Namen und ohne Hinweis darauf, dass es Auslassungen gibt. GW I, S. $79 \mathrm{ff}$. 
\$. I5.

Seit Babegaft foll bei ber allgemeinen Safel, ober aud wenn ex Unpáslidfefts baf:

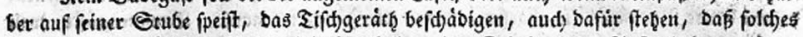

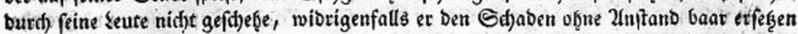

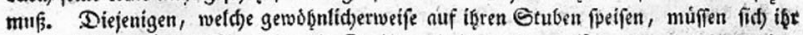

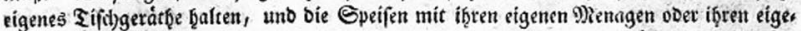
nen Tellern und Sifuiffeln abţolen faffen. Bei einjelnen feltenen Fällen, als Unpáf*

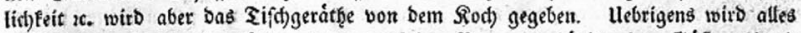

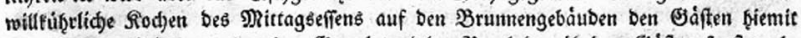

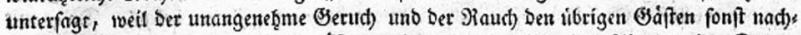
tḩeilig fállt; rogegen Den ß̧aoegáften unbenommen bleibt, Des 2lbenos eine Eupper ein Betid)t Sifide ober Sirebfe in Den Raminen ikgrer Stuben fid) jubereiten ju faffert. Sollte injwifthen jemano feine ganj eigene Mienage ju madjen notb̨wentig balten; fo folt

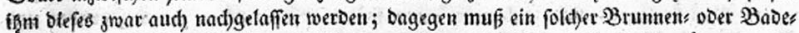
gaft woddentlid) einen ₹(̧aler ad)t Egr. jur SBrunnen s Defonomie, Eaffe prámumeranbo Gejablen, weil auferbem biefe nid)t wütbe befteḩen fonnen. Derjenige aber, weldjet fitd)

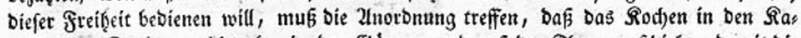

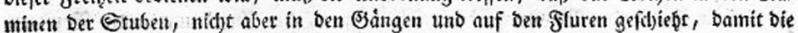

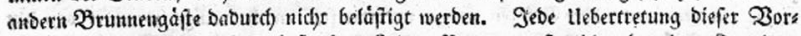

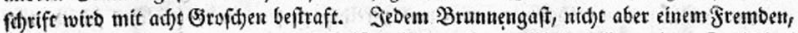

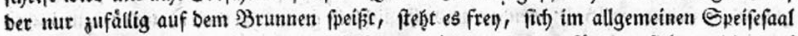
von feinen Bebienten aufiwarten ju laffen, auch wenn ex es für gut finbet, jebesmal

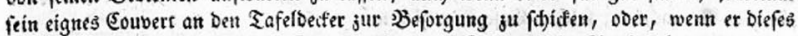

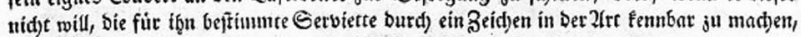
Dá̧ fie nidje mit anoern verwed) felt werbe.

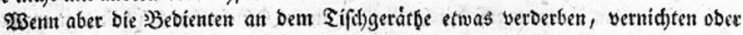

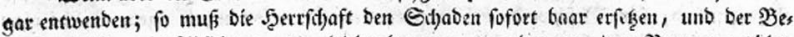
biente, weldger aus 2lbjïd, etwas verbirbt ober gar entwender, von bem \$Brunnengeridfte zur linterfuchung unb Errafe gezogen werben. Soldje Beodenten múfen, wenn bie Brunnen. Direction es veriangt, weggefd)afft, wenigftens von ber 2lufwartung ausger fdloffen werden. Diejenigen Bebienten, weli)e bei Dem 2luf; uno 2lotragen Der Speifen etwas bavon ju jĭd) nebeman ober entwenden, follen gebuib̨reno bejtraft werben, ba für

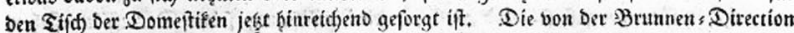
beftellte Bebienten mitien vorjüglid) fúr bie ?(ufwartung ber nid)t mit B̉ebiencen ver.

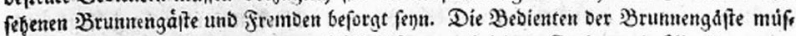

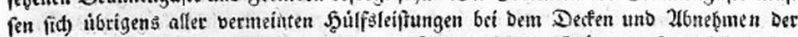
Tafel entḩalten, und wenn etwas feblt, als Teller, Ssffel, Bläer u. f. w. fid) fold)es

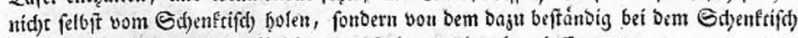
fid) aufbaltenden Btunnen: Bebienten abfordern und geben laffen.

5. 16.

Seinem billigen Brunnengaft famn Die Bemerfung entgeøen, baf, wenn er auf bie

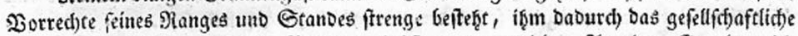
ungejwungene \{eben auf Dem לBrunnen fel6it entjogen wirt. 2fus Dem Srumbe wíro

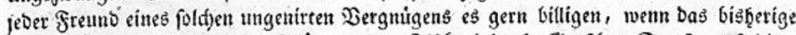

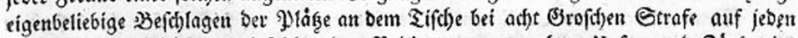
Fall unterfagt wirb, jumal folthes Den Bebienten ju mand)em linfug unb Zánfereien

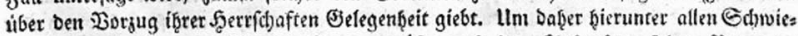

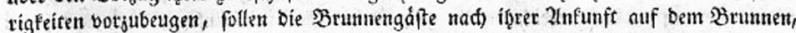
fie mogen bort ober in bet Stabt oder Doritabe woḅnen, went fie gewóthnlid) auf bem

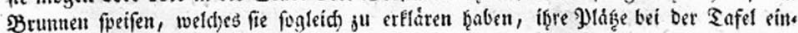

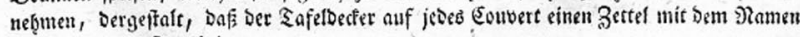
Des B̧runnengaftes ḩintegt.

Tือกท

Abb. 14: Auszug aus dem Brunnenreglement für Freienwalde ... 
๑. 16.

Reinem billigen Brunnengaft fann Die Bemerfung entgeb̨en, baß̧, wenn er auf bie

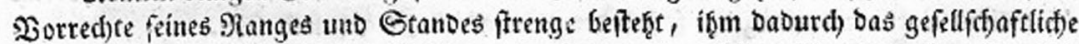

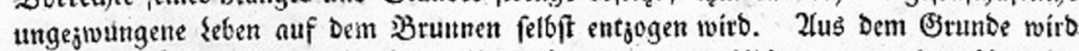
jeber Freuns eines fold)en ungenirten Dergmügens es gern billigen, wenn bas bíş̨erige

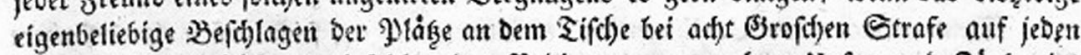
Fall unterfage wirb, jumal fold)es ben Bebienten ju mandbem linfug unb Bánfeteien

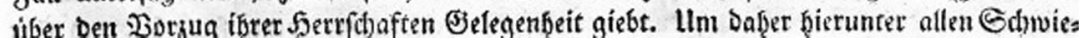

Abb. 15: ... mit der Bemerkung zur Wahrung der Standesgleichheit, 1792.

Nachbarn kennen, Hausgemeinschaften machten Ausflüge. Hitzel Fließ Boye Sparre erwähnte, dass sie mit einer Frau von Hacka in einem Haus wohne, Rahel Levin Varnhagen nannte als neue Bekannte daneben Madame Kircheisen, Herrn von Poch, später einen Herrn O’Grady. ${ }^{547}$ Auch einen Abé Hatzfeld und Familie Cesar mit der Tochter Pauline, die später ihre beste Freundin werden sollte, lernte Rahel Levin Varnhagen in Freienwalde kennen. ${ }^{548} \mathrm{Im}$ Jahr darauf wurden diese Bekanntschaften von Friederike Liman schnell erneuert, dazu kamen die des Schauspieldirektors Reck und verschiedener Offiziere und Aristokraten. Am Tage nach der Ankunft konnte sie schon berichten, dass man Blindekuh gespielt hätte - allerdings machte Liman auch deutlich, dass gemeinsame gesellige Aktivitäten nicht unbedingt Gefallen bedeuteten. So heißt es über die Hofdame von Retzow, „mit der ich zwar schon liirt bin [...]“: „[...] sie gefält mir gar nicht“. 549 Über die Gesellschaft im allgemeinen schrieb „die Fließ“: „die Gesellschaft alhier kann werden, wenn sie ein reiferes Alter erhällt“, und Friederike Liman erwähnt, dass man Ausflüge jetzt mit der „Ellite der Gesellschaft“ mache. ${ }^{550}$ Auch in Freienwalde gab es private Gastgeber, ein Herr von H. gab einen Tee, und zum Mittagessen war sie bei Frau Bernard, der Mutter von Hitzel Fließ Boye Sparre und Philippine Cohen. ${ }^{551}$

Die Ambivalenzen in der Volksnähe der Hohenzollern, denen das Bad gehörte, lassen sich laut heutigen Stadtführern am Beispiel des „Teehäuschens“ ablesen: Der quadratische Pavillon wurde inmitten des Schlossparks

547 Hitzel Fließ Boye Sparre an Gustav von Brinckmann, 16. 7. 1794, in: Rahel Levin Varnhagen an Gustav von Brinckmann, 15. 7. 1794, in: GW I, S. 76 und an dens., 5. 2. 1795, SV 38.

548 Rahel Levin Varnhagen an Gustav von Brinckmann, 25. 7. 1794, die betreffende Stelle, und nur diese in: Hahn / Bosold / Isstelstein 1998, S. 170.

549 Friederike Liman an Rahel Levin Varnhagen, 5. 7. 1795, in: Bosold 1996, S. 21.

550 Hitzel Fließ Boye Sparre, Nachschrift zum Brief der Friederike Liman, 5. 7. 1795, in:

Bosold 1996, S. 22. Friederike Liman an Rahel Levin Varnhagen, 8. 7. 1795, in: Bosold 1996, S. 23

551 Friederike Liman an Rahel Levin Varnhagen, 5. 7. 1795, in: Bosold 1996, S. 21. 
1794/95 für die Königinmutter Friederike Luise errichtet, die regelmäßig in Freienwalde ihre Sommer verbrachte und sich im Pavillon auch von Schauspieler- und Musikgruppen unterhalten ließ. Bei diesen Gelegenheiten wurden die Parktore für die Stadtbevölkerung und gemeine Kurgäste geöffnet, die dann von der Terrasse durch die Fenster zusehen durften. Nach der Veranstaltung wurde der Park wieder verschlossen.552 Die Briefe Friederike Limans könnten auch dies Bild durchaus um einen interessanten Aspekt erweitern. Mehr unter ,ferner liefen‘ erwähnt sie eine Einladung der Königin. „Gestren gab die Königin auf dem Brunnen ein deujeuner dansans; wozu alles invitirt und ich hatte das ,Glück“ der Königin vorgestellt zu werden“. 553 Zwar nicht im Pavillon, sondern am öffentlichen Ort des Brunnens war es dem gemeinen Badevolk damit durchaus möglich, in Kontakt zu den Hohenzollern zu kommen, anders als heute überliefert wird. Allerdings werden auch arrogante Gesten von Adligen überliefert, so von einem Graf von Kalckreuth: „[...] anfänglich nahm er sich sehr ekelicht, stolz und severe nicht allein gegen mich; (den er machte als kente er mich gar nicht) aber auch zu den übrigen Freileins“. 554

\section{Teatime im Alaunwerk}

Wenn mit dem Abstecher zum Alaunwerk an dieser Stelle ein Hinweis auf ein hartes, nicht ungefährliches Handwerk als eine Basis des Überbaus Salongespräch eingeflochten wird, geschieht es im doppelten Sinne cum grano salis: Alaun war ein in aufwändigem Prozess gewonnenes Salz, ein wichtiger Rohstoff für verschiedene Berliner Gewerke. ${ }^{555}$ Das Alaunwerk in Freienwalde könnte für seinen Pächter Aaron Meyer, Vater der beiden Salonièren Sara und Marianne, mit Lieferungen an Manufakturen und Fabriken in ganz Preußen und einem Gewinn von „einigen 20.000 Reichsthalern“ im Jahr als eine

552 So die Recherche-Ergebnisse von Dr. Reinhard Schmook, Leiter des Oderlandmuseums Bad Freienwalde, mündlich mitgeteilt am 30. 6. 2005.

553 Friederike Liman an Rahel Levin Varnhagen, 23. 7. 1795, in: Bosold 1996, S. 26.

554 Friederike Liman an Rahel Levin Varnhagen, 23. 7. 1795, in: Bosold 1996, S. 26 und 29. 555 Während der so genannte Neapolitanische Alaun direkt aus Lava in Bleipfannen zur Kristallisation gebracht werden konnte, mussten u.a. in Freienwalde Rohmaterialien verarbeitet werden, die monate- bzw. jahrelange Verwitterung und mehrere Laugeprozesse benötigten. Zu den zahlreichen Einsatzgebieten von Alaun siehe den Artikel „Alaun“ in: Meyers Großes Konversationslexikon, Bd.1 (1903), S. 256-257. Alaun wurde von Apothekern, Malern und vor allem Färbereien abgenommen. Besonders für die Farbfixierung war das Alaunwerk in Freienwalde für die Berliner Manufakturen unentbehrlich. 
wesentliche materielle Grundlage des familiären Reichtums und damit auch der Ausbildung der Töchter gelten. ${ }^{556}$ Eine Kupferstich-Darstellung von 1789 verweist auf Anlagen und Unterkünfte für 177 Bergleute und 69 Arbeiter. ${ }^{557}$

Die Schwestern Sara und Marianne scheinen ihren Vater und nach dessen Tod die geschäftsführenden Brüder häufiger nach Freienwalde begleitet und dort auch Bekannte besucht $\mathrm{zu}$ haben, mehrere Briefe tragen den Absender „Alaunwerk bey Freyenwalde“. 558 Ein berühmter, wenn auch meist nur ausschnittsweise zitierter Brief Sara Meyer Grotthus' an Goethe wurde auf dem Alaunwerk verfasst. Über ein Jahr nach der Bekanntschaft mit Goethe in Karlsbad knüpfte sie neu Kontakt mit dem Dichter, indem sie ihm einen gestickten Talisman schickte und den aktuellen Religionskonflikt mit ihrer Familie schilderte. Dass in unmittelbarer Nachbarschaft zu schwefelsaurer Tonerde und Vitriolhütten die Erinnerung an Gespräche mit Goethe und die Lektüre des Wilhelm Meister „den größten Eindruck“ machten, ist vorstellbar. ${ }^{559}$ Neben Goethe hatte ihr in ihrer Lebenskrise vor allem die Abgeschiedenheit des Ortes gut getan:

5561717 gegründet von der Adelsfamilie Derfflinger, dann von König Friedrich Wilhelm I. erworben, gehörte das Werk 1738 bis 1811 dem Militärwaisenhaus in Potsdam. 1782 war es von diesem an den Kaufmann Aaron Meyer auf 20 Jahre verpachtet worden. Allerdings kam Meyer in finanzielle Schwierigkeiten und musste Geld aufnehmen. Die Söhne und Nachfolger Meyers führten jahrelange das Anwesen betreffende Prozesse. Vgl. Historisches Ortslexikon für Brandenburg: Teil VI: Barnim, bearbeitet von Lieselott Enders, unter Mitarbeit von Margot Beck, Weimar 1980, S. 5 f. Vgl. auch: Erika Herzfelde: Preußische Manufakturen. Großgewerbliche Fertigung von Porzellan, Seide, Gobelins, Uhren, Tapeten, Waffen, Papier u. a. im 17. und 18. Jahrhundert in und um Berlin, Bayreuth 1994.

557 Johann Friedrich Nagel: Vue d’Aluniere Pris De Freyenwalde, Kolorierter Stich, 1789 Oderlandmuseum, Bad Freienwalde.

558 Ein erster solcher Brief - mit Text in hebräischer Schrift [!] - ist aus dem Jahr 1786 überliefert mit der Aufschrift ,abzugeben an Md Sara Wulff / Franco In des Major v Wolffrath Hause in der Neu Müntz Straße Berlin“; 24. 10. 1786, ungedruckt, SV 78. Vgl. auch Sara Meyer Grotthus an Johann Wolfgang von Goethe, 14. 12. 1796, GSA 28/15, teilweise gedruckt in: Geiger 1893, S. 46-50.

559 Sara Meyer Grotthus an Johann Wolfgang von Goethe, 14. 10. 1796, zit. nach: Geiger 1893, S. 46-50, hier S. 47. Ihre Lektüre des „Meister“, die sie als „erschütert“ und „in Thränen“ schilderte, wurde den Lesern des Goethejahrbuchs als höchst empfindsame, wenn nicht orgiastische Reaktion eines typischen weiblichen Anhängers geschildert. Silke Schlichtmann weist in ihrer Dissertation über männliches und weibliches Leseverhalten um 1800 u. a. nach, dass körperliche Reaktionen auf Goethewerke kein Frauenspezifikum waren. Auch wenn Grotthus mit Weinen und Exaltiertheit genauso reagierte, wie man es sich nach dem Polaritätsmodell vielleicht wünschte, (Schlichtmann S. 198-199) finden sich auch in Carl Friedrich Zelters Berichten Ausdrücke „übersteigerter Körperlichkeit“. Ebd., S. 194. 


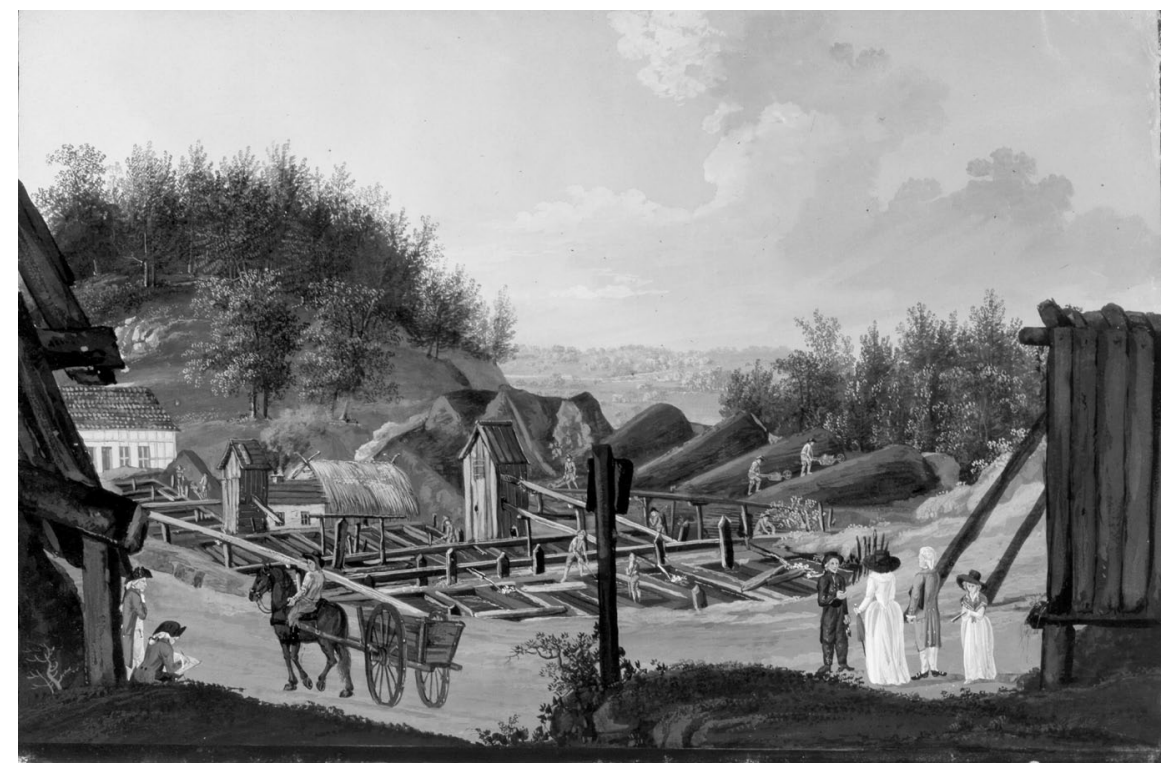

Abb. 16: Das Alaunwerk in Freienwalde. Industrie, Sehenswürdigkeit und Salon-Ort.

Ich lebe bey meinen Brüdern [...] in der Nähe des Brunnens der so heilsam auf mich gewürkt und von den ich imerfort Bade, weil ich unsäglich von Gicht, [...] und von Krämpfen leide, 6 Meilen von Berlin auf dem Alaun Bergwerk dass ein niedliches Dörfchen in einer Paradiesischen Gegend Formirt, hier kann ich mich ungestört nach meiner Fantasie beschäftigen, meine Bücher, mein Stickrahm und Piano und Schreibtisch machen mir die Zeit Feilschnel verfliessen. ${ }^{560}$

Ihre Berliner Freunde und Gäste hielten aber Verbindung dorthin. Gustav von Brinckmann schickte einen Brief an „die Fließ“, die in Freienwalde kurte, und bat, ihn im Alaunwerk mit Empfehlungen abzugeben, was diese zu einer Ausfahrt dorthin nutzte. ${ }^{561}$ Die Kurende selbst sprach von wochenlangen Besuchen ihrer Berliner Freunde in Freienwalde. Für Teestunden vor Ort, direkt auf dem Werk, oder vermutlich im Wohnhaus der Familie Meyer reichte aber sogar die ,spirituelle' Anwesenheit der als Salonièren bekannten Töchter. So schrieb Friederike Liman im Juli 1795 nach Berlin: „[...] grüsse Meyers und sage Ihnen ich

560 Sara Meyer Grotthus an Johann Wolfgang von Goethe, 14. 10. 1796, Ebd., S. 48.

561 „Noch diesen Morgen fahre ich nach dem Alauenwerk und werde eigenhändig Ihren Brief abgeben, verlaßen Sie Sich darauf.“ Hitzel Fließ Boye Sparre an Gustav von Brinckmann, 16. 7.1794, ungedruckt, BA F. 
habe letzt mit einer grosse geselschaft die ich mit brachte in ihren Hause auf den Alauenwerck thee getruncken; und ihr geist hat mich umschwebt“. ${ }^{562}$

Der Bezug zu Freienwalde hatte schließlich noch eine materielle Begleiterscheinung für das Salonnetzwerk. Die Störzucht der an der Alten Oder gelegenen und von Fischhandel geprägten Stadt lieferte die Grundlage für den Kaviar, der im Briefwechsel der Schwestern Meyer mit Goethe eine nicht unwesentliche Rolle spielte. Ihre Brüder, später Oberhütteninspektoren, schickten auf deren Verlangen mehrere Fässchen des schwarzen Goldes nach Weimar. ${ }^{563}$

Trotz des Kaviars und der guten Erholung haftet den Berichten der Besucher in Freienwalde oft ein Hauch Langeweile an. Das Publikum wurde als „artig“, nicht als besonders fesselnd, geschweige denn mondän beschrieben. Oder, in der Kategorisierung Reinhold Kuhnerts: Eine gewissen „Urbanität“, die Karlsbad und Teplitz mit Blick auf das Kultur- und Freizeitangebot und gemessen an der hier verkehrenden Prominenz für sich in Anspruch nehmen konnten, blieb dem Provinzbad Freienwalde versagt. Insofern ist der Wechsel des Kurortes bei Rahel Levin Varnhagen möglicherweise auch strategisch zu verstehen. Einige andere Mitglieder der Berliner Salongesellschaft fuhren auch zur Kur nach Pyrmont. Beispielsweise begleitete Henriette Herz ihren Mann in den 1780er-Jahren nach seiner schweren Krankheit dorthin. Leider sind dazu aber keine Kommentare überliefert. Ende des 18. Jahrhunderts sahen sich viele Kurorte bei der wachsenden Mobilität der Gäste gezwungen, sich ein Profil zu geben. Kleinere Orte machten zunehmend mit der sie umgebenden Idylle oder dem eher „bürgerlichen Anstrich“ für sich Werbung. Was ein Brunnenarzt aus Bad Driburg 1792 schrieb, hätte auch für Freienwalde gesagt sein können: „Wer Bäder besucht, um sich in großen Cirkeln zu amüsieren [...] und abends gern verderbliche Spiele spielt, der findet hier nicht den Ort seines Vergnügens. [...Hier] versammelt sich eine kleine Zahl von Menschen vom guten Stande,

562 Friederike Liman an Rahel Levin Varnhagen, 16. 7. 1795, in: Bosold 1996, S. 25.

563 Ein begleitendes Billet ist überliefert: „Auf Verlangen seiner jüngsten Schwester, der Frau von Eybenberg verwitwete Reuß, hat unterzeichneter die Ehre Ew Exellence anbey 6 Fäßer Caviar - in Ihrem Nahmen zu besorgen, und eilt nun so sehr, diesen angenehmen Auftrag zu erfüllen, da es ihm Gelegenheit verschafft auch unbekant, die wahre aufrichtige Hochachtung versichern zu können, die jeder Zeit gegen dieselbe gefühlt hat. Ew Excellence ganz ergebenster Dr Meyer K: Pr: Ober Hütten Inspector [unleserliches Kürzel] Alaun Bergwerk bey Freyenwalde an der Oder den 3: Febry 1800." Heymann Meyer an Goethe, 3. 2. 1800, ungedruckt, GSA 3/585. In den Einnahmen der Stadt 1792/93 nahm der „StörLachs-Aalfang“ einen nicht unbedeutenden Platz ein. Vgl. [ohne Hrsg.]: Bad Freienwalde (Oder). Geschichte der Stadt in Einzeldarstellungen (Oberbarnimer Heimatbücher, 14), Bad Freienwalde 1935, 2. Bd., S. $184 \mathrm{f}$. 
um das Landleben zu genießen“. ${ }^{564}$ Das war 1794 kein Motiv mehr für die Badereise einer Berliner Salonière.

\subsection{Teplitz und Karlsbad}

Sah der Achtungswürdigen und angenehmen Menschen viel [...], glüklich und unterhaltend gemischt. Alle neuere Bücher aus Deutschl:, Frankr:, und Engl: im Hause, und zu unserm Gebrauch. Den beßten Thee den ich kenne; spät wie ich ihn brauche; niedre Kanapeés, gemaches Gespräch; und Schweigen so viel man will.

Rahel Levin Varnhagen über einen Kuraufenthalt in Teplitz ${ }^{565}$

Teplitz, das älteste Bad Böhmens ${ }^{566}$ muß für den Untersuchungszeitraum 1794/ 95 als ebenso berühmt und anerkannt wie das heute bekanntere Karlsbad gelten. ${ }^{567}$ Nach einem Brand war es 1793 gänzlich dem Zeitgeschmack entsprechend im Empire-Stil neu errichtet worden und galt daher als sehr modisches Bad. Teplitz war Residenzstadt der Fürsten Clary-Aldringen, und die besondere Rolle der Stadt speiste sich auch aus deren „Hausherrenpflicht“, bei ausgesuchten und fürstlichen Gästen den König zu vertreten. Das frühe 19. Jahrhundert war die Blütezeit der Stadt, aus der noch der Name „Salon von Europa“ herrührt. Heute ist von den im 18. Jahrhundert verwandten Brunnen an den Quellen nur der älteste noch erhalten. Dass ihnen das Wasser hier von einem

564 Brunnenarzt Brandis über Bad Driburg, zit. nach: Rolf Bothe: Kurstädte in Deutschland. Zur Geschichte einer Baugattung, Berlin 1984, S. 305 f., bzw. nach: Lotz-Heumann 2003, S. $33 \mathrm{f}$.

565 Rahel Levin Varnhagen an Ludwig Robert, 11. 10. 1821, in: ERLV II, S. 365.

566 Der Ort im südöstlichen Vorland des Erzgebirges wurde bis ins 19. Jh. meist „Töplitz“ geschrieben, heißt tschechisch „Teplice“. Die seit 762 bekannten Heilquellen waren und sind Haupteinnahmequelle der Stadt. Im 19. Jh. wurde Teplitz bekannt für Monarchenzusammenkünfte. Die Stadt schmückt sich heute vor allem mit den Namen ihrer berühmtesten Gäste: Peter der Große, Goethe, Beethoven und Chopin. Die Anziehungskraft für internationale Gäste außerhalb des Badebetriebs speist sich heute vor allem aus dem nahe gelegenen Schloss Dux (in Duchcov), auf dem Casanova seine letzten Lebensjahre (1785-1798) verbrachte. Die alten Badeanlagen zerfielen nach dem Krieg mangels Sanierung und wurden großenteils durch modernere Anlagen ersetzt. Restaurierte Gassen im alten Zentrum vermitteln einen Eindruck von der baulichen Nähe, in der sich Brunnen und Gästeunterkünfte befanden. Die Geschichte des Kurorts lebt vor allem weiter in dem im Schloss errichteten Teplitzer Heimatmuseum, Regionální muzeum v Teplicích.

567 In der ersten Hälfte des 19. Jahrhunderts kamen jährlich 5.000-6.000 Kurgäste, deren Namen in, 1795 noch handgeschriebenen, Kurlisten gesammelt wurden. Ende des 19. Jahrhunderts zählte das statistische Lexikon bereits 10.000 Gäste jährlich. Ritters Geographisch-statistisches Lexikon [...], 8. Auflage, unter der Redaktion von Johs. Penzler, 2 Bde., Leipzig 1898, Bd. 2, S. 904. 
Schweinekopf ausgespuckt wurde, wurde in den Briefen der jüdischen Kurgäste dieser Zeit nie thematisiert. ${ }^{568}$

Karlsbad, vom 19. Jahrhundert bis in die Mitte des 20. Jahrhunderts als einer der berühmtesten Kurorte Europas bekannt, ${ }^{569}$ war in der hier interessierenden Zeit vor 1800 für politische und Repräsentations-Zwecke noch nicht entdeckt und eher eines unter mehreren böhmischen Bädern. ${ }^{570}$ Nicht nur Goethe nutzte Karlsbad und Teplitz mehrfach und oft in Kombination, ${ }^{571}$ auch Rahel Levin Varnhagen besuchte beide Bäder. ${ }^{572}$ Für einen schon professionalisierten Kurbetrieb sprechen ein differenziertes Abgabesystem, vor allem eine

568 Das Schwein könnte auf die Sage anspielen, nach der die Quellen 762 durch eine Herde Schweine entdeckt worden seien.

5691325 wurde der nach Kaiser Karl IV. benannte Badeort an der Tepl erstmals urkundlich erwähnt. Das erste öffentliche Badehaus entstand 1711. Mitte des 19. Jahrhunderts ,überholte“ Karlsbad die benachbarte Konkurrenz Teplitz an Popularität und Besucherzahl. Die Gästezahl stieg von 229 Parteien im Jahre 1756 auf 2.127 Parteien anno 1827. 1901 wurden 25.330 Parteien gezählt. Vgl. Brockhaus' Konversations-Lexikon. 14. Auflage, Neue Revidierte Jubiläums-Ausgabe, Leipzig [u. a.] 1901-1908, Bd. 10 (1902), S.167. Eine Partei bezeichnet eine Reisegesellschaft von etwa 1-3 Personen.

570 Die am Kurbetrieb orientierte Entwicklung der böhmischen Stadt ist heute noch erkennbar an den großen Brunnen und Kolonnaden im Zentrum und den sie umgebenden Villenvierteln sowie alten Wanderwegen, die sich an den Bergen entlangziehen. Ihre prächtigsten, heute bekanntesten Bauten, wie das Kaiserbad und die Mühlbrunnenkolonnade, sind allerdings erst nach 1870 errichtet worden. In der ersten Hälfte des 19. Jahrhunderts wurde Karlsbad Austragungsort politischer Entscheidungen.

571 Die Quellen der beiden böhmischen Städte wurden und werden gegen verschiedene Krankheiten angewandt und im 18. Jahrhundert, anders als heute, häufig im Wechsel genutzt. Die Karlsbader Quellen wurden bei Leber-, Galle- und Magenkrankheiten genutzt. Teplitzer Wasser galt als hilfreich bei Gicht, Ischias und rheumatischen Beschwerden, unter denen u. a. Rahel Levin Varnhagen zeitlebens zu leiden hatte. Auch wurde eine Kur in Karlsbad bei schweren psychischen Erschütterungen als heilsam erachtet. Der Salonière Dorothea von Kurland war die Badereise nach dem Verlust ihres Sohnes empfohlen worden. Die schnelle Wirkung bei Verletzungen und Knochenbrüchen trug Teplitz den Titel „Bad der Krieger“ ein. Zumindest für letztere galt die Brunnen-Freiheit: in Kriegszeiten hatte Teplitz Sonderstatus, Verwundete aller Parteien wurden hier geheilt.

5721795 reiste sie erstmals nach Teplitz und von dort einige Tage nach Karlsbad, wo es zu einer ersten kurzen Begegnung mit Goethe kam. 1796 kam sie wieder, 1811 verbrachte sie erstmals gemeinsam mit Varnhagen einen Sommer in Teplitz, während dessen sie Clemens Brentanos und vermutlich Beethovens Bekanntschaft machte. Zur These, dass Rahel Levin Varnhagen dessen „unsterbliche Geliebte“ gewesen sei vgl. die lange Beweiskette bei Sigmund Kaznelson: Beethovens ferne und unsterbliche Geliebte, Zürich 1954. Nach dem Krieg traf sie Varnhagen 1814 in Teplitz wieder und verbrachte hier mit ihm den Sommer, an dessen Ende sie in Berlin heirateten. Während der Aufenthalte in Wien und Karlsruhe verbrachte Rahel Levin Varnhagen allsommerlich einige Wochen in den dortigen Badeorten. Erst 1821 und 1822 kam es noch einmal zu Aufenthalten in Böhmen. 
nach Klassen unterschiedene, nicht geringe Kur- und Musiktaxe, sowie die bereits im 18. Jahrhundert verbreitete Mode, aus Karlsbad Andenken und Sprudelprodukte mitzubringen. ${ }^{573}$ In dem hier untersuchten Jahr 1794/95 verfügte Karlsbad bereits über mehrere öffentliche Badehäuser und Promenaden, überdachte Wandelbahnen zu verschiedenen Brunnen und ein Theater. Das eigentliche Kurleben in Karlsbad spielte sich im Zentrum der Stadt, vor allem beim größten der Brunnen, Sprudel genannt, ab. Die beliebteste und schönste Straße Karlsbads war um 1790 bereits die „Alte und Neue Wiesengasse“. Hier lagen mehrere Geschäfte, Hotels, Cafés und „Lusthäuser“, das heißt Versammlungshäuser, in denen man sich zum gemeinsamen Mahl oder Tanz traf. Musikalische Untermalung des Kurbetriebes war eine Selbstverständlichkeit, die von den Gästen extra finanziert wurde. Ein Bild von den Karlsbader Kommunikationsstrukturen ergibt sich aus der Kostenwarnung zeitgenössischer Reiseführer. Für einen Aufenthalt in Karlsbad im gewählten Jahr mussten neben den Kosten für Wohnung, Essen und Badearzt folgende Posten mit einberechnet werden: Ab- und Aufpacken des Reisewagens, Brunnenweiber, Schlüssel zum Abtritt beim Brunnen, Aufwärter im Saal, Einlass zu Bällen. Bezahlt werden mussten auch der Türmer, der zur Ankunft blies, und die Bedienten, die Visitenkarten herumtrugen, um die Ankunft jedes Gastes anzuzeigen.

Ein wesentlicher Treffpunkt und Kommunikationsort für die Besucher waren auch in Karlsbad gemeinsame Spaziergänge und Ausflüge, auf denen, beziehungsweise am Rande derer, sich besonders für die Frauen neue Gesprächsmöglichkeiten ergaben. Nicht nur Goethe spielte mit dem Zusammenhang von Naturschönheit und Geselligkeit. Das Tagebuch von der Reckes belegt verschiedentlich den Zusammenhang von Ausflug und Gedankenflug in Karlsbad: „Ich hatte, indessen die gesamte Gesellschaft die Trümmer durchwanderte, mit Bode am Fuße des Berges ein interessantes Gespräch, welches meinen Blick über die geheimen Gesellschaften bei Staatsveränderungen sehr erweiterte“. ${ }^{574}$ Umgekehrt schrieben Verehrer ihrer Schwester die Bewunderung deren geselligen Talents in die Landschaft bei Karlsbad ein: „Diesen Morgen wurden über 50 Personen durch die Anmut ihres Umganges so hingerissen, dass alle einstimmig beschlossen, die entfernte Wiese hinter dem

$573 \mathrm{Im}$ Goethehaus am Frauenplan in Weimar sind noch einige solcher Andenken zu besichtigen, u. a. Goethes persönliches Karlsbader Trinkgefäss, zahlreiche geologische Funde und eine größere Sammlung geschliffener Sprudelsteine, d. h. Halbedelsteine aus dem böhmischen Gebirge.

574 Elisa von der Recke, Tagebucheintrag 19. Juni 1790, in: Träger 1984, S.78. Gemeint ist Johann Joachim Christoph Bode, Buchhändler und Übersetzer von Laurence Sterne, aus Weimar. 
Böhmischen Saale solle meiner Schwester zu Ehren Dorotheens Aue genannt werden“. .575

1794/95 war „Dorotheens Aue“ ein etablierter Platz und einer der möglichen Ausflugsorte für Goethe und die an ihm interessierten, ihn interessierenden Frauen. ${ }^{576}$

\section{Brunnenfreiheiten}

Wie in Freienwalde oder Pyrmont fanden sich in Karlsbad gemischte Gesellschaften bei Mahlzeiten im Freien zusammen. Diese halbformellen Picknicks erweckten den Eindruck, dass ebenso wie auf die echten Wände auch auf die Zwischenwände der Gesellschaft verzichtet werden könnte.

Um die von ihr [Dorothea von Kurland] gewünschte Vereinigung der Landsmannschaften und Stände noch vollständiger herbeizuführen, gab sie eines Tages ein Frühstück am linken Ufer der Tepel, in dem anmutigen Tale zwischen den Bergen [...]. Meine Schwester, ihre Hofdame [...] und ich, wir hatten auf dieser von Felsen umschlossenen und von der Tepel durchflossenen Wiese jede einen Tisch, an welchem wir Wirtinnen waren. ${ }^{577}$

Dies ist eine der wenigen schriftlichen Absichtserklärungen einer Salonière, die Stände vorsätzlich zu mischen. Dass die Berliner jüdischen Salonièren solche Gesellschaften im Badeort arrangiert und sich als Gastgeberin vergleichbar inszeniert hätten, ist nicht bekannt. Ein Hinderungsgrund waren sicher die Preise in Karlsbad. Die Herzogin von Kurland, die sich an all ihren Wohn- und Kurorten als Gastgeberin von Diners betätigte, investierte nicht wenig in die Details ihrer eigenen und der Empfänge Erscheinung. ${ }^{.78}$ Umgekehrt waren dem Gelingen des Experiments sicher die vornehme Herkunft der Gastgeberin ebenso förderlich wie die originelle Idee, die Kurgäste nach regionaler Herkunft

575 Elisa von der Recke, Tagebucheintrag 22. Juni 1790, in: Träger 1984, S.79. Dem Tag zum Andenken wurde 1791 sogar ein „Dorotheentempel“ im Südosten der Stadt auf einem Felsen in der Dorotheenaue errichtet.

576 Vgl. den nostalgischen Eintrag von der Reckes, die den Ort am 29. 4. 1795 aufsuchte. Träger 1984, S. 323.

577 Elisa von der Recke, 1790, zit. nach: Günter Elbin: Macht in zarten Händen. Dorothea Herzogin von Kurland, München 1968, S.110. Leider arbeitet diese erste umfängliche Biografie Dorothea von Kurlands gänzlich ohne Quellennachweise und dieses Tagebuch Elisa von der Reckes ist im Original nicht mehr zugänglich.

578 Vgl. dazu die Berichte ihrer Schwester, die sie 1790/91 begleitete und die fast stereotypen Einträge: „Unsere Daria gab heute im Saal verschiedenen Personen ein Diner“; „Den Abend war bei Daria zahlreiche Gesellschaft“; ebenso ist von reichen, mit echten Juwelen „wie übersäten“ Garderoben die Rede. Einträge August und September 1791, in Werner 1927, S. 37, 55, 67. 


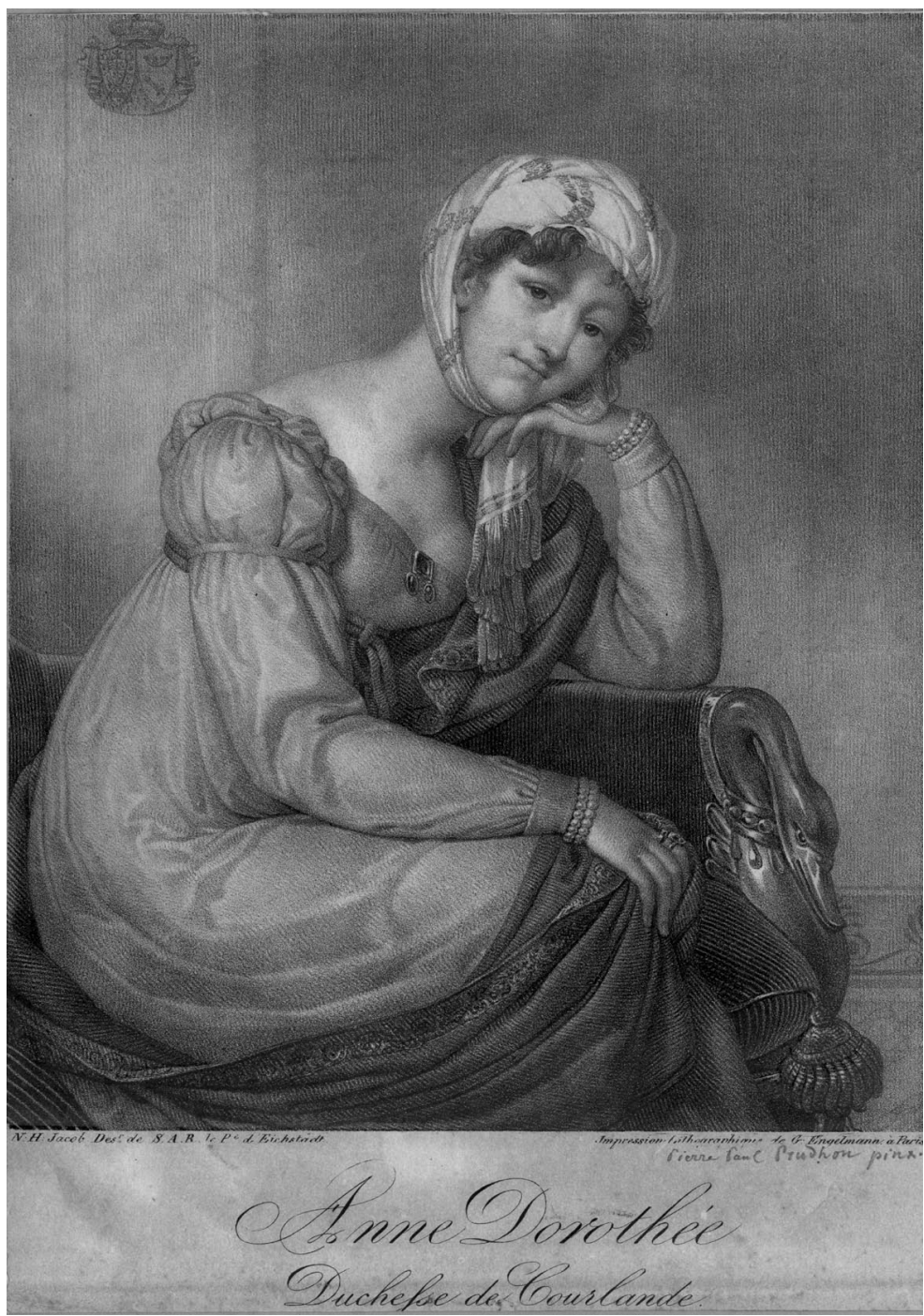

Abb. 17: Dorothea, Herzogin von Kurland, Salonière in Berlin, Paris und Karlsbad. (1761-1821).

zusammenzusetzen: „Bode, Schulz, einige Berlinerinnen und Schlesierinnen waren meine Gäste, [...] meine Schwester bewirtete die vornehmen Prager und Polen, die Stock die Sachsen“. ${ }^{579}$ Aber nicht notwendig alle Gäste schienen das

579 Zit. nach: Elbin 1968, S. 110. 
Ideal der Brunnenfreiheit verinnerlicht zu haben. Elisa von der Recke erinnert sich auch 1795 an den Standesdünkel eines Grafens, der bei einem gestürzten Kurgast erst nach dem Stand fragte, bevor er ihm aufhalf. 580

Interessant im Zusammenhang mit den Freiheiten des böhmischen Badelebens sind die positiven Argumente, die Rahel Levin Varnagen für einen Aufenthalt in Teplitz anführte, nachdem sie mehrfach dagewesen war; sie lobte sowohl die „Lebensart, mit der jetzt möglichen belebendsten Gesellschaft“ als auch die „Möglichkeit, [...] ihr, soviel als Sie nur wollen, auszuweichen“. ${ }^{581}$ Zur Brunnenfreyheit gehörte demnach das Aussuchen der Gesellschaft und auch wesentlich ein Genderaspekt des Kurens: Kurorte waren für Frauen paradoxerweise oft leichter zu erreichen als näher gelegene Großstädte. Esther Gad macht die Bedeutung des „Etiketts“ einer Reise deutlich, als sie erklären musste, dass der Bruder eine Reise nach Berlin nicht erlauben würde, eine ins Bad sehr wohl, denn

[...] der der ein Recht hat über meine Handlungen - mein Bruder, würde eine kostspielige, ohne ihm wichtig scheinende Motive, unmöglich billigen können. [...] Ganz was anders ist es mit einer Sommerreise, die entschienenen Einfluß, entweder auf die Wiederherstellung, oder Befestigung meiner Gesundheit hat, die ihm theurer ist, als mir selbst. Inwiefern Berlin und die Angebethete auf meiner Gesundheit influiren würden, begreift er mit aller seiner Fühlbarkeit wohl nicht. ${ }^{582}$

\section{Treffpunkte im böhmischen Badebetrieb}

Da sahen wir galante Herren auf den Wannen der badenden Damen sitzen und ihnen durch Scherzen die Zeit vertreiben. Das finden wir wirklich recht artig. Taschenbuch für Brunnen- und Badegäste, 1794583

Anders vermutlich als beim gesellschaftlichen Überbau des Kurlebens wurde in der eigentlichen Kur-Anwendung zwischen den Geschlechtern kaum ein Unterschied gemacht. Zur Kurpraxis in beiden Orten zählten um 1800 für alle Gäste sowohl Bade- als auch Trinkkuren. Der berühmte Badearzt Dr. Becher hatte darauf hingewiesen, dass die Wirkung des Wassers größer sei, wenn es

580 Er wurde von Frau von der Recke ermahnt, „er ist ein Mensch und bedarf unserer Hilfe“, und ärgerte sich hinterher darüber, einem Diener aufgeholfen zu haben. Vgl. den Eintrag vom 9. 5. 1795, in: Träger 1984, S. 330.

581 Rahel Levin Varnhagen an Alexander von der Marwitz, 28. 6. 1811, in: GW I, S. 521.

582 Esther Gad an Rahel Levin Varnhagen, 13. 12. 1797, ungedruckt, SV 53. Die beiden Freundinnen trafen sich dann in diesen Jahren mehrfach in Kurorten.

583 Zwierlein / Kühn 1794, S. 158 ff. 
vor Ort getrunken würde, was dazu führte, dass am Brunnen Wandelhallen errichtet wurden und die Frequenz der Kontakte am Brunnen sich erhöhte.584

Das Baden fand in Karlsbad zu Hause mit vom Brunnen herbeigebrachtem Wasser oder gemeinsam in öffentlichen Bädern statt. Dazwischen sollten ausgiebige Spaziergänge oder -ritte, für Frauen Ausfahrten liegen. Ein interessantes Licht auf die herrschende Badepraxis wirft die Warnung, beim Bad nicht fette Speisen zu essen, sondern sich lieber unterhalten zu lassen. Die Unterhaltung beim Bad oder am Brunnen erfolgte, wie im Kur-Taschenbuch angedeutet, grundsätzlich geschlechterübergreifend, die empfohlene Kleidung drückte morgens noch Privatheit oder Standeslosigkeit aus: „Das erste Geschäft der Gäste ist im Negligé die benöthigte Anzahl Becher bey einem der hiesigen Brunnen zu trinken“. 585

Nach ausgiebigen Spaziergängen am Brunnen wurde in öffentlichen Räumen gefrühstückt, hier scheint es allerdings Prioritäten der Geschlechter gegeben zu haben: Im „Sächsischen Saal“ frühstückten mehr die Damen, daher war hier das Tabakrauchen verboten, im „Böhmischen Saal“ mehr die Männer, dort war es erlaubt.586 Das Mittagessen wurde hingegen auf seiner Stube oder bei einer bestellten Tafel mit ausgesuchten Gästen eingenommen, eine gemeinsame standesübergreifende Tafel als Ort arrangierter zufälliger Treffen, wie in Freienwalde, gab es in Karlsbad nicht. ${ }^{587}$ Praktisch bedeutete das, dass Kurgäste eine eigene, recht repräsentative Unterkunft nehmen mussten oder auf Einladungen angewiesen waren, bevor man jemanden „bei Tische“ zwanglos näher kennenlernen konnte.

Zum Abend hin wurden die Veranstaltungen offizieller. Das Schauspiel begann bereits nachmittags um vier, um abends Zeit für einen Ball oder eine Assemblée zu lassen. Dies war für viele eine Gelegenheit, große Toilette zu machen. Eine nicht unwesentliche Rolle müssen privat organisierte Feiern gespielt haben, wie zum Beispiel das chinesische Fest, dass eine Gräfin in ihren Räumen für Goethes Geburtstag arrangierte. ${ }^{588}$

Anders als in Karlsbad war es in Teplitz auch (jüdischen) Kaufmannstöchtern möglich, sich auf einem Ball in einem Fürstenhaus zwanglos auf jeman-

584 Becher empfahl die heute unwahrscheinlich klingende Menge von 12 bis 20 Bechern Sprudelwasser pro Tag - als Maximum. Vorher waren größere Mengen üblich gewesen und Klagen über die abführende Wirkung laut geworden. Karl Ludwig: Med. Dr. David Becher. Badearzt in Karlsbad 1795-1792, Karlsbad 1925, S. 8.

585 Joseph Carl Eduard Hoser: Beschreibung von Karlsbad, Prag 1797, S. 128 f.

586 Hoser 1797, S. $128 \mathrm{f}$.

587 „Eine öffentliche Tafel giebt es im Karlsbad nicht, sondern man speiset allein oder wählt sich eine gewisse Anzahl von Personen, in deren Gesellschaft man auf seinem Zimmer ist. “ Zwierlein / Kühn 1794, S. $230 \mathrm{ff}$.

588 Karell 1949, S. 16. 
den zuzubewegen. Mehrfach werden Besuche beim Fürsten Clary erwähnt, dessen Bekanntschaft vermutlich über seinen Schwiegervater, den Prinzen de Ligne, gemacht wurde. Rahel Levin Varnhagen erwähnte, dass sie dort getanzt habe und nach dem Badeurlaub erhielt Friederike Unzelmann zumindest einen Privatbrief des Fürsten Clary. ${ }^{589} 1800$ beschwor Friederike Liman ein Treffen mit dem Aristokraten Burgsdorf auf der Duxschen Treppe und noch 1827 erinnerte sie sich genau an den „Clarischen garten“.590

Bevor gefragt wird, wo und wie jüdische Frauen 1795 die Bekanntschaft Goethes gemacht haben können, ist an dieser Stelle daher ganz allgemein festzuhalten, dass die größere räumliche Nähe und die vermehrte Überschneidung von privatem und öffentlichem Tun in den Badeorten nicht nur Bekanntschaften erleichterten, sondern auch die Abstände zwischen den Gesellschaftsschichten verringern konnten - wenngleich nicht notwendig alle Aristokraten diese neue Nähe suchten. In den Ereignissen des Jahres 1794/95 bebildert heißt das: während man als Tochter eines Levin oder eines Markus 1795 in Berlin von der Gräfin nur die Brillanten im Theater sah und sich als Ausgleich von einem bei Hofe verkehrenden Diplomaten wie Brinckmann Interna berichten lassen musste, tanzte man in Freienwalde beim Fest der Königin und war im böhmischen Bad bei Graf Waldstein Gast auf einem Schlossball!

\section{3 „Ein kleiner Roman aus dem Stegreife“? - Begegnungen mit Goethe in Karlsbad}

Nicht nur das Thema „Goethe und die Juden“, mitsamt der Gegenperspektive „Goethe in der Wahrnehmung der jüdischen Zeitgenossen“, muss als ein seit Jahrhunderten bearbeitetes Forschungsfeld gelten, 591 auch ist bereits, als Unterthema, der so genannten „Goethe-Kult“ in den Berliner Salons ein Topos

589 Friederike Liman an Rahel Levin Varnhagen, 10. 10. 1795, in: Bosold 1996, S. 41. 590 Friederike Liman an Rahel Levin Varnhagen, 6. 10. 1800 bzw. 14. 8. 1827, in: Bosold 1996, S. 46 bzw. 115.

591 Bereits von Zeitgenossen kontrovers diskutiert, gilt das Verhältnis Goethes zum Judentum heute als rundum erforscht und wird doch zu jedem großen Goethe-Jubiläum wieder Anlass für eine multidisziplinäre Auseinandersetzung. Exemplarisch der Konferenzband zum 250. Geburtstag: Annette Weber (Hrsg.): „Außerdem waren sie ja auch Menschen“. Goethes Begegnung mit Juden und Judentum (Schriftenreihe des Jüdischen Museums Frankfurt/M. Bd.7), Berlin [u. a.] 2000. Der Forschungskonsens geht heute dahin, die Einstellung Goethes zu Juden und Judentum als zumindest zwiespältig zu begreifen. Die meisten Forscher sind sich darin einig, dass zwischen Goethes Verhältnis erstens zum alttes- 
der Literaturgeschichte und der Goethebiografik geworden. ${ }^{592}$ Der folgende Abschnitt kann sich daher mit einer notwendigen Mikroperspektive beschäftigen: dem Zusammentreffen dreier Berliner Salonièren mit Goethe in Karlsbad im Juli 1795, sowie den Folgen für beide Seiten. Da die Beziehung, oder genauer das Nichtvorhandensein einer Beziehung, zwischen „Rahel und Goethe“ mehrfach ausführlich diskutiert wurde, ${ }^{593}$ konzentriert sich dieses Kapitel auf eine

amentarischen Judentum und dem Bibeltext, zweitens seiner Haltung gegenüber einzelnen Juden und drittens zu der politischen Situation der Juden unterschieden werden muss. Dazu zuletzt Günter Hartung: Goethes Verhältnis zu Juden und Judentum, in: Schoeps 2006, S. 205-219. Zur Gegenperspektive „Goethe in der jüdische Rezeption“ s. vor allem Wilfried Barner: Von Rahel Varnhagen bis Friedrich Gundolf. Juden als deutsche Goethe-Verehrer, Göttingen 1992. Die Frage, warum und inwieweit Goethe primäre Identifikationsfigur für das jüdische Bürgertum wurde, ist eigentlich noch nicht endgültig beantwortet. Mit Bezug auf spätere Goethe-Biografien hat Willi Jasper darauf hingewiesen, dass „innerhalb der jüdischen Klassikerverehrung Goethe gegenüber Schiller bewußt als Autor einer Elite bevorzugt“" worden sei. Willi Jasper: Faust und die Deutschen, Berlin 1998, S.141f. Nach Marion Kaplan ist es das Bildungskonzept Goethes gewesen, das Juden angezogen hätte. Marion Kaplan: 1812. The German romance with Bildung begins with the publication of Rahel Levin's correspondence about Goethe, in: Sander L. Gilman / Jack Zipes (Hrsg.): Yale Companion to Jewish Writing and Thought in German Culture, 1096-1996, New Haven 1997, S. 124-128. Die jüngste Tagung, die das Verhältnis „Weimars“ zum Judentum behandelte, stellte vergleichend fest, dass Schiller in der populären Rezeption größere Bedeutung zukam: „Für manche jüdische Verehrer trägt Schiller messianische Züge, der ein neues Gesetz der Freiheit stiftet." Hans Herrmann Henrix: Nicht ihr Freund, aber auch nicht ihr Feind. Zum Verhältnis von Goethe und Schiller zu Juden und Judentum.Tagungsbericht zur Tagung des Salomon Ludwig Steinheim-Instituts, 2005, unter: http://sti1.uni-duisburg.de/ veranstaltungen/2005/weimar-und-die-juden-tagungsbericht.xml (29. 1. 2008).

592 Der Goethe-Kult in Berliner und Wiener Salons wurde zuletzt und besonders detailliert untersucht von Seibert 1993(a), bes. S. 406 ff. Rahel Levin Varnhagen wird oft - und historisch nicht ganz korrekt - als die Begründerin des Goethe-Kults in Berlin bezeichnet. Die Beschäftigung mit Goethe hat de facto im früher „eröffneten“ Hause Herz eingesetzt. Florian Krobb sieht Rahel Levin Varnhagen als „Bahnbrecherin“ der jüdischen Goetherezeption. Florian Krobb: „Überdies waren die Mädchen hübsch“. Goethes Jüdinnen, in: Oxford German Studies 20/21 (1991/1992), S. 33-45, hier S. 34. Zur These, dass in den Berliner Salons tatsächlich um die richtige Goethe-Lesart gewetteifert wurde, s. Barbara Hahn: Streit um Goethe. Kontroverse Lektüren in den Berliner Salons, in: Osterkamp 2002, S. 121-132.

5931930 erschien eine Dissertation, deren Titel die Einseitigkeit der Beziehung deutlich macht: Charlotte Albarus: „Rahel Varnhagens Goethe-Erlebnis“, Dissertation, Univ. Jena 1930. Eine sehr ausführliche, wenn auch in Einzelheiten streitbare Darstellung als kritiklose Goethe-,Priesterin“ findet sich bei Scurla 1962, besonders S. 294-338. Eine sachlichere Bewertung liefert Heidi Thomann Tewarson, die Levin Varnhagen als „Kennerin, Interpretin und unermüdliche Befürworterin Goethes“ kennzeichnet, lange bevor sein Name Synonym für die deutsche Literatur geworden sei. Thomann Tewarson 1992, S. 39. Allerdings ist möglich, dass Rahel Levin Varnhagen selbst durch ihre Wortwahl, die Goethe mehrfach als 
kurze Skizzierung der Entwicklung im Vergleich zu den beiden Freundinnen und auf die Bedeutung dieses Treffens. Die unterschiedlichen Konsequenzen der „Begegnung mit Goethe im Bad“594 für die drei Frauen ${ }^{595}$ werden mit den in der Forschung aufgestellten Thesen zur Goethe-Rezeption in literarischen Salons verglichen: In der Salonforschung und in der Goethebiografik wurde das Verhältnis bisher fast immer auf die Goethe-Verehrung in den Berliner Salons reduziert, die dem Dichter ein Publikum in der Hauptstadt gesichert habe. Oft wird dabei übersehen, dass die Salonièren mit ihrem Engagement nicht einer herrschenden Mode nacheiferten, sondern aktiv in einen fortdauernden literarischen Disput eingriffen. Zugleich wurden in der Summierung „der Berliner Jüdinnen“als Hauptakteurinnen der Goethebewegung individuelle Unterschiede ausgeblendet, andererseits wurde nach den Konsequenzen ihrer Goethe-Verehrung für die Frauen selbst fast nicht gefragt. ${ }^{596}$ Außerdem ist, obwohl die böhmischen Badeaufenthalte Goethes als bekannt und in allen Einzelheiten des sozialen Umgangs und des geografischen Aufenthalts belegt gelten, auf die Frage, wie und wo seine Bekanntschaft von jüdischen Kauf-

Gott und sie selbst als Anbetende darstellt, diese Metapher mit provozierte. Geiger nennt die Berliner Salonièren allgemein die „Verkünderinnen des Goetheschen Evangeliums in Berlin“. Ludwig Geiger: Goethe und die Juden, in: ders. 1910, S. 81-101, hier S. 92. Dass Goethetexte für Jüdinnen zu einer Art ,Ersatzbibel‘ werden konnten, meint auch Silke Schlichtmann. Die Funktion Goethes im Akkulturationsprozess bestand demnach darin, dass seine Schriften einer Rahel Levin Varnhagen das eigene Leiden widerspiegeln und zugleich Sicherheit bieten konnten. Schlichtmann 2001, S. 267.

594 Auch die Begegnung mit Goethe im Bade ist lange Zeit eher romantisiert als untersucht oder in den Zusammenhang „Goethe und die Juden“ eingeordnet worden. In der Sekundärliteratur finden sich sachdienliche Hinweise v. a. in Überblicksaufsätzen zu Goethe in Badeorten, Romanen und in der spärlichen biografischen Forschung zu den Schwestern Meyer.

595 Erst in jüngerer Zeit erschienen einige literaturwissenschaftliche Aufsätze, die sich explizit und vergleichend mit der Bedeutung dieser (Bade-)Begegnungen beschäftigen. Die Goethelektüren verschiedener jüdischer Frauen beschreibt vergleichend Andrea Schatz: „freilich sagt Göthe nur was wir wißen.“ Sophie, Henriette, Dorothea und Rahel, in: Kalonymos. Beiträge zur deutsch-jüdischen Geschichte aus dem Salomon Ludwig SteinheimInstitut 3 (1999), S. 1-3; Vermutlich in Fortschreibung der These Hannah Arendts vom Salon als exterritorialen Ort geht Barbara Hahn davon aus, dass die Freundschaft zwischen Goethe und jüdischen Kaufmannstöchtern ,auf der Voraussetzung [beruhte], dass sie sich fast ausschließlich auf exterritorialem Gebiet trafen“. Barbara Hahn: Mit Goethe im Bad. Begegnungen im Exterritorialen. Rahel Levin Varnhagen, Sara und Marianne Meyer, in: Monatshefte, Vol. 92, Nr.3, 2000, S. 336-350, hier S.336. Florian Krobb fragt nach den Konsequenzen der Begegnung auf Goethes Seite. Krobb 1991/1992.

596 So beispielhaft: „Von Berlin geht die stärkste Goethe-Bewegung aus und die Berliner Jüdinnen sind ihre Hauptträger.“ Richard Friedenthal: Goethe. Sein Leben und seine Zeit. München 1985, S. 428. 
mannstöchtern praktisch gemacht werden konnte, noch keine Antwort gesucht oder gefunden worden.

\section{„Badeschwindel?“ Zur Rekonstruktion eines nicht festgehaltenen Treffens}

„Ich habe nur gesehen und geschwätzt, was sonst noch werden und gedeihen wird, muß abgewartet werden“.597 Mit diesem Satz verwies Goethe gleich nach Ankunft in Karlsbad auf ein Paradox, das die Geselligkeitsforschung zu Badeorten grundsätzlich erschwert: je ausgefüllter das Badeleben war, umso weniger fanden die Badegäste Zeit oder Lust, sich darüber in Briefen zu äußern. Die drei Berlinerinnen selbst haben sich überraschend wenig zu den Details des Monats Juli 1795 und speziell der ersten Goethe-Begegnung geäußert. Nur in späteren Briefen lassen sich rückblickend einige Hinweise auf den Umgang in Karlsbad finden. Auch die zahlreichen Darstellungen der Goetheschen Badeaufenthalte zehren für den Kuraufenthalt 1795 alle von denselben wenigen Quellen: Es gibt drei Briefe an Schiller, fünf Billets an Christiane Vulpius und vor allem das Tagebuch der Schriftstellerin Friederike Brun. Selbst bei den vorhandenen Quellen aber schlägt häufig die ,Goethe-Falle‘ zu. Texte, insbesondere die letztgenannte Quelle, werden nur in den auf den Dichter bezüglichen Stellen gedruckt. Kommentare zu den anderen hier interessierenden Personen oder Alltagsgeschehen finden sich oft nur im Original und werden in der Forschung nicht immer berücksichtigt. 598

Hand in Hand den Tanz zu schweben / Und der Freude hingegeben [...]

Ist auch unser das Vergnügen / und gesellig jede Lust.

Johann Wolfgang Goethe, Gelegenheitsgedicht, Karlsbad 1795599

Die Schwestern Marianne und Sara Meyer kamen nach bisheriger Quellenkenntnis 1795 erstmals nach Böhmen zum Kuren. Später wurde Marianne

597 Johann Wolfgang von Goethe an Friedrich von Schiller, 8. 7. 1795, in: Beetz 2005, Bd. I, S. 91.

598 Das Tagebuch von Friederike Brun ist als Ganzes noch ungedruckt. Die Auszüge Karlsbad betreffend wurden nur einmal, 1905, komplett veröffentlicht, danach wurden nur noch die auf Goethe bezüglichen Stellen tradiert und so einige interessante Eindrücke der Autorin unterschlagen. Die vielfach geäußerte Verwunderung, dass die bekannte Intellektuelle Brun sich nicht zu ihrer Bekanntschaft mit Rahel Levin geäußert habe, beruht nur auf fehlender Quellenkenntnis. Im Folgenden wird nach der Ausgabe von 1905 zitiert. Vgl. Louis Bobé: Aus Friederike Bruns Tagebuch, in: Deutsche Rundschau 123 (1905), S. 231245.

599 „Chor welcher am 21. Juli 1795 bei dem zur Ergötzung der hohen Kur- und Badegäste gegebenen Freiballe gesungen wurde. Von Herrn von Goethe“, Karlsbad, Separatdruck, 1795, zit. nach: Hlawacek 1883, S. 19. 
Meyer Eybenberg mit Wohnsitz in Wien, ständiger Sommergast in Teplitz und Karlsbad. In der Familie Meyer hatten Kurfahrten allerdings seit mehreren Generationen Tradition. Der Großvater der Schwestern, Veitel Heine Ephraim, fuhr beispielsweise 1773 nach Pyrmont, in Begleitung Moses Mendelssohns. Im Folgejahr fuhr der Philosoph mit ihrer Mutter Rösl Meyer wiederum nach Pyrmont, wo sich die Brunnenfreiheit für ihn insofern bewahrheitete, als er einige einflussreiche Freundschaften schloss. „Er befindet sich mit Gottes Hilfe recht wohl bam [beim?] Gebrauch des Brunens, ein jeder sucht seine Bekantschaft zu machen“, schrieb seine Gastgeberin an seine Frau. Diese Fahrt muss bereits für eine der Schwestern Meyer die erste Badereise gewesen sein, denn Rösl Meyer fuhr fort: „[...] nun libe Fromet habe Sie keine Ursache auf meine Tochter eifersichtig zu sein[,] nun sein Sie es auf der Gräfin von Bükeburg“. 600

Für ihren ersten Aufenthalt in böhmischen Bädern reisten die Schwestern Meyer am 14. Juni Richtung Karlsbad. Die Art des Reisens sprach für eine wohlhabende Herkunft: Sie reisten mit eigenen Pferden und planten einen längeren Aufenthalt in Dresden. Ihr Quartier in Karlsbad hatten sie sich wie Goethe auf der vornehmen „Alten Wiese“ gemietet, ${ }^{601}$ sodass als erste Begegnung ein zufälliges Zusammentreffen von Nachbarn denkbar wäre.602

Keine der Getroffenen hat aber notiert, wie oder wo sie des „Olympiers“ zum ersten Mal ansichtig geworden sei. Lediglich das Tagebuch Friederike Bruns legt den Schluss nahe, dass sie, die den Dichter von Luise von Göchhausen vorgestellt bekommen hatte, Goethe ihrerseits gleich mit ihren neuen Freundinnen aus Berlin bekannt gemacht hat. ${ }^{603}$ Anfang Juli, vor der Goethes, stand die Bekanntschaft mit „Mariane Mayer und Sara Wolff [sic]“ in Friederike Bruns Tagebuch verzeichnet. ${ }^{604}$ Nicht untypisch für die Zeit, lernte sie die

600 Rösl Meyer an Fromet Mendelssohn, Juli 1774, in: JubA, Bd. 24, S. 329.

601 Goethe kam 1795 zum dritten seiner insgesamt dreizehn Besuche nach Karlsbad. Sein Aufenthalt begann am 4. Juli 1795. Im zentralen, vornehmen und teureren Wohngebiet auf der „Alten Wiese“ nahm er Quartier im „Grünen Papagei“, das ihm eine vorgereiste befreundete Hofdame, Luise von Göchhausen, reserviert hatte. Sein Bade-Biograf Karell kommentierte: „So entgeht dem Dichter keine schöne Frau, die am Sprudel auftaucht.“ Karell 1949, S. 20.

602 Alle Informationen nach Friederike Liman, Brief an Rahel Levin Varnhagen, 13. 6. 1795, in: Bosold 1996, S. 8. Auf der Reise starb der sie begleitende Vater der beiden, Aaron Meyer, - ein Vorfall, der den Karlsbader Aufenthalt anscheinend nicht verhindert, nur verschoben hat. Der Formulierung Hahns, dass Goethe „in den von Aaron Meyer verlassenen Ort" einrückte und u. a. deswegen symbolische Vaterfigur wurde, kann ich mangels Quellen nicht zustimmen. Hahn 2000, S. 337.

603 „Abends brachte mir die brave Göchhausen den Goethe. [...] Ich sehe ihn seitdem täglich und versäume keine Gelegenheit, ihn zu sehen.“ Friederike Brun, Tagebucheintrag 7. Juli 1795, in: Bode 1999, Bd. 2, S. $34 \mathrm{f}$.

604 Friederike Brun, Tagebucheintrag 4.-6. 7. 1795, in: Bobé 1905, S. 236. 
Schwestern als „ein paar verwandte Wesen“ kennen, da diese einen gemeinsamen Freund (und womöglich einen Brief von ihm) als Empfehlung anbringen konnten, vom in Berlin lebenden dänischen Grafen Bernstorff. ${ }^{605}$ Man scheint sich bald gegenseitig die Lebensgeschichten anvertraut $\mathrm{zu}$ haben. Friederike Brun wusste nach kurzer Zeit von den unglücklichen Liebesaffären der beiden Schwestern, die diese ihr umso liebenswürdiger machten. Daneben notiert sie: „Die Älteste hat viel mit Mendelssohn, Lessing ec. in früheren Jahren gelebt“, 606 ein Umstand, den Sara Meyer anscheinend als positive Erfahrung ihrer Jugend gern erzählt hat, von dem sie auch Goethe mehrfach berichten sollte. Über Meyers machte Brun auch die Bekanntschaft Rahel Levin Varnhagens, an der die Dichterin, anders als an „Meiers“, etwas spezifisch Jüdisches erkannt haben wollte: „7.-8.-9. Juli. Viel mit Meiers gelebt u. ihre Freundin Levin kennen gelernt, ein gar lebendiges, sinnreiches Geschöpf, die aber ganz den interessanten Pli der jüdischen Weiber hat. Hübsch und so gutmüthig wie klug“. 607

Auf die nützliche Verbindung zu der dänischen Dichterin war Rahel Levin Varnhagen ihrerseits von David Veit aufmerksam gemacht worden, der sie selbst nur vom Hörensagen kannte. Sein Brief kann als ein typisches Beispiel der Kontaktanbahnung in dieser Gesellschaft gelten:

In Karlsbad selbst finden Sie einen Menschen, dem die holden Töne meines Namens sanft klingen, [...]. Hofmeister bei einem Jungen der Brun heißt, und ich nenne ihn erstlich um dieser Eigenschaft willen, und zweitens, um seiner Prinzipalin willen (die ich nicht persönlich kenne). [...]. Sie ist gewiß eine gescheidte Frau, und sie werden sie äußerst leicht kennen lernen. ${ }^{608}$

605 Ebd. Christian Günther Bernstorff, späterer dänischer und preußischer Staatsminister, war in den 1790er-Jahren ein Verehrer Marianne Meyers. Sein Vater hatte die geplante Hochzeit untersagt. Womöglich fühlte sich Friederike Brun den Schwestern darin „verwandt“, dass sie beide als von unglücklicher Liebe gezeichnet fand.

606 Friederike Brun, Tagebucheintrag 7.-9. 7. 1795, in: Bobé 1905, S. 236.

607 Friederike Brun, Tagebucheintrag 7.-9. 7. 1795, in: Bobé 1905, S. 236. Diese hochinteressante Bemerkung wurde von der Forschung bisher kaum wahrgenommen. So schreibt Scurla fälschlich: „Über den Eindruck, den Rahel auf Friederike Brun machte, erfahren wir nichts.“ Scurla 1962, S. 303. Auch die Tatsache, dass Brun sie hübsch fand, hat keinen Einfluss auf die stereotype Darstellung „der Kleinen“ als unscheinbar oder sogar hässlich.

608 David Veit an Rahel Levin Varnhagen, 15. 6.1795, in: GW VII/II, S. 156. Als wesentlichen Grund seiner Empfehlung nannte Veit die Beziehung der Brun zu Goethe. Er ging vermutlich mit Recht davon aus, dass seine Freundin mit allen neuen Bekannten über den Dichter sprechen würde: „[...] sie ist Dichterin mit ziemlichen Sukzeß. Der Original-Text zu dem ,Ich denke Dein“ ist von ihr; daher Sie ihr das Goethische nicht füglich zeigen können, ohne das zu wissen [...].“ Ebd. 
Irgendwann zwischen dem 7. und 12. Juli muss die erste Begegnung zwischen Goethe und den Schwestern Meyer bzw. zwischen Goethe und Rahel Levin Varnhagen in Begleitung Friederike Unzelmanns stattgefunden haben. Eine folgende beschreibt die Brun so:

Am Abend war er hier bei uns mit der kleinen Levin und der Unzelmann, die sehr verständig tut und etwas treuherziges in ihrem Blick hat, welches mir gefällt. Sein Ton mit Frauen, die nicht streng auf sich halten, ist nicht fein, und an zarter Grazie fehlt's ihm überhaupt [...]. Nachmittags kam Goethe, um mit mir zu Sarah und Marianna [Meyer] zu gehen. [...] Bey Meyers war er gar hold Marianne, die holde Seele, geht ihm ans Herz. ${ }^{609}$

Das Zusammentreffen mit Goethe und den Berlinerinnen war anscheinend von der Brun geplant, denn missmutig verzeichnet sie: „Der Herr Rittmeister von Gualtieri war ungebeten dazu gekommen, ein avantageuser fât“'.610

In der Sekundärliteratur wird meistens angenommen, dass sich bereits Goethes erste ,Erfolgsmeldung، an Schiller, er habe am Brunnen „einen kleinen Roman aus dem Stegreife“ begonnen, auf Marianne Meyer Eybenberg bezogen hatte. Schiller gegenüber gab der Dichter seiner Hoffnung (den) Ausdruck, den „Roman“ so zu gestalten, „dass er vierzehn Tage aushalten kann“.611 Christiane Vulpius gegenüber hielt er es ebenso allgemein: Er versicherte ihr neben anderen Annehmlichkeiten: „Äugelchen setzts auch genug“.612 Die nachhaltige Wirkung der Begegnung mit Marianne Meyer Eybenberg sollte erst später sichtbar werden, in der auffallend liebevollen Korrespondenz, die dem Badeflirt folgte und der Intensität des Umgangs in späteren Badebesuchen. ${ }^{613}$

609 Friederike Brun, Tagebucheintrag 12. 7. 1795, in: Bobé 1905, S. 238 f.

610 Im Sinne von „ein billiger Geck“. Friederike Brun, Tagebucheintrag 12. 7. 1795, in: Bobé 1905, S. 238.

611 Tatsächlich scheint Goethe, den wenigen Briefen gemäß, anregende weibliche Bekanntschaft als wesentlich für seine Gesundung betrachtet zu haben. Johann Wolfgang von Goethe an Friedrich von Schiller, 8. 7. 1795, in: Beetz 2005, Bd.1, S. 91.

612 Eine Woche später folgt das bekannte Zitat, es gäbe „Äugelchen die Menge“. Am 25. Juli versicherte er seiner Lebenspartnerin: „Die Äugelchen nehmen sehr ab, denn es kann von beiden Seiten kein Ernst werden.“ Johann Wolfgang von Goethe an Christiane Vulpius, 25. 7. 1795, in: Hans Gerhard Gräf (Hrsg.): Goethes Ehe in Briefen. Der Briefwechsel zwischen Goethe und Christiane Vulpius. Mit zeitgenössischen Abbildungen. Frankfurt/M. 1994, S. 104 u. 106. Wie ernst es nach Goethes Geschmack mit den „Äugelchen“ aber in den zehn Tagen zwischen den beiden Briefen hätte werden dürfen, bleibt offen.

613 Diese Intensität wird gern einseitig ausgelegt. 1808 schrieb beispielsweise August Goethe aus Teplitz an seinen Vater: „Frau von Eybenberg excellirt in Anhänglichkeit an Dich; Sie wird sehr geplagt, um ihr Gefühl für Dich in die richtige Classe zu ordnen.“ 4. 8. 1808, zit. nach: Hlawacek 1883, S.64, Fn. 2. 
Abgesehen vom eigentlichen Brunnenverkehr und öffentlichen Großereignissen wie Bällen spielte sich das gesellschaftliche Leben überwiegend in den einzelnen Privatunterkünften, bei Besuchen („Visiten“ und „Gegenvisiten“), gemeinsamen Frühstücken, Abendessen oder Nachmittagen mit spontanen Lesungen ab. Der Umgang zwischen Friederike Brun und Goethe gewann, wie sie im Tagebuch mit Stolz verzeichnet, beinahe familiären Charakter. Er lehrte die Tochter richtig lesen, nahm sich des Sohnes väterlich an, und auf gemeinsamen Spaziergängen sprach er, wie sie besonders betonte, sogar von seinen häuslichen Verhältnissen. ${ }^{614}$ Vermutlich spielte sich auch der freundschaftliche Umgang mit den drei Berliner Jüdinnen wesentlich auf Spaziergängen und Besuchen ab, gemeinsam und à deux. So bat Marianne Meyer Eybenberg den Dichter im Oktober desselben Jahres: „Vergessen Sie unser Gespräch auf der Brücke beim Neubrunnen nicht, ich bitte, bitte“.615 Mögliche Themen der Gespräche kann man ebenfalls nur aus dem Tagebuch der Brun herauslesen, die die lockere Bademischung der Konversation und andere Teilhabende daran getreu verzeichnete. ${ }^{616}$ Der Kurrhythmus scheint dabei der Konversation förderlich gewesen zu sein, denn Friederike Brun verzeichnet unter einer langen Liste der ,Themen des Tages‘: „Kunst, Epigramme, Elegisches, Improvisiren, Liebe als Mittel zum Zweck über Hoffnung, die in ihm [Goethe, H. L. L. ]. erstorben ist“, darunter das bezeichnende: „Dies ist alles beim Sprudeltrinken auf und ab geredet". 617

Es scheint so, als habe sich innerhalb der Badegesellschaft ein kleiner Kreis um Brun und Goethe zusammengefunden, der $\mathrm{zu}$ jeder Tages- und Abendzeit zum ruhigen Gespräch, gemeinsamen Frühstücken und Brunnengängen zusammenkam. „Mit Meyers, Diedes und Goethe abwechselnd gelebt“,

614 Die Begeisterung beruhte nicht ganz auf Gegenseitigkeit. Bereits aus Karlsbad gab Goethe seiner Verwunderung Ausdruck, „welch eine sonderbare Mischung von Selbstbetrug und Klarheit diese Frau zu ihrer Existenz braucht“. Johann Wolfgang von Goethe an Friedrich von Schiller, 19. 7. 1795, in Beetz 2005, Bd. I, S.92. Später wurde „Madame B**“ ein wenig schmeichelhaftes Xenion gewidmet: „Jetzt noch bist Du Sybille, bald wirst Du Parze; doch fürcht ich / Hört Ihr zuletzt grässlich als Furien auf." Johann Wolfgang von Goethe: An Madame B** und ihre Schwestern, in: Goethe 1992, S.61.

615 Marianne Meyer Eybenberg an Johann Wolfgang von Goethe, 6. 10. 1795, dieser Teil des Briefes ungedruckt, GSA 28/306.

616 Am Abend des 12.7. 1795, an dem Goethe in ihrem Quartier Besuch machte und u.a. Levin Varnhagen und Unzelmann dort vorfand, ging es u. a. um „Theater und Kunst [...] über das Theater der Italiener [...] Vergleich mit dem Französischen.“ Friederike Brun, Tagebucheintrag 12.7.1795, in: Bobé 1905, S. 238.

617 Friederike Brun, Tagebucheintrag 7.-9.7.1795, in: Bobé 1905, S. 237. 
oder „Abend still und ruhig mit Goethen, Mariannen und Sarah“ lauten die Einträge. 618

Zur selben Zeit waren nicht wenige Aristokraten in Karlsbad, die allerdings dem bürgerlichen Umgang nicht unbedingt aufgeschlossen waren, und von der dänischen Dichterin im Gegenzug summarisch charakterisiert wurden als ,alte adelige Schachteln, die allen Schmelz der Wiesen an ihren dünnen Gestalten umhertragen und alle rostigen Vorurtheile auf Ihren Nasen“".619 Apropos Vorurteile: Die genaue Beobachterin Brun, die Goethes verwöhnten Umgang mit Frauen mehrfach kritisch vermerkte, schrieb zu etwaigen Vorurteilen des Dichters gegenüber Jüdinnen oder Schauspielerinnen nichts. Es scheint im Bad davon nicht gesprochen worden zu sein. Aber nur einen Monat nach der Begegnung der Berliner Salonièren mit Goethe in Karlsbad kursierten in Berlin Gerüchte über den Erfolg „der Jüdinnen“: Wilhelm von Humboldt schrieb von seinen Berlinbesuchen an Schiller: „Er [Goethe] hat sich in Carlsbad mit einigen hübschen Judenmädchen, und einer actrice von hier amüsirt, wie wenigstens diese in Briefen rühmen. Wahrscheinlich ist das das artige Abenteuer von dem er schreibt“". ${ }^{620}$ Briefe der Frauen sind in dieser Art nicht überliefert. Wie dieses „Sich-Rühmen“ aussah oder ob Humboldt davon ausging, dass sich ein „Judenmädchen“ der Bekanntschaft mit Goethe notwendigerweise rühmen müsse, bleibt daher unklar.

Im Oktober, nach der Rückkehr der Badereisenden nach Berlin, kam Humboldt noch einmal auf diese Begegnung zurück. Sein Kommentar wird in Aufsätzen über Goethes Badeurlaube zwar oft angeführt, aber nicht in Gänze. In der bekannten Fassung berichtete Humboldt:

Von Goethe höre ich hier allerlei possierliche Geschichten erzählen, die von zwei getauften Jüdinnen, die mit in Karlsbad waren, herkommen. Außerdem, dass er ihnen soll erstaunlich viel vorgelesen, in Stammbücher und auf Fächer geschrieben und ihre Produktionen korrigiert haben, erzählt auch die eine, die sonst ein sehr schönes Mädchen war, dass er ihnen die einzelnen Gelegenheiten erzählt habe, die ihn zu den „Elegien“ veranlasst, namentlich die zu dem Vers „Und der Barbar beherrscht römischen Busen

618 Friederike Brun, Tagebucheintrag 12. und 20.7. 1795, in: Bobé 1905, S. 239. An sonstigen Kurbekanntschaften der Brun - und damit auch der Meyers, mit denen sie drei Wochen lang fast täglichen Umgang hatte - werden genannt: der Präsident des Kammergerichts von Berlin Kircheisen, Freiherr von Diede, der dänische Gesandte und seine Frau Louise, die mit Goethe gut befreundet war, und Therese Brzozowska aus Polen. In Begleitung der Friederike Brun befand sich außerdem der Dichter Friedrich von Matthison. 619 Friederike Brun, Tagebucheintrag 14.-16. 6. 1795, in: Bobé 1905, S. 235. 620 Wilhelm von Humboldt an Friedrich von Schiller, 15. 8. 1795 in: Leitzmann 1900, S.76. 
und Leib!“ [...] Sie sollen auch, wie sie erzählen, bei dem erwarteten neuen Ankömmling in Weimar Patenstelle vertreten. ${ }^{621}$

Die erotische Konnotation dieser Gerüchte hängt vermutlich damit zusammen, dass gerade in diesen Monaten die Römischen Elegien die lesenden Gemüter in Berlin und Weimar erhitzten, aus denen Humboldt hier auch zitierte. Die Auslassung ist bemerkenswert, denn sie enthält nicht nur einen interessanten und typischen Seitenhieb Humboldts auf die Beherrschung von römischen Busen und Leib - „Dies lässt doch wohl auch auf die Unterwürfigkeit des Jüdischen schließen, nicht wahr?“ -, sondern auch eine treffende Charakteristik der literaturpolitischen Szene in Berlin:

Übrigens aber, obgleich dieser mit vieler Indiskretion herumgetragnen Geschichtchen Goethes Bild hier mit einigen neuen Zügen ausgestattet haben, finde ich es äußerst vernünftig, einige so genannten aufgeklärte Männer und denkende Köpfe von hier, die zugleich da waren und über ihre Zurücksetzung sehr missmutig schienen, vernachlässigt und diese Getauften erwählt zu haben, die in der Tat, viel Pretiöses und Affektiertes abgerechnet, recht geistvoll und angenehm sind. ${ }^{622}$

Humboldt sah damit voraus, dass Goethe sich mit diesem selbst „erwählten“ freundlichen Umgang in Karlsbad zwei nicht nur treue, sondern nützliche Verehrerinnen herangezogen hatte. Er billigte dies als literaturstrategischen Schachzug, insbesondere da die Schwestern Meyer, die er jetzt erst kennenlernte, Goethes Wert besser erkennen könnten als einige „so genannten aufgeklärte Männer“.623 Zugleich fällt auf, dass Humboldt die beiden Goethefreun-

621 Wilhelm von Humboldt an Friedrich von Schiller, 12. 10. 1795, in: Leitzmann 1900, S. 177. Die Anmerkung der meisten Herausgeber, es handle sich bei diesen beiden um Marianne Meyer Eybenberg und Rahel Levin Varnhagen, ist falsch, da letztere 1795 keineswegs getauft war und Humboldt das wusste. Die zweite Getaufte ist die Schwester Sara, die allerdings in den Aufsätzen zu Goethes Badebekanntschaften fast immer vergessen wird.

622 Wilhelm von Humboldt an Friedrich von Schiller, 12. 8. 1795, in: Siegfried Seidel (Hrsg.): Der Briefwechsel zwischen Schiller und Wilhelm von Humboldt, 2 Bde., Berlin 1962, Bd.1, S. 177.

623 Barbara Hahn, die als eine der wenigen das Zitat komplett wiedergibt, bemerkt, dass Humboldt hier eine Analogie zwischen der Unterwerfung des weiblichen und des jüdischen Körpers herstellt. Die beiden erwähnten Frauen seien dadurch verbal ausgegrenzt. „Ihre Taufe wird in der Parallelisierung mit der römischen Frau zum Unterwerfungsakt, der ihnen keinen neuen und anerkannten Platz in der christlich dominierten Kultur bietet. Sie repräsentieren weiter ,das Jüdische‘, das in der Folge den aufgeklärten Männern der Berliner Gesellschaft entgegengesetzt wird." Hahn 2002 (b), S.125 f. M. E. ist Humboldts Formulierung eher im Gesamtzusammenhang seines spezifischen Umgangs mit jüdischen Themen zu betrachten, die durchweg erotisch konnotiert sind. [Vgl. V] 
dinnen als „getaufte Jüdinnen“ markierte, was Goethe in seinen Berichten nicht getan hatte.

\subsection{Nach 1795 - Goethe-Kult in den Berliner Salons? Drei Ausblicke}

Insofern man aus den rückerinnernden Briefen Marianne Meyer Eybenbergs auf den Umgang im Bad schließen kann, hatte man „Freundschaft“ geschlossen, die durch kleine, zum Teil romantisierende Andenken, wie eine Locke von Goethes Haar, erhalten werden sollte. Auf intime Geständnisse etwaiger erotischer Erfahrungen, auf die Humboldt anspielte, gingen die Frauen in ihren Briefen nicht ein.

Auch den kontinuierlichen Klatsch zwischen Berlin und Weimar um das Treffen in Karlsbad und die daraus sich entwickelnde Freundschaft kann man, positiv gewendet, als Anzeichen einerseits für ein echtes Interesse des Dichters nehmen und andererseits dafür, dass eben dies den Frauen ein Zuwachs an Renommee verschaffte. Bereits 1797 wurden Bemerkungen über „die schöne Marianne Meyer“ im Briefwechsel zwischen Berlin und Weimar ein Epitheton „Korrespondentin des Herrn von Goethe“ angehängt. Als solche war sie eine zitierfähige Autorität.624 Ihre weiteren Zusammentreffen mit Goethe wurden zwar mit ironischen Kommentaren, aber aufmerksam verfolgt. Zwischen den Verlegern Sander und Böttiger kam es dabei zu fantasievollen Ausschmückungen: „Die schöne Marianne Meyer u. der Herr von Göthe haben sich ein Rendezvous in Dresden gegeben $u$. werden von da zusammen weiter gehen“. ${ }^{625}$ Auch Friedrich Schlegel musste seiner Schwägerin Caroline gegenüber bemerken: „Marianne tut dicke mit Goethe, ist übrigens sehr elegant, sehr artig und unbedeutend genug“. ${ }^{626}$ Sein Bruder August Wilhelm fragte direkt bei Goethe nach und suchte sogar über die Bekanntschaft mit Marianne Meyer Eybenberg die Gunst des Dichters für sich zu gewinnen. Goethe bestätigte: „Die Bekanntschaft meiner werten Berliner Freundin wird Ihnen gewiß viel Freude gemacht haben. Ich schätze beide Frauenzimmer sehr hoch und habe alle Ursache, für die Gesinnungen dankbar zu sein, die sie für mich hegen“. ${ }^{627}$

624 So z. B.im Brief von Johann Daniel Sander an Böttiger, 7. 2. 1797, in: Bode 1999, Bd. 2, S. 100 .

625 Johann Daniel Sander an Carl August Böttiger, 28. 3. 1797, in: Maurach 1990, Bd.1, S. 136 .

626 Friedrich Schlegel an Caroline Schlegel Schelling am 29. 10. 1798, in: KFSA, Bd. 24, S. 190 .

627 Johann Wolfgang von Goethe an August Wilhelm Schlegel, 18. 6. 1798, zit. nach: Erna Arnhold: Goethes Berliner Beziehungen, Gotha 1925, S, 214. Die zweite erwähnte Frau war Karoline von Berg. 


\section{,Erfrischende Goethe-Lektüren` - Goethe und Meyer Eybenberg}

Von einem späteren gemeinsamen Badeaufenthalt, währenddessen Goethe, im Unterschied $\mathrm{zu}$ 1795, Tagebuch führte, wissen wir, dass er Marianne Meyer Eybenberg prätentionslos zu jeder Tageszeit besuchte oder ausfuhr, um sich mit ihr über aktuelle Arbeiten wie über Neuigkeiten aus ihrem Wiener Lebenskreis zu unterhalten. Die Wahlverwandtschaften übersandte er ihr mit dem Hinweis: „Gedenken sie mein unter dem Lesen, gedenken Sie der guten Tage, in welchen diese Werkchen größtentheils in Ihrer Nähe entstand”.628 Man kann sagen, dass sich sich die Freundschaft 1808 auf dem Höhepunkt befand, danach teilte sich Goethe mit seinem Freund und Reisebegleiter Riemer das Vergnügen und die Arbeit der Korrespondenz mit ihr. Dennoch spricht nichts dagegen, dass man sich das freundschaftliche Andenken nicht noch länger gegenseitig in Wort und Tat ausgedrückt hätte, wenn nicht Meyer Eybenberg 1812 einer langwierigen Krankheit erlegen wäre. ${ }^{629}$

Der Briefwechsel Goethes mit Marianne Meyer Eybenberg630 umfasst vielfältige Themen und ist, den heute erhaltenen Teilen nach, unterhaltsam zu lesen, getragen von einem leichten Plauderton, der durch kritische Beobachtungen in der Gesellschaft einen besonderen Reiz erhält. Nicht von ungefähr haben die bisherigen Herausgeber des Briefwechsels sich jeweils das sie Interessierende aussuchen und so ein neues Licht auf, Goethe im Umgang mit Frauen' oder ,Goethe und Österreich' werfen können. Dabei wurden die Briefe allerdings manchmal um die für die Schreiberin kennzeichnende Mischung aus Verehrung und Selbstbewusstsein gekürzt.631

628 Johann Wolfgang von Goethe an Marianne Meyer Eybenberg, 1. 10. 1809, zit. nach: Hahn 1990(b), S.64. In der Literaturwissenschaft wurde die Frage mehrfach diskutiert, welchen Einfluss sie dabei nahm und ob eine und welche Frauenfigur in diesem Roman nach ihr modelliert worden ist.

629 Sie starb nach längerem Leiden, während dessen ihre Schwester sie pflegte, an Wassersucht.

630 Der erste überlieferte Brief, der vermutlich die Korrespondenz auch eröffnete, ist der zitierte vom 22. 9. 1795. Der letzte Brief datiert vom 10.12. 1810.

631 Vgl. die unterschiedlichen Teilabdrucke der Korrespondenz bei Ludwig Geiger 1893 und Sauer 1904. Als ein weiteres typisches Beispiel für verkürzte Überlieferung sei hier ein Billet angegeben, das ihre Ankunft in Weimar vermeldet. (Das Kursive ist ungedruckt, die sehr gekürzte Fassung in: Goethe. Begegnungen und Gespräche. Begründet von Ernst Grumach und Renate Grumach, Band V: 1800-1805, hrsg. von Renate Grumach, Berlin u.a. 1985, S. 171 f., Fn.) : ///,Ich habe dem Wunsch, Sie wiederzusehn mein verehrter Freund, nicht wiederstehen können und befinde mich also, seit 5 minuten, würklich in Weimar - Ihnen so nah zu sein und nicht einen kleinen Umweg machen um wieder einmahl eine reine Freude zu genießen, konnte ich mir unmöglich versagen - wenn es wahr ist, was ein Alter Schriftsteller sagt, „dass ein jeder der Gesellschaft gleicht, die Er liebt“ so bin ich es gewiß werth mich Ihnen zu nähern, wann nämlich das letztere die Ähnlichkeit bestimmt, den was ist mir lieber, was schätze ich höher als Ihre Gesellschaft; ich rechne mit der Fortdauer Ihres Wohlwollens, 
In einem scheinbar ungeordneten Stil, der in seinem Anspruch auf Natürlichkeit dem Gellertschen Ideal eines Frauenzimmerbriefes ${ }^{632}$ gänzlich entspricht, behauptete Marianne Meyer Eybenberg Freundschaft und forderte sie zugleich ein. Bereits im ersten Brief vom September 1795 setzte sie sein Interesse an ihrer Gesundheit voraus, derer sie ihn versichert, nannte ihn „Guter Göthe“ und „Lieber Freund“ und gab vor, damit nur seinem Wunsch zu entsprechen: „Dass Sie mir antworten werden, dafür bürgt mir ihre Freundschaft, Ihr gegebenes Wort und so lieber Freund leben wir miteinander fort, ich schreibe Ihnen wie es aus dem Herzen kömmt, durch den Sinn fährt, damit müssen Sie zufrieden sein, und das werden Sie auch“.633 Meyer Eybenberg behauptete ihre Briefe als Fortsetzung der Gespräche in Karlsbad, und die Erlaubnis dafür läge in der guten Wirkung, die der Umgang Goethe auf sie habe: „Fahren Sie fort liebster Goethe mich fortzuhelfen, so wie Sie in Carlsb. thaten, ich bin Ihnen viel viel schuldig“. ${ }^{634}$

Als sie trotz allem nicht sofort Antwort bekam, ließ sie sich nicht entmutigen, sondern kokettierte zwei Wochen später mit ihrer Hartnäckigkeit: „Da bin ich schon wieder guter Göthe - Sie sehen dass ich mich an keiner Regel binde, und dass Sie mich nicht loswerden, auch wenn Sie mir nicht antworten“. ${ }^{635}$ Diese Hartnäckigkeit ${ }^{636}$ unterstützte sie mit fantasievollen Aufmerksamkeiten,

durch dass Sie mich so beglückten und verwöhnten, - und freue mich unendlich auf den Augenblick des wiedersehens, Sie werden bestimmen wann es mir so wohl werden soll einen so lieben Freund zu sehen. Marianne Eybenberg/// An Johann Wolfgang von Goethe, 16. 9. 1801, GSA $28 / 34$.

632 Dazu passt auch die hier zum Ausdruck kommende Unbekümmertheit oder „Ungezogenheit“. Hier ist partiell Silke Schlichtmann zu widersprechen, die Meyers briefliches Verhalten als dem Geschlechtermodell nach untypisch betrachtet. Dem Ideal „weiblichen Schreibens“ entspricht sie durchaus. Schlichtmann 2001, S. $166 \mathrm{f}$.

Hingegen hat Schlichtmann mit dem Hinweis Recht, dass Meyers Berichte darüber, wie sie anderen Lesern Goethe erklärt, durchaus nicht in das Schema einer weiblichen „rezeptiven“ Seele passe. Ebd., S. 168.

633 Marianne Meyer Eybenberg an Johann Wolfgang von Goethe 22. 9. 1795, zit. nach: Geiger 1893, S. 27. Hervorhebungen im Original.

634 Marianne Meyer Eybenberg an Johann Wolfgang von Goethe 22. 9. 1795, zit. nach: Geiger 1893 S. 27. Sowohl Florian Krobb als auch Barbara Hahn sehen in dem „Forthelfen“ eine Bitte um konkrete Hilfe beim Abschied vom Judentum. Hahn 2000, S. 339. Krobb 1991/ 1992, S. 40.

635 Marianne Meyer Eybenberg an Johann Wolfgang von Goethe, 6. 10. 1795, diese Stelle erstmals gedruckt bei Hahn 1990, S. 63 .

636 Christiane Vulpius konstatiert bereits ein halbes Jahr nach der ersten Bekanntschaft in Karlsbad: „Hier folget wie ich sehe wieder ein Briefchen von Mariannichen. Das ist eine fleißige Schreiberin, das wird am Ende noch gefährlich werden.“ Christiane Vulpius an Johann Wolfgang von Goethe, 2. 3. 1796, in: Gräf 1994, S. 122. 
sie sandte mit demselben Brief versprochene Schriften von Brinckmann, ein Gedicht vom Prinzen de Ligne, eine Vertonung Goethescher Gedichte von ihrem Freund Fürst Reuß und kündigte ein Andenken aus ihren eigenen Haaren an.

Das primäre Thema in den erhaltenen Briefen blieb ihre Verehrung seines dichterischen Schaffens - „Das nennen Sie also ein Wagestück? Mir sind seitdem, Meisterstück und Wagestück, Synonime geworden“637 -, Kommentare zu seinen Werken und Äußerungen des Glücks, wenn er sie damit bedachte, häufig noch vor Drucklegung. Daneben finden sich viele Äußerungen zu gemeinsamen Treffen oder die Erinnerung daran, immer die Sehnsucht, mit ihm zu sprechen, brieflich oder mündlich. Sie adressierte Goethe durchweg als „Freund“, sprach zu ihm manchmal als Beichtvater bzw. Vertrauten, sogar in Familiendingen. Materielle Aufmerksamkeiten, Genussmittel wie Schokolade, aber auch klug ausgewählte Gegenstände für seine Sammlungsinteressen, wie Münzen, Kupferstiche oder Steine, schickte sie mit dem Hinweis: „[...] mich aber nicht zu kräncken und mir von contos zu sprechen; wollen Sie mir den Genus rauben, Sie mit einer solchen Kleinigkeit zu versorgen“.638 Für diese Kombination von Freundlichkeit und Klugheit revanchierte Goethe sich mit freundlichen Komplimenten, einem Ring (der ihr zum „Talismann“ wurde) oder eben mit Manuskripten. ${ }^{639}$

Nicht ohne Stolz merkte sie bald, dass ihre Freunde sie als etablierte Korrespondentin Goethes schätzten und einige ihren guten Draht zu Goethe ausnutzen wollten. Und nicht ohne Spott berichtete sie nach Weimar, zum Beispiel über ihren Bekannten Brinckmann: „Der Narr hat mir einen langen brief über das bekentnis der schönen Seele geschrieben ein wahres untereinander, von dem er glaubt es athme reine Begeistrung. [...] obendrein glaube ich hat er in der Absicht geschrieben, es würde Ihnen vielleicht unter die Augen kommen; wenn Sie es wollen schicke ich es Ihnen“.640 Zwei Monate später verstärkte sie diese Kritik zu einer boshaften Charakteristik:

B. ist so ein Verstandskrämer der affectirt oft von seinem Gefühl hingerißen zu sein, und sich alle Mühe giebt einen weis zu machen, die reine heilige Flamme des Enthusiasmus

637 Marianne Meyer Eybenberg an Johann Wolfgang von Goethe, 29.10. 1796, dies auch bei Hahn 1990, S. 62.

638 Marianne Meyer Eybenberg an Johann Wolfgang von Goethe, 4. 12. 1798, dies ungedruckt, GSA 28/306.

639 Dank für den Talismann in: Marianne Meyer Eybenberg an Johann Wolfgang von Goethe, 2. 2. 1796 , dies ungedruckt, GSA $28 / 306$

640 Marianne Meyer Eybenberg an Johann Wolfgang von Goethe, 11. 12. 1795, GSA 28/306, erstmals gedruckt bei Hahn 2002(b), S. 121. 
habe ihn ergriffen, [...] und dadurch, bey einer ausgezeichneten Bildung, Scharfsinn und talent, doch höchst fade und lästig, nur weil er die Kunst aufzuhören nicht kennt, und das topic, sein klein einziges-Ich, ewig ist, und bleibt dies zu Ihnen gesagt. ${ }^{641}$

Der Kult-Betreibende war nach ihrer Darstellung eindeutig Brinckmann, sich selbst schilderte sie dabei als kritische rationale Leserin. Möglicherweise ahnte sie, dass Goethe solche deutlichen, klatschenden Charakterisierungen durchaus zu schätzen wusste. Zugleich aber erhob sie, indem sie Brinckmanns Goethe-Lektüre diskreditierte, Anspruch darauf, den Dichter selbst besser zu verstehen. ${ }^{642}$ Was sie dazu trieb, über ihren Gast, mit dem sie zumindest seit 1793 in freundlichem Kontakt stand, herzuziehen, kann bei der spärlichen Quellenlage nur vermutet werden: Im Brinckmannschen Nachlass findet sich das Konzept eines Briefes an sie, in dem er ihr seitenweise seine Lektüre-Erfahrung des „Wilhelm Meister“ nahebringen wollte, nicht ohne sie als „schöne Seele“ zu komplimentieren. Tatsächlich nutzte er die Lektüre vor allem für eine Analyse seiner selbst: „Was kein Mensch, der mich blos in Weltverhältnissen kennt, erahnden oder glauben möchte, darf ich Ihnen, als einer schönen Seele, ja wol gestehen, dass Religiosität noch diesen Augenblick den Grundzug meines Charakters ausmacht"“!643 Wenn es dieser Brief war, auf den sie anspielte, war sie durch Brinckmanns Anspruch erzürnt, Goethe am besten zu verstehen, denn er schrieb mehrfach in diesem Brief: „Wie ich denn [...] dies alles unstreitig noch besser verstehe als Goethe selbst“".644

Wenn sie auch in ihrem Zugang konkurrierten, glaubten doch sowohl Brinckmann als auch Marianne Meyer Eybenberg sich allerdings in ihrer jeweiligen Goethe-Verehrung von derselben Person am besten verstanden, von Rahel Levin Varnhagen. Letztere wurde in den Briefen Meyer Eybenbergs an Goethe mehrfach als „Mitgenießende“ seiner Werke präsentiert, ohne dass sie selbst ihm darüber Auskunft gäbe: „Meinen Enthusisamus für das Produkt und

641 Marianne Meyer Eybenberg an Johann Wolfgang von Goethe, 2. 2. 1796, GSA, 28/306, ungedruckt, teilweise zitiert bei Hahn 2002(b), S. 122.

642 Diesen scheint die Beschreibung seines Verehrers amüsiert zu haben. Auf einen nicht überlieferten Brief antwortet Marianne Meyer Eybenberg noch einmal: „Nicht leicht hat mich etwas mehr amusirt als was sie über Brinckmann sagen, mit ein paar Worten haben Sie den kleinen Sprenßel besser, richtiger, gezeichnet als alle die klugen Herrn hier.“ Marianne Meyer an Johann Wolfgang von Goethe, zit. nach: Geiger 1893, S. 30. Sprenßel bezeichnet laut Auskunft des Herausgebers einen Heuschreck.

643 Gustav von Brinckmann an Marianne Meyer Eybenberg, o. D. [vermutlich 1795], BA E. Ohne Unterstreichungen und leicht modernisiert auch in Wachtmeister 1871, S. 2.

644 Gustav von Brinckmann an Marianne Meyer Eybenberg, o. D. [vermutlich 1795], BA E. Einen Schlüssel zu diesem Verständnis sah Brinckmann in seiner fundierten religiösen Erziehung bei den Herrnhutern. 
seinen Schöpfer haben sogleich 3 Wesen mit mir theilen müssen, ich gönnte mir diesen Genuß nicht allein, und diese Menschen machten sich deßen würdig, durch die Art wie sie es genießen und verstehen; [...] Reuß, die Berg, und die kleine Levy“.645

\section{Kein geistiger Vater - Sara Meyer Grotthus und Goethe}

Für die ältere Schwester Meyer, 1795 geschiedene Sara Wulf, hatte das Zusammentreffen mit Goethe 1795 keine unmittelbaren Folgen. Ihre Korrespondenz mit ihm begann zögerlich Ende 1796 und trat erst während der Abwesenheit und nach dem Tod der Schwester Marianne in eine intensive Phase. ${ }^{646}$ Diese Verzögerung war allerdings mehr in ihrer persönlichen Familiengeschichte ${ }^{647}$ begründet als in einem geringeren Interesse am Dichter - im Gegenteil. Wie Sara Meyer Grotthus Goethe später mehrfach gestehen sollte, war sein Werk eine Art ,Katalysator' für ihre eigene Entwicklung gewesen: Ein junger Hamburger, in den sie mit 13 Jahren verliebt gewesen sei, habe ihr „den göttlichen Werther“ geschickt, den sie „mit 1000 unterstrichenen Stellen und einem sehr glühenden Billet“ zurücksenden wollte. ${ }^{648}$ Dieser Brief von ihr wurde abgefangen und führte zu kontroversen Reaktionen in der Generation der Väter und Aufklärer: „Mendelssohn der mein Mentor war, erschien und machte mir bittre Vorwürfe, ob ich Gott und Religion vergessen könnte und was der Alfanserei mehr war, nahm den lieben W. [...] und warf ihn [...] aus dem Fenster." Mendelssohns Freund Lessing hingegen habe ganz anders reagiert: „Ausser sich

645 Marianne Meyer Eybenberg an Johann Wolfgang von Goethe, 20. 3. 1798, Teildruck des Briefes bei Geiger 1893, S. 35, diese Stelle ungedruckt.

646 Der Beschenkte ließ sich das Teamwork bzw. die Konkurrenz der Schwestern nicht ungern gefallen: „Wie sehr freut mich's, dass Sie noch an mich denken, und jetzt nicht verschmähen, als Marianens Stellvertreterin, mir die gewohnten fremden Leckerbissen zuzusenden.“Johann Wolfgang von Goethe an Sara Meyer Grotthus, 1. 2. 1806, in: Goethes Werke, Weimarer Ausgabe [im Folgenden WA], Bd.19, S. $100 \mathrm{f}$.

647 Sie war 1778 im Alter von 15 Jahren nach Wahl der Eltern mit dem Kaufmann Jacob Isaac Wulf(f) verheiratet worden, worauf nach ihrer Aussage Goethe gegenüber ihre Existenz „10 Jahre lang zur Höllen Qual“ wurde. 1788 wurde die Ehe kinderlos geschieden. Die Zeit nach ihrer Scheidung und vor ihrer Eheschließung mit dem Baron von Grotthus 1797 scheint ihr von ihrer Familie sehr schwer gemacht worden zu sein. Mehrfach berichtete Marianne Meyer Eybenberg an Goethe, dass Sara ihrer Lage wegen nicht schreiben könne bzw. sich hysterisch benehme. Dieser Kampf war ihr auf die Gesundheit geschlagen, sodass sie „mager und hässlich“ nach Karlsbad kam. Sara Meyer Grotthus rückblickend an Goethe, 31. 1. 1801 , ungedruckt, GSA 28/32.

648 Sara Meyer Grotthus an Johann Wolfgang von Goethe, 20. 3. 1797, zit. nach: Geiger 1893, S. 51. 
über meine Erzählung, bot er mir seinen Schutz an, im Fall ich den jungen Menschen heiraten wollte, [...] war indignirt gegen Mendelsohn und brachte mir ein ander Exemplar von Werther (das ich aber lange nicht ohne Schauer ansah) sagte mir alles was er darüber dachte“. 649

Die für Sara Meyer Grotthus wesentlichste Konsequenz dieser Liebesgeschichte war vermutlich, „dass diese Epoque in meinem Leben die Ursache war, warum ich zu 15 Jahren durch Moses Gewalt und der Mutter Zwang an einen Elenden verheiratet wurde“. ${ }^{650}$ Zehn Jahre nach Beendigung dieser Ehe mit einem jüdischen Kaufmann war es ein wesentlicher Anlass für ihre Briefe, Goethe diesen Widerspruch zu schildern, zwischen ihrer Begeisterung für seinen Roman und der radikalen Abwehr durch Mendelssohn und ihre Eltern. Dabei sind zwei Unterschiede bedeutsam, der zwischen Vater und Mutter und der zwischen den Freunden Mendelssohn und Lessing. Durch der „Mutter Zwang“ wurde sie verheiratet, während der Vater über die Affäre mit dem Werther selbst desolat gewesen sei, denn „durch wie viel Liebe hat er diese Misshandlung bezahlt, ach er liebte mich über alles, der ewig geliebte Selige"!651 Sara Meyer Grotthus war sich des Paradoxes bewusst und entschuldigte es, dass die Männer, die ihr die Bildung und den Zugang zu Goethes Werk erst ermöglichten, sich vor den Konsequenzen fürchteten.652 Die Mutter wurde hier zur Repräsentantin des zu überwindenden traditionellen Judentums, zumindest aber der Familie, die ihr auch nach der Ehescheidung ihr Verhältnis zu Baron Grotthus jahrelang erschwerte. Nach diesem Geständnis, das mit der Bitte endete, sie doch gelegentlich etwas von ihm lesen zu lassen, bevor es das „gemischte Publikum“ bekäme, setzte der Briefwechsel offenbar erst 1801 wieder ein. Goethe hatte auf ihren Lebensbericht nicht geantwortet.

Bemerkenswert ist, dass Sara Meyer Grotthus 1814, ganz am Ende des Briefwechsels, noch einmal auf diese Werther-Episode zurückkommen sollte, sie allerdings mit leicht anderer Wertung erzählte. Diesmal hatte sie den Roman nur versehentlich im Comptoir, in dem sie als Übersetzerin arbeitete,

649 Dies und das folgende Zitat: Sara Meyer Grotthus an Johann Wolfgang von Goethe, 20. 3. 1797, zit. nach: Geiger 1893, S. 51.

650 Sara Meyer Grotthus an Johann Wolfgang von Goethe, 20. 3. 1797, zit. nach: Geiger 1893, S. 53.

651 Sara Meyer Grotthus an Johann Wolfgang von Goethe, 20. 3. 1797, zit. nach: Geiger 1993, S. 51.

652 Während Sara Meyer Grotthus Mendelssohn als unbelehrbaren Alten darstellte, wurde Lessing zu ihrem Ritter, dessen wahrhaftes Verständnis des „Werther“ sie Goethe durch lange wörtliche Zitate glaubhaft machen möchte. „Du wirst einst erst fühlen, sagte er, was für ein Genie Goethe ist.“ Sara Meyer Grotthus an Johann Wolfgang von Goethe, 20. 3. 1797, zit. nach: Geiger 1893, S. 52. 
liegen lassen, „weil mich die Sendung gar nicht sehr interessierte. [...] Mendelssohn (der wie Sie wissen mein Mentor war) kam mit Strafpredigten, sagte man müsse das Buch aus dem Fenster werfen. [...] Mendelssohns Religionseigensinn war das Hauptmotiv; er fürchtete ich würde den Christen lieben“.653 In der Folge habe Lessing dem Vater „das Versprechen abgelockt, mich so oft als möglich nach Wolfenbüttel zu senden, um meine Fortschritte zu leiten und $\mathrm{zu}$ beurtheilen“, er habe sie auch die Druckfahnen von Nathan dem Weisen sehen lassen, dessen Hauptfigur ,als liberaler Kaufmann nach meinem Vater, als Denker nach Mendelssohn“ geformt sei.654 Mit einigem Abstand wurden sowohl Mendelssohn als auch die - in der Zwischenzeit verstorbene - Mutter, sanfter beurteilt, auch sich selber stellte Sara Meyer Grotthus nicht mehr als verschreckte Empfindsame, sondern gelehrige verständige Schülerin Lessings dar. Möglicherweise versuchte sie tatsächlich, über ihren Umgang mit den Geistesgrößen der Aufklärung rückwirkend ,in der deutschen Literaturgeschichte einen Platz zu beanspruchen“, 655 allerdings antwortete Goethe auf diese biografische Ausführung ebenso wenig wie auf die erste Version.

Warum Goethe ihre Schwester bevorzugte, erschließt sich nicht aus den Briefen. In der Sekundärliteratur gilt die ältere oft als die weniger hübsche, weniger gewandte der beiden Schwestern, was sich mangels einer bildlichen Überlieferung nicht überprüfen lässt. ${ }^{656}$ Das Diktum Rahel Levin Varnhagens, Frau von Grotthus gehöre unter die vier eitelsten Menschen, die sie kenne, hängt dieser ebenfalls noch in der Forschungsliteratur an. ${ }^{657}$ Allerdings blieben Levin Varnhagen und Meyer Grotthus lebenslang befreundet. Auch andere intellektuelle Frauen scheinen sie besonders geschätzt $\mathrm{zu}$ haben, wie etwa Madame Genlis, die eigens für sie Theaterstücke schrieb. Wie ihre Schwester las und zitierte Sara Meyer Grotthus in mehreren Sprachen, schrieb selbst auf Deutsch und Französisch und erhielt von ihren Gästen lobende Kommentare zu ihrem Schreiben. Anders als ihre Schwester Marianne richtete sie an Goethe

653 Sara Meyer Grotthus an Johann Wolfgang von Goethe, 25. 5. 1814, zit. nach: Hahn 2002(a), S. $45 \mathrm{f}$.

654 Sara Meyer Grotthus an Johann Wolfgang von Goethe, 25. 5. 1814, zit. nach: Hahn 2002(a), S. 46.

655 Hahn 2002(a), S. 47

656 Geiger charakterisiert sie als „weniger hübsch und weniger begabt als jene“. Hingegen erinnert sich Zelter, dass sie viele Verehrer gehabt habe und „ein hübsches Wesen“ gewesen war. Geiger 1893, S. 97; Carl Friedrich Zelter an Johann Wolfgang von Goethe, 15. 7. 1824, in: Hecker 1987, Bd. 2, S. 325.

657 „Die vier eitelsten Menschen, die ich gekannt habe, sind Frau von Gr., Doktor Böhm, Major von Gu. und Graf Tilly“. Tagebucheintrag 1805, in: GW I, S. 274. Der Zusammenhang ist unklar. Dennoch schreibt Hannah Arendt von einer „pathologischen Eitelkeit“, an der Grotthus auch gestorben sei. Arendt 2001, S. 47. 
tatsächlich nie kokette Anmerkungen zu seinen Werken, sondern immer nur Reflektionen ähnlich den obigen. Sie baute an dem Gegensatz zwischen traditioneller jüdische Lebens- und Familienordnung und deutscher Literatur, die ihrem Wesen viel mehr entspräche. Goethe antwortete nicht unfreundlich, bedankte sich aber vor allem für ihre Anteilnahme, ihre Empfindungen und Aufmerksamkeiten sowie ihr Interesse an seinen Schriften. Überspitzt könnte man formulieren, Goethes Interesse an der Beziehung zu Frau Grotthus werde im fröhlichen Nebeneinander der Wünsche in seinen Briefen deutlich; ihn interessierten Gerüchte - und Gerichte: „Lassen Sie von Zeit zu Zeit etwas von sich hören und geben uns einige Nachricht, besonders auch wie es mit dem academischen Wesen in Berlin aussieht. [...] Nun aber empfehle ich Ihnen meine Küche, und meine Tafel, für welche Sie mir zu rechter Zeit einige Leckerbissen $\mathrm{zu}$ senden versprochen haben, als da sind: Caviar, Sander und Dorsche“.658 Diese Überspitzung würde aber den Fakt ausblenden, dass sie ihm auch als Gastgeberin eines gemischten Literaturzirkels von Interesse war. Durch ihre Vermittlung von Goethes Werken in ihrem „Zirkel“ trat sie schließlich in wirkliche Verbindung mit dem Weimarer Dichter. ${ }^{659}$ Bei späteren Begegnungen in Badeorten muss es dann zu intensiverem, freundlicherem Umgang gekommen sein. Goethes Reisebegleiter Riemer schrieb 1811 höflich: „Gar schön wäre es, wenn Teplitz der Versammlungsort werden, und Sie, verehrte Frau, wieder den Vorsitz führen könnten“.660 Nach dieser Begegnung fand auch Sara Meyer Grotthus selbstbewusstere Formulierungen für ihre „Anbetung“: „[...] es gibt hier in Berlin, ein Häuflein Gläubiger, die Sie anzubethen verstehen, [...] ich liebe Berlin nicht, aber wie ich Sie mit Herz Kopf würdigen höre, in dem kleinen circle den ich mir gebildet, davon hatte ich keine Ahndung“661.

Ludwig Geiger sieht in dem Umstand, dass Goethe sich bei beiden Schwestern mit der Übersendung seiner neuesten Werke bedankte, „nicht blos die

658 Johann Wolfgang von Goethe an Sara Meyer Grotthus, 28. 10. 1810, in: WA, Bd. 2, S. 409-411.

659 Dass Goethe ihr 1797 überhaupt antwortete, lag weniger an einer von ihr für ihn selbstgestickten Weste, sondern daran, dass er ihr ein gerade fertiggestelltes episches Gedicht schicken wollte, „dem ich eine so gute Aufnahme, auch in Ihrem Zirkel wünsche als die Neigung stark ist womit ich es angegriffen habe“. Johann Wolfgang von Goethe an Sara Meyer Grotthus, 9. 2. 1797, in: WA, Bd. 12, S. 36-38. Auch als „Literatur-Agentin“ wurde sie ernst genommen. Sie hatte Goethe ein Stück des jungen Autors Ludwig Roberts gesandt mit der Bitte um Kommentar und womöglich Aufführung. Goethe antwortete - ihm durch sie mit detaillierter Kritik.

660 Friedrich Wilhelm Riemer an Sara Meyer Grotthus, 2. 1. 1811, zit. nach dem Manuskript, SV 71.

661 Sara Meyer Grotthus an Johann Wolfgang von Goethe, 13. 1. 1811, ungedruckt, GSA 28/54. 
Quittungen für substantielle Tafelgenüsse, die ihm von Wien und Berlin aus bereitet wurden, auch nicht blos galante Aufmerksamkeiten, sondern eine Anerkennung der geistigen Stellung der Beschenkten“.662 Auch Peter Seibert bestätigt mit seiner Analyse, dass Goethe durch die Schwestern Meyer in Berlin und Wien Terrain gewonnen habe. Goethe habe seiner positiven Aufnahme in Berlin sogar gelegentlich „,beinahe erpresserisch“ nachzuhelfen verstanden, wenn er zum Beispiel darauf hinwies, dass der Bruder Rahel Levin Varnhagens, Ludwig Robert „einige Gefälligkeiten“ gegen das Schauspielerpaar Wolf hätte und dass er und Sara Meyer Grotthus deshalb sicher für eine gute Aufnahme dieser Goethefreunde sorgen würden. ${ }^{663}$ Dass wie Wilhelmy schreibt, „Goethes Antworten auf Sara von Grotthuß’ Briefe [...] stets sehr herzlich“ ausfielen, stimmt so nicht. ${ }^{664}$ Bedeutsam ist vielmehr, dass und wo in dieser schließlich Jahrzehnte überspannenden sonst freundlichen Korrespondenz Goethe eindeutige Grenzen zog. Als Gastgeberin und Vermittlerin von Dichtern und Künstlern nahm er Sara Meyer Grotthus durchaus ernst. Als „Beichtvater“ ihres persönlichen Akkulturationssprozesses fühlte er sich anscheinend nicht angesprochen - oder überfordert? Sein Nichtantworten auf so persönliche Geständnisse kann man, in der Formulierung Florian Krobbs, als Weigerung deuten, die ihm zugedachte Rolle des „Emanzipationsbefürworters“ zu übernehmen. ${ }^{665}$

Mit Schweigen antwortet er auch auf Sara Meyer Grotthus’ zweiten Emanzipationsversuch, als Autorin. ${ }^{666}$ Vermutlich im Badeort hatte sie sich ihm erstmals als Schreibende präsentiert. ${ }^{667}$ Als politische Leserin hatte er sie selbst adressiert und eine ernsthafte Debatte über die Ansichten Madame de Staëls mit ihr begonnen. ${ }^{668}$ Auf ihre Bitte jedoch, ihn in einem eigenen politischen Aufsatz zitieren zu dürfen, schwieg er. Dabei war das Ansinnen ebenso höflich wie dem Zeitgeschmack entsprechend national gesinnt und ,weiblich devot“ formuliert:

662 Geiger 1893, S. 101.

663 Seibert 1993(a), S. 413.

664 Wilhelmy 1989, S. 68.

665 Krobb 1991/1992, S. 42.

666 Bereits zu Salonzeiten hatte sie Dramen auf Deutsch und Französisch geschrieben. 667 Ein Hinweis, dem die Forschung bisher noch nicht nachgegangen ist, findet sich in Goethes allerdings nur stichtwortartigem Tagebuch: An einem Nachmittag verzeichnet er sich zu Hause allein und „Fr. v. Grothus Erzählungen“. Da er in diesem Sommer mit beiden Schwestern in Teplitz war, ist gut möglich, dass sie ihm Texte überreicht hat. Johann Wolfgang von Goethe, Tagebucheintrag 30. 8. 1810, zitiert nach: Sauer 1904, S. 383. 668 Zur Staël-Rezeption in der Korrespondenz zwischen Grotthus und Goethe und den Versuchen des Dichters, Grotthus einen vergleichbar ,ausländischen' Blick zu bescheinigen vgl. ausführlich Anderson 2006 und 2008. 
Dürfte ich wohl an Riemer einige Aufsätze zur Durchsicht schicken, die er wenn er sie nicht ganz unwerth findet Ihnen zur Beurtheilung vorlegen dürfte?, [...] so habe ich zum Beyspiel einen Aufsatz gegen die hier herrschende Vorliebe der Franzosen \& ihre Sitte und Sprache geschrieben, der sich blos fürs weibliche Geschlecht eignet, auch ziemlich schwächlich ist, aber doch ein Wort zu seiner Zeit enthält, wenn Sie mir erlauben, so schicke ich es Riemer, [...] dass aufrichtig mir sagt, ob das Gesandte sich zur Publicität oder zum Verbrennen eignet. ${ }^{669}$

Als Goethe einen Monat lang nicht antwortete, obwohl auch dieser Brief von Schokolade, Zander und Gänsen begleitet war, verzichtete sie sofort auf den ganzen Plan:

Verehrungswürdiger Freund! Ob es zwar scheint dass ich in meinem letzten Brief etwas Ihnen misfälliges geschrieben, so halte ich's für Pflicht Ihnen darüber etwas zu sagen dass ich nie indiscret sein kann noch werde daher bitte meine Anfrage als nicht geschehen anzusehen. ich habe auf dieses Project etwas zu schreiben renoncirt, nur bitte ich entziehen Sie mir Ihr schätzbares Vertrauen nicht. ${ }^{670}$

Versöhnlich bot ihr der Dichter daraufhin an, er würde ihre Veröffentlichung gern unterstützen - in seinem Weimarer Kreis: „Mögen Sie von Ihren Empfindungen und Gedanken irgend etwas schriftlich mittheilen, so senden Sie es nur grade an mich, damit in dem Kreise unserer Weimarischen Natur=, Kunst=, und Sittenfreunde wir uns an diesen noch immer langen Abenden erbauen“.671 Möglicherweise war diese gönnerhafte Haltung für sie ein Grund, den Briefwechsel hier abzubrechen. Zehn Jahre später nahm sie ihn wieder auf, mit dem Hinweis auf gemeinsame Tage in Teplitz, ihren schweren Verlust durch den Tod ihres Ehemannes und ihre Einsamkeit. Vom Schreiben hatte sie sich nicht abbringen lassen und anders als in der Sekundärliteratur behauptet, sich nicht primär als Goethe-Freundin definiert. Vielmehr zählte sie ihm 1824 mehrere eigene erfolgreiche, da gedruckte Versuche in verschiedenen Gattungen auf, anonym gedruckte Übersetzungen und Dichtungen: „Wenn Ihnen vielleicht eine Erzählung Die 12 Worte und ein Roman Julie von Fiorabella und ein Lust-

669 Sara Meyer Grotthus an Johann Wolfgang von Goethe, 25. 11. 1814, hier nach dem Manuskript zitiert, gedruckt bei Geiger 1893. S. 59.

670 Sara Meyer Grotthus an Johann Wolfgang von Goethe, 26. 12. 1814, ungedruckt, GSA $28 / 375$.

671 Johann Wolgang von Goethe an Sara Meyer Grotthus, 2. 2. 1815, in: WA, Bd. 25, S. $127 \mathrm{f}$. Hier nach Manuskript zitiert, SV 71. Die Empfängerin kommentierte den Inhalt auf dem Umschlag: „Als ich ihm Vorwürfe über seine Schweigen gemacht und die Manuscripte die ich geschrieben ihm zu senden versprochen.“ Ebd. 


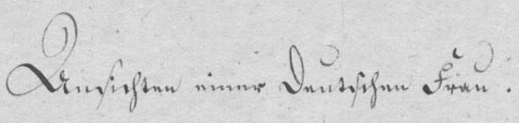

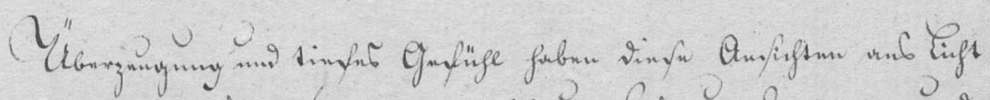

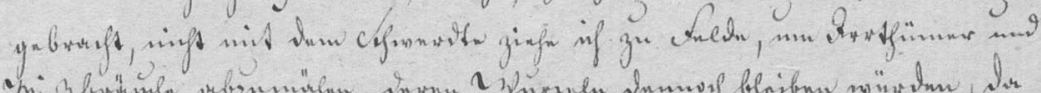

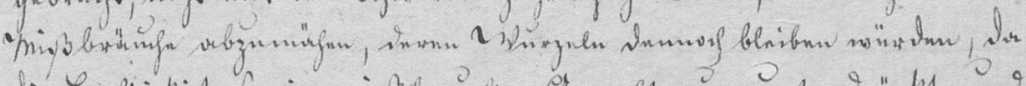

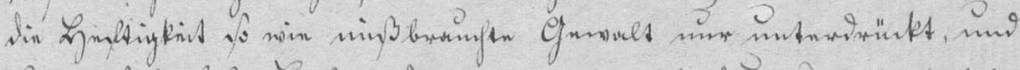

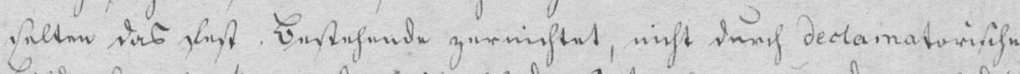

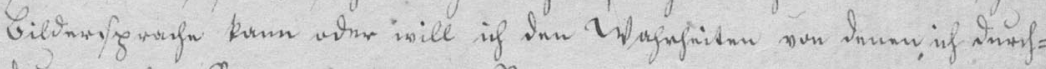

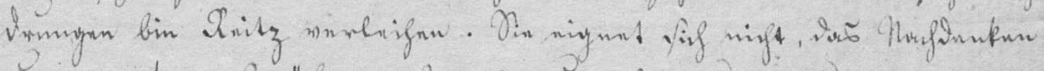

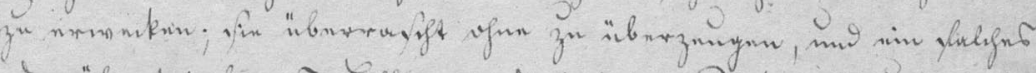

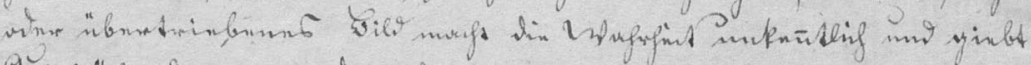

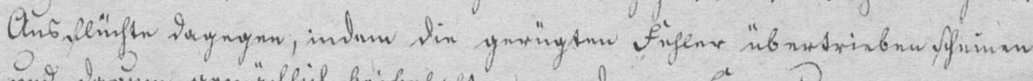

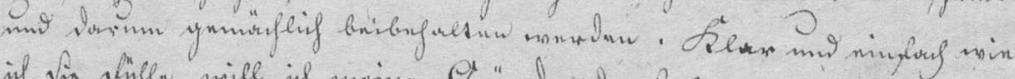

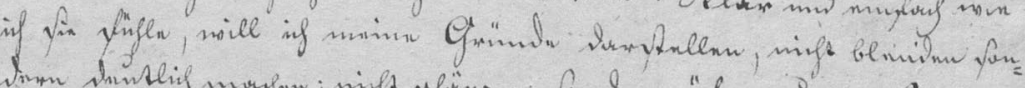

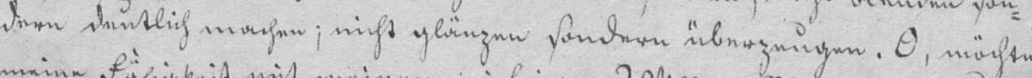

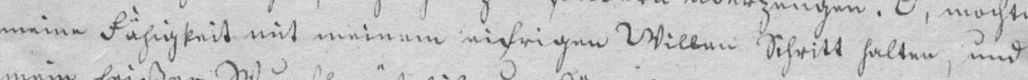

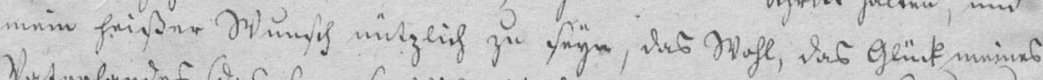

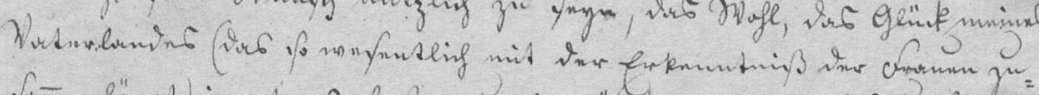

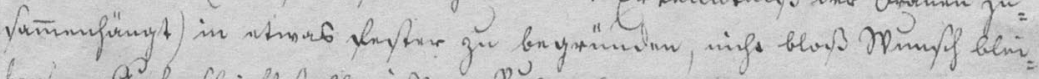

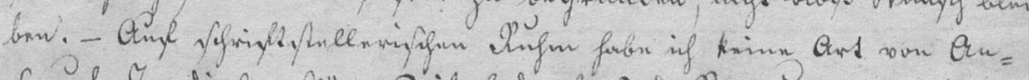

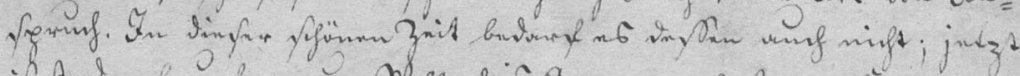

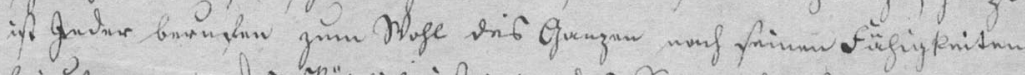

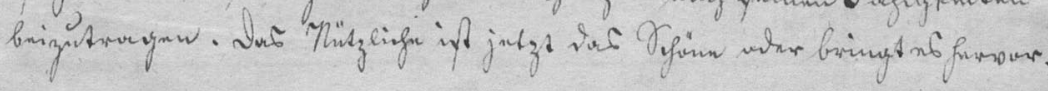

\section{$\hat{Q}$}

Abb. 18: „Überzeugung und tiefes Gefühl...“: „Ansichten einer deutschen Frau“. Eine der Schriften von Sara Meyer Grotthus, die Goethe nicht drucken lassen wollte.

spiel die Wahl zur Ansicht kömt, so seyn Sie nachsichtig, denn sie sind in doloribus scripcit“. 672

672 Sara Meyer Grotthus an Johann Wolfgang von Goethe, 19. 2. 1824, ungedruckt, GSA 28/375. Die hier erwähnten Werke sind leider nicht aufzufinden. 
Goethe antwortet freundlich, ein Treffen in Teplitz wurde nicht ausgeschlossen. Als sie ihn jedoch bat, sie in ihrem Schreiben zu unterstützen, nämlich bei Cotta ein freundliches Wort für sie einzulegen, antwortete er nicht mehr. Eines ihrer letzten Präsente beendete den Briefwechsel metaphorisch: Sara Meyer Grotthus schickte „einen Korb von Zuckerblumen so täuschend die Natur nachahmend gemacht“. 673

\section{„[...] ein Bad ist immer ein Medizin, die man nimmt, nicht trinkt" - Verehrung aus der Distanz: Rahel Levin Varnhagen und Johann Wolfgang von Goethe}

Im Nachhinein bezeichnete Rahel Levin Varnhagen ihr Zusammentreffen mit Goethe 1795 als puren Zufall: „[...] ich mußte mich Dienstag entschliessen, Mittwoch nach Karlsbad zu gehen, mußte plötzlich einen neuen Karakter bekommen, Goethe, der in elf Jahren nicht in Karlsbad war, mußt' auch denken, und hinreisen, in diesen kleinen Berg-Einschuß, wo ich grade bin, und die Welt ist so breit, so groß. Und das ist nicht Wunder, ist nicht Glück“?674 Obwohl sie es aber ein „Wunder“ nannte, war die Möglichkeit eines Zusammentreffens schon vorher überlegt und mit ihrem Freund David Veit erörtert worden. Goethes Person und Werk können bekanntlich als ein Leitmotiv im Jugendbriefwechsel dieser beiden jüdischen Intellektuellen gelten. ${ }^{675}$ Bereits 1794 glaubte Rahel Levin Varnhagen, ein besonderes Verständnis für Goethes Schaffen zu besitzen, das sie von anderen unterschied: „Dass ich aber Goethe nicht kenne, ist wirklich niedlich; denn wie Viele hat der nicht schon umsonst gekannt (das weiß ich, das seh' ich aus jedem Gedicht), und dafür hätt' er mich doch lieber kennen können“.676 Zwei Gründe sprachen aber ihrer Meinung nach dagegen, dass Goethe sie wirklich in einem persönlichen Gespräch kennenlernen könne: „Niedlicher als alles aber ist, dass ich ein Mädchen bin, und in meiner Situation, ein Judenmädchen. Sie haben Recht; lächerlich

673 Sara Meyer Grotthus an Johann Wolfgang von Goethe, 18. 5. 1824, ungedruckt, GSA 28/375.

674 Rahel Levin Varnhagen an Gustav von Brinckmann, 14. 8. 1795, gedruckt in und viel zitiert nach: GW I, S.148. Das Zitat in der Überschrift: David Veit an Rahel Levin Varnhagen, 15. 6. 1795, in: GW VII/II, S. 158.

675 Anders als Barbara Hahn würde ich aber nicht davon ausgehen, dass sich alle Debatten des Briefwechsels „in Goethes Namen bündeln“. Eine Analyse der Diskussion Lessings oder jüdischer Autoren im Briefwechsel wäre zusätzlich lohnend. Hahn 2002(b), S. 128.

676 Rahel Levin Varnhagen an David Veit, 31. 10. 1794, in: GW VIII/I, S. 264. 
könnte ich mich wohl machen [...]: aber was sollte der Mann denken, als was ich mich ihm präsentiren"?677

Im Juni 1795 hatte sich bei Rahel Levin Varnhagen eine Notwendigkeit zur Kur bemerkbar gemacht. ${ }^{678}$ Anscheinend kam der Vorschlag für Karlsbad von der Mutter. „Seit Montag früh wußt ich, dass ich Mittwoch früh aus Berlin reisen würde“.679 Im folgenden Brief wies Veit sie umgehend darauf hin, dass Goethe ebenfalls nach Karlsbad zu reisen plane. Er versuchte, sie auf ein potentielles Treffen so gut wie möglich vorzubereiten: „Berlin haßt er ziemlichermaßen. Dies für's Gespräch! Sollte die Vulpius mit ihm sein? Die Bekanntschaft mit ihr dürfte wohl von ihm ganz entfernen. Doch hierüber weiß ich nichts Gewisses“.680

Rahel Levin Vaernhagen fuhr Anfang Juni mit ihrer Freundin, der Schauspielerin Friederike Unzelmann nach Dresden und weiter nach Karlsbad und Teplitz. Die vielen Kontakte der Schauspielerin waren für Levin Varnhagen ein Glücksumstand, den sie reichlich genoß. Veit ging davon aus, dass ihr diese Freundschaft auch das Knüpfen von Kontakten im Bad, beispielsweise zu Goethe, erleichtern werde, „da er ohne Zweifel begierig sein wird, die Unzelmann kennen zu lernen“.681 Wichtig für diesen Badeaufenthalt ist, dass der Name „Robert“ den Rahel Levin Varnhagen bis zu ihrer Ehe synonym verwandte, hier zum erstenmal auftauchte, quasi als Bade-Incognito. ${ }^{682}$

677 Rahel Levin Varnhagen an David Veit, 31. 10. 1794, in: GW VIII/I, S. 264. Hervorhebung im Original. David Veit hatte seinen letzten Brief mit dem Hinweis geendet: „Kommen Sie einmal hieher, so gehen Sie zu ihm, und wagen Sie eine Lächerlichkeit, die sich gewiß belohnt.“ David Veit an Rahel Levin Varnhagen, 23. 10. 1794, in: GW VIII/I, S. 255. Hier ist möglicherweise der These Charlotte Albarus' beizupflichten, dass Levin Varnhagen kein wirkliches Interesse an einer persönlichen Zusammenkunft gehabt habe, da sie befürchtete, sich im Gespräch allein mit dem verehrten Mann nicht von ihrer besten Seite zeigen zu können. Vgl. Albarus 1930. Als sich die Gelegenheit aber zufällig bot, muss stärker als diese Furcht die Aussicht gewirkt haben, Goethe selbst sehen zu können.

678 Ursprünglich scheint eine Wiederholung des vorjährigen Aufenthalts in Freienwalde geplant gewesen zu sein, im Juni hieß es, dass sie „den andern Monath gar nicht schreiben werde wegen Freienwalde“. Rahel Levin Varnhagen an David Veit, 1. 6.1795, in: GW VII/II, S. 131. Ein Grund für die Planänderung ist nicht überliefert.

679 Rahel Levin Varnhagen an David Veit, 6. 6.1795, in: GW VII/II, S. 154.

680 David Veit an Rahel Levin Varnhagen, 5. 6.1795, in: GW VII/II, S. 152.

681 David Veit an Rahel Levin Varnhagen, 5. 6. 1795, in: GW VII/II, S. 152.

682 In einem Brief an Veit bat sie, seine Briefe „an Mlle. Robert“ zu senden. Die Briefe wurden in einen weiteren Umschlag gesteckt, der an „Mad. Unzelmann Karlsbad“ adressiert werden sollte, mit der sie dort zusammen wohnte. Rahel Levin Varnhagen an David Veit, 6. 6. 1795, in: GW VII/II, S.154. Allerdings muss hinzugefügt werden, dass Friederike Liman ihre Briefe aus der Zeit noch an „Mlle. Levy“ adressierte. 
Eine Schilderung ihres ersten Zusammentreffens mit Goethe ist nicht überliefert, die Briefe an die nächsten Freunde, in denen sie vermutlich davon gesprochen hat, müssen als verloren gelten. Aus den Antwortbriefen ist ersichtlich, dass ihre Freunde die Nachricht, in unterschiedlichem Grade, erfreut aufnahmen. Brinckmann schrieb zwar: „Und Sie haben Göthe kennen gelernt! [...] meine Freude darüber ist so groß, bei weitem größer als wenn das Glück mich selbst getroffen hätte [...]. Sie von Göthen gekannt zu wissen!“ Allerdings reagierte er auf die Nachricht dieses Treffens in einem Brief, in dem er seine Themen durchnummerierte, erst bei Nummer 8, nach einigem irrelevanten Stadtklatsch. ${ }^{683}$ Friederike Liman hingegen stellte ihren Antwortbrief ganz unter das Motto eines erreichten Lebenszieles: „Einzige! welch einen Brief habe ich heut von Dir erhalten der erste den du mir in deinem Leben schriebst; den es stand drin dass du dich Glücklich fühlst - also hast du doch Göthe kenen gelernt“. ${ }^{684}$ Der Herzenswunsch scheint im Kreis ihrer Freunde als solcher bekannt gewesen zu sein. Liman las den Brief sogleich der befreundeten Henriette Mendelssohn vor und versprach, sogar auf die Bekanntschaft der „Einzigen“ zu verzichten, wenn diese immer so glücklich sein könnte. ${ }^{685}$

Weitergereist nach Teplitz machte Rahel Levin Varnhagen kurz darauf eine neue Bekanntschaft, die für sie zunächst viel folgenreicher war als die Goethes, und von der sie begeistert und ausführlich berichtete, die der böhmischen Gräfin Pachta. ${ }^{686}$ Man lernte sich kennen, indem man nebeneinander wohnte, und war bald von einander so begeistert, dass man gemeinsames Quartier nahm. An Brinckmann erging die Warnung, Gräfin Pachta sei „eine der liebenswürdigsten Creaturen, blond, blauäugig, mit Phisiognomie u Wuchs, Gra-

683 Gustav von Brinckmann an Rahel Levin Varnhagen, 25. 7. 1795, ungedruckt, SV 38. 684 Friederike Liman an Rahel Levin Varnhagen, 16. 7. 1795, in: Bosold 1996, S. 24. Schreibung im Original.

685 In den folgenden Briefen - Rahel Levin Varnhagen verlängerte ihren Aufenthalt in Teplitz bis Anfang September - wurde dann allerdings die Person Goethes gar nicht mehr erwähnt. Das Briefgespräch der beiden Freundinnen dreht sich um gemeinsame Bekannte, die jeweiligen Kurerfolge und Pläne für Berlin. Allerdings blieb der Dichter in Form von Zitaten und Anspielungen auf seine Werke präsent, beispielweise wenn die Unzelmann „filinenstreiche“ erzählte - eine Anspielung auf die Philine in „Wilhelm Meister“. Friederike Liman an Rahel Levin Varnhagen, 21. 8. 1795, in: Bosold 1996, S. 32.

686 Josephine Gräfin von Pachta, geb. Gräfin Canal-Malabaila (?-1834). Karl August Varnhagen schildert sie als „ein reines, wahrhaftes, treues Naturkind [...] mit regem Geist“, von ausgesprochener Schönheit, ihren zahlreichen Verehrern gegenüber aber unbestechlich. Varnhagen 1836, S.57. Mit Rahel Levin Varnhagen verband sie eine jahrelange Freundschaft, deren wenige überlieferten Dokumente, zärtliche Du-Briefe, für eine große persönliche Nähe sprechen. In den darauffolgenden Jahren gibt es zahlreiche Wiedersehen. Noch 1811 heißt es: „Eigentlich meine beste Freundin, meine verehrteste.“ Rahel Levin Varnhagen an Karl August Varnhagen, 2. Weihnachtstag 1811, in: GW I, S. 580. 
zie. Karakter, Ausdruck, kurz wenn sie länger in Berlin bliebe als 2 Tage, so wären Sie den unbequemsten Gast, das so genannte Herz, auf einmal los“.687 Gräfin Pachta war nach Rahel Levin Varnhagens eigener Aussage ein wesentlicher Grund, die Kur fortzusetzen, man teilte unter anderem die Begeisterung für Musik und Tanz, sodass Levin Varnhagen, von sich selbst und dem Kurerfolg bei ihrem Rheuma überrascht, nach Berlin schreiben konnte, sie tanze wie eine „Pikniks-Mamsell“. ${ }^{688}$ Die Gräfin machte, späteren Briefen nach zu urteilen, selbst einen großen Unterschied zwischen Gleichgesinnten, als die sie Rahel Levin Varnhagen ansah, und anderen Personen, die sie nur um ihres Titels wegen kontaktierten. Zu letzteren zählte sie zum Beispiel Marianne Meyer Eybenberg, der sie auf Briefe nicht antworten wollte: „[...] sie ist doch nur neugierig zu wissen, wie ich schreibe: $\mathrm{zu}$ ungeschminkt, um ihr zu gefallen, zu alltäglich, um mich zu nutzen, und zu wahr, um ihr zu schmeicheln“. 689 Im Falle der Gräfin Pachta blieb die Freundschaft nicht an den Badeort gebunden. Nicht nur wurde die Gräfin während ihrer Berlinaufenthalte häufiger Gast bei Levins, sie lud selbst Rahel Levin Varnhagen so nachdrücklich nach Prag ein, dass diese im Jahr darauf heimlich hinreiste. ${ }^{690}$ Der Herrensitz der Grafen Pachta wurde eines der wenigen gräflichen Häuser, das Rahel Levin Varnhagen vor ihrer Ehe von innen sah.

Auch von David Veit ist leider kein Brief mit Kommentar zu der Begegnung Rahel Levin Varnhagens mit Goethe überliefert, vermutlich weil er zusammen mit seinem Freund Horn seine Freundin in Teplitz selbst besuchte. Wie sehr aber Rahel Levin Varnhagens Neugier auf Goethe in Karlsbad gerichtet war, zeigt die Bitte an den rückreisenden Veit, ihr ,ausführlich von Karlsbad, und alles, jede Kleinigkeit die Sie von Goethe wissen“ sofort $\mathrm{zu}$ schreiben. ${ }^{691} \mathrm{Er}$

687 Rahel Levin Varnhagen an Gustav von Brinckmann, 14. 8. 1795, in SV 38, modernisiert in GW I, S. 146.

688 Rahel Levin Varnhagen an Gustav von Brinckmann, 4. 9.1795, in: GW I, S. 155.

689 Jospehine von Pachta an Rahel Levin Varnhagen, 2. 3. 1796, in: Varnhagen 1836, S. 60. Auch die Schwestern Meyer hatten ihren Badeurlaub 1795 in Teplitz beendet und dort die Gräfin kennengelernt. In den Folgejahren mäßigte sich das Urteil der Gräfin zusehends und sie scheint am Teetisch der Meyers Gast gewesen zu sein.

690 Dieser Besuch ist wegen seiner Heimlichkeit auch nicht in vielen Biografien erwähnt. Ein Beleg ist ein Billet Burgsdorfs, der seine Freundin nach Prag begleitete: „Sagen Sie es keinem, bester B., daß ich mit der Kleinen hierher zur Gräfin Pachta gereist bin, sie will es nicht.“ Wilhelm von Burgsdorf an Gustav von Brinckmann, 25. 9. 1796, in: Cohn 1907, S. 10. Ein weiterer: „Morgen früh reis’ ich zur Gräfin Pachta nach Prag. Ich mache, zum erstenmal, einen von den Streichen, die Sie mir immer wünschen; und vielleicht, billigten Sie diesen doch nicht." Rahel Levin Varnhagen an Gustav von Brinckmann, 21. 9. 1796, in: GW I, S. 165. Ein Grund für die Heimlichkeit wird nicht angegeben.

691 Rahel Levin Varnhagen an David Veit, 1. 8.1795, in: GW VII/II, S.161. Hervorhebung im Original. 
erfüllte diese Bitte prompt und schrieb stolz, dass er „denn Goethe oft gesprochen, in der ersten Viertelstunde über Sie gesprochen“ habe. In direkter Rede kolportierte er Goethes Kommentar: „,[...] o die Levin hat sehr viel gedacht, hat Empfindungen und Verstand, es ist was Seltenes; das muß ich sagen wo findet man das? Wir haben auch so vertraut zusammen gelebt, wir waren beständig zusammen. Ja - das ist gewiß““. ${ }^{692} \mathrm{Da}$ Veit nicht wusste, ob sie den Brief mit dem Bericht über ihren „Triumph“ erhalten habe, schrieb er ihr die Goetheschen Worte zwei Wochen später in leichter Modifikation noch einmal: „,Ja es ist ein Mädchen von außerordentlichem Verstand, die immer denkt, und von Empfindungen - wo findet man das? Es ist etwas Seltenes. O wir waren beständig zusammen und haben sehr freundschaftlich und vertraulich mit einander gelebt'“. ${ }^{693}$ Ein drittes Mal hörte sie Goethes Worte von ihrem und Veits Freund Horn: ,,Ja es ist ein liebevolles Mädchen; sie ist stark in jeder ihrer Empfindungen und doch leicht in jeder Äußerung; [...].““ Horn erinnerte die Worte Goethes anders als Veit, er erwähnte dessen Kompliment an ihre "Originalität“ - womit diese ihr im Nachhinein immer wieder zugestandene Qualität von Goethe erstmals erwähnt worden wäre - und den prägnanten Nachsatz: „[...] kurz, sie ist, was ich eine schöne Seele nennen möchte“.694 Hier ist allerdings zu fragen, ob darin Goethes eigenes oder Horns Kompliment zum Ausdruck kommt, da es unwahrscheinlich ist, dass David Veit ein Kompliment mit Bezug auf Wilhelm Meister, ein Topos in der damaligen Zeit, vergessen hätte. 695

Zugleich ist dieser Bericht Veits und Horns der Beginn von Rahel Levin Varnhagens konsequent indirekter Kommunikation mit Goethe. Bis zu einem eher zufälligen Wiedersehen anno 1815 sollte sie den verehrten Dichter nur noch indirekt adressieren, über gemeinsame Bekannte und eigene Veröffentlichungen zu seinen Werken. ${ }^{696}$ Goethes Kommentare erreichten sie ebenfalls nur über Dritte, vor allem über ihren späteren Mann Karl August Varnhagen, der Goethe ihre Kommentare vor Veröffentlichung zuschickte.

692 David Veit an Rahel Levin Varnhagen, 14. 8. 1795, in: GW VII/II, S. 167.

693 David Veit an Rahel Levin Varnhagen, 3. 9. 1795, in: GW VII/II, S. 179.

694 Anton Ludwig Ernst Horn an Rahel Levin Varnhagen, 3. 9. 1795, zit. nach: de Bruyn 1985, S. 68.

695 Dieser Begriff entfaltete Breitenwirkung nach Veröffentlichung des 6. Bandes von Wilhelm Meister, mit den dort enthaltenen „Bekenntnissen einer schönen Seele“.

6961812 erschienen Auszüge aus ihrem Briefwechsel mit Karl August Varnhagen Goethe betreffend im „Morgenblatt für gebildete Stände“. 1815 kam es zu einem kurzen Besuch Goethes bei Frau von Varnhagen in Frankfurt, bei dem diese mit ihrer Selbstpräsentation nicht zufrieden war. Von zwei weiteren Besuchen des Ehepaars Varnhagen in Weimar 1825 und 1829 finden sich überraschend wenige Nachrichten in den Schriften Rahel Levin Varnhagens. 
Die - vielleicht etwas stilisierte - Begründung für ihre Distanz formulierte Rahel Levin Varnhagen selbst so:

grüßen Sie ihn von dem Menschen, der ihn immer angebetet, vergöttert hätte, auch wenn ihn niemand rühmte, verstände, bewunderte. Und wenn er sich wunderte, dass ein gemäßigtes Mädchen ihm eine anscheinende Extravagance sagen ließe, so soll er's nicht thun, und lieber bewundern, dass sie ihn so respektirte, dass es einen Respekt gäbe, der sie allein zurück hielte, [...]. Sagen Sie ihm, es wäre nicht Affectation, sondern Pflaumenweichheit. 697

\subsection{Badeschwindel: Salons und Kurbäder - Emanzipation auf Zeit}

Alle drei hier genannten Frauen erhoben mit Recht Anspruch auf eine besondere Kennerschaft der Goetheschen Werke. Allen dreien kann ein Verdienst an der Verbreitung und vertieften Diskussion seiner Werke sowie eine besondere Beziehung zum Autor selbst nachgesagt werden. Dennoch wäre es vereinfacht, von dem Goethe-Kult der Berliner Salons zu sprechen. Die drei Frauen versuchten ihre Verbindung zum Dichter auf sehr unterschiedliche Weise zu knüpfen und zu halten. Marianne Meyer Eybenberg erwies sich als angenehme Begleitung im Bad, beide genossen den täglichen Umgang, die Diskussion von Literatur bis zum Austausch von Klatsch. In der Zeit zwischen Badebesuchen ließ es Meyer Eybenberg an klugen Komplimenten und geschickter Herausforderung seines Charmes nie fehlen. Goethe erlaubte sich in den Briefen an sie einen verbindlicheren Ton als in den an die meisten anderen Bekannten, der manchmal ins Verspielte ging. Sara Meyer Grotthus hatte durch Goethes Kenntnis ihrer schwierigen Ehegeschichte und ihres angegriffenen Zustandes einen schweren Start im Kampf um die Anerkennung des Dichters. Ihre anhaltende Verbindlichkeit in Worten und Sachwerten, ihr Engagement für ihn in Berlin und die Treue gegenüber ihrer Schwester gewannen ihr schließlich höfliche Aufmerksamkeiten aus Weimar. Ihre Verbindung zu Goethe blieb aber insgesamt etwas eindimensional. Mehrfach wurde er ihr zum Beichtvater ihrer innerlichen religiösen Kämpfe. Auf diese Selbstdarstellungen und ihre schriftstellerischen Ambitionen reagierte der angebetete „Olympier“ nicht.

Rahel Levin Varnhagen erhob schließlich den Anspruch auf eine besondere Beziehung zu Goethe, die in einem tiefen, fortdauernden Verständnis seiner Persönlichkeit bestand, in den Worten der Zeit in einem Gleichklang der Seelen, die sich einander indirekt kommunizierten. Dieser Anspruch war, unabhängig von der Umsetzung, folgenreich für die Rezeption: Da in der Lite-

697 Rahel Levin Varnhagen an A. E. L. Horn und David Veit, 8. 9. 1795, in: GW VII/II, S. 185. 
raturgeschichte des 19. und beginnenden 20. Jahrhunderts die Bedeutung und der Geschmack der mit Goethe bekannten Frauen daran gemessen wurde, wie schnell und tief sie die Bedeutung des Klassikers erfasst hätten, ${ }^{698}$ wurde Rahel Levin Varnhagen deswegen zur „bedeutendsten Frau Berlins“ stilisiert, weil sie eine lebenslange Begeisterung für Goethe mit der damenhaften Zurückhaltung verband, ihm davon nie direkt zu sprechen. ${ }^{699} \mathrm{Im}$ Vergleich wurde Sara Meyer Grotthus' anmaßendes oder anstrengendes Verhalten kritisiert. Und Dorothea Mendelssohn Veit Schlegel, die ihre Begegnungen mit Goethe relativ kurz und humorvoll fasste, bekam unter anderem mangelnde literarische Unabhängigkeit attestiert. ${ }^{700}$

In der Sekundärliteratur ist es weiterhin üblich, darauf hinzuweisen, dass die Bekanntschaft zwischen Goethe und Meyer Eybenberg für ihn nur eine Marginalie des Kurlebens, für sie aber von zentraler Bedeutung für ihr Leben gewesen sei. ${ }^{701}$ Tatsächlich haben die meisten hier genannten Frauen umfassendere Erwähnungen in der Literatur und Marianne Meyer Eybenberg ihre Überlieferung überhaupt zum nicht unwesentlichen Teil ihrer Bekanntschaft mit Goethe zu verdanken, da sie „Mitwisserin seines Lebens und Thuns“ wurde, und ihre Korrespondenz mit ihm „uns Goethe durch das Medium dieses Weltkindes sehen lässt“".702 Diese Form der Wertung verdeckt aber leicht das wahre Vergnügen, das beide 1795 am gegenseitigen Umgang gefunden haben müssen und

698 Um ein wirkliches Bild von Goethes Begegnungen mit gebildeten jüdischen Frauen zu gewinnen, müsste man diesen Goetheerlebnissen solche Zeitgenossinnen entgegensetzen, in deren Leben er keine zentrale Rolle spielte. Mit Recht vergleicht z. B. Andrea Schatz das Goethe-Erlebnis von Dorothea Mendelssohn Veit Schlegel mit dem oft analysierten der Salonièren und kommt zu dem Ergebnis, dass sie dem Dichter eigentlich „befremdet“ gegenüberstand und dennoch die einzige war, die „die alte göttliche Excellenz“ unbefangen schildern konnte. Schatz 1999, S. 2. Dorothea Mendelssohn Veit Schlegel an Friedrich Schleiermacher, 15. 11. 1799, ebd.

699 Paradigmatisch für diese Wertung: Arnold 1925, bes. S. $216 \mathrm{ff}$.

700 „Ihr, der leidenschaftlichen, subjektiven, romantischen Natur konnte das klare, objektive, klassische Wesen Goethes im tiefsten Grunde nicht zusagen.“ Arnold 1925, S. 213. 701 Ein Artikel zu ihrem Todestag stand unter dem Tenor: „Über der Hälfte ihres kurzen Daseins leuchtete die Sonne Goethes und gab ihrem Leben Schönheit und Sinn.“ Jakob Seifensieder: Marianne von Eybenberg. Zum 125. Todestag am 26. Juni 1937, in: Der Morgen, Heft 3 (1937), S. 123-127, hier S.124. Prägend für die Rezeption war vermutlich die Formulierung Ludwig Geigers, dass Goethe sich „einen ,kleinen Liebesroman' gemacht hat. Im Leben der Schwestern bildete die Bekanntschaft dagegen Epoche.“ Geiger 1893, S. 105. Ähnliche (Ab-)Wertungen finden sich auch in Darstellungen über Goethes Frauenkontakte. Vgl. Christina Kröll: Begegnungen - Kontakte - Geselligkeit, in: Göres 1982, S. 121-141. Demnach habe Goethe ein Verliebtsein im Bad einfach als Teil seines Kurerfolges gewertet. Ebd. S. 126.

702 Geiger 1893, S. 95, Hervorhebung H. L. L.; Seifensieder 1937, S. 124. 
das noch 13 Jahre später beim Wiedersehen in Karlsbad dazu führte, dass Frau von Eybenberg Goethes täglicher Kontakt wurde. Man kann zusammenfassend mit einiger Berechtigung behaupten, dass die enge Beziehung der beiden an den Ort Karlsbad geknüpft blieb. Trotz gemeinsamer Kuraufenthalte und gelegentlicher Höflichkeitsbesuche in Weimar lebte die jahrelange Brieffreundschaft wesentlich, neben der Diskussion Goethescher Werke, von der Erinnerung an und Vorfreude auf einen gemeinsamen Badeaufenthalt. ${ }^{703}$

Grundsätzlich wird der Dichter sich die tiefreichende Kenntnis und Schätzung seiner Werke der drei Berlinerinnen gern gefallen lassen haben. Denn beides war auch beim gebildeten Badepublikum nicht selbstverständlich, und wie er Schiller berichtete, wurde er manchmal mit anderen Autoren verwechselt und „überhaupt hat das Publikum nur den dunkelsten Begriff vom Schriftsteller. [...] Doch muß ich billig sein und sagen, dass ich einige gefunden habe die hierin eine merkwürdige Ausnahme machen“. ${ }^{704}$ Eine dieser Ausnahmen war Marianne Meyer Eybenberg, die er um Kommentare zu seinen jeweiligen Texten bat. Eine andere war Rahel Levin Varnhagen, der er hohe Empfindsamkeit attestiert hatte.

Am Beispiel des Karlsbader Aufenthaltes der drei jüdischen Salonièren zeigt sich, dass Badeorte durchaus darin Salons verglichen werden können, dass sie Orte sind, an denen Grenzen zwischen Ständen und Schichten leichter übertretbar erscheinen. Der Weg zum verehrten Dichter war kürzer. In beiden Fällen blieb aber diese Übertretung oder Aufhebung der Schranken an den Ort gebunden und war temporärer Natur. Die Augenhöhe auf der Brücke in Karlsbad war über die Entfernung Berlin-Weimar kaum zu halten.

In Karlsbad und Teplitz und ihren eigenen Salons konnten die drei hier erwähnten Frauen als Kennerinnen und Freundinnen Goethes gelten, denen er einiges Renommee in den Berliner Kreisen verdankte. Außerhalb dieser Kreise bis in die Forschungsliteratur hinein waren sie bald wieder ,getaufte Jüdinnen“, die dem verehrten Meister sogar die eigene Überlieferung schuldeten. Goethe selbst, der sich weder in Karlsbad noch später, nach deren Eheschließung mit Adligen, für die jüdische Herkunft seiner Bekannten interes-

703 Zumindest für Goethe war die Einrichtung eines, modern gesprochen, „Badeflirts“ nicht unüblich. Neben den naturwissenschaftlichen Studien ziehen sich seine „romantischen Badebekanntschaften“wie ein roter Faden durch die 15 Besuche in böhmischen Bädern. Andere Frauen sind in diesen Zusammenhang bekannter geworden, wie Sylvie von Ziegesar und besonders natürlich Ulrike von Levetzow, der Anlass zur „Marienbader Elegie“. Keine andere aber war über einen Zeitraum von 15 Jahren wiederholt Anlass für „Äugelchen“, wie ein Flirt in der Sprache des Ehepaars Goethe genannt wurde.

704 Johann Wolfgang von Goethe an Friedrich von Schiller, 8. 7. und 19. 7. 1795, in: Beetz 2005, Bd.1, S. 91 und $94 \mathrm{f}$. 
sierte, wurde allerdings durch diese Bekanntschaften auch nicht in seiner Haltung zum Judentum irgendwie beeinflusst. Im kleinen Ausschnitt der Beziehung Goethes zu Marianne Meyer Eybenberg spiegelt sich sowohl das ambivalente Verhältnis des Dichters Juden gegenüber als auch die auf den Widersprüchen aufbauende, zum Teil verzerrende Rezeptionsgeschichte. ${ }^{705} 1797$ konnte Goethe in persona Marianne Meyer Eybenbergs seinem Herzog eine jüdische Bankierstochter vorbehaltlos als angenehme Gesellschafterin empfehlen. Zum Ende seines Lebens fürchtete er kaum etwas mehr, als dass jüdische Frauen bei Hofe tätig würden. ${ }^{706}$

\section{6 „Freymüthige Kaffeegespräche“ - Die Freiheiten des Sprachraums Salon}

Bei dem Brunnen soll keiner fluchen oder ärgerliche Discourse führen.

Brunnen-Reglement Bad Freienwalde

Schreiben Sie mir bald wieder ein Billet; es gehört zu meinen größten Ergötzlichkeiten, Ihre Billets aufzumachen; es steht immer soviel drin; sie riechen so gut.

Friedrich von Gentz an Gustav von Brinckmann 707

705 Im persönlichen Umgang war Goethe die jüdische Herkunft keineswegs immer präsent. Allerdings hatte kein noch so positiver Eindruck von jüdischen Bekannten Einfluss auf seine zumindest konservativ zu nennende politische Haltung, die in der vehementen Ablehnung des Gesetzes zur Ehe zwischen Juden und Christen als „skandalös“ gipfelte. So unterhielt sich Goethe zwar gern mit David Veit, fand aber die Einrichtung, dass kein Jude in Jena übernachten dürfe, eine „öbliche Anordnung“. Johann Wolfgang Goethe an Johann Sulpiz Boisseree, 24. 6. 1816, zit. nach: Schramm-Häder 2001, S. 243.

706 So der Bericht des Weimarer Kanzlers von Müller über einen Besuch 1823, ,als der alte Herr seinen leidenschaftlichsten Zorn über unser neues Juden-Gesetz, welches die Heirath zwischen beiden Glaubensverwandten gestattet, ausgoß. [...] alle sittlichen Gefühle [...] würden durch solch ein skandalöses Gesetz untergraben; überdies wolle er nur sehen, wie man verhindern wolle, daß einmal eine Jüdin Oberhofmeisterin werde. Das Ausland müsse durchaus an Bestechung glauben, um die Adoption des Gesetzes begreiflich zu finden; wer wisse, ob nicht der allmächtige Rothschild dahinter stecke.“ Zit. nach: W. Daniel Wilson: Goethes Haltung zur Judenemanzipation und jüdische Haltungen zu Goethe, in: Weber 2000, S. 19-46, hier S. 36.

707 Brunnenreglement von 1706, in: Hagen 1784, S. 123 f., hier S. 123; Friedrich von Gentz an Gustav von Brinckmann, 5. 3. 1802, in: Wittichen 1910, S. 90. Das Zitat aus der Überschrift bezieht sich auf Markus Herz’ „Freymüthiges Kaffeegespräch“ aus dem Jahr 1771, das allerdings im Wesentlichen vom Theater handelt und einen anderen Tonfall abbildet. Als höchst variantenreicher Text aber, der unverdient schwer zugänglich ist und das selbst für Ludwig Geiger war, verdiente er dringend eine Neuauflage. Herz 1771. Vgl. dazu Ludwig Geiger: Kleine Beiträge zur Geschichte der Juden in Berlin, in: ders.: Zeitschrift für die Geschichte der Juden in Deutschland, Bd. 4. (1890), S. 29-65, bes. S. 46-49. 


\section{1 „Salon-Ton“?}

Den Tonfall eines oder gar des Berliner Salongesprächs um 1800 bestimmen zu wollen, ist - historisch unmöglich. ${ }^{708}$ Der Tatsache der verlorenen Mündlichkeit ungeachtet, gibt es in der Salonforschung zahlreiche - und nicht immer als Vermutung formulierte - Charakterisierungen des Salongesprächs, auch gegensätzliche. Beispielsweise wird der Berliner Salon-Ton ebenso als in „französischer Tradition“709 stehend, wie „aufgeklärt“,710 „romantisch“,711 auch „frühromantisch“ definiert. ${ }^{712}$ Am häufigsten finden sich Begriffe wie „originell“, „geistreich“ oder „gebildet“. Immer wieder wird auch von einer

708 Schon im Bereich der zeitgeschichtlichen Oral History wird beklagt: „Wenn etwas Gesprochenes zum Geschriebenen wird, geht etwas Essentielles verloren: Nebengeräusche, Zwischentöne, Stockungen, Kunstpausen. [...] Ein mehrdimensionales kommunikatives Netz wird auf eine einzige Dimension reduziert.“ Carlo Moos: „die Zeit gehet nicht, sie stehet still“, in: unimagazin. Die Zeitschrift der Universität Zürich, Nr.4/98, unter: http:// www.kommunikation.uzh.ch/static/unimagazin/archiv/4-98/zeit.html (22. 1. 2008). Betonung im Original. Frappierend ähnlich hatte Brinckmann formuliert, was beim Niederschreiben verloren ginge: „Ton und Blick und Seufzer und Aufschreien, oft bei einem einzelnen Wort, ohne welche doch Rahels Schrift für den fremden Leser oft eben so unverständlich wird, als eine unpunktirte hebräische Bibel für den ungeübten Anfänger.“ Brinckmann 1876, S. 246. Betonung im Original.

709 Horst Möller: Aufklärung in Preußen. Der Verleger, Publizist und Geschichtsschreiber Friedrich Nicolai, (Veröffentlichungen der Historischen Kommission zu Berlin, 15), Berlin 1974, S. 234 f. Nicht selten findet sich auch der, nie belegte, Zusammenhang der Berliner mit den Pariser Salons, nach dessem urbanen, galanten, espritvollen Vorbild man sich gerichtet habe.

710 An verschiedenen Stellen werden die Ursprünge der Salonkultur in der (jüdischen) Aufklärung verortet, die eine Vorläuferrolle der Gelehrtengespräche im Hause Moses Mendelssohns suggeriert, u. a. Ingrid Lohmann: Über die Anfänge bürgerlicher Gesprächskultur. Moses Mendelssohn (1729-1786) und die Berliner Aufklärung. In: Pädagogische Rundschau 46 (1992) 1, S.35-49. Allerdings verrät der Aufsatz mehr über Mendelssohns schriftstellerische Tätigkeit und tatsächlich wenig über diese Anfänge und Übergänge in die Salongespräche.

711 Basis dieser Urteile sind dabei mehr oder minder pauschale Einordnungen nach Epochen, die allerdings zwischen verschiedenen Salons und auch bei derselben Salonière differieren können. So wird, wie erwähnt, oft von „romantischen Berliner Salons“ gesprochen. Für das Kapitel „Rahel - die Romantik selbst“ und zum romantischen „Klima“ s. Anny Latour: Kulturgeschichte der Dame (Das Moderne Sachbuch 14), o. 0. 1963, S.155. Die Einordnung von Levin Varnhagen und von Arnim als „romantische Salons“ in: Schultz 1997. 712 Gelegentlich wird ihr auch alles zugleich attestiert: So wie Sabina Becker im selben Atemzug (d.h. auf nur einer Druckseite) die Salons „ein Produkt der jüdischen Aufklärung“ und ein „romantisches Phänomen“ nennt, so konnte nach ihrer Deutung Rahel Levin Varnhagen die frühromantische Maxime vom Gespräch als Kunstwerk umsetzen, noch bevor Schlegel sie formuliert hatte. Becker 2001, S. 19 bzw. 29. 
nie definierten „weiblichen Kultur“ des Umgangs ausgegangen. ${ }^{713}$ Nicht selten drückt sich die Faszination durch die Salons eben darin aus, dass ihnen gegensätzliche Stilformen zugleich attestiert werden. Demnach sei die „Salongesprächskultur“ gekennzeichnet durch „Intrigen und spöttische Betrachtungen einerseits, und andererseits Ausdruck von Toleranz und geistiger Freiheit“. ${ }^{714}$

Es wird vermutlich nicht mit einem Wort $\mathrm{zu}$ beschreiben sein, was die Attraktivität dieses Umgangs ausmachte. Auch eine der Hauptzeuginnen brauchte für eine Annäherung eine ganze Briefseite. Man kann es nostalgisch lesen, aber als Nostalgie einer Dabeigewesenen: An einer Stelle charakterisierte Rahel Levin Varnhagen 1819 das, was ihr an der Salongesellschaft der 1790erJahre typisch erschienen war bzw. was sie „in unserm Viertel, wo sonst Unsrige wohnten“ erinnernd vermisste: „Die ganze Konstellation von Schönheit, Grazie, Koketterie, Neigung, Liebschaft, Witz, Eleganz, Kordialität, Drang die Ideen zu entwickeln, redlichem Ernst, unbefangenem Aufsuchen und Zusammentreffen, launigem Scherz - ist zerstiebt." Schon in ihrer eigenen Lebenszeit hatten sich die Begriffe für einzelne Elemente der Geselligkeit nachhaltig gewandelt: „Alles Rez-de Chausses sind Laden, alle Zusammenkünfte Dinés oder Assembléen, alle Diskussionen beinah - Sie sehen am Ausstreichen meine Verlegenheit um ein Wort“, und sie konstatiert abschließend: „Eine fade Begriffsverwirrung“. ${ }^{715}$ Ebenso skeptisch äußerte ${ }^{716}$ sie sich $\mathrm{zu}$ der Möglichkeit einer Veröffentlichung dieses Umgangs: „Meine Briefe, oder abgerissenen Zettelchen an Sie und wirkliche Vertraute, sind nur - ein Stückchen Leben mit Euch; Papier und Federn sind nur ein Reisebehelf damit wir schneller zusammenkommen. Dann plaudern wie bei verschlossenen Thüren. - Für die heißhungrige Lesewelt sollte ich mich abmühen?“

Diese Indizien mögen ausreichen, um anzudeuten, dass schon die Beteiligten große Zweifel daran hatten, dass ihre Sprache im Schriftlichen aufgehoben oder abgebildet werden könne, geschweige denn, dass Nicht-Eingeweihte sie wirklich verstünden.

Des Umstands der verlorenen Mündlichkeit eingedenk, besteht daher die fundiertere Forschung zum Gespräch und zur Gesprächskunst im 18. Jahrhun-

713 So das titelgebende Motto bei Heyden Rynsch 1995, oder als positives Gegenbeispiel die klassisch gewordene Untersuchung zum frühen französischen Salon durch Lougee 1976. 714 So die Zusammenfassung eines Vortrags der Henriette-Herz-Biografin Marjanne E. Goozé im Rheingau-Echo vom 12. 7. 2007, zit. nach: Gazzetino. Mitteilungen der VarnhagenGesellschaft e. V., No. 20 (2007), o. S.

715 Rahel Levin Varnhagen an Gustav von Brinckmann, 30. 11. 1819 in: GW II, S. 609 f. 716 Um genau zu sein, erinnerte sich Gustav von Brinckmann daran, dass sie das Folgende gesagt habe. Akzeptiert man diese Erinnerung als Quelle, hieße sie: Rahel Levin Varnhagen an Gustav von Brinckmann, mündlich, o. D., überliefert in dessen Nachruf. Brinckmann 1876, S. 244. Hervorhebung im Original. 
dert überwiegend in der Auseinandersetzung mit zeitgenössischen Konversationstheorien, der Analyse präskriptiver Texte oder der Widerspiegelung der Gespräche in der Literatur. ${ }^{717}$ Darunter gibt es zum Thema Salon einige gut begründete Näherungswerte, die vom Briefstil auf den Gesprächsstil schließen. ${ }^{718}$ Vor allem in der Literatur zu französischen Salons und Salonièren ist über die mögliche Wechselwirkung zwischen gesprochenem und geschriebenem Dialog viel gearbeitet worden. ${ }^{719}$

Auch wenn in der Forschung wie von den Beteiligten die Bedeutung des (Brief-)Gesprächs als Medium der Bildung und Selbstbildung explizit oder implizit fortwährend bestätigt wurde, gibt das keinen Aufschluss über das eigentlich Mündliche. Lediglich Rahel Levin Varnhagens Gesprächskunst ist viel beschrieben worden, nicht zuletzt von ihr selbst. Ihr sokratisches Talent ${ }^{720}$ hat mehrere, auch fürstliche Zeugen, und ihr dialogisches Anliegen kann als ebenso nachweisbar wie bereits vielfach erforscht gelten, wenn es auch wechselweise als typisch ,jüdisches“ oder bürgerliches Bildungsgespräch, als „geschmackvoll“, „hemmungslos“ oder „psychoanalytisch“, auch als „kritische Intersubjektivität“ charakterisiert wird. ${ }^{721}$

717 Als Grundlagenwerk ist exemplarisch zu nennen: Markus Fauser: Das Gespräch im 18. Jahrhundert. Rhetorik und Geselligkeit in Deutschland, Stuttgart 1991.

$718 \mathrm{Da}$ in der vorliegenden Arbeit Billets primär als Quellen für Salongeschehen gelesen wurden, möchte ich an dieser Stelle auf ein ebenso risikobehaftetes wie interessantes Forschungsfeld hinweisen, das erst kürzlich eröffnet wurde: die literaturwissenschaftliche Analyse derjenigen Brief-Dispute im Salon, die jetzt kritisch ediert vorliegen. Einen interessanten Weg geht hier Conrad Wiedemann, der mit einer literaturwissenschaftlichen Analyse des Briefwechsels zwischen Pauline Wiesel und Prinz Louis Ferdinand überraschende Einsichten zur strategischen Nutzung der Zweisprachigkeit gewinnt. Conrad Wiedemann: Deutsch-französische Rederaison. Louis Ferdinand, Pauline Wiesel und Rahel Levin führen einen Brief-Disput über die Liebe, in: Ute Tintenmann / Jürgen Trabant: Sprache und Sprachen in Berlin um 1800 (Berliner Klassik, 3), Hannover-Laatzen 2004, S. 67-87. 719 Vgl. Brunhilde Wehinger, Conversation um 1800. Salonkultur und literarische Autorschaft bei Germaine de Staël, Berlin 2002. Grundlegend zum früheren französischen Salon Baader 1986. Dass diese Wechselbeziehung für Frankreich besser untersucht ist, liegt u. a. daran, dass einige französische Salonièren selbst sich theoretisch mit der Konversation auseinandergesetzt haben.

720 Der explizite Vergleich mit Sokrates stammt von Brinckmann, der damit allerdings auch seiner eigenen Theorie von ihrem Selbst-Nicht-Veröffentlichen-Wollen ein gewichtiges Argument verlieh. „Sokrates, wie Rahel, theilte sich eigentlich nur mit durch mündliche Gespräche, und diese sind immer berechnet auf bestimmte Zuhörer. [...] ,Ich bin keine Schriftstellerin' sagte sie mir einmal, ,und wozu?““ Brinckmann 1876, S. 242 f.

721 Beispielsweise meinte Gottfried Keller im Hinblick auf die Dialoge zwischen David Veit und Rahel Levin Varnhagen: „Die übertriebene Haarspalterei im Wahrsein, GegenseitigVerstehen, [...] diese Art Luxus in tugendhaftem Scharfsinn ist jüdisch [...], besonders was die äußere Form, den Jargon und die besagte Kümmelspalterei dieser Briefe betrifft.“ 
Über das Wie des Miteinander-Sprechens gibt es aber kaum Aussagen. So ist es beispielsweise unwahrscheinlich, aber nicht unmöglich, dass Brinckmann im Haus Levin die erste Stunde immer erst geschwiegen oder gelesen hat. Zwar schreibt Rahel Levin Varnhagen, dass Gentz spräche wie Humboldt, was das aber für einen Abend bedeutete, wieviel sie sprachen und wie, welche Komplimente die Damen bekamen, ob durcheinandergesprochen wurde - weiß man nicht. Sätze wie „Humboldt gestern wieder prächtig mit Metaphern wie ..." sind nicht überliefert. Auch die Frage, ob und von wem im Salon jiddische Begriffe verwendet oder satirisiert wurden, ist noch nicht untersucht. ${ }^{722}$ Schließlich ist die Frage noch unbeantwortet, ob eventuell im Schriftlichen etwas möglich war, das im mündlichen Salongespräch, vor mehr potentiellen Mithörern, nicht angezeigt war. ${ }^{723}$ Von Henriette Herz heißt es beispielsweise in der Literatur oft, sie sei zwar klug, aber nicht geistreich oder charmant gewesen, ${ }^{724}$ was sich für ihre Billets der 1790er-Jahre so gar nicht bestätigen lässt. Hier ließe sich fragen, ob sie schriftlich und quasi privat formulieren konnte, was vielleicht im Salon ihres Mannes nicht passend gewesen wäre?

Im Paradox gesprochen geht dieser Ausblick einen anderen Weg und konzentriert sich auf den Tonfall der Korrespondenzen im Untersuchungszeitraum. Gefragt werden kann eigentlich nur, welche Stilelemente und Sprachformen in den untersuchten Briefen und Billets zu finden sind und was das über den

Gottfried Keller an Ludmilla Assing, Himmelfahrtstag 1861, in: SV 16, zit. nach: Gottfried Keller: Gesammelte Briefe in vier Bänden, hrsg. von Carl Helbling, Bern 1950-1954, Bd. 2, S. 99. Heidi Thomann Tewarson sieht die Gespräche in der Dachstube als die einer geschmackvollen Gesellschaft. Thomann Tewarson 1992, S. 32 f. Von „hemmungloser Aussprache“ spricht Hannah Arendt. Arendt 2001, S. 34. Eine „psychologisierende Gesprächs- und Briefkultur von hoher Emphase“ sieht Wiedemann 2004, S. 45. Die These der kritischen Intersubjektivität entfaltet Irmgard Roebling 1993.

722 Dies könnte ein Forschungsprojekt an dem gerade edierten Familienbriefwechsel und weiterer innerjüdischer Korrespondenzen sein. Als interessanten Forschungsansatz bietet Roland Gruschka eine Analyse der zeitgenössischen satirischen Theaterstücks „Reb Henoch“ an und zeigt auf, wie sich in eingebildetes Hochdeutsch und Französisch jüdische Formulierungen schleichen. Roland Gruschka: Der Sprachenkosmos in Isaak Euchels Aufklärunsgkomödie Reb Henoch, in: Tinternmann / Trabant 2004, S. 89-113.

723 Hier sei nochmals auf zwei Arbeiten verwiesen, die auf die Disparität zwischen Brief und Salongespräch hinweisen. Dass der Brief einen freien Umgangston vor-entworfen habe, bevor er in der Realität anzutreffen gewesen sei, vertreten Gert Mattenklott / Hannelore Schlaffer / Heinz Schlaffer: Einleitung der Herausgeber, in: dies. 1988, S.7-18, hier bes. S.13. Den Brief als Erbe der Kommunikationsepoche sieht Schmölders 1986.

724 Häufig wird beispielsweise der Kontrast zwischen Rahel Levin Varnhagen und Henriette Herz auch im Gesprächsstil gespiegelt gesehen, der etwa bei ersterer intelligent, bei letzterer nur gebildet und nahezu kühl gewesen sei. Exemplarisch Valerian Tornius 1929, S. $287 \mathrm{ff}$. 
Umgang der Sprechenden bzw. Schreibenden aussagt. Zugleich möchte dieser Ausblick mit einigen ausgewählten Funden zur eingehenderen Beschäftigung mit dem Sprachraum Salon anregen. Es werden daher am Quellenmaterial des Querschnittsjahres solche Stilmittel aufgezeigt, die überraschen können bzw. in der Sekundärliteratur nicht genannt oder anders gewertet werden. Dabei sei noch einmal Gustav von Brinckmann in Erinnerung gerufen, der nach einem Besuch an Rahel Levin Varnhagens Teetisch ihr von seinem Schreibtisch solche Worte schrieb, „die sich zuvor nicht auf die Lippen wagten“. Briefe, Billets, weitere erwähnte Textsorten und Gespräche waren, wie in diesem Kapitel dargelegt, unterschiedliche Kommunikationswege zwischen diesen Personen. Dass dieselben Themen diese Wege berührten, ist wahrscheinlich. Dass derselbe Ausdruck für die Gedanken gewählt wurde, ist - möglich. Die Frage des folgenden Abschnitts ist daher nur: Gibt es ein Gemeinsames, etwas SalonSpezifisches in den Billets der ausgewählten Personen untereinander anno 1794/95? Und welche Bedeutung maßen die Beteiligten ihrer schriftlichen und mündlichen Unterhaltung bzw. dem Unterschied zwischen beiden Formen bei?

\subsection{Reflektionen der Salongesellschaft über das Verhältnis von Brief und Gespräch}

[...] wer solte wohl den Brief Verstehen wo von der cousine die sich kämt die rede ist. Waß soll man dagegen sagen wen Jemand über die briefe wo von Ifland die rede ist sich wundert; diese briefe die der Augenblick erzeugte [...] waß gar beynah nicht zu glauben ist dass eine Frau die Fichte, und Goethe so Verstanden, und Vergöttert hat so über diesen Gegenstand schreiben soll. ${ }^{725}$ Friederike Liman über die Briefe Rahel Levin Varnhagens

Unter denjenigen Gästen Rahel Levin Varnhagens, die die Veröffentlichung der Briefe ihrer Salonière im Buch des Andenkens noch erlebten, war die Meinung deutlich geteilt. Varnhagen erhielt begeisterte Rückmeldungen und Dank für die Erinnerung. Seine ebenso vehementen Kritiker und Kritikerinnen fürchteten aber, dass er seiner Frau ein schlechtes Denkmal gesetzt habe. Möglicherweise spricht die Empörung, dass Varnhagen seiner Gattin kein „rein erhabnes Monument“"726 gesetzt habe, dafür, dass seine Herangehenweise „wahrheitsge-

725 Friederike Liman an Gustav von Brinckmann, 25. 5. 1835, in: Bosold 1996, S. 136.

726 Friederike Liman an Gustav von Brinckmann, 18. 2. 1835, in: Bosold 1996, S.133. Vgl. die Analyse der Mediendiskussion zwischen Varnhagen und Brinckmann bei Isselstein 2002. 
treu“ war, soweit eine Briefauswahl dies überhaupt sein kann. Bemerkenswert sind die grundsätzlichen Bedenken, die zwei der langjährigsten Freunde und Salongäste, Liman und Brinckmann, gegen eine Veröffentlichung ihrer gemeinsamen Sprache äußern: „Solche Briefe, wie diese, drucken zu lassen, heißt doch im eigentlichsten Sinne des Wortes: den Geist durch den Buchstaben ermorden“. .727

Ich habe so viel auf dem Herzen, daß Sie mir schon erlauben müssen, manchmal, wie sonst Ihnen Bücher statt Briefe zu schreiben. Ewig Ihr Br.

Gustav von Brinckmann an Rahel Levin Varnhagen ${ }^{728}$

Es gibt, zusammenfassend, in der höchst selbstreflexiven Salongesellschaft viele Kommentare zu Schreib- und Lesesituationen, aber nicht viele zum Sprechgeschehen. ${ }^{729}$ Stattdessen wurde der Zusammenhang beziehungsweise Vergleich zwischen Schriftlichem und Mündlichem von den Beteiligten auffallend häufig thematisiert und spielerisch ironisiert. Durchgängig wurde viel Energie darauf verwandt, einander die Bedeutung des jeweiligen gemeinsamen Briefaustauschs zu bestätigen. Individuelle Korrespondenzen wurden ausführlich charakterisiert, manchmal personalisiert: „[...] wie unendlich lieb ich diesen Briefwechsel habe"!730 Einerseits bestätigte man sich, dass briefliche Schilderungen einen „täuschend auf die Jägerbrücke versetzen“ und das Briefe zu Gesellschaftern werden könnten. ${ }^{731}$ Andererseits wurde der Unterschied zwischen den Kommunikationsformen betont, das Unvollständige jedes einzelnen Mediums. Während Brinckmann manchmal lieber schrieb, wenn seine Adressatin von Besuch umlagert war, gab es umgekehrt Billets, die „nur mündlich“

727 Gustav von Brinckmann an Karl August Varnhagen, 10.-12. 5. 1835, zit. nach: Isselstein 2002, S. 202.

728 Gustav von Brinckmann an Rahel Levin Varnhagen, 1. 7. 1796, ungedruckt, BA V.

729 Dies mag verwundern angesichts der umfänglichen Literatur zum Gespräch auch und gerade aus dem 18. Jahrhundert, angesichts der Bedeutung, die dem Dialog zugemessen wurde und vor allem dem Umstand, dass viele Personen aus dem Umfeld der Salons sich theoretisch oder literarisch mit dem Gespräch und dem Sprechen auseinandergesetzt haben. Neben dem Gespräch als literarische Form, wie im Kaffeegespräch von Markus Herz, sind beispielsweise zu nennen Karl Philipp Moritz: Vom richtigen deutschen Ausdruck oder Anleitung, die gewöhnlichsten Fehler im Reden zu vermeiden. Für solche, die keine gelehrte Sprachkenntniß besitzen, Berlin 1792, und Friedrich de la Motte-Fouqué: Gespräch zweier Preußischer Edelleute über den Adel, Berlin 1808.

730 David Veit an Rahel Levin Varnhagen, 4. 3. 1794 und 23.10. 1794, in: GWVII/I, S. 190 bzw. 253.

731 David Veit an Rahel Levin Varnhagen, 23. 12. 1793, in: GWVII/I, S. 96. 
zu beantworten waren. ${ }^{732}$ Auch bestätigt man sich schriftlich, dass diese mündliche Unterhaltung miteinander exzeptionell sei, etwa wenn ein Gast wirkliche Lektüreerlebnisse am liebsten im Haus Levin besprach, „weil ich immer verzweifelte, den feinen Weltleuten begreiflich zu machen, daß es noch etwas weit schöneres als Lebensart und Eleganz gäbe“. ${ }^{733}$

Wichtig ist auch festzuhalten, dass Schreiben und Reden ineinander übergingen, Briefe schreiben und lesen nicht nur Konkurrenzsituationen zur Geselligkeit waren, sondern wesentlicher Teil des geselligen Lebens. Folgende Darstellung Brinckmanns, vom eingangs gewählten Datum 21. 8. 1795 gibt einen kurzen Eindruck in das hektische Leben eines Diplomaten, ist aber eigentlich vorrangig ein Kompliment an die Briefschreibekunst Rahel Levin Varnhagens:

Ganz fürchterlich ermüdet von einem Ritt von Tegel, wobei ich mich und mein Pferd ruiniert hatte, um nach einem Humb. Dinner noch zurrechten Zeit nach Bellevue zu kommen, erhielt ich Ihren Brief, sezte mich auf die Rampe vor meinem Hause, $u$ las $u$ wiederlas so gründl. dass [...] meine Bediente mich noch darauf aufmerksam machte, dass der Wagen schon da sei.734

Auch das vielbeschriebene dialogische Schreiben der Salonièren war früh von einem ihrer Gäste wörtlich genommen worden. Alexander von Humboldt imaginierte einen Dialog zwischen seiner Gastgeberin Henriette Herz und ihrer Freundin Dorothea Veit Mendelssohn Schlegel, über die vermeintliche Untreue seiner eigenen Person und sandte diesen als Brief an das Haus Herz: „Fr[au] Hofräthin Herz: ,Hab ich nicht immer gesagt, dass der Humboldt ein rechter Windbeutel sei?‘ // Mad[ame] Veit: ,Er verspricht so viel und hält so wenig [... [“". ${ }^{735}$ Humboldts Brief zitierte das Modell, dem er folgte, Wielands Dialoge im Elysium, eine im 18. Jahrhundert sehr beliebte literarische Gattung, und er stand unter dem Motto: „Wer des Scherzes Feind ist, trete nicht in unser Heiligthum“. ${ }^{736}$ Dementsprechend scherzhaft, also scheinbar unernst und ironisch, verhandelte Humboldt seinen eigenen Charakter und die Briefwut der

732 S. a. VI „Der Inhalt Ihres Billets ist von der Art dass ich glaube es sey besser für mich ihn mündlich zu beantworten, so bald ich die Ehre haben werde Sie zu sehen soll es geschehen. MM.“ Marianne Meyer Eybenberg an Gustav von Brinckmann, o. D., ungedruckt, BA E.

733 Über die Lektüre des Woldemar. Gustav von Brinckmann an Rahel Levin Varnhagen, 20. 5. 1794, ungedruckt, SV 38.

734 Gustav von Brinckmann an Rahel Levin Varnhagen, 21. 8. 1795, ungedruckt, SV 38.

735 Alexander von Humboldt an Henriette Herz, 4. 9. 1788, in: Landsberg 2000, S. 198.

736 Dies ist auch eine Gattung, in der international betrachtet, mehrere Salonièren brillierten. Von den englischen Bluestockings verfasste Elizabeth Montagu beispielsweise drei Totengespräche, die als „by another hand“ gekennzeichnet im Band ihres Freundes erschienen. Georg Lyttelton: Dialogues of the Dead, London 1760. 


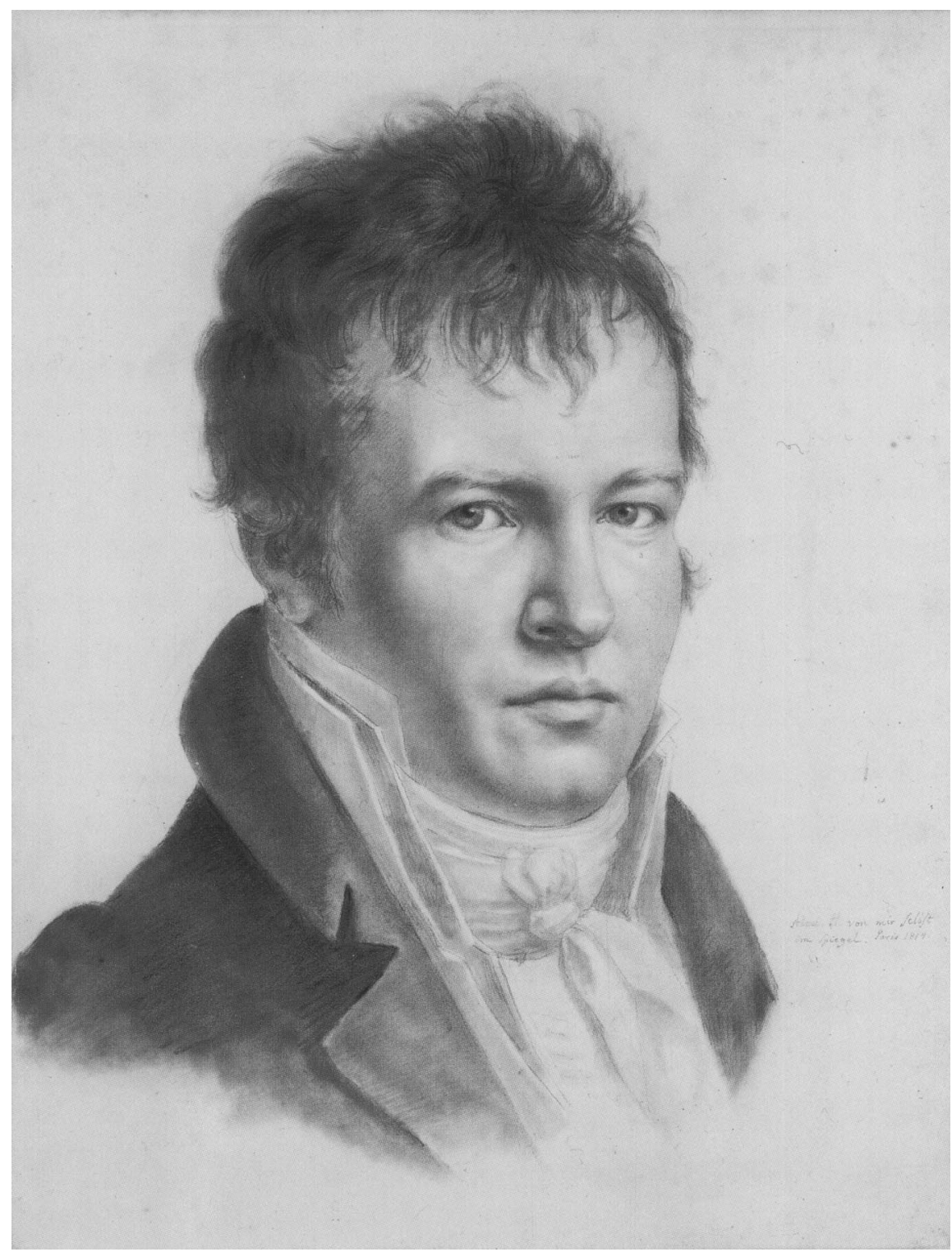

Abb. 19: Alexander von Humboldt (1769-1859), Salongast in Berlin und Paris.

Freunde: Während die Damen noch über Humboldts Faulheit im Briefschreiben spotteten, ließ er ein Schreiben von ihm ankommen, einen Brief im Brief. Anders betrachtet hat Humboldt seinen eigenen Brief in diesem imaginierten Dialog versteckt. Um die Spielerei auf die Spitze zu treiben, ließ er Henriette 
Herz komplimentierend sagen: „Der Brief ist wie ein Gespräch“, und „Der gute Humboldt! Wenn er unser voriges Gespräch gehört hätte. [...] Und hätt er’s auch gehört! Unter all seinen Eigenschaften ist das mit die Beste, dass er Scherz mit Scherz erwiedert“.737

\subsection{Vehikel auf der Kommunikationsstraße - pragmatisch-funktionale Aspekte der Billets}

Aus den zahlreichen und vielfältigsten Anlässen zu Kurznachrichten 1794/95 können drei wesentliche und spezifische Funktionen von Billets innerhalb der Salongesellschaft ermittelt werden: Billets übermittelten in erster Linie Einladungen, $\mathrm{Zu}$ - oder Absagen, enthielten Details zu Treffen oder deren Änderungen, waren damit Bestandteil oder Mittel des Geselligkeitsmanagements. Zweitens traten sie als elegante Begleitung und Kommentatoren ausgeliehener oder zurückgesandter Bücher, übersandter Medizinen oder privater Gegenstände auf, wie etwa eines vergessenen Handstocks, und bewirkten durch die Herausforderung, viel Bildung und persönliches Gepräge auf wenig Papier zu bringen, einen eigenen Stil. Hier wurden Billets Begleiter der materiellen Verbindlichkeiten der Salonkommunikation. Im folgenden Billet drückte eine Gastgeberin zugleich Mitgefühl für einen erkrankten Gast und ihren Geschmack aus, da sie Kotzebue als Schlafmittel übersandte:

///Ich bezeuge hiermit das Bedauern der Familie über Ihre Schmerzen, Sie Aermster! Kann es Sie heilen- Hier ist Kotzebue, ich hoffe Sie sollen nicht über die ersten drey Seiten kommen und schlafen sans compassion wie eine Katze. - Buona notte, Ich hoffe wir sehen Sie bald, $u$ ohne Schmerzen. Jetty///738

Drittens konnte das Billet selbst eine Verbindlichkeit, Aufmerksamkeit oder ein Kompliment werden. David Veit verglich das Billet einmal mit dem „reinen Theer“, mit dem man die Kommunikationsstraße schmieren müsse. ${ }^{739}$ Es konnte als verschriftlichter Ausdruck einer spontanen Idee, einer Assoziation oder Neckerei dienen, die zumeist als Kompliment gemeint war, und erfüllte damit den Zweck eines verbalen Handkusses. Andere Billets enthielten, wie das nachstehend zitierte von Lea Mendelssohn, elegante ,Kopfnüsse‘, Ausdrücke gespielter Empörung und damit auch eigentlich indirekte Komplimente:

737 Alexander von Humboldt an Henriette Herz, 4. 9. 1788, in: Landsberg 2000, S. 198.

738 Henriette Arnstein Pereira an Gustav von Brinckmann, 3. 12. 1801, ungedruckt, BA P.

739 David Veit an Rahel Levin Varnhagen, 3. 11. 1794, in: GW VII/I, S. 267. 
///Sie sind so unbeschreiblich schlecht, dass ich Ihnen weder über Jettens wirkliche Krankheit, noch über T. E. vielleichtige Niederkunft ein Wort sagen werde. - Zum Thee bei meiner Cousine Friedländer will ich Sie auch nicht mitnehmen, obgleich ich's könnte, $\mathrm{u}$ essen mag ich morgen auch nicht mit Ihnen. Ich habe einen Brief v. 14 Seiten, Ihnen lese ich aber kaum in 14 Tagen 14 Silben daraus vor. Ich ersterbe in höchstem Grimm Miß Lilla, aber gar nicht Ihre Miß.

Unter dies Billet lasse ich Ihnen Platz den Datum zu schreiben; ewig möge Ihnen diese Epoche des comble d'horreur bleiben.///740

Obwohl oder weil sie leichter einsehbar und so ,öffentlicher‘ zugänglich waren, konnte man sich im Billet inhaltliche Wagnisse leisten, da sie durch die inoffizielle Form relativiert wurden.

\section{4 „Extraordinaires“ - inhaltlich-stilistische Aspekte der Billets}

Mit Blick auf die für das 18. Jahrhundert als typisch geltenden bzw. auf die dem Berliner Salon pauschal attestierten Stilelemente finden sich in den untersuchten Briefen und vor allem den Billets der Salongesellschaft eine Natürlichkeit, die kunstvoll appliziert wurde, ein durchaus ambivalentes Verhältnis zum viel gepriesenen Witz, ein ausgeprägter Hang zur Galanterie und eine handfeste Prise Klatsch.

\section{Esprit versus Ennui}

Es hieße Goethe einen großen Dichter nennen, wenn man dem Salon noch einmal Geist attestieren wollte. Interessant ist hier vielmehr, welchen Wert oder welche Bedeutung die Beteiligten dem Witz zumaßen. Witz im Sinne des 18. Jahrhunderts meint, ähnlich wie „wit“ oder „esprit“, zunächst das Talent einer Person, „eine Leichtigkeit, die Ähnlichkeiten wahrzunehmen“ zwischen scheinbar entfernten Dingen, Worten oder Theoremen. Als Produkt bezeichnet der Witz „den glücklichen und sinnreichen Vergleich selbst“, der gegen Pedanterie und Schwerfälligkeit helfe und daher im 18. und 19. Jahrhundert als Teil

740 Lea Mendelssohn Bartholdy an Gustav von Brinckmann, 6. 3. 1802, ungedruckt, BA M. Als Ausdruck höchster Empörung (vor der wirklichen Empörung, die meist zum Einstellen des Briefkontaktes führte), sandte ihre Cousine einmal ein quadratisches Stück Papier, dass allseitig nur mit zahlreichen „Ph“s als Ausruf der Empörung bezeichnet war. Henriette Arnstein Pereira an Gustav von Brinckmann, o. D., BA P. 
einer gepflegten Geselligkeit empfohlen wurde. ${ }^{741}$ Im Unterschied zur Komik bezeichnet Witz ein bewusst eingesetztes intellektuelles Mittel. ${ }^{742}$ Witz setzt ein Publikum voraus und entfaltet sich am besten im Dialog. ${ }^{743}$ Wortwitz galt als unterste Stufe des Witzes. ${ }^{744}$

$\mathrm{Zu}$ dem in den untersuchten Billets der Salongesellschaft vorhandenem Witz gehören kühne oder abwegig scheinende Analogien, etwa wenn Brinckmann seine Zähne der Revolution gegen ihren Oberherren verdächtigte oder Gualtieri sich fragte, ob Musen lügen können: „Ich war vor meiner Abreise 10 Minuten oben in Ihr kleines Carnappe, die Muse war glaub' ich ausgeflogen, ich suchte Sie bey der Grazie (und wo hätt ich Sie sonst gesucht?) die eine kann ja nicht ohne die andere existiren - und fand Sie bey ihr nicht - denn, da verleugnen, eine höfliche Art zu lügen ist lässt sich dies vom Göttlichen Geschlechte nicht denken“. ${ }^{745}$

Sinnreiche oder doch mindestens amüsierende Metaphern und Metonymien sind regelmäßiger Bestandteil der Billets 1794/95, sie wurden als solche anerkannt und eingefordert. Auch witzige, streichähnliche Einfälle wurden erwähnt, leider nicht näher beschrieben.746

Witz wurde grundsätzlich anerkannt, geschätzt und weiterverbreitet, als eine Art Gebrauchsgut, wie auch Brinckmann seiner Freundin im Scherz vor-

741 Vgl die Einträge unter „Witz“ bei Johann Heinrich Zedler: Großes vollständiges UniversalLexikon, (Photomechanischer Nachdr. der Ausgabe Leipzig und Halle) 64 Bde. und 4 Supplementbände, Graz 1993-1999, Bd. 57 [1748], 1998, S. 1987-1990, hier S. 1989 und in: Allgemeine deutsche Real-Encyklopädie für die gebildeten Stände. Conversations-Lexikon, 5. Auflage, 10 Bde., Leipzig 1819-1820, Bd. 10, 1820, S. 772-773.

742 Da der Großteil der Protagonisten in jüdischem Umfeld groß geworden ist, stellt sich die Frage, ob es sich bei dem im Salon angebrachten Witz um den in der Forschung so bezeichneten „jüdischen Witz“ handelt. Dazu ist zu bemerken, dass einerseits auch aristokratische oder bürgerliche nichtjüdische Gäste sich dessen bedienten und andererseits aber die Definition dieses Witzes als „seelische Waffe des Mannes, der den realen Kampf für aussichtslos hält“", eine eigene Antwort auf die Frage nach dem Emanzipationspotential des Salons darstellte. Landmann, der die Soziologie des jüdischen Witzes verfasste, ergänzte noch, dass die besten jüdischen Witze nicht nur weltkritisch, sondern auch selbstkritisch seien, „Kampf für die richtige Forderung gegen die falsche“. Salcia Landmann: Jüdische Witze, München 1973, S. 24 und 36.

743 Jacob und Wilhelm Grimm: Deutsches Wörterbuch (Fotomechanischer Nachdruck der Erstausgabe 1960), 33 Bde., München 1984-1991, Bd. 30, S. $874 \mathrm{ff}$.

744 Nicht dazu gerechnet wurden bei Zeitgenossen ebenfalls die von Cornelia Saxe gelobten „witzigen Anekdoten“ der Salons. Saxe 1999, S. 11.

745 Peter Albert Samuel Gualtieri an Rahel Levin Varnhagen, o. D., ungedruckt, SV 79. Die Muse ist Rahel Levin Varnhagen, die Grazie vermutlich eine befreundete Schauspielerin.

746 So bestätigt Friederike Liman Rahel Levin Varnhagen, dass sie über ihre „Witzigen einfälle und filinenstreiche“ in Teplitz gehört habe. 14. 8. 1795, in: Bosold 1996, S. 32. 
warf, sie habe bei ihm Witz geordert, „gerade wie man einen Digestiv bestellt“". ${ }^{747}$ Er beantwortete diese Anfrage mit einem Gedicht über seinen Versuch, ein dummes Pferd zu verkaufen:

\section{Zwar käuft ein dummes Vieh kein rechtlicher Philister wenn es mit Frömmigkeit auch noch so albern prahlt, ich aber rathe Dir, verkauf es als - Minister denn Wöllner wird nicht schlecht bezahlt. ${ }^{748}$}

Als Gegenteil von Witz galt „Ennui“, „wie ich [mich] [...] mit Wess: F und die F anuirt habe könte ich bogens schreiben von die elende discoure“749 - bzw. war Witz das Gegenmittel gegen diese gesellschaftliche Langeweile: „Damit aber dieser Brief auch, wie Sie dem vorigen Schuld geben, Ernst und Scherz enthalten mag, so wissen Sie doch nun in allem Ernst, daß ich mich ein wenig vor dem steifen ennui fürchte, der bei Herzens ausgegessen sein möchte“. .750 Deswegen wurde Witz auch mehrfach verwendet, vorgelesen ${ }^{751} \mathrm{bzw}$. weitergetragen. So bestätigte Henriette Mendelssohn Brinckmann ein besonders gutes Exemplar von Brief: „Ich habe ihn (versteht sich mit versionen) allen unseren Bekannten mitgetheilt, $u$ eine jede von ihnen wußte Ihnen dank dafür. - Sie sollen der Levy einen sehr witzigen Brief geschrieben, manche Stelle daraus, klingt in unserem Zirkel immer wieder, aber ich sehe diese Levy jetzt so selten, dass ich noch nichts näheres davon erfahren konnte“.752 Bezeichnend für die Salongesellschaft ist die Rhetorik im Kreis, sodass Brinckmann an „die Levy“ zurück schrieb: „Henriette sagt mir, ich hätte einen sehr witzigen Brief an Sie geschrieben“, womit er eine ebensolche Antwort einfordern wollte.753

Bezeichnend ist aber auch, dass nicht jeder den spezifischen Witz verstand und einige, besonders ältere, religiöse Personen davor ,beschützt ${ }^{`}$ werden mussten: „Aber doch mus ich Ihnen noch sagen daß ich gestern Abend recht viel Menschen durch ihren witzigen Brief erfreut habe, ich habe ihn sogar meiner Mutter vorgelesen, wo ich nur freylich Ihre schreckliche Verachtung der Juden $u$ ihres Gottes gemildert habe, $u$ so ist sie ihnen sehr gewogen“.754

747 Gustav von Brinckmann an Rahel Levin Varnhagen, o. D. [1794 einsortiert], SV 38.

748 Dies bezog sich auf den bigotten Justizminister Johann Christoph von Wöllner, der die Religions- und Pressefreiheit einzuschränken suchte.

749 Friederike Liman an Rahel Levin Varnhagen, 20. 6. 1795, in: Bosold 1996, S. 13.

750 Gustav von Brinckmann an Rahel Levin Varnhagen, 29.1. 1793, ungedruckt, SV 38.

751 So dankt Rahel Levin Varnhagen Gustav von Brinckmann für seine „wizigen Billette“, die sie bei der Unzelmann auch vorgelesen habe, 3. 10. 1802, ungedruckt, SV 207.

752 Henriette Mendelssohn an Gustav von Brinckmann, o. D. [1799], ungedruckt, BA M.

753 Gustav von Brinckmann an Rahel Levin Varnhagen, 6. 3. 1799, ungedruckt, SV 38.

754 Henriette Mendelssohn an Gustav von Brinckmann, o. D. (aus Strelitz), ungedruckt, BA M. 
Im Bereich des Witzes galt, laut Brinckmann, ganz besonders, was über die Verschriftlichung von Gesprächen gesagt wurde. Rahel Levin Varnhagen galt Eingeweihten als Verkörperung des Witzigen, „aber von wem lernte ich auch bestimmter, als von ihr, die feine Gränzlinie zu gewahren zwischen dem schriftstellerischen, dem brieflichen $\mathrm{u}$. dem mündlichen, ja selbst dem mahlerischen Witz; der bloß durch Blick u. Ton flüchtig hingespielt wird“. ${ }^{755}$

Friedrich Schleiermachers empfahl besonders zwei Gattungen, die der Unterhaltung eigentlich sehr förderlich seien: die Persiflage und die Anspielung. Letztere sei anzuwenden, um Ähnlichkeiten zwischen getrennten Sphären zu schaffen, erstere, um Ernstes heiter zu sagen. In idealer Form angebracht diene beides dem von ihm angestrebten freien Ton in der idealen Geselligkeit. Aber man müsse sich davor hüten, durch diese Anspielungen eine „geheime Gesellschaft“ zu bilden. ${ }^{756}$

Witz wurde von den hier untersuchten Schreibenden als Charakteristikum der eigenen Berliner Gesellschaft verstanden. In Hannover konnte man im Vergleich „viele solide Äußerungen“, aber keinen Witz hören. ${ }^{757}$ Die jüngere Generation verstand ihn überhaupt als das, was sie von den Aufklärern unterschied: „Meinen so genannten Witz müssen Sie überhaupt mitgenommen haben, denn ich bin seitdem so deutlich, platt $\mathrm{u}$ vernünftig geworden, dass man mich zum Aufklären brauchen könnte“. 758

Bemerkenswerterweise scheinen schon Zeitgenossen Berliner Jüdinnen bzw. ihre Salons mit „Witz“ verbunden zu haben, nicht immer im positiven Sinne. So behauptete etwa Caroline Schlegel Schelling, Bettina von Arnim sähe aus „wie eine kleine Berlinerjüdin [..., die] sich auf den Kopf stellt, um witzig zu sein“. ${ }^{759}$ Anders formuliert war Witz eine Erwartung, die auch von außen an die Salonteilnehmer herangetragen wurde, bzw. man ging davon aus, dass man sich in dieser ,Szene' witzig zeigen wolle. So berichtete Rahel Levin Varnhagen David Veit leicht irritiert, dass man ihre gemeinsame Korrespondenz für besonders „witzig“ halte. ${ }^{760}$ Da sie aber keine Lust habe, viel davon zu erklären, habe sie es einfach geleugnet. Von gewissen Leuten wollte man nicht für nur witzig gehalten werden. Als David Veit diese Meinung bei Humboldt fürch-

755 Brinckmann 1876, S. 247, Hervorhebung im Original.

756 Schleiermacher 1984, S. 61

757 David Veit an Rahel Levin Varnhagen, 16. 1. 1794, in: GW VII/I, S. 116.

758 Gustav von Brinckmann an Rahel Levin Varnhagen, 30. 7. 1795, ungedruckt, SV 38.

759 Caroline Schlegel Schelling an Luise Wiedemann, Februar 1809, in: Buchwald 1923, S. 431 .

760 Rahel Levin Varnhagen über Henriette Herz an David Veit, 25. 1. 1794, in: GW VII/I, S. 132 . 
tete, las er ihm die Briefe seiner Freundin im Original vor, damit sie nicht „bloß witzig“ scheine. ${ }^{761}$

\section{Natürlichkeit, Erotik, Galanterie}

An Eulalia, als sie um 12 Uhr Mittags den Verf. noch nicht annahm weil sie noch nicht aufgestanden wäre

Den Göttern in der Oberwelt /

gönn ich Unsterblichkeit und Cypris trunkne Freuden /

mehr als sie alle scheint mir Morfeus zu beneiden /

der Dich so lang in seinen Armen hält. ${ }^{762}$

Die Epoche der Galanterie war literaturhistorisch betrachtet 1794 natürlich bereits vorüber. ${ }^{763} \mathrm{Da}$ aber mit dem französischen Salon Galanterien in jeder Form assoziiert wurden und selbiger in der Forschung als Vorbild der Berliner genannt wird, ist hier ein ausführlicheres Nachfragen berechtigt, ob der galante Umgangston der Franzosen für die Berliner als vorbildlich galt, auch inwieweit er das Verhältnis der Geschlechter charakterisierte.

In den zwei wesentlichen Anwendungsbereichen des Begriffs, dem Umgang bei Hofe ${ }^{764}$ und dem Umgang mit Frauenzimmern bedeutete galantes Wesen ein bewusstes Gefallenwollen, eine Reihung von scheinbar zweckfreien

761 David Veit an Rahel Levin Varnhagen, 20. 12. 1794, in: GW VII/II, S. 40.

762 Gustav von Brinckmann an Marie Cock geb Hesse, o. D. ungedruckt, BA H. Das Gedicht ist auf den Anfang der Bekanntschaft zu datieren, als sich die anderweitige Vermählung Marie Hesses noch nicht abzeichnete. Obwohl vielfach Verse zitiert oder beigelegt werden, ist Gustav von Brinckmann der einzige, dessen Texte der galanten Dichtung zugerechnet werden könnten. Dies Billet, das er zu dieser Zeit bei einem vergeblichen Besuch der Dame des Hauses hinterließ, dient als Beispiel für seine zahllosen Gelegenheitsgedichte.

763 Das Galante als Stil- und Modeideal des ausgehenden 17. und beginnenden 18. Jahrhunderts umfasst neben einem galanten Verhalten auch eigene Textgattungen und eine Richtung der Komposition. In der Dichtkunst ist besonders eine Hinwendung zu kleinen Formen und Gelegenheitsdichtungen damit verbunden, vornehmlich Liebesliedern, die auch ins Anzügliche spielen konnten. Als Literatursammlung vgl. Conrad Wiedemann: Der galante Stil. 1680-1730, Tübingen 1969.

764 Ausgehend vom französischen Hof wurde mit galant primär ein neues Ideal des höfischen Lebens verbunden, eine kluge elegante Höflichkeit und ein geschliffener Umgang zwischen den Geschlechtern. Galant bezeichnet im weitesten Sinne gefällig, wobei in den deutschen Sprachgebrauch sowohl Elemente des englischen „gallant“, tapfer und herrlich, als auch der französischen „Galanterie“, im Sinne von urbanitas und elegantia eingeflossen sind, immer auch in der negativen Konnotation von Stutzertum und übertriebener Höflichkeit. Vgl. Ferdinand Wächter: „Galant“, in: Allgemeine Encyclopädie der Wissenschaften und Künste, Bd.52, Leipzig 1851, S. 257-286, bes. S. 260. 
Aufmerksamkeiten, eine „Geschmeidigkeit ohne Niederwürfigkeit“. ${ }^{765} \mathrm{Im} \mathrm{Zu-}$ sammenhang der hier untersuchten Briefe wird galant verstanden als Haltung, sich anderen, besonders dem weiblichen Geschlecht gegenüber, gefällig zu erweisen, ohne dass damit auf den ersten Blick eine Absicht verfolgt werden musste.

Tatsächlich lassen sich in den Schreiben einiger Beteiligter Galanterien im zeitgenössischen Verständnis finden: Gustav von Brinckmann liest sich, wenn man seine Briefwechsel mit mehreren Salonièren nebeneinander legt, wie eine personifizierte Definition des Galanten, mit seiner „beständigen Aufmerksamkeit auf die Wünsche und kleinen Bedürfnisse aller Frauen ohne Unterschied“.766 Viele Adressatinnen wurden zur „Muse“ stilisiert, kein Brief kam ohne Handkuss aus und, wenn dieser selbst noch als Höflichkeitsfloskel durchgehen könnte, so muss als Beispiel der Galanterie ein Billet gelten, das nichts wollte als für ein anderes Billet danken, denn „ich kann mir das Vergnügen nicht versagen Ihnen selbst noch die Hände dafür zu küssen. Es ist doch recht hübsch von Ihnen dass Sie troz des schlechten Herzens, das Sie doch allerdings besitzen, mir doch diese Freude gönnten“. ${ }^{767}$

Die Salonfrauen bekamen von vielen beteiligten Männern oft unaufgefordert die neuesten Drucke zugesandt, und dies nur selten ohne beiläufiges Kompliment. Beide Geschlechter erwiesen einander und untereinander Aufmerksamkeiten. Es gibt neben dem Lektüreversand beispielsweise Bitten um und Dank für frisch geschnittene Schreibfedern, diese allerdings vorrangig von Männern gespitzt. Apropos genderspezifischem Schreiben wurde im Abschnitt zu Karlsbad dargelegt, dass Marianne Meyer Eybenberg Strategien des so genannten natürlichen Briefstils nutzte, wenn sie ihre Gedanken scheinbar unsortiert präsentierte oder sich mit ihrem Geschlecht als neugierige „Tochter Evas“ dafür entschuldigte, unaufgefordert an Goethe zu schreiben. Diese Entschuldigungen für den eigenen Briefstil finden sich in den untersuchten Schriftstücken tatsächlich nur bei Frauen, aber auffallend wenig. Stattdessen

765 Wächter 1851, S. 264. Ratgeber zu galanter „Conduite“ behandelten Themen wie erlaubte Gesprächsthemen, wie man Komplimente oder Gelegenheitsgedichte verfasste oder entgegennahm. Zeitgenössische Lexika warnten allerdings zugleich vor der negativen Seite der Galanterie, indem sie auf die abfälligen Bezeichnungen eines „schein-galanten“ Menschen oder der „Galanterie-Seuche“, einer Geschlechtskrankheit, hinwiesen. Ebenso kam es zu einer Übernutzung des Wortes in unpassenden Bereichen, so erwähnt ein Universallexkon die Unsitte „des Pöbels“, auch ein Pferd, das gefällt, als galant zu bezeichnen. Vgl. den Eintrag „Galanterie“ bei Zedler 1993-1999, Bd.10 [1735], Graz 1994, S. 78-79, hier S. 79 .

766 Wächter 1851, S. 286.

767 Gustav von Brinckmann an Friederike Liman, 24. 5. 1794, in: Bosold 1996, S. 122. 
wurde oft mit Selbstbewusstsein kokettiert und die eigene Rolle etwa gegen den Hof gesetzt, denn: „Alle soupés in der Stadt, fürchte ich nicht“ ${ }^{768}$

Einladungen zum Tee wurden generell an und von Männern und Frauen ausgesprochen, wobei der Überlieferung zufolge bei Ehepaaren es öfter die Frauen waren, die die Einladungen schrieben bzw. die Kontakte pflegten. (So wie Henriette Herz ihren „verdrüsslichen“ Gatten entschuldigte und Sara Levys Mann sich nur in deren Abwesenheit selbst an Brinckmann wandte.) Geschlechterspezifische Unterschiede der Formulierung sind hierbei nicht pauschal auszumachen: Zwischen denselben Briefpartnern lassen sich kokette wie sachlich informative Einladungen finden. Henriette Herz wandte gegenüber Gustav von Brinckmann mal den koketten mal den sachlichen Ton an. Ähnlich hielt es Friedrich von Gentz. Auch Gefälligkeiten waren gegenseitiger Natur: Gustav von Brinckmann versorgte anscheinend seinen gesamten Berliner Kreis mit gutem Tee und Literatur. Seine Freunde und Freundinnen ,revanchierten sich mit medizinischen Hausmitteln und Ratschlägen oder geheimen Rezepten. An Brinckmann gingen gleichermaßen Vermittlungswünsche und Empfehlungsbriefe wie an die Gastgeberinnen der Salons. Umgekehrt ist es natürlich als Kennzeichen der guten gesellschaftlichen Vernetzung einer jüdischen Frau zu sehen, wenn sie ebenso sehr als Vermittlerin beansprucht wurde wie ein Diplomat, und es muss festgehalten werden: diese Mittlerposition der jüdischen Häuser war um 1794 allen Beteiligten bewusst.

Obwohl Männer und Frauen einander Gefälligkeiten erwiesen und auch Männer untereinander sich Komplimente machten, nutzen die Salonteilnehmer selbst den Begriff Galanterie nur für Kommunikation zwischen den Geschlechtern. David Veit galt als galant, wenn er Rahel Levin Varnhagen kluge Komplimente machte, ${ }^{769}$ und Gustav von Brinckmann wurde wegen seiner „abominablen" Galanterie scherzhaft getadelt, weil er bei dem Unterfangen, alle Damen eines Zusammentreffens am Arm nach Hause zu geleiten, sich eine heftige Erkältung holte. ${ }^{770}$ Überhaupt wurde Galanterie keineswegs nur positiv betrachtet, jedenfalls nicht, wenn eine Seite ein ernsthaftes Anliegen hatte: Als Friedrich von Gentz später die Briefe der Rahel Levin Varnhagen in Prag nicht ernst genug nahm, sollte sie ihn enttäuscht einen ,galanten Notenverfertiger" schimpfen. ${ }^{771}$ In derselben Zeit, unter dem Eindruck der nationalen Wende, verfasste Sara Meyer Grotthus ihr Drama Die deutsche Erzieherin, in

768 Rahel Levin Varnhagen an Gustav von Brinckmann, 6. 3. 1795, ungedruckt, BA V.

769 Rahel Levin an David Veit, 25. 1. 1794, in: GW VII/I, S. 134.

770 Rahel Levin Varnhagen an Gustav von Brinckmann, 18. 1. 1794, ungedruckt, SV 207. 771 „Interesse nennt der galante Notenverfertiger die Liebe die ich ihm ausgedrückt habe.“ Rahel Levin Varnhagen an Caroline von Humboldt, 26. 12. 1813, in: Kemp 1979, Bd. III, S. 144. 
dem ein galanter Mann zumindest ironisch kritisiert wurde, ,seine unbestrittenen Vorzüge in Rücksicht der galanterie, sein Auffassen jeder Kleinigkeit, um einen Gegenstand des Gesprächs daraus zu drechseln, das den Damen zeitverkürzend ist; und was noch mehr“. ${ }^{772}$ Dies war zugleich als Mahnung zu verstehen, sich vom französischen Vorbild abzuwenden. ${ }^{773}$

Zusammenfassend ist festzuhalten: Galanterie wurde in den Berliner Salons zitiert und kurzzeitig genossen, aber nicht als nachzueiferndes Modell verstanden, geschweige denn als haltbare Grundlage von Freundschaftsbeziehungen. Auch war es weder Voraussetzung noch angestrebtes Modell der Gesprächsbeziehungen. So wird etwa von der Salonière Sara Levy berichtet, dass sie den gesellschaftlich ungehobelten Philosophen Maimon regelmäßig zu Gast hatte und ihm sein ungalantes Verhalten gegenüber Frauen nicht nur nicht übelnahm, sondern auch nicht verwehrte. ${ }^{774}$

Während Vergleiche und Metaphern aus dem Reich der Musen in Briefen zwischen den Geschlechtern häufig eingebaut wurden, sind Galanterien im Sinne von wirklich erotischen Anspielungen in den Briefen kaum zu finden. Am deutlichsten kommen Sinnlichkeit ${ }^{775}$ und Erotik in den Briefen eher der

772 Sara Meyer Grotthus: Die deutsche Erzieherin, Manuskript, SV 78. Deutlicher noch wird der verderbliche französische Einfluss in ihren „Ansichten einer deutschen Frau“ kritisiert, als Warnung vor „der reitzenden Galanterie, womit leichtsinnige Franzosen ihre Jugend vergiftet und sie zu Sprachkundigen gemacht; denen kein Laster mehr grell erscheint; denn seit Galanterien einheimisch geworden, giebts keinen Ehebruch mehr.“ Dies.: Ansichten einer deutschen Frau, Manuskript, SV 78.

773 Dass Galanterie keineswegs immer als zweckfrei verstanden bzw. gegen Franzosen zweckvoll eingesetzt wurde, zeigt eine parallele Briefstelle von Goethe, der mit Schiller plante, mit seiner Übersetzung der Staël sie und das französische Publikum zu gewinnen: „Ich wünschte, dass Sie sich die Mühe gäben in Ihrer Arbeit so klar und galant als möglich zu sein, damit man es ihr in der Folge zuschicken und dadurch einen Anfang machen könnte den Tanz der Horen auch in das umgeschaffne Frankreich hinüber zu leiten.“ Johann Wolfgang von Goethe an Friedrich von Schiller, 6. 10. 1795, in: Beetz 2005, Bd. 1, S. 114. 774 „Madame Levy schätzte er sehr hoch und achtete sie als eine sehr kluge Frau, auch suchte man sich hier, nach seinem eigenen Geständnisse, in ihn zu schicken. In diese Hinsicht sagte er selbst, daß es ihn wundere, wenn Mad. Levy so manches in seinem Benehmen nicht übel genommen hätte. So behauptete er einst in ihrer Gegenwart, es wäre ein Mißbrauch, der sich von den Franzosen beschriebe, daß man den Frauenzimmern Hochachtung schuldig sei, - sie verdienen in mancher Hinsicht eher unser Mitleiden. Bei einer anderen Gelegenheit, wo Maimon einst ebenfalls in der Gegenwart der Mad. Levy etwas gelinder vom anderen Geschlecht sprach, rief ihm Mad. Levy zu: ,Sparen Sie Ihre Mühe, Herr Maimon, wie Sie gegen unser Geschlecht denken, ist schon bekannt!““ Sabattia Joseph Wolff: Maimoniana oder Rhapsodien zur Charakteristik Salomon Maimons, hrsg. von Martin L. Davies und Christoph Schulte (Jüdische Geistesgeschichte, hrsg. von Christoph Schulte, 4), Berlin 2003, S. 67.

775 Und auch Verklemmung wie in den Briefen Humboldts und Gentz untereinander. [Vgl. V] 


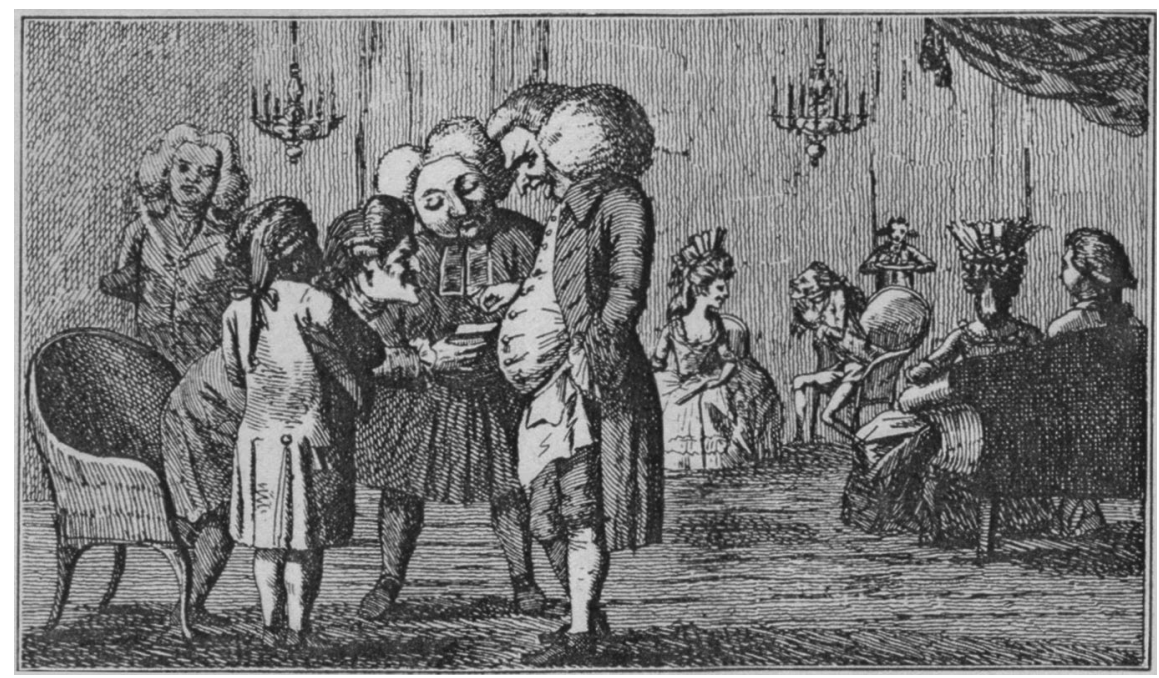

Abb. 20: „Conversatione“. Salonkarikatur aus dem 18. Jahrhundert.

Männer untereinander zum Ausdruck, z. B. denen Wilhelm von Humboldts oder auch Friedrich Schlegels an Brinckmann, die einen freien Umgang mit Affären durchaus andeuteten. [Vgl. IV]. Vor der Benennung erotischer Verwicklungen und außerehelicher Liebesbeziehungen hingegen scheuten sich die Schreibenden aller Geschlechter nicht. Dass Wilhelm von Burgsdorf Vater eines der Humboldtschen Kinder werden sollte, war ein offen diskutiertes Geheimnis. Hierbei kam es gelegentlich zu einem fließenden Übergang von freimütigem Umgang mit galanten Abenteuern zu handfestem Klatsch. Nur wenige Tage nach dem 21. 8. 1795 schrieb Brinckmann über das Ehepaar Humboldt, mit dem er fast täglich verkehrte: „Übrigens müssen Sie wissen, daß B. [Burgsdorf] förmlich in die Humb. verliebt ist, $u$. daß ein förmliches Verhältnis zwischen ihnen existiert, freil. wie Humb. mich versichert, ein solches, wo der Amor von einem Kuß 10 Jahre lebt.“ Den klatschenden Brinckmann freute diese Geschichte, weil es die Humboldt menschlicher mache. Aus demselben Grunde freute ihn eine Verliebtheit des Ehemanns: „Humb. ist derweile in die Mühlheim verliebt [...]. Sie wissen ich glaube an die Wahrheit von Humb. Liebe ungefehr eben so wie an die seiner gewöhnlichen Behauptungen." Der Brief ging schließlich nahtlos über in einen Kommentar zu den zahlreichen Liebschaften der Hitzel Fließ Boye Sparre: „Meine Doktorn gedenkt, nachdem sie hier $u$. in Freienwalde ungefehr alles ausgeliebt hat, was mitzunehmen war, 
ihren Zirkel gar sehr zu erweitern, u. nach England, Frankreich u. Holland zu gehen“. 776

\section{Die Dialektik der Klatschsucht}

Eine böse Zunge - heißt es bei den Rabbinern - tötet drei:

den Verleumder, den Zuhörer und den Verleumdeten.

Jüdisches Sprichwort ${ }^{777}$

Klatsch war kein zentraler Begriff, aber durchaus ein Phänomen dieser Zeit und dieses Ortes. ${ }^{778}$ Von Interesse sind in dieser Arbeit die speziellen Funktionen, die der Klatsch als „Sozialform der diskreten Indiskretion“ erfüllt: „Im unerlaubten Überschreiten der Grenze zu einer Sphäre, die die Person, über die gesprochen wird, als ihre ,private، reklamieren würde, wüsste sie nur von diesem Gespräch, liegt ein konstitutives Element und zugleich ein wesentlicher Reiz des Klatsches““. ${ }^{779}$ Mit Blick auf die in der Literatur diskutierten unterschiedlichen Funktionsanalysen von Klatsch ist zugleich festzuhalten: Im Zusammenhang mit jüdischen offenen Häusern um 1800 ist Klatsch nicht primär als weibliches Ausdrucksmittel und auch nicht als Kampfmittel Niedriggestellter zu verstehen, allerdings auch nicht als frauenspezifische Gegenkultur, sondern eher als eine weit verbreitete, situativ von allen Beteiligten verwandte Gattung der Alltagskommunikation. ${ }^{780}$

776 Gustav von Brinckmann an Rahel Levin Varnhagen, 27. 8. 1795, ungedruckt, SV 38. Zu „Mühlheim“ merkt Varnhagen an: „nachherige Frau des Oberstallmeisters von Knobelsdorff“. 777 Abraham Tendlau: Jüdische Sprichwörter und Redensarten. Als Beitrag zur Volks-, Sprach- und Spruchwörterkunde, Köln 1998, S. 437.

778 In Konversationslexika des 18. und 19. Jahrhunderts taucht der Begriff nicht auf, und erst seit den 1980er-Jahren gibt es wissenschaftliche Untersuchungen zu dieser Kommunikationsform, die doch für Gruppenbildung oft ausschlaggebend ist. Mit Blick auf das gelesene Briefmaterial wird Klatsch hier nach der soziologischen Definition als Gattung der alltäglichen Kommunikation gefasst. Vgl. Karl Heinz Hillmann, Wörterbuch der Soziologie, Stuttgart 1982, S. 415. Grundlegend ist hier die Habilitation von Jörg Bergmann, der eine Theorie des Klatsches als kommunikativer Praxis entworfen hat. Zwar arbeitet Bergmann vorrangig auf der Grundlage mündlicher Quellen der Jetztzeit, die von ihm ermittelten Funktionen des Klatsches für die Gruppenbildung sind jedoch abstrakt und zeitübergreifend anwendbar. Bergmann 1987.

779 Bergmann 1987, S. 73.

780 So war und ist es Konsens in der populären Literatur. Vgl. die Beschreibung des Kaffeeklatsches auf dem Lande in der Tagespressse 2005: Fanny Müller: „Aber bitte mit Sahne. Die Kaffeetafel kennt keine Tabus“, in: Der Tagesspiegel, 30. 10. 2005. Übertrieben scheint jedoch auch die Theorie, dass Klatsch eine weibliche Strategie gegen männlich dominierte Öffentlichkeit sei. Vgl. Birgit Althans: „Halte Dich fern von den klatschenden Weibern“ Zur Phänomenologie des Klatsches, in: Feministische Studien 4/2 (1985), S. 46-53. 
Von den drei wesentlichen Funktionen, die Jörg Bergmann dem Klatsch zuschreibt, können aus der Salongesellschaft 1794/95 nur zwei bestätigt werden: Durchaus diente er der „Netzwerkaktualisierung“, das heißt er brachte Neuigkeiten für eine Gruppe. Etwa wenn der Redakteur Humboldt den Herausgeber Schiller darüber informierte, dass Goethe sich über die „Judenmädchen“ einen guten Draht nach Berlin und zum dortigen Lesepublikum verschafft habe. Zweitens diente Klatsch nach Bergmann zur Erhaltung dieser sozialen Gruppen, er bestätigte gemeinsame Normen, indem er Aggressionen abbaute und Verbindlichkeiten schaffte. Dies traf auf verschiedene Untergruppen der Salons zu, insofern sich Brinckmann und Levin Varnhagen über die neue Menschlichkeit Humboldts, der beiden oft auch ,mephistophelisch' vorkam, freuten, oder David Veit seiner Freundin riet, die Naivität Henriette Herz auszunutzen. ${ }^{781}$ Der nachlebende Leser kann in der Zusammenschau auch feststellen, dass Salonière und Salongast extern gegeneinander klatschten, etwa wenn Marianne Meyer Eybenberg und Gustav von Brinckmann sich Goethe gegenüber als jeweils einzig wahre/r Leser/in präsentierten, indem sie den jeweils anderen als „Narr“ oder „Jüdin“ bezeichneten. Deutlich versuchte Meyer Eybenberg, mit ihrem lästerlichen Kommentar über Brinckmann eine Ebene der Vertrautheit zwischen sich und Goethe einzuziehen, trotz dessen eingestandener Nützlichkeit: „mich protegirte er übrigens ausgezeichnet, das kann mich aber wirklich nicht abhalten, ihn Ihnen zu zeichnen wie er ist. und nun Basta -“. 782

Demgegemüber kann die von Bergmann benannte dritte Funktion des Klatsches als soziale Kontrolle - vor allem in präventiver Hinsicht, wonach man sich aus Angst vor Klatsch in bestimmter Weise benehme - aus dem Zusammenhang der Salongesellschaft nicht bestätigt werden. Rahel Levin Varnhagen beispielsweise wehrte sich explizit gegen diese Auswirkung, indem sie die „erhabenen Klatscher“ offen diskutierte und deren Meinung dann ignorierte [vgl. V]. ${ }^{783}$

Dass die Kontrollfunktion fehlt, mag einerseits daran liegen, dass man sich sowieso dessen bewusst war, sich in einem klatschgefährdeten Grenzraum der Gesellschaft zu bewegen. Eine andere Erkärung wäre, dass es zwischen den gesellschaftlich doch sehr ungleich Gestellten im Ernstfall des Klatsches nicht wirklich bedurfte. Wie sich später in Wien oder Prag zeigen sollte, brauchten

781 Gustav von Brinckmann an Rahel Levin Varnhagen, 29.1. 1793, ungedruckt, SV 38. David Veit an Rahel Levin Varnhagen, 10. 11. 1794, in: GW VII/I, S. 272.

782 Marianne Meyer Eybenberg an Johann Wolfgang von Goethe, 2. 2. 1796, GSA, 28/306, ungedruckt, teilweise zitiert bei Hahn 2002(b), S. 122.

783 Rahel Levin Varnhagen an Gustav von Brinckmann, 15. 7. 1794, in: GW I, S. 78. 
ein Wilhelm von Humboldt oder Friedrich von Gentz keinen Klatsch, um Rahel Levin Varnhagen auszugrenzen.

An dieser Stelle soll daher betont werden, dass nicht nur christliche Männer über Berliner Jüdinnen lästerten, und ebenso soll angemerkt sein, dass letztere sich über die Lästereien im Klaren waren. Über einen Besuch der Verlegergattin Frau Sophie Sander in Weimar und Jena sollte Dorothea Mendelssohn Veit Schlegel 1800 das Folgende berichten:

\begin{abstract}
Sagen Sie doch der Herz: Die Sander hatt hier brilliante Fortune gemacht, besonders bey Goethe; [...] Dafür hat sie aber auch hier in Gesellschaft brav auf die Berliner Jüdinnen geschimpft. Dies ist aber wie ich gehört habe ziemlich kaltsinnig aufgenommen worden; auf jeden Fall ist es aber sehr malicieuse von der Dame, so viel ich weiß, hatte sie niemals in Berlin beßre Gesellschaft als die Jüdinnen.
\end{abstract}

Sie schloss mit einem klugen Vorschlag, wie sich die Berliner Jüdinnen gegen diese Klatschoffensive wehren könnten: „Wenn die Herz sie sieht, so sollte sie doch sehen daß sie mit ihr auf die alte Unger zu sprechen kömmt und mit gehöriger Verachtung von deren Schimpfen auf die Jüdinnen etwas sagen“.784 Helene Friederike Unger war für antijüdische Äußerungen stadtbekannt und dieser Vergleich eine elegante Möglichkeit, Frau Sander wissen zu lassen, was man von ihren Klatschereien hielt.

Bestätigen lässt sich in Salonzusammenhängen daher folgende soziologische Definition des Klatsches: Man veriet privates Wissen, aber nur an ausgewählte Zuhörer, und stellte damit eine gemeinsame Basis her, die man nicht naturgegeben hatte. (Dass Klatsch seine Wirkung entfalten kann, setzt eine gewisse Distanz zwischen Klatschproduzent und Klatschrezipient voraus). ${ }^{785}$ Es lässt sich innerhalb der Salongesellschaft von einer Dialektik der Klatschsucht sprechen: man grenzte brieflich einige Personen kurzzeitig aus, verband sich dadurch aber andererseits dem Adressaten. Beispielsweise versicherten sich Brinckmann, Veit und Levin Varnhagen gegenseitig einer aufgeklärten Grundhaltung, indem sie über Jeannette Ephraim, frisch nach Hannover verheiratete Stieglitz, und ihre bigotte Hausfrauenrolle klatschten. (Alle verkehrten dennoch freundschaftlich mit ihr). ${ }^{786}$ Es handelt sich um jene Jeannette, die

784 Dorothea Mendelssohn Veit Schlegel an Friedrich Schleiermacher, 9. 6. 1800, in: KFSA, Bd. 24, S.120. Damit ist Wilhelmys Aussage, dass Sophie Sander keine antijüdischen Vorurteile gehabt habe, in dieser Pauschalität nicht zu halten. Wilhemy 2000, S. 82. Umgekehrt kann solche Lästerei, die ein Ausdruck für Konkurrenz oder empfundene Konkurrenz sein kann, ein Zeichen für den Stellenwert der jeweiligen Geselligkeiten sein. 785 Eheleute „klatschen“ per definitionem nicht, sie informieren sich oder „lästern“. Vgl. Bergmann 1987.

786 „Jeannette spricht ganz rasend viel von Gutmütigkeit und Häuslichkeit.“ David Veit an Rahel Levin Varnhagen, 16. 1. 1794, in: GW VII/I, S. 115. 
gemeinsam mit ihrer Schwester am oben zitierten Herzschen Freitag anwesend war und dort nur von ihrer glücklichen Ehe geschwatzt hatte. Nicht ihre vorherigen Affären nahmen ihre Berliner Freunde ihr übel, sondern dass sie ihr Vorleben jetzt als Gattin gänzlich leugnete: „nicht daß ich nicht schon wüsste, daß aus diesem Schmetterling eine moralische Raupe gekrochen wäre, [...] aber daß sie ihre staubige Moral jedem Fremden an den Kopf werfen würde“, das konnte man nicht glauben. ${ }^{787}$ Die eigene, problematisierende Haltung gegenüber der Ehe und der Tonfall, indem diese verhandelt wurde, sahen die Klatscher als Ausweis einer freieren Einstellung an. In den bezeichnenden Worten David Veits, der das Ehepaar in Hannover besuchte: „Die Stieglitz hat sich überhaupt nie in den freien, spitzen Ton in Berlin finden können“.788 Darüber muss Brinckmann informiert worden sein, denn er eilte sich zu bemerken, dass die Stieglitz im Privatgespräch ihre „Tugendfirniß“ verlöre und noch „Canaille genug“ sei. Sie habe lediglich ein „nützliches Benehmen“, wenn sie mit den Besuchern des Hauses Herz anders rede als mit ihnen. ${ }^{789}$ Es ist bezeichnend für den „freien, spitzen“ Ton in den hier untersuchten Kreisen, dass Brinckmann seine Leserin mit folgenden Worten beruhigen konnte: „Nun werden Sie mir zugeben, daß wenn jemand selbst gesteht, wie er die Tugend nur als einen Regenmantel anzieht, so ist nicht viel verloren. Auch hat sie über die gepriesene eheliche Liebe, [...] so prächtig gottlos und skandalös mit mir gesprochen, daß ich mir gar nicht einreden lasse, daß der Himmel an ihr viel gewonnen hätte“.790

\section{Berliner Ton und Berliner Gesellschaften}

Die Geschichte des Berliner Tons zu schreiben, den Nachweis, wie er sich gebildet, das wäre ein Kapitel für sich und wäre ziemlich gleichbedeutend mit einer Kulturgeschichte unserer Stadt. Theodor Fontane ${ }^{791}$

787 Rahel Levin Varnhagen an David Veit, 25.1.1794, in: GW VII/I, S.135. Dennoch hielt sie ihre Freundin für eine „gute Kreatur, [...] nur in eine andere Stadt eingesperrt“. Ebd., S. 136. 788 David Veit an Rahel Levin Varnhagen, 16.1.1794, in: GW VII/I: S. 116.

789 Sie habe inn gefragt: „Ob ich es denn gewünscht hätte, daß sie vor Kiesewetter, u [x] und Friedländer und Herz eben so hätte sprechen und sein sollen wie vor mir?“ Ein Name unleserlich. Gustav von Brinckmann an Rahel Levin Varnhagen, 14. 7. 1794, ungedruckt, SV 38.

790 Gustav von Brinckmann an Rahel Levin Varnhagen, 14. 7. 1794, ungedruckt, SV 38. 791 Theodor Fontane: Berliner Ton [aus dem Nachlass], in: ders.: Das Ländchen Friesack und die Bredows. Unbekannte und vergessene Geschichten aus der Mark Brandenburg, hrsg. von Gotthard Erler unter Mitarbeit von Therese Erler (Theodor Fontane. Große Brandenburger Ausgabe. Wanderungen durch die Mark Brandenburg, 7), Berlin 1997, S. 23-32, hier 24. 
Die Frage schließlich, wem dieser so genannte freie Ton Berlins um 1800 gehörte und welche Möglichkeiten sich dahinter verbargen, führt zurück auf Lessings berühmte Formulierung zur Ambivalenz „der Berlinischen Freiheit zu denken und zu schreiben“. Selbige beschränke sich „allein auf die Freiheit, gegen die Religion so viel Sottisen zu Markte zu bringen, als man will.“ Wolle man aber politisches Unrecht öffentlich machen oder gar „dem vornehmen Hofpöbel“ die Wahrheit sagen, erführe man schnell „welches Land bis auf den heutigen Tag das sklavischste Land von Europa ist“.792 Ganz unironisch wurde Lessing darin sekundiert von Friedrich Nicolai, der mehrere Seiten seiner Stadtbeschreibung der Verteidigung der religiösen Sittlichkeit Berlins widmete: Religionsgleichgültigkeit, schreibt er, sei ein „grobes Vorurtheil, welches jeder unbefangene Mann für falsch erkennen wird, wenn er Berlins Einwohner näher kenn lernt. [...] es gibt andere große Städte in Deutschland, wo Irreligion, Lasterhaftigkeit und Verderbnis der Sitten viel weiter als hier gehen“" ${ }^{793}$ Allerdings schrieb Nicolai dies in der Absicht, die (Vor-)Urteile über die lasterhaftige Religionsfreiheit seiner Heimatstadt zu beschwichtigen.

Während Freiheit sich um 1770 vorrangig auf Religionsfreiheit bezog - religiöse Toleranz bzw. intellektuelle Zusammenarbeit mit Juden hatte in berlinkritischen Schriften der Aufklärungszeit der Stadt den Titel „Berlin-Jerusalem“ oder „Aufklärungssynagoge“ eingetragen ${ }^{794}$-, erfuhr der Begriff in Stadtbeschreibungen der Jahrhundertwende eine leichte Verschiebung. Frei wurde zunehmend im Sinne von „sich etwas herausnehmend“, frei-mütig, geistreich verstanden, aber auch als moralisch oder politisch ungeniert oder ungezwungen in Gesellschaften. Reiseführer sprachen etwa allgemein vom freien Ton und der Gastfreiheit der Stadt, 795 erwähnten aber auch die „freye Denkungsart der Einwohner und freye Lebensart“.796 „In Gesellschaft lachte ein Witzling [sic!] über die Dreyeinigkeit“, und ein Fremder hörte mit Erstaunen „die dreusten [dreistesten] und freimütigsten Gespräche über die ersten Bedienten des Staats“.797

792 Gotthold Ephraim Lessing an Friedrich Nicolai, 25. 8. 1769, zit. nach: ders. Sämmtliche Werke, 30 Bde., Karlsruhe 1823-1825, Bd. 27: Briefwechsel. Ersther Theil (1824) (Sammlung der vorzüglichsten deutschen Classiker, 177), S: $269 \mathrm{f}$.

793 Nicolai 1786, Bd I, 603. Er hält aber auch Eifer für schädlich und lobt die Wohlthätigkeit im stillen und „das unschätzbare Glück einer völligen Gewissensfreiheit“. Ebd., S. 604.

794 Ursula Goldenbaum nennt als so formulierende Berlinkritiker Zimmermann, Hamann und Jacobi. Ursula Goldenbaum: Friedrich II. und die Berliner Aufklärung, in: Lottes / d’Aprile 2006, S. 123-142, hier S. 138.

795 Krögen 1986, S. 32 und 44.

796 Friedell 1987, S. 30.

797 Krögen 1986, S. 44. 
Diese ,freimütige Denkungsart gegenüber Personen von Stand' in den Jahren um 1800 ist aus mehreren Zusammenhängen belegbar: Bekannt ist die Anekdote von Frau Nicolai, die, als Elisa von der Recke sie besuchen wollte, zu ihrem Mann laut sagte: „Ich will von Deinem adligen Pack nichts wissen“, worauf die Aristokratin charmant entgegnete, sie wolle ja bloß Freundin sein und so dazu auch wurde. ${ }^{798}$ Der Arzt Heim äußerte sich mit ähnlichem Bürgerstolz in seinem Tagebuch: „In Bellevue gewesen, wo mir die Frau Landgräfin von Hessen einen Kuß gab. Vielleicht wird sie mich nun dafür desto schlechter bezahlen“, und er versah jemanden, der der Eigenliebe der „Vornehmern“ schmeichelte, mit einem „Pfui“!799

Es gibt auch einige Hinweise in den Schriften von Personen aus dem Salonumfeld, dass sich der gesellschaftliche Umgangston zwischen Lessings Aufenthalt in Preußen und ihrer Lebenszeit um 1800 bzw. auch das Verständnis vom „freien Ton“ möglicherweise geändert hat - zumindest in einigen Gesellschaften: Sophie Becker, Freundin und Reisebegleiterin der Salonfrau Elise von der Recke, hatte noch 1784 festgehalten: „Der Konversationston ist übertrieben steif. Der Grafenstand will nicht einmal mit dem kleineren Adel zu thun haben“.800 Und Alexander von Humboldt beschwerte sich 1788, „ich size in dem großen aufgeklärten königlichen Berlin [...]. Der eine ist gelehrt, der andere klug, der dritte witzig [...]“, aber niemand sei so offen wie der Adressat. 801

Aus dem Jahr 1801 hingegen stammt das viel zitierte Wort Jean Pauls, der diesen Winter auch in Berliner Salons verbrachte: „Gelehrte, Juden, Offiziere, Geheime Räthe, Edelleute, kurz alles was sich an andern Orten (Weimar ausgenommen) die Hälse bricht, fället einander um diese, und lebt wenigstens freundlich an Thee- und Estischen beisammen“.802 Interessant ist die sehr ähnliche Bemerkung an einen anderen Freund, mit einem Focus auf dem Ton in eben den gemischten Zirkeln, in denen er verkehrte: „Unter allen gesellschaftlichen Tönen stell' ich den hiesigen am höchsten. Juden, Minister, Offiziere, Gelehrte, Weiber, diese macht das gesellige Band oft zu Einem Straus; in Dresden hätten sie in einem ganzen Garten nicht Plaz“.803

798 Parthey 1907, Bd. 1, S. $38 \mathrm{f}$.

799 Heim 1989, S. 87 und 90.

800 Sophie Becker: Vor hundert Jahren: Elise von der Reckes Reisen durch Deutschland 1784-86 nach dem Tagebuch ihrer Begleiterin Sophie Becker, hrsg. und eingeleitet von G. Karo und M. Geyer. Stuttgart o. J., zit. nach: Seibert 1993(a), S. 134.

801 Alexander von Humboldt an Wilhelm Gabriel Wegener, 12.12. 1788, in: Jahn / Lange 1973, S. 31.

802 Jean Paul an Karoline Herder, 12. 1. 1801, in: Jean Pauls Sämtliche Werke [im Folgenden JPSW], Bd. 3.4, S. 41.

803 Jean Paul an Paul Emil Thierot, 17. 1. 1801, in: JPSW, Bd. 3.4, S. 39. 
Zu frei durfte man sich in politischer Hinsicht außerhalb eines Salons oder Privathauses allerdings auch in Berlin und auch nach dem Tode Friedrichs II. nicht äußern. Als Graf Kalckreuth, der Gönner des Philosophen Maimon, 1795 aus Berlin verwiesen wurde, hieß es, er solle sich zu frei über politische Dinge geäußert haben. ${ }^{804}$ Hingegen, in seinem spitzen mokanten Ton an Lessing gemahnend, kommentierte ein Salongast, allerdings nur in einem Privatbrief, den Vorgang so, dass Kalckreuth und seine Freunde „schon öfters so öffentliche Beweise einer sehr vorurtheilsfreien und aufgeklärten Denkart abgelegt haben, daß S. Majesät keine nützlichern Werkzeuge glaubt anwenden zu können, um auch in den am wenigsten kultivierten Winkeln seiner Staaten das Licht der Aufklärung und einer liberalen Denkart zu verbreiten“.805

Mochte auch die Freiheit in privatem Rahmen größer geworden sein, die Freiheit der politischen Äußerung hatte vergleichbare Grenzen wie zu Lessings Zeiten.

\section{5 „Schaumspritzer der Freiheit“ - \\ Fazit der Zusammenschau. Der Salon als Sprachraum}

Die inhaltliche und stilistische Zusammenschau der 1794/95 getauschten Briefe führt noch einmal zu der vielleicht naheliegenden, aber wichtigen Feststellung, dass kein einzelner Briefwechsel einen gültigen Eindruck von Themenspektrum oder Tonfall der Salongesellschaft oder nur dem des Salons Rahel Levin Varnhagen vermitteln kann. Der berühmte Jugendbriefwechsel mit David Veit verrät nicht, wie intensiv Rahel Levin Varnhagen mit Künstlerinnen wie der Unzelmann oder der Marchetti befreundet war, geschweige denn den fast täglichen Umgang mit ihnen, wie er aus den Briefen der Friederike Liman herausscheint. Umgekehrt gibt es in der Korrespondenz mit Liman kaum einen Hinweis auf den Umfang oder die Varianz der Lektüre Rahel Levin Varnhagens, die von Homer bis zur zeitgenössischen Dichtung reichte. Beide Briefwechsel enthalten Anmerkungen zum Diplomaten Gustav von Brinckmann, der hier aber überwiegend als Kommissionär und funktional erwähnt wird. Aus der zeitgleichen Korrespondenz mit ihm selbst ergibt sich aber ein ganz anderer Eindruck: Wie im Briefwechsel mit David Veit erweist sich Levin Varnhagen auch dem schwedischen Adligen gegenüber als gleichberechtigte und anteilnehmende Brieffreundin. Ihre Charakterisierung Brinckmanns als bloß „lauffertig“ im Brief an Veit, hinderte sie nicht, ihn fast täglich zu empfangen und

804 Wilhelm von Humboldt an Friedrich von Schiller, 4. 8. 1795, in: Leitzmann 1900, S.69. 805 Gustav von Brinckmann an Rahel Levin Varnhagen, 17. 5. 1795, ungedruckt, SV 38. 
mit ihm ernsthafte Auseinandersetzungen über Literatur und Philosophie zu führen. 806

So besteht Grund zur Annahme, dass jeder neu dazukommende Briefwechsel die Kommunikation innerhalb der Salongesellschaft um eine Tonlage oder ein Thema reicher scheinen lässt. Andererseits ist festzuhalten, dass die Salonfrauen und -männer verschiedene Sprachebenen bzw. Konversationsstile zeitgleich nebeneinander pflegen konnten: Friederike Liman gegenüber wurden vermehrt jiddische Begriffe und familiäre Anspielungen gebraucht, Brinckmann erhielt gleichermaßen französische wie deutsche Billets.

Aber und apropos freier Ton: Gemeinsam sind allen hier untersuchten untereinander gewechselten Briefen und Briefwechseln der Salongesellschaft des Jahres 1794/1795, unabhängig von Geschlecht, Stand oder Religion der Schreibenden, eine sich meist in Ironie kleidende Distanz zu religiösen Begriffen, Riten und Instanzen, eine fast konstante Politikferne (trotz des politischen Engagements einiger Salonteilnehmer und der nachweislichen politischen Lektüre vieler) sowie eine umfassende Kenntnis der zeitgenössischen Literatur, die in zahllosen Zitaten zum Ausdruck kommt. Die Briefe sind fast durchweg zweioder mehrsprachig. Vornehmlich bei Schreiberinnen findet sich, zumindest im ungedruckten Original, die vielfach angemerkte orthografische oder grammatikalische Unordnung, die aber nachweislich auch bewusst und kreativ eingesetzt wurde, im Sinne eines „natürlichen“ Briefstils. Unterschiedliche Namensschreibungen (Goethe, Göte, Göthe) sind bei Männern und Frauen, auch innerhalb eines Briefes, die Regel, ebenso die Angewohnheit, Namen abzukürzen oder gemeinsame Spitznamen zu verwenden, die für heutige Leser oft nur in Parallellektüre mehrerer Korrespondenzen auflösbar sind.

Trotz der stilistischen und thematischen Vielfalt wird ein weiteres gemeinsames Merkmal der Briefe und Billets erkennbar. Vergleicht man Salonbriefe mit solchen Briefen, die an Außenstehende gerichtet sind, ${ }^{807}$ etwa die in Kapitel V beleuchteten Briefe Brinckmanns an adlige Freundinnen, so findet man in den Briefen der Salongesellschaft intern überwiegend eine bewusste Lockerheit, eine auch in Abmahnungen bewahrte Leichtigkeit des Tons. Unzuverlässigkeiten wurden als „Windbeuteleien“ geziehen, den Schwächen des jeweili-

806 Rahel Levin Varnhagen an Gustav von Brinckmann, 13.12. 1793, in: GW VII/I, S. 72. 807 Der Vergleich der hier untersuchten quasi salon-internen Billets mit nach außen gerichteten Schreiben kann nur eklektisch ausfallen. Um zu zeigen, dass der ungenierte Ton nicht der der Zeit oder der Generation ist, sei exemplarisch auf Caroline und Wilhelm von Humboldts Briefe aus diesem Jahr verwiesen, die gleichermaßen liebevoll, höflich und detailreich, aber im Eigentlichen unironisch sind. Auch die oben erwähnten Briefe zwischen Humboldt und Schiller enthalten neben einer ironischen Sicht auf Berlin vor allem sachliche und verehrende Äußerungen, gelegentlich ein ungebrochenes Pathos. 
gen Geschlechts oder etwa einer Krankheit angelastet. Nirgendwo finden sich schmeichlerische Annäherungen ,von niedrigerer Position aus‘, eine gleiche Ausgangsebene wird immer behauptet. Äußerst selten und fast nur unter engen Freunden findet sich eine ernsthafte Auseinandersetzung, bei der sich der Charme verlöre. Selbst biografisch einschneidende Erlebnisse wie Taufe oder Scheidung wurden eher mit einem Sprüchlein pariert denn tiefschürfend besprochen: „So warf ich mich denn zum Verteidiger des Teufels und der Christen wechselseitig auf.“

Anders formuliert gibt es, nach dem hier angestellten Querschnitt zu urteilen, keinen durchgehend gehaltenen, für die Salongesellschaft spezifischen freien Tonfall, aber durch jedes und in jedem in oben skizziertem Tonfall abgefassten Billet manifestiert sich ein freier Sprach-Raum, den die Mitglieder der Salongesellschaft nutzen konnten:808 Anders formuliert kann man mit Fug und Recht behaupten, dass, wer so ein Billet verfasste, sich in einen Sprachraum begab, in welchem gesellschaftliche Schranken irrelevant waren. Billets dieses charmant verbindlichen bis provokant mokanten Stils wurden zwischen den Geschlechtern wie innerhalb desselben Geschlechts gewechselt, zwischen Vertretern des Adels, des Bürgertums, Angehörigen der jüdischen Gemeinde oder bekennenden Agnostikern unterschiedlicher Herkunft. Da lästerte die Gattin eines Maskil mit einem Ex-Herrnhuter über christliche Handküsse, da nannte ein jüdisches Mädchen einen Freiherrn einen schlechten Charakter, er verglich sie mit Friedrich II. - was besonders pikant wird, wenn man dessen Einstellung zu Juden und Frauen bedenkt.

Aber: Dieser charmante, fast frech zu nennende Ton war vielleicht der einzige, dessen sich eine jüdische Haustochter und ein preußischer Junker im gemeinsamen Gespräch bedienen konnten, wenn sie weder nur Höflichkeiten austauschen noch ein Liebespaar werden wollten. Um ihre Beziehung zu charakterisieren, nannte Gustav von Brinckmann Rahel Levin Varnhagen seine Freundin, Lehrerin oder Muse. Zugleich aber schuf er mit jedem Brief eine sprachliche Ebene der gleichberechtigten Kommunikation.

Hierzu passt auch der inhaltliche Befund der relativen Politikferne der schriftlichen Salonkommunikation: An dieser Stelle muss noch einmal betont

808 Hier muss nochmals verwiesen werden auf Garves Definition der Wirkung und Bedingung einer „Gesellschaft“: eine gemeinsame Sprache: „Conventionen und eine eigene Sprache des Umgangs“. Diese bestünde aus allen „Formeln und Gebräuchen der Politesse“. Garve 1792, S.157. Beides sei den Moden unterworfen und regiere nur in gewissen „Perioden“ durch Beispiele und Nachahmung. Zu den Konventionen zählt er die Regeln, wer wem zuerst einen Besuch macht oder welche Erfrischungen gereicht werden. Das sei den Moden unterworfen, werde dann stillschweigend aber angenommen (oder entstehe durch Beispiel einer Person von Rang). 
werden, dass das Hinterlassene an schriftlicher Kommunikation keineswegs eindeutige Hinweise auf das mündliche Geschehen in den Salons liefert. Es ist durchaus möglich, dass Gustav von Brinckmann bei den Levins die Treppen hochstürmte und begeistert von der Emanzipation der Juden in Frankreich berichtete, aber es ist weder wahrscheinlich noch belegbar. Statt diese Befunde aber rein defizitär zu deuten, kann ebenso positiv angenommen werden, dass die Schreibenden als Themen bewusst solche wählten, die als gemeinsame Basis taugten, sozusagen als verbindende Ebene. Mit dem Theater, der Literatur, der menschlichen Natur im Allgemeinen und dem Charakter gemeinsamer Bekannter im Besonderen waren Themen gegeben, in deren Beurteilung es allen gleichermaßen zur Meisterschaft gereichen konnte und bei denen unterschiedliche Meinungen der Debatte auch förderlich sein konnten. Wenn es hier zur „Partheiung“ kam, musste es für die Geselligkeit nicht wirklich eklatante Folgen haben. Dies hätte durchaus der Fall sein können, wenn die Rechte der jüdischen Bevölkerung debattiert worden wären. So banal es klingt: Es war ein Unterschied, einem Prinzen moralische Dachstubenwahrheiten zu sagen oder politische Privilegien von ihm zu fordern.

Im Vergleich zu langen analytischen Briefen können Billets zwar einerseits mit Heinrich Heine als „Briefe im Negligé-Gewand“809 gelten, andererseits war das artifizielle Element des Billets bzw. die Tatsache, dass man den Ton selbst gestalten konnte, den Mitgliedern der Salongesellschaft durchaus bewusst. An einer Stelle beschreibt Friederike Liman Rahel Levin Varnhagen, wie sie der Sängerin Marchetti ein passendes „ordentlich ein francoisisches Billet“ verfasst habe, „nicht allein ein ordinaires sondern ein exagerirtes, wie man eigentlich mit Italiener reden muss, den was in unserer sprache schon Süden ist; ist bey sie noch Norden“. ${ }^{810}$ Leider ist das erwähnte Billet an die Italienerin nicht überliefert, sodass die Kriterien des „Exagerirten“, also Aufgeregten oder Übertriebenen, nicht mehr festzustellen sind. Für heutige Leser mögen allerdings die Billets der Liman und ihrer Freunde durchweg exageriert klingen, wurden aber nicht so empfunden.

Die erwähnten Stilelemente des Klatsches, der Galanterie und des Witzes haben einen Effekt gemeinsam. Sie können Distanzen bzw. scheinbar Unvereinbares überbrücken und sie schaffen eine gemeinsame Ebene. Nicht ohne

\footnotetext{
$809 \mathrm{lhm}$ war „der Brief im Negligé-Gewand tausendmahl lieber als der Galla-Brief“. Heinrich Heine an Rudolf Christiani, 7. 3. 1824, zit. nach: Christian Liedtke / Bernd Füller (Hrsg.): „... und grüßen Sie mir die Welt“. Heinrich Heine. Ein Leben in Briefen, Frankfurt/M. 2005, S. 121. Dabei ist Negligé nicht als Unterwäsche, sondern im Sinne des 18. Jahrhunderts als bequemes Hauskleid zu verstehen.
}

810 Friederike Liman an Rahel Levin Varnhagen, 6. 6.1795, in: Bosold 1996, S.6. 
Grund sah Kant in dem Scherz die höchste Stufe der Konversation. ${ }^{811}$ Indem Brinckmann Rahel mit Friedrich II., „dem Einzigen“, verglich, ihr Einzigartigkeit attestierte, enthob er sie beide der Notwendigkeit, sie mit anderen Frauen oder Nichtjuden $\mathrm{zu}$ vergleichen oder sich darüber $\mathrm{zu}$ definieren. Wenn sie beide über Humboldts mangelnde Menschlichkeit klatschten, attestierten sie sich selbst eine solche als verbindende Gemeinsamkeit.

Der Brief und vielleicht das Salongespräch waren im doppelten Sinne Kommunikationsorte mit emanzipatorischem Gehalt: Zum einen waren diese Kommunikationsformen so definiert, dass sie jedem die Möglichkeit gaben zu exzellieren: Jüdische Kaufmannstöchter durften sich im Briefeschreiben internationalen adligen Bestsellerautoren ebenbürtig fühlen. Zum anderen ergaben sie die Möglichkeit, sich durch einen speziellen Tonfall eine eigene Verbindung zu schaffen, einen eigenen Sprachraum. Man erschrieb sich ein Terrain, auf dem man sich begegnen konnte.

Wann und inwieweit dieses Terrain von einzelnen Schreibern und Schreiberinnen wieder verlassen wurde, ist eine wesentliche Frage an die folgenden Längsschnitt-Kapitel.

811 Markus Fauser sieht Kants „1) Erzählen, 2) Räsonieren, 3) Scherzen“ als Verlaufsmodell, in dem die „launichte Atmosphäre der Originalität als Vorstufe des Ästhetischen“ erreicht werden soll. Fauser 1991, S. 34. 
